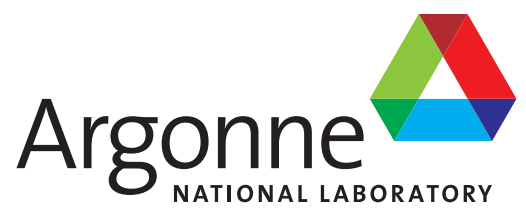

\title{
Power Distributions in Fresh and Depleted LEU and HEU Cores of the MITR Reactor
}

Revision 0

Nuclear Engineering Division 


\begin{abstract}
About Argonne National Laboratory
Argonne is a U.S. Department of Energy laboratory managed by UChicago Argonne, LLC under contract DE-AC02-06CH11357. The Laboratory's main facility is outside Chicago, at 9700 South Cass Avenue, Argonne, Illinois 60439. For information about Argonne and its pioneering science and technology programs, see www.anl.gov.
\end{abstract}

\title{
Availability of This Report
}

This report is available, at no cost, at http://www.osti.gov/bridge. It is also available on paper to the U.S. Department of Energy and its contractors, for a processing fee, from:

U.S. Department of Energy

Office of Scientific and Technical Information

P.O. Box 62

Oak Ridge, TN 37831-0062

phone (865) 576-8401

fax (865) 576-5728

reports@adonis.osti.gov

\begin{abstract}
Disclaimer
This report was prepared as an account of work sponsored by an agency of the United States Government. Neither the United States Government nor any agency thereof, nor UChicago Argonne, LLC, nor any of their employees or officers, makes any warranty, express or implied, or assumes any legal liability or responsibility for the accuracy, completeness, or usefulness of any information, apparatus, product, or process disclosed, or represents that its use would not infringe privately owned rights. Reference herein to any specific commercial product, process, or service by trade name, trademark, manufacturer, or otherwise, does not necessarily constitute or imply its endorsement, recommendation, or favoring by the United States Government or any agency thereof. The views and opinions of document authors expressed herein do not necessarily state or reflect those of the United States Government or any agency thereof, Argonne National Laboratory, or UChicago Argonne, LLC.
\end{abstract}




\section{Power Distributions in Fresh and Depleted LEU and HEU Cores of the MITR Reactor}

\section{Revision 0}

by

E.H. Wilson', N.E. Horelik², F.E. Dunn', T.H. Newton, Jr. ${ }^{2}$, L. Hu², and J.G. Stevens ${ }^{1}$ ${ }^{1}$ Nuclear Engineering Division, Argonne National Laboratory

${ }^{2}$ MIT Nuclear Reactor Laboratory and Nuclear Science and Engineering Department

January 31,2012

This work is sponsored by the U.S. Department of Energy,

National Nuclear Security Administration Office of Global Threat Reduction (NA-21) 


\begin{abstract}
The Massachusetts Institute of Technology Reactor (MITR-II) is a research reactor in Cambridge, Massachusetts designed primarily for experiments using neutron beam and in-core irradiation facilities. It delivers a neutron flux comparable to current LWR power reactors in a compact $6 \mathrm{MW}$ core using Highly Enriched Uranium (HEU) fuel.

In the framework of its non-proliferation policies, the international community presently aims to minimize the amount of nuclear material available that could be used for nuclear weapons. In this geopolitical context, most research and test reactors both domestic and international have started a program of conversion to the use of Low Enriched Uranium (LEU) fuel. A new type of LEU fuel based on an alloy of uranium and molybdenum (UMo) is expected to allow the conversion of U.S. domestic high performance reactors like the MITR-II reactor.

Toward this goal, core geometry and power distributions are presented. Distributions of power are calculated for LEU cores depleted with MCODE using an MCNP5 Monte Carlo model. The MCNP5 HEU and LEU MITR models were previously compared to experimental benchmark data for the MITR-II. This same model was used with a finer spatial depletion in order to generate power distributions for the LEU cores. The objective of this work is to generate and characterize a series of fresh and depleted core peak power distributions, and provide a thermal hydraulic evaluation of the geometry which should be considered for subsequent thermal hydraulic safety analyses.
\end{abstract}




\section{Table of Contents}

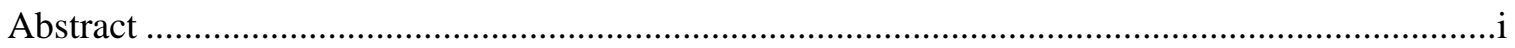

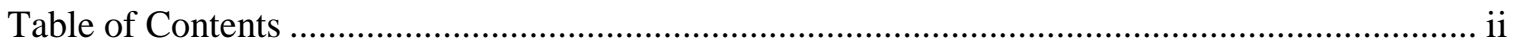

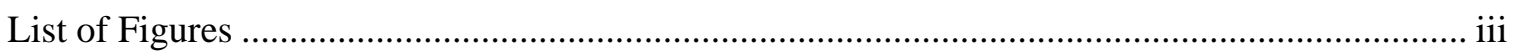

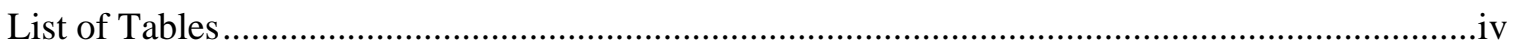

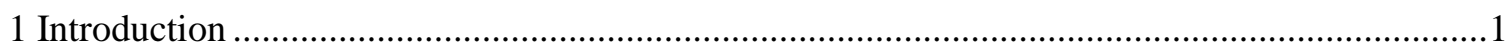

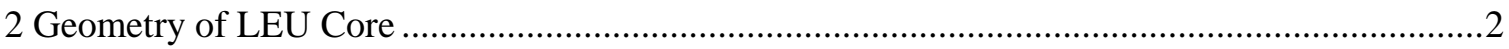

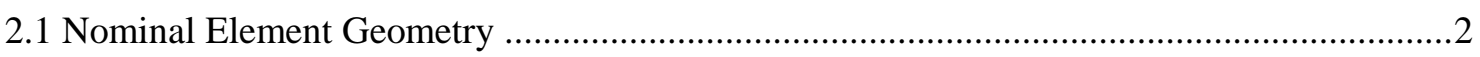

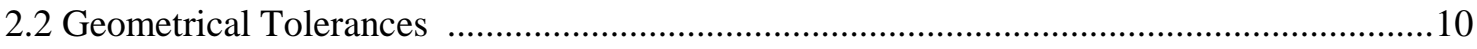

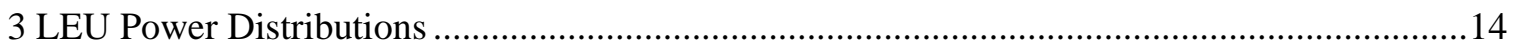

3.1 Calculation Methodology for Power Distributions …....................................................... 14

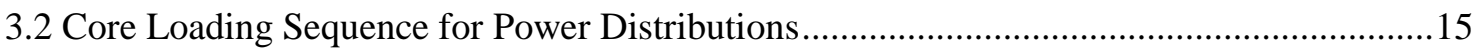

3.3 Power Distributions of Fresh and Depleted LEU Cores ..................................................18

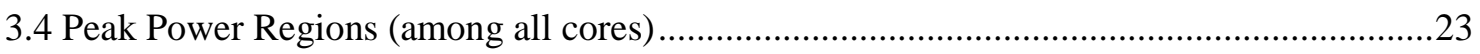

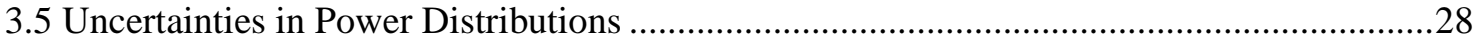

4 Thermal Hydraulic Determination of Limiting Power Distributions .........................................30

4.1 Lateral Heat Conduction Basis for Lateral Power Segmentation..........................................30

4.2 Determination of Limiting Power Distribution and Comparison of End Channel to

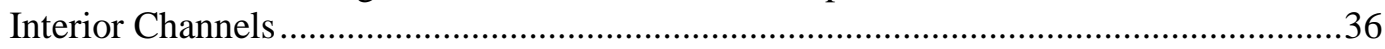

4.3 Additional Comparison of End Channel to Interior Channels .............................................38

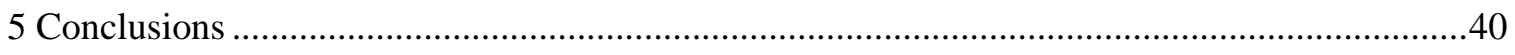

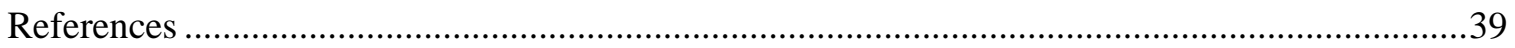

APPENDIX A: Hydraulic Geometries of Channels ........................................................... A-1

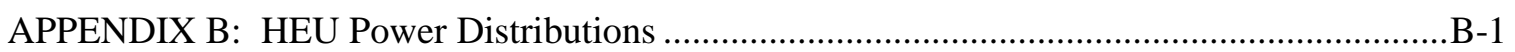

APPENDIX C: Power Distributions by HEU Core Loading …….............................................

APPENDIX D: Power Distributions by LEU Core Loading ……......................................... D-1 


\section{Table of Figures}

Figure 1. Layout of the MIT reactor core.

Figure 2. Schematic of MITR LEU fuel element drawn with 18 plates........................................

Figure 3. Schematic of MITR LEU fuel element (outer 4 of 18 plates shown). .............................5

Figure 4. HEU fuel element MITR specification R3F-201-4 ...............................................6

Figure 5. Cross-section of fuel elements illustrating end channels (side plates not shown)..........8

Figure 6. Cross-section of LEU element with neighboring element and structural wall (top view) 9

Figure 7. End channels of element in various core positions (see also Table 2) ..........................10

Figure 8. Depiction of radial plate grouping used in the depletion of MITR LEU cores. ............16

Figure 9. Critical control blade position throughout the depletion of LEU Cores 179-190..........17

Figure 10. Critical control blade position throughout HEU and LEU Cores 179-190, comparing equivalent performance (EFPD based on full power $6 \mathrm{MW}$ HEU, 7 MW LEU)........18

Figure 11. Peak locations of LEU fresh and depleted cores at BOC and EOC ...........................23

Figure 12. Axial heat flux profile of LEU cores with maximum heat flux locations ....................24

Figure 13. Heat flux and burnup vs. axial position with control blade shim bank position

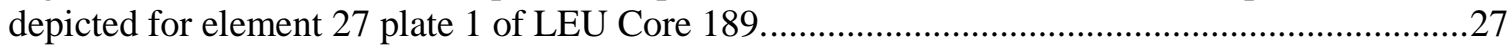

Figure 14. Axial power shapes for 16 stripes, 18 axial nodes, in the plate with the hottest stripe .30

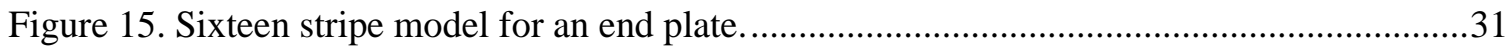

Figure 16. Coolant outlet temperatures, in degrees Celsius, by stripe ..........................................

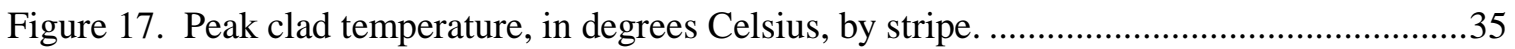

Figure 18. Influence of end channel gap size on peak clad temperature .....................................39

Figure B-1. Peak locations of HEU fresh and depleted cores at BOC and EOC .........................

Figure C-1. Elemental power distribution in the all-fresh HEU Core 2 .....................................

Figure C-2. Elemental power distribution in HEU depleted Core 179 at BOC. ..........................

Figure C-3. Elemental power distribution in HEU depleted Core 179 at EOC............................5

Figure C-4. Elemental power distribution in HEU depleted Core 180 at BOC. ...........................6

Figure C-5. Elemental power distribution in HEU depleted Core 180 at EOC.............................

Figure C-6. Elemental power distribution in HEU depleted Core 181 at BOC. ........................... 8

Figure C-7. Elemental power distribution in HEU depleted Core 181 at EOC.............................

Figure C-8. Elemental power distribution in HEU depleted Core 182 at BOC. ..........................

Figure C-9. Elemental power distribution in HEU depleted Core 182 at EOC...........................11

Figure C-10. Elemental power distribution in HEU depleted Core 183 at BOC. ...................... -12

Figure C-11. Elemental power distribution in HEU depleted Core 183 at EOC........................13

Figure C-12. Elemental power distribution in HEU depleted Core 184 at BOC. ....................... 14

Figure C-13. Elemental power distribution in HEU depleted Core 184 at EOC......................... 15

Figure C-14. Elemental power distribution in HEU depleted Core 185 at BOC. .......................16

Figure C-15. Elemental power distribution in HEU depleted Core 185 at EOC..........................17

Figure C-16. Elemental power distribution in HEU depleted Core 186 at BOC. ........................18

Figure C-17. Elemental power distribution in HEU depleted Core 186 at EOC........................19

Figure C-18. Elemental power distribution in HEU depleted Core 187 at BOC. ......................2-20

Figure C-19. Elemental power distribution in HEU depleted Core 187 at EOC..........................2-21

Figure C-20. Elemental power distribution in HEU depleted Core 188 at BOC. ......................22

Figure C-21. Elemental power distribution in HEU depleted Core 188 at EOC.........................23 


\section{Table of Figures (continued)}

Figure C-22. Elemental power distribution in HEU depleted Core 189 at BOC. ...................... -24

Figure C-23. Elemental power distribution in HEU depleted Core 189 at EOC........................ 25

Figure C-24. Elemental power distribution in HEU depleted Core 190 at BOC. ......................2-26

Figure C-25. Elemental power distribution in HEU depleted Core 190 at EOC........................27

Figure D-1. Elemental power and burnup distribution in the all-fresh LEU Core 2 .............. D-4

Figure D-2. Elemental power and burnup distribution in LEU depleted Core 179 at BOC.... D-5

Figure D-3. Elemental power and burnup distribution in LEU depleted Core 179 at EOC..... D-6

Figure D-4. Elemental power and burnup distribution in LEU depleted Core 180 at BOC..... D-7

Figure D-5. Elemental power and burnup distribution in LEU depleted Core 180 at EOC..... D-8

Figure D-6. Elemental power and burnup distribution in LEU depleted Core 181 at BOC..... D-9

Figure D-7. Elemental power and burnup distribution in LEU depleted Core 181 at EOC... D-10

Figure D-8. Elemental power and burnup distribution in LEU depleted Core 182 at BOC... D-11

Figure D-9. Elemental power and burnup distribution in LEU depleted Core 182 at EOC... D-12

Figure D-10. Elemental power and burnup distribution in LEU depleted Core 183 at BOC... D-13

Figure D-11. Elemental power and burnup distribution in LEU depleted Core 183 at EOC... D-14

Figure D-12. Elemental power and burnup distribution in LEU depleted Core 184 at BOC... D-15

Figure D-13. Elemental power and burnup distribution in LEU depleted Core 184 at EOC... D-16

Figure D-14. Elemental power and burnup distribution in LEU depleted Core 185 at BOC... D-17

Figure D-15. Elemental power and burnup distribution in LEU depleted Core 185 at EOC... D-18

Figure D-16. Elemental power and burnup distribution in LEU depleted Core 186 at BOC... D-19

Figure D-17. Elemental power and burnup distribution in LEU depleted Core 186 at EOC... D-20

Figure D-18. Elemental power and burnup distribution in LEU depleted Core 187 at BOC... D-21

Figure D-19. Elemental power and burnup distribution in LEU depleted Core 187 at EOC... D-22

Figure D-20. Elemental power and burnup distribution in LEU depleted Core 188 at BOC... D-23

Figure D-21. Elemental power and burnup distribution in LEU depleted Core 188 at EOC... D-24

Figure D-22. Elemental power and burnup distribution in LEU depleted Core 189 at BOC... D-25

Figure D-23. Elemental power and burnup distribution in LEU depleted Core 189 at EOC... D-26

Figure D-24. Elemental power and burnup distribution in LEU depleted Core 190 at BOC... D-27

Figure D-25. Elemental power and burnup distribution in LEU depleted Core 190 at EOC... D-28

Figure D-26. Axial power distribution of stripes with peak heat flux by pseudoequilibrium core

D-30

Figure D-27. Plate-average heat flux for elements containing peak stripes in pseudoequilibrium $7 \mathrm{MW}$ LEU cores (with element \# noted)

Figure D-28. Axial power distribution of stripes within plate containing inner ring peak stripe among all cores (7MW LEU Core 185 BOC element 12 plate 18 stripe 4)

Figure D-29. Axial power distribution of stripes within plate for 7 MW LEU Core 185 EOC element 12 plate 18 stripe 4

Figure D-30. Axial power distribution of stripes within plate containing inner ring peak stripe among all cores (7 MW LEU Core 185 BOC element 12 plate 18 stripe 4) shown at BOC and EOC. D-32 


\section{Table of Figures (continued)}

Figure D-31. Axial power distribution of stripes within plate containing peak stripe among all cores (7 MW LEU Core 189 EOC element 27 plate 1 stripe 1) shown at BOC.

Figure D-32. Axial power distribution of stripes within plate containing peak stripe among all cores (7 MW LEU Core 189 EOC element 27 plate 1 stripe 1) shown at EOC.

Figure D-33. Axial power distribution of stripes within plate containing peak stripe and peak spot among all cores (7 MW LEU Core 189 element 27 plate 1 stripe 1) shown at BOC and EOC.

Figure D-34. Axial power distribution of stripes within plate containing peak stripe among all cores and adjacent plate (7 MW LEU Core 189 EOC element 27).

Figure D-35. Axial power distribution of outer two plates on opposite end of element containing peak stripe among all cores (7 MW LEU Core 189 EOC element 27).

Figure D-36. Heat flux in each axial segment of each plate (7 MW LEU Core 189 EOC).

Figure D-37. Average plate heat flux shown by element (7 MW LEU Core 189 EOC). ....... D-38

Figure D-38. Lateral peaking factor for each plate of each element (7 MW LEU Core 189 EOC).

Figure D-39. Hot stripe heat flux for each plate of each element (7 MW LEU Core 189 EOC). D-40 


\section{List of Tables}

Table 1. HEU and LEU element dimensions.

Table 2. Nominal dimensions in end channels of LEU elements facing core housing (C-ring)...11

Table 3. Nominal and minimum end channel gaps for various core locations where no direct specification is assumed from fin-tip to nozzle.

Table 4. Nominal and minimum end channel gaps for various core locations where the fin-tip to nozzle dimension is specified.

Table 5. Discretization of the LEU depletion zones and power regions used to generate neutronic power shapes.

Table 6. Control blade position in MITR fresh and depleted LEU cores......................................17

Table 7. Peak heat flux in MITR fresh and depleted LEU 7 MW cores. ....................................20

Table 8. Power peaking versus core average in MITR fresh and depleted LEU cores.................21

Table 9. Peak power regions in MITR fresh and depleted 7 MW LEU cores.............................21

Table 10. Peak power locations in MITR fresh and depleted LEU cores. ...................................22

Table 11. Axial heat flux distributions of $7 \mathrm{MW}$ LEU cores with locations of maximum power.25

Table 12. Axial power distribution of LEU cores with maximum heat flux location or stripe.....26

Table 13. Axial burnup of LEU cores with maximum heat flux locations..................................27

Table 14. Fuel overloading factors for a foil at the upper limits of thickness and ${ }^{235} \mathrm{U}$ content. ..28

Table 15. Combined power distribution uncertainties.............................................................29

Table 16. Stripe peaking factor for various numbers of stripes...................................................

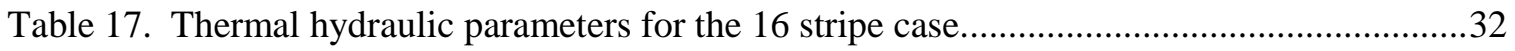

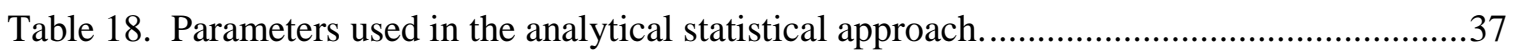

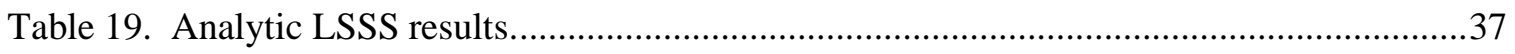

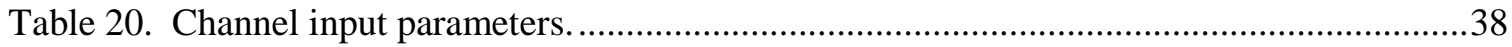

Table A-1. Interior and end channel hydraulic geometry. ..................................................... A-2

Table A-2. Interior and end channel hydraulic geometry (SI units). ................................... A-3

Table A-3. Stripe of interior and end channel hydraulic geometry. ....................................... A-4

Table A-4. Stripe of interior and end channel hydraulic geometry (SI units). ......................... A-5

Table B-1. Peak heat flux in MITR fresh and depleted HEU 6 MW cores ..................................

Table B-2. Power peaking versus core average in MITR fresh and depleted HEU cores. .........B-3

Table B-3. Peak power locations in MITR fresh and depleted HEU cores. ................................ -4

Table C-1. Power peaking by element in HEU fresh and depleted cores at BOC......................... -1

Table C-2. Power peaking by element in HEU depleted cores at EOC. .......................................2-2

Table D-1. Power peaking by element in LEU fresh and depleted cores at BOC.................... D-1

Table D-2. Power peaking by element in LEU depleted cores at EOC................................. D-2

Table D-3. Burnup at peak power locations in MITR depleted LEU cores. ............................ D-3 


\section{Introduction}

The Massachusetts Institute of Technology Reactor (MITR-II) is a research reactor in Cambridge, Massachusetts designed primarily for experiments using neutron beam and in-core irradiation facilities. It delivers a neutron flux comparable to current LWR power reactors in a compact $6 \mathrm{MW}$ core using Highly Enriched Uranium (HEU) fuel.

In the framework of its non-proliferation policies, the international community presently aims to minimize the amount of nuclear material available that could potentially be diverted for nuclear weapons. In this geopolitical context, most research and test reactors both domestic and international have started a program of conversion to the use of Low Enriched Uranium (LEU) fuel. A new type of LEU fuel based on an alloy of uranium and molybdenum (UMo) is expected to allow the conversion of compact high performance reactors like the MITR-II reactor.

The MCNP5 HEU and LEU MITR neutronic models were previously compared to experimental benchmark data for the MITR-II [1]. This same model was used with a finer spatial depletion in order to generate power distributions. This report discusses LEU core power distributions which were generated for the MITR reactor to provide power shapes and associated geometries for thermal hydraulic analysis. The MITR core loading is very flexible, and consists of 27 fuel element positions in addition to the ability to rotate or flip elements. Additionally, the MITR reactor typically reloads fuel that has been loaded in the reactor over the course of the previous several years. Due to this versatility, a variety of core states were studied in order to obtain representative power shapes over a range of conditions. 


\section{Geometry of LEU Core}

The MIT Reactor (MITR-II) core has a hexagonal design that contains twenty-seven fuel positions in three radial rings (A, B, and $\mathrm{C}$ ), as shown in Figure 1. Typically three of these positions (two in the A-ring and one in the B-ring) are filled with either an in-core experimental facility or a solid aluminum dummy element to reduce power peaking. The remaining positions are filled with standard MITR-II fuel elements.

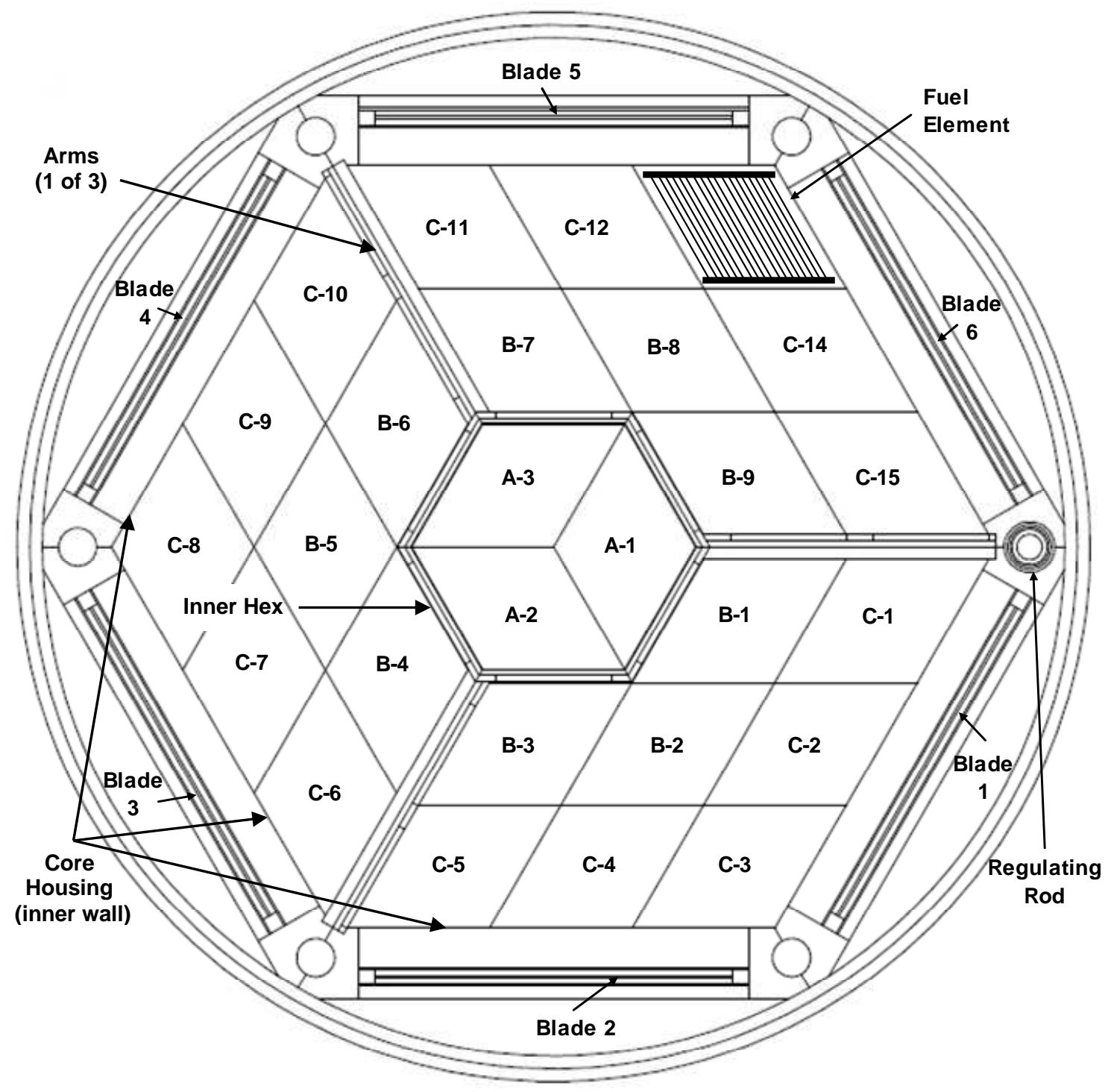

Figure 1. Layout of the MIT reactor core.

\subsection{Nominal Element Geometry}

The proposed LEU design was discussed in [1]. Each rhomboid-shaped LEU fuel element contains eighteen aluminum-clad fuel plates with a fuel zone thickness of $0.508 \mathrm{~mm}(0.020 \mathrm{inch})$ and fuel zone length of $56.8325 \mathrm{~cm}$ (22.375 inch). The LEU fuel modeled is a uraniummolybdenum monolithic alloy enriched up to $19.75 \%{ }^{235} \mathrm{U}$, and with $10 \mathrm{wt} \%$ Mo at an overall 
fuel density of $17.02 \mathrm{~g} / \mathrm{cm}^{3}$. The cladding, (consisting of 6061 aluminum alloy and a thin zirconium layer at the fuel interface) of each fuel plate is $0.254 \mathrm{~mm}(0.010 \mathrm{inch})$ thick. In order to increase heat transfer to the coolant, there are $0.254 \mathrm{~mm}(0.010 \mathrm{inch})$ longitudinal fins in addition to the $0.254 \mathrm{~mm}$ ( 0.010 inch) cladding ( $\mathrm{Zr}$ interlayer and 6061 aluminum). The thickness of the fuel plate is $1.524 \mathrm{~mm}(0.060 \mathrm{inch})$ from fin-tip to fin-tip.

The gaps between fuel plates which form the coolant channels within an element are referred to as interior channels. These interior channels are $1.8288 \mathrm{~mm}(0.072 \mathrm{inch})$ from fin-tip to fin-tip. End channels are present on the outside of the outer fuel plates. Table 1 compares dimensions of the LEU element to HEU, as illustrated schematically (not to scale) in Figures 2-3. The LEU element design, other than as noted, is based upon the MITR HEU fuel element drawing specification shown in Figure 4 [2]. Figures 5, 6 and 7 illustrate fuel element end channels with neighboring elements and also with structural walls (inner hex, arms, core housing). Note that the dimension mil represents 0.001 inches or 0.0254 millimeters.

Table 1. HEU and LEU element dimensions.

\begin{tabular}{|c|c|c|c|}
\hline & $\begin{array}{l}\text { Plate and Channel Dimensions } \\
\text { (Schematic Labels Figs. 2-3) }\end{array}$ & HEU & LEU \\
\hline & Fuel plate length (inch) & 23 & 23 \\
\hline & Fuel meat length (inch) & 22.375 & 22.375 \\
\hline & Fuel plates per assembly & 15 & 18 \\
\hline & Interior (full) channels per assembly & 14 & 17 \\
\hline & End (partial) channels per assembly & 2 & 2 \\
\hline (a) 1 & Fuel meat thickness (mil) & 30 & 20 \\
\hline (b) & Fuel meat width (inch) ${ }^{\mathrm{a}}$ & 2.082 & 2.082 \\
\hline (c) & $\begin{array}{l}\text { Clad thickness } \\
\text { (base of fin to fuel surface) }\end{array}$ & $\begin{array}{c}15 \\
(6061 \mathrm{Al})\end{array}$ & $\begin{array}{c}10 \\
(6061 \mathrm{Al}+\mathrm{Zr})\end{array}$ \\
\hline (d) & Plate to plate pitch, CL to CL (mil) & 158 & 132 \\
\hline (e) 1 & Interior channel water gap (fin tip-to-tip) (mil) & 78 & 72 \\
\hline (f) & Effective interior channel thickness (mil) & 88 & 82 \\
\hline (g) & Finned width (inch) ${ }^{\mathrm{a}}$ & 2.2 & 2.2 \\
\hline & Number of fins per plate & 110 per side & 110 per side \\
\hline (h) & Fin depth (mil) & 10 & 10 \\
\hline (i) 1 & Fin width (mil) & 10 & 10 \\
\hline (j) & Width between fuel meat and side plate (mil) & 113 & 113 \\
\hline$(\mathrm{k})$ & Width between fins and side plate (mil) & 54 & 54 \\
\hline & Channel width (inch) $^{\mathrm{a}}$ & 2.308 & 2.308 \\
\hline$(\mathrm{m})$ & Side plate thickness (mil) & 188 & 188 \\
\hline (n) & $\begin{array}{l}\text { Side plate flat-to-flat, outer edge of one side plate to outer } \\
\text { edge of second side plate on element (inch) }\end{array}$ & 2.375 & 2.375 \\
\hline (o) & Element end flat-to-flat (inch) & 2.380 & 2.380 \\
\hline (p) & Outer plate fin-tip to side plate end plane (mil) & 44 & 38 \\
\hline$(q)$ & Effective outer plate gap to side plate end plane (mil) & 49 & 43 \\
\hline & Outer plate fin-tip to nozzle at full width (mil) & 56.5 & 50.5 \\
\hline & Effective outer plate gap to nozzle at full width (mil) & 61.5 & 55.5 \\
\hline & Outer plate fin-tip to adjacent surface (mil) & \multicolumn{2}{|c|}{$\begin{array}{c}\text { Varies by location, } \\
\text { See section 2.1-2.2, and Appendix A }\end{array}$} \\
\hline & $\begin{array}{l}\text { Effective outer plate gap to } \\
\text { adjacent surface (mil) }\end{array}$ & \multicolumn{2}{|c|}{ See Appendix A } \\
\hline
\end{tabular}




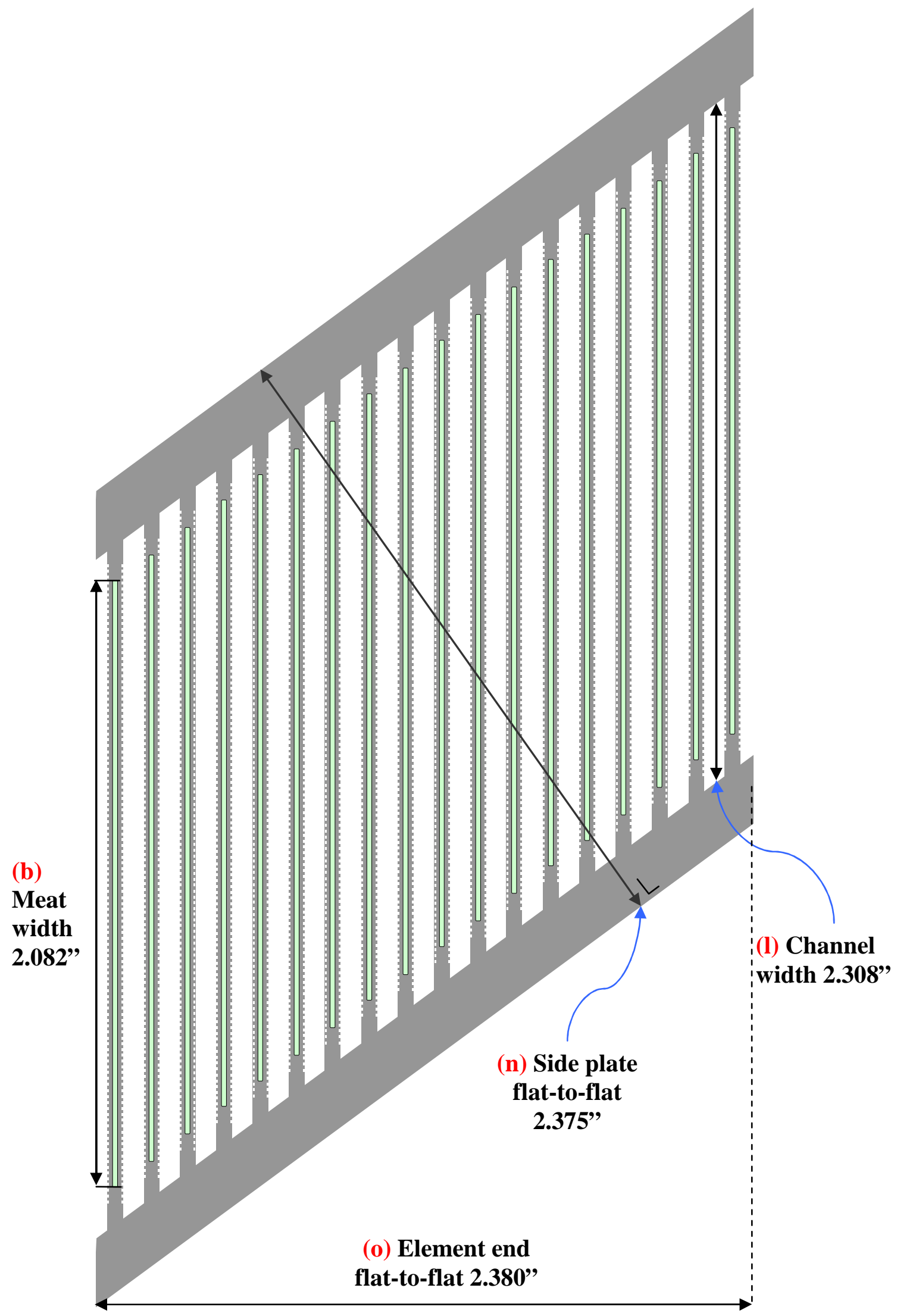

Figure 2. Schematic of MITR LEU fuel element drawn with 18 plates.

(Letters indicate dimensions listed in Table 1) 


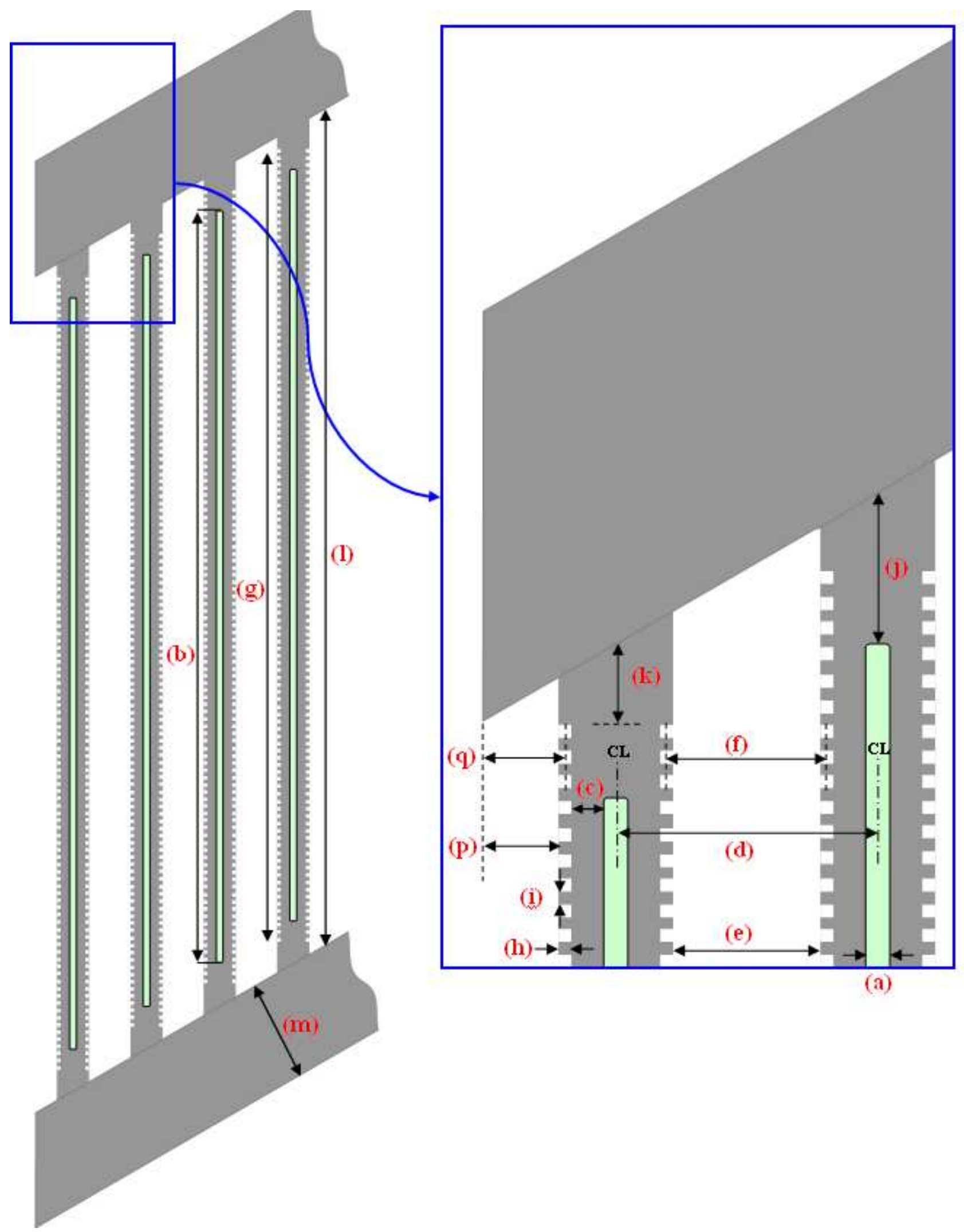

Figure 3. Schematic of MITR LEU fuel element (outer 4 of 18 plates shown). (Letters indicate dimensions listed in Table 1) 


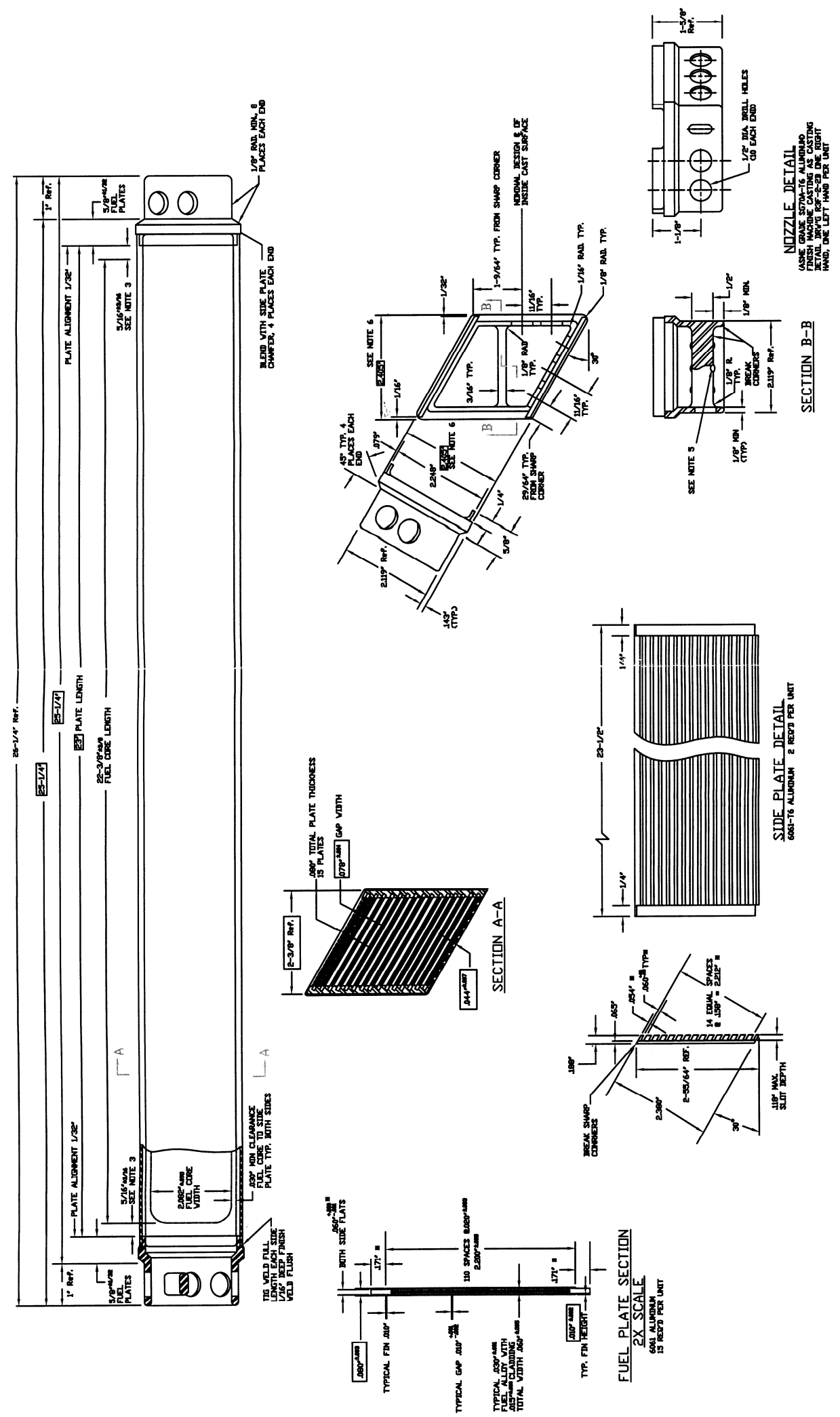

Figure 4. HEU fuel element MITR specification R3F-201-4. 


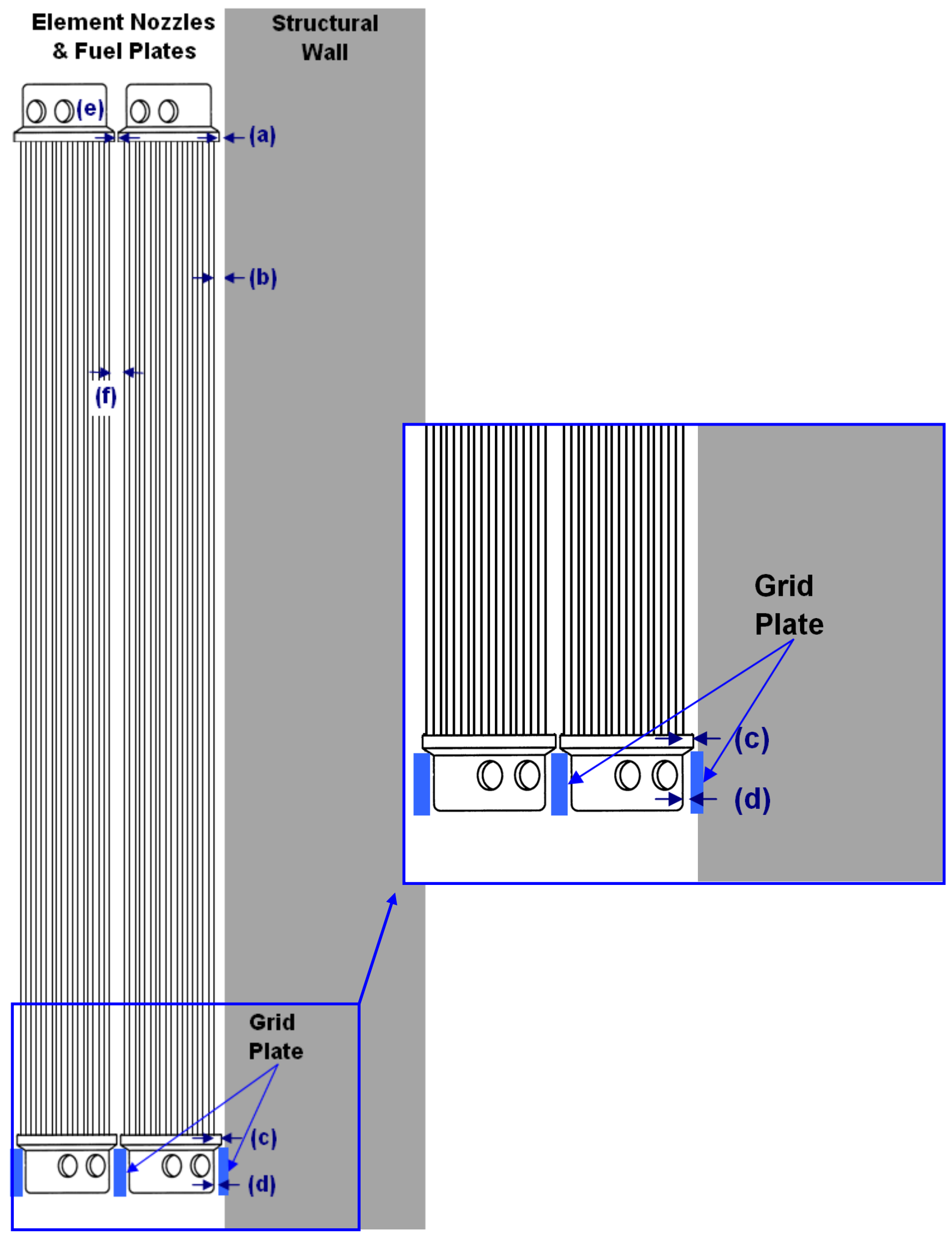

Figure 5. Cross-section of fuel elements illustrating end channels (side plates not shown). (Letters indicate dimensions listed in Table 2) 


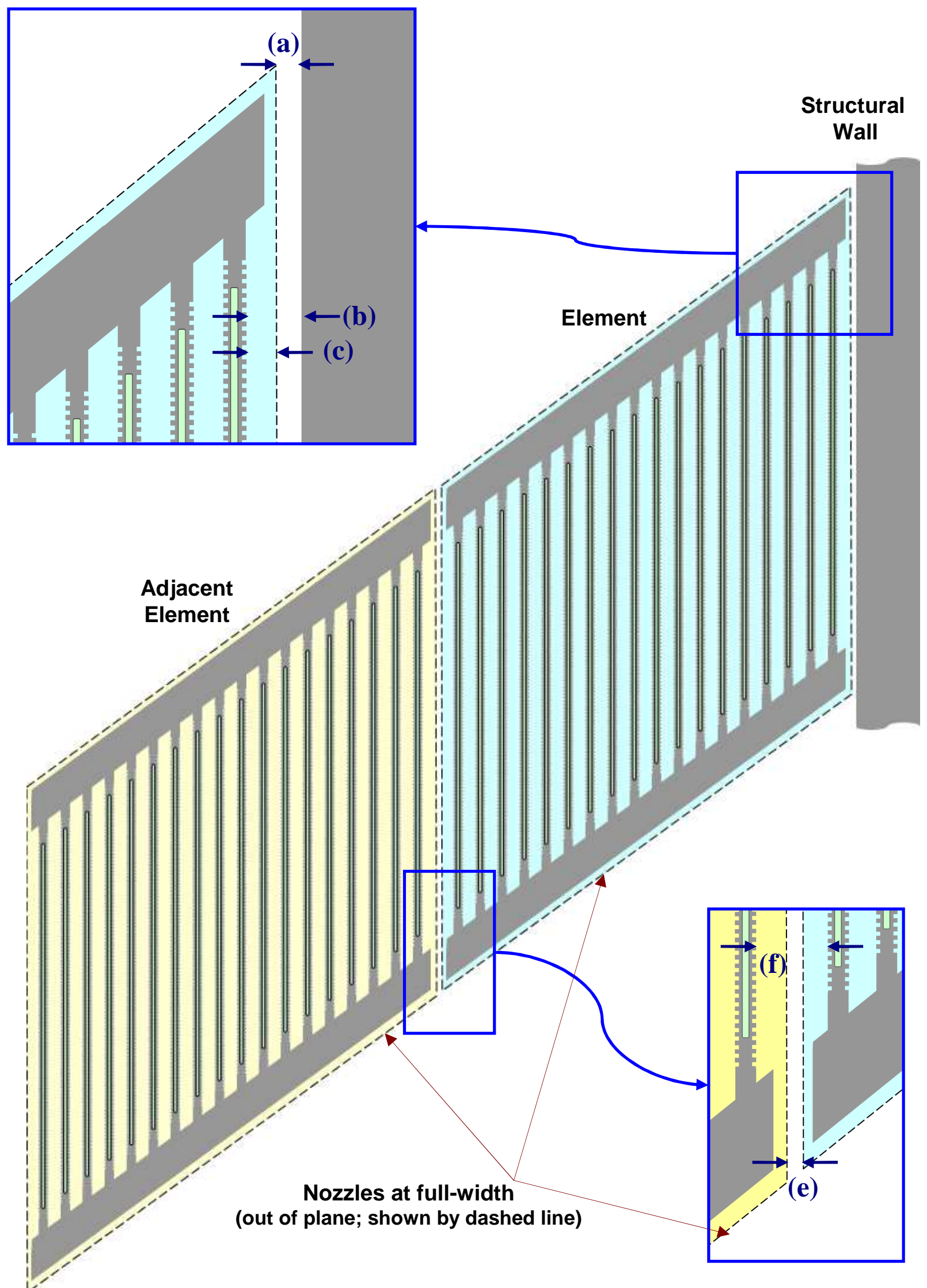

Figure 6. Cross-section of LEU element with neighboring element and structural wall (top view). (Letters indicate dimensions listed in Table 2) 
The definition of the end channel depends upon core geometry outside of the fuel element since it is only defined on one side by the element fuel plate. Figure 7 illustrates the various locations within the core which can define the end channel in MITR. Although listed, configuration (a) in Figure 7 is not a core loading utilized since it would lead to unacceptable power peaking.

The A-ring pitch (2.405 inch) differs from the B and C-ring pitch (2.415 inch). Also, the element distance to various core structural walls (inner hex, arms, core housing) varies. Table 2 gives the various nominal dimensions of each end channel for an example C-ring end channel facing the core housing. Since tolerances are also important, a detailed list of end channels for other configurations is covered in the discussion of off-nominal geometry in section 2.2.2.

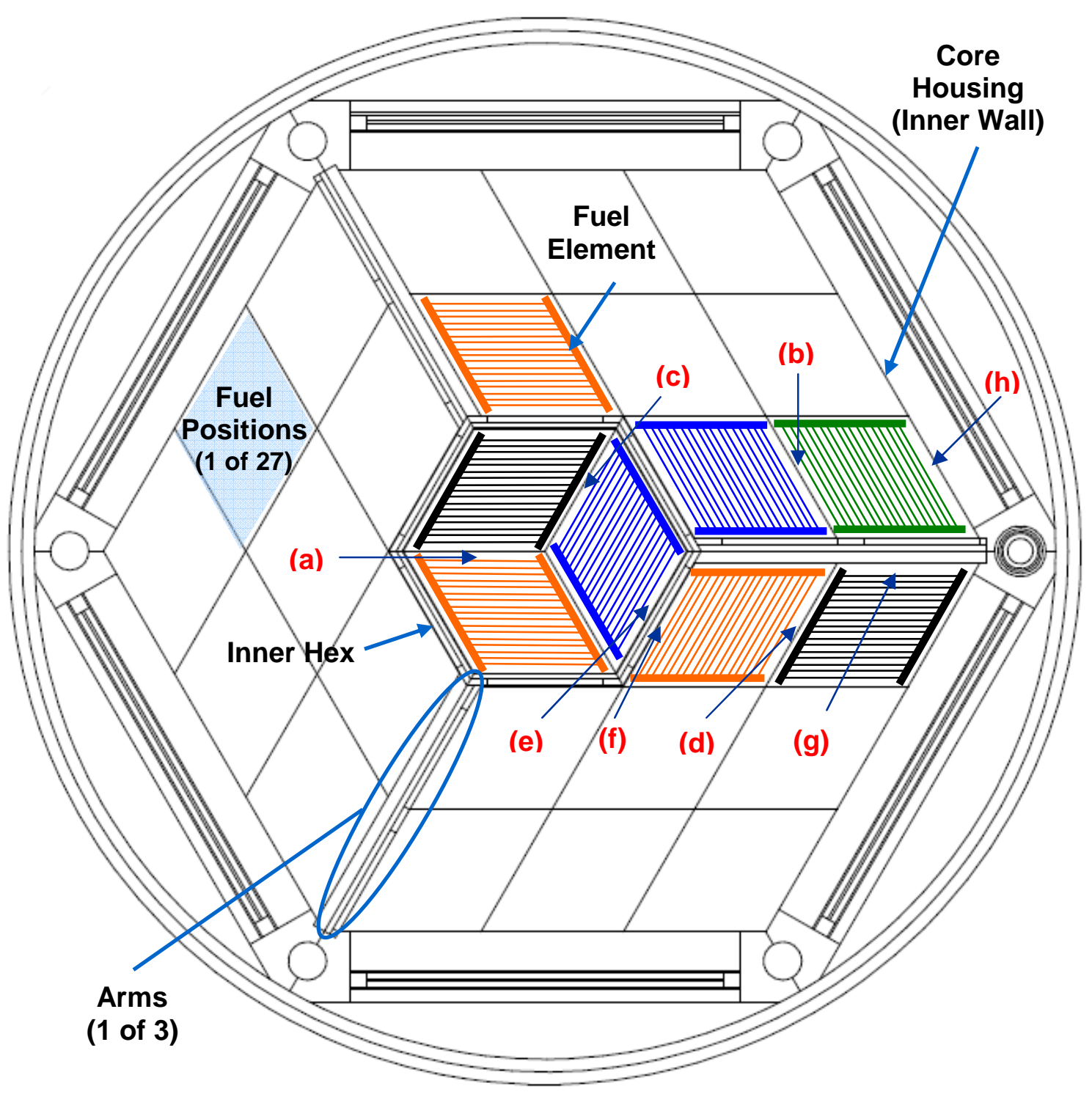

Figure 7. End channels of element in various core positions (see also Table 2). 
Table 2. Nominal dimensions in end channels of LEU elements facing core housing (C-ring).

\begin{tabular}{|c|l|c|}
\hline $\begin{array}{c}\text { Schematic } \\
\text { Label } \\
\text { (Figs. 5-6) }\end{array}$ & Gap between Components & $\begin{array}{c}\text { Dimension } \\
\text { (mil) }\end{array}$ \\
\hline (a) & Nozzle to core housing wall & $15^{\mathrm{a}}$ \\
\hline (b) & Fin-tip to core housing wall & $65.5^{\mathrm{a}}$ \\
\hline (c) & $\begin{array}{l}\text { Fuel plate fin-tip to } \\
\text { full-width of nozzle }\end{array}$ & 50.5 \\
\hline (d) & Nozzle insert to grid plate & 13 \\
\hline (e) & Gap between nozzles & $10^{\mathrm{a}}$ \\
\hline (f) & $\begin{array}{l}\text { End channel between adjacent } \\
\text { elements (fuel plate fin-tip to fin-tip) }\end{array}$ & $111^{\mathrm{a}}$ \\
\hline
\end{tabular}

${ }^{a}$ Listed for C-ring element end channel facing the core housing. Tables 3-4 detail end channels in other configurations.

\subsection{Geometrical Tolerances}

In the preceding section the nominal reactor geometry was discussed. Each nominal interior HEU channel may vary according to a channel average specification of $78 \pm 4$ mil (fin tip-tip) [2]. The nominal interior LEU channel was assumed to have the same specification tolerance, $72 \pm 4$ mil (fin tip-tip) [3]. Since the end channels are not enclosed within the element, tolerances depend upon several factors in addition to the fabricated element.

For the various end channel configurations, as shown in Figure 6, Tables 3-4 lists the end channel dimensions in the nominal case as well as with tolerances considered. Before considering any tolerances in fabrication, the element has a small freedom of movement as inserted in the grid plate. The nozzle at the bottom of the MITR fuel element is smaller than the opening in the grid plate to allow for proper insertion, and so the element may move off-center. The off-center case is defined as element movement towards the adjacent component. In this case dimension (a) as shown in Figures 5-6 would go towards zero at both the top and bottom nozzle of the element even without considering fabrication tolerances. In some cases dimension (a) would not be able to be zero at the lower nozzle due to the lower grid plate; however, after considering the tolerance of the lower grid plate, the (top and bottom) nozzles of an off-center element could touch the adjacent component for all cases, as listed in Tables 3-4, and dimension (a) would be zero if fully off-center.

Due to this, an element fully off-center with grid tolerance considered has the same end channel dimension regardless of whether it resides in A, B or C-rings, and is the same for the different structural walls (inner hex, arm, core housing). The only factor influencing the end channel is the facing component. Thus before considering fabrication tolerances on the element or facing component, the end channel (from the fin-tip) is 101 mil for end channels facing another end channel, 65.5 mil facing a side plate, and 50.5 mil next to a structural wall. Since in Tables 3-4, the end channel dimensions for off-center with grid tolerance considered do not include fabrication tolerances for the element or adjacent components, these are considered next. 


\subsubsection{LEU geometrical tolerances based upon current HEU specifications}

Element fabrication tolerances considered are listed in Table 3 based upon the HEU element specification, and preliminary LEU analysis [2] [3]. Additionally, the core structural wall (inner hex, arm, or core housing) is not flat, and so a bulge (axially averaged) toward the element would reduce the end channel flow area. As in the case of off-center with grid tolerances, the end channel depends only on the facing component. For an end channel facing another end channel, where both elements are off-center towards each other, the minimum end channel (minimum offcenter with tolerances) is 73 mil (fin tip-tip). Since this is more than the nominal interior channel gap, this could not be the limiting channel thermal hydraulically (unless the heat flux from multiple plates were to be analyzed in a multi-channel model). The minimum off-center with tolerances end channel is $41.5 \mathrm{mil}$ (from fin tip) facing a side plate, and $31.5 \mathrm{mil}$ (from fin tip) facing a core structural wall such as the inner hex, arm or core housing.

\subsubsection{LEU geometrical tolerances based upon fuel plate to nozzle specification}

Since the minimum end channels are defined by the nozzles touching the adjacent component, a direct specification of the fuel plate to nozzle dimension would allow fewer tolerances to be considered, and if fabrication permits, a tighter tolerance to be directly specified for the end channel dimension. Instead of having to combine separate tolerances for fuel plate fin-tip to side plate, side plate, and nozzle, Table 4 instead lists the end channel minimum off-center with tolerances based upon a dimension from the fuel plate fin-tip to the full width of the nozzle. This assumption is based upon fuel fabrication yet to be performed and hence confirmed.

As previously, the end channel minimum off-center with tolerances in Table 4 depends only upon the facing component and tolerances. Based upon the fin-tip to nozzle specification, Table 4 lists a larger minimum end channel than does Table 3 (allowing additional margin for safe operation). The end channel (from fin-tip) facing a core structural wall (inner hex, arm, core housing) is 37.5 mil, facing a side plate $47.5 \mathrm{mil}$, and for two end channels facing one another 85 mil.

In these cases the minimum dimension of the end channel, based on a direct fin-tip to nozzle specification, as per Table 4, of the end channel is:

$\begin{array}{lll}\text { Two facing end channels } & 101 \mathrm{mil}-16 \mathrm{mil} \text { tolerance }=85 \mathrm{mil} & (16 \% \text { reduction }) \\ \text { Facing side plate } & 65.5 \mathrm{mil}-18 \mathrm{mil} \text { tolerance }=47.5 \mathrm{mil} & (27 \% \text { reduction }) \\ \text { Facing core structural wall } & 50.5 \mathrm{mil}-13 \mathrm{mil} \text { tolerance }=37.5 \mathrm{mil} & (26 \% \text { reduction })\end{array}$

Since as discussed in section 2.2.1, two facing end channels cannot be limiting (unless considering heat flux from multiple plates), and the peaking of end channels facing side plates has not been found to present the highest peaking factors in analyses to date (see Chapter 3), the appropriate, and limiting, case for the end channel will be 50.5 mil less an additional $26 \%$ uncertainty, for a minimum of 37.5 mil given the assumptions on the element fabrication specification. If a direct fin-tip to nozzle specification is not assumed, then the minimum end channel dimension would be $50.5 \mathrm{mil}-19 \mathrm{mil}=31.5 \mathrm{mil}$ (based on HEU element tolerances and [3], see Table 3) which would be a more severe reduction in the end channel of $38 \%$ instead of 26\%. As will be shown in Chapter 3, the fuel plate end cooling channels facing structural walls are found to have the stripes with peak power and so will be important to consider in future thermal hydraulic calculations in coordination with the fuel element tolerances requirements set by safety basis calculations. 
Table 3. Nominal and minimum end channel gaps for various core locations where no direct specification is assumed from fin-tip to nozzle.

\begin{tabular}{|cc|c|c|c|c|c|c|c|}
\cline { 2 - 10 } \multicolumn{1}{l|}{} & \multicolumn{3}{c|}{ End Channel Dimension (from fin-tip) } & \multicolumn{3}{c|}{ Tolerances } \\
Considered
\end{tabular}

${ }^{a}$ Grid opening is larger than the portion of the element nozzle inserted into the grid plate, and so the element may be off-center by up to \pm 13 mil without considering fabrication tolerances.

b Top and bottom element nozzles can touch adjacent components in all cases when grid plate tolerance is considered.

c Tolerances considered, [2] unless noted, were:

Exterior plate fin-tip to end of side plate $38 \pm 4$ mil [3]

Side plate length $2380 \pm 5$ mil

Side plate thickness $188 \pm 5$ mil

Nozzle outer dimension at full width $2405 \pm 5$ mil

Core structural wall (inner hex, arm, or outer hex) tolerance \pm 5 mil so could bulge 5 mil (axial average) towards fuel plate.

${ }^{\mathrm{d}}$ Cases where off-center in the grid plate opening, without accounting for any tolerances, is limited by nozzles contacting the adjacent surface; e.g. in case (g) the nominal distance between fin-tip and the nozzle is 50.5 mil as derived from the nozzle full-width of 2.405 inch and the distance between the end plates of 2.304 inch (outer fin-tips). 
Table 4. Nominal and minimum end channel gaps for various core locations where the fintip to nozzle dimension is specified (assumed pending confirmation when fuel fabrication has been performed).

\begin{tabular}{|c|c|c|c|c|c|c|c|c|}
\hline & \multirow{2}{*}{\multicolumn{4}{|c|}{ End Channel Dimension (from fin-tip) }} & \multirow{2}{*}{\multicolumn{3}{|c|}{$\begin{array}{l}\text { Tolerances } \\
\text { Considered }\end{array}$}} \\
\hline & & & & & & & & \\
\hline $\begin{array}{l}\text { Fig. } 7 \\
\text { Label }\end{array}$ & $\begin{array}{l}\text { End Channel } \\
\text { Configuration }\end{array}$ & $\underset{(\mathrm{mil})}{\text { Nominal }}$ & $\begin{array}{l}\text { Element } \\
\text { Off-Center }^{\mathrm{a}}\end{array}$ & \begin{tabular}{|c|} 
Element \\
Off-Center \\
with Grid \\
Tolerance $^{b}$ \\
\end{tabular} & $\begin{array}{c}\text { Minimum } \\
\text { Off-Center } \\
\text { With } \\
\text { Tolerances }^{\mathrm{c}}\end{array}$ & $\begin{array}{l}\text { Fin-tip } \\
\text { to } \\
\text { Nozzle } \\
\end{array}$ & $\begin{array}{l}\text { Side } \\
\text { Plate }\end{array}$ & $\begin{array}{l}\text { Core } \\
\text { Wall }\end{array}$ \\
\hline (a) & $\begin{array}{l}\text { End channel facing } \\
\text { adjacent element end } \\
\text { channel, A-ring }\end{array}$ & 101 & $101^{\mathrm{d}}$ & 101 & 85 & $\mathrm{x} 2$ & & \\
\hline (b) & $\begin{array}{l}\text { End channel facing } \\
\text { adjacent element end } \\
\text { channel, } \mathrm{B} / \mathrm{C} \text { ring }\end{array}$ & 111 & $101^{\mathrm{d}}$ & 101 & 85 & $\mathrm{x} 2$ & & \\
\hline (c) & $\begin{array}{l}\text { End channel facing } \\
\text { adjacent element side } \\
\text { plate, A-ring }\end{array}$ & 65.5 & 65.5 & 65.5 & 47.5 & $\mathrm{x}$ & $\mathrm{x}$ & \\
\hline (d) & $\begin{array}{l}\text { End channel facing } \\
\text { adjacent element side } \\
\text { plate, B/C-ring }\end{array}$ & 75.5 & $65.5^{\mathrm{d}}$ & 65.5 & 47.5 & $\mathrm{x}$ & $\mathrm{x}$ & \\
\hline (e) & $\begin{array}{l}\text { End channel facing } \\
\text { inner hex (A-ring) }\end{array}$ & 68.5 & 55.5 & 50.5 & 37.5 & $\mathrm{x}$ & & $\mathrm{x}$ \\
\hline (f) & $\begin{array}{l}\text { End channel facing } \\
\text { inner hex (B-ring) }\end{array}$ & 67.5 & 54.5 & 50.5 & 37.5 & $\mathrm{x}$ & & $\mathrm{x}$ \\
\hline (g) & $\begin{array}{l}\text { End channel facing } \\
\text { Arm }\end{array}$ & 55.5 & $50.5^{\mathrm{d}}$ & 50.5 & 37.5 & $\mathrm{x}$ & & $\mathrm{x}$ \\
\hline (h) & $\begin{array}{l}\text { End channel facing } \\
\text { outer hex }\end{array}$ & 65.5 & 52.5 & 50.5 & 37.5 & $\mathrm{x}$ & & $\mathrm{x}$ \\
\hline
\end{tabular}

${ }^{a}$ Grid opening is larger than the portion of the element nozzle inserted into the grid plate, and so the element may be off-center by up to \pm 13 mil without considering fabrication tolerances.

b Top and bottom element nozzles can touch adjacent components in all cases when grid plate tolerance is considered.

c Tolerances considered, [2] unless noted, were:

Exterior plate fin-tip to nozzle outer dimension $\mathbf{5 0 . 5} \pm \mathbf{8}$ mil (assumed in this report pending confirmation when fuel fabrication has been performed)

Side plate thickness $188 \pm 5$ mil

Core structural wall (inner hex, arm, or outer hex) tolerance \pm 5 mil so may bulge 5 mil (axial average) towards fuel plate.

${ }^{\mathrm{d}}$ Cases where off-center in the grid plate opening, without accounting for any tolerances, is limited by nozzles contacting the adjacent surface; e.g. in case (g) the nominal distance between fin-tip and the nozzle is 50.5 mil as derived from the nozzle full-width of 2.405 inch and the distance between the end plates of 2.304 inch (outer fin-tips). 


\section{LEU Power Distributions}

In order to characterize power distributions over a range of MITR LEU core configurations, a set of fresh and depleted cores was generated. The LEU depleted cores are analogous to a set of 12 historical HEU cores from the years 2007-2009. The depleted HEU cores were previously studied, in addition to the HEU all-fresh Core 2, for comparison and validation of HEU and LEU modeling results to HEU experimental benchmark data [1].

\subsection{Calculation Methodology for Power Distributions}

Power distributions generated are based upon an MCODE [4] depletion using ORIGEN2 [5] with independently depleting spatial zones as given in Table 5, where divisions are equally spaced other than plate groupings. The grouping of the plates used in the depletion is depicted in Figure 8. Dimensional details of the fuel, as well as a detailed description of the MITR MCNP core model, are found in reference [1]. All calculations of heat flux are based upon an area of fuel meat (referred to as foil for LEU) without considering any additional area for the fins or un-fueled regions on either side of the foil. Thus the area used to calculate heat flux from the fueled portion of each plate is both sides of the fuel meat zone 22.375 inches in length and 2.082 inches in width. Consideration of the additional heat transfer provided by fins is not taken into account during calculation of power distributions, but instead in the thermal hydraulic modeling of MITR.

Table 5. Discretization of the LEU depletion zones and power regions used to generate neutronic power shapes.

\begin{tabular}{|c|c|c|c|}
\hline Regions & $\begin{array}{c}\text { MCNP Model } \\
\text { Geometry }\end{array}$ & Depletion & Power Shape \\
\hline Plate division & Each plate discrete & $\begin{array}{c}\text { Each plate discreet } \\
6 \text { zones }\end{array}$ & $\begin{array}{c}\text { Each plate discreet } \\
15 \text { (HEU) } \\
18 \text { (LEU) }\end{array}$ \\
\hline Fuel axial division & Continuous & 6 & 18 \\
\hline Fuel lateral division & Continuous & 1 & 4 \\
\hline $\begin{array}{c}\text { Mesh Zones in } \\
\text { LEU core }\end{array}$ & - & 864 & 31104 \\
\hline
\end{tabular}




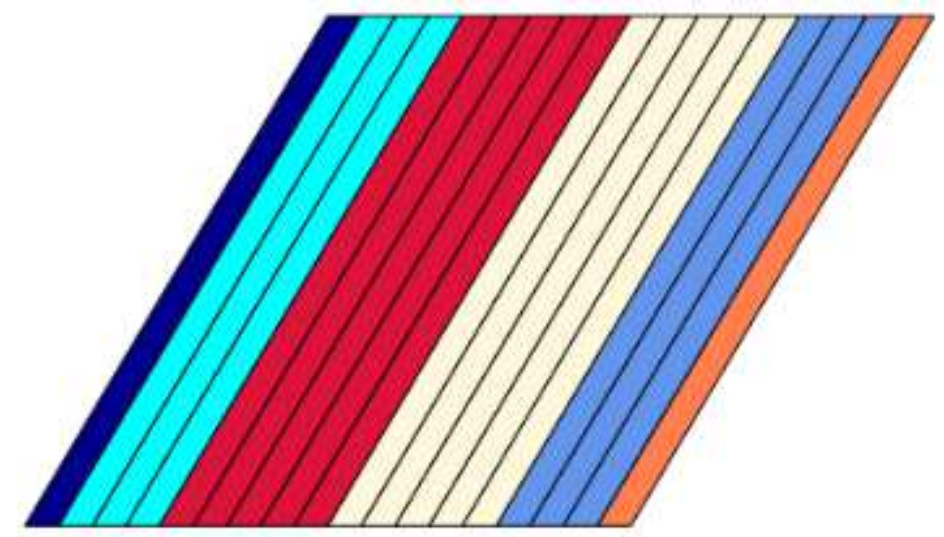

Figure 8. Depiction of plate grouping used in the depletion of MITR LEU cores.

With this discretization, the all-fresh LEU core (22 elements) consists of 28512 regions for power distribution, and the LEU depleted cores (24 elements) consist of 864 independently depleting material regions and 31104 regions for power distribution. Based upon the analysis described in section 4.1 of this work, power distributions are generated by dividing each plate into 4 stripes along the 2.082 inch width. The four stripes were shown in section 4.1 to conservatively represent the power peaking at the outside of each plate without explicitly taking into account lateral heat conduction. Since striping is based upon this analysis, the results presented in this work are intended only for use in a thermal hydraulic analysis which does not explicitly model or otherwise incorporate the effects of lateral heat conduction.

With this discretization used for generation of the power distributions, each axial region is 3.16 $\mathrm{cm}$ tall, and each stripe $1.32 \mathrm{~cm}$ wide laterally along each plate. Thus the smallest region is the intersection of these comprising a region of $4.17 \mathrm{~cm}^{2}$ of fuel meat area which is referred to as a spot in this report where locations are reported as peak spots.

\subsection{Core Loading Sequence for Power Distributions}

The LEU depleted cores were modeled with the same MCNP model used in prior work on LEU fresh and HEU fresh and depleted core analysis [1] and with identical fuel loading and movement operations. Since the reactivity characteristics of the LEU fuel have changed, most notably that LEU fuel lifetime is significantly longer, the LEU Beginning of Cycle (BOC) burnup was scaled so that the control blade position was matched to HEU for Core 179 BOC. A fixed operating cycle was used to deplete each of the twelve LEU cores at a constant 7 MW power for a duration of 47 days. A critical blade height search was performed at each time step to ensure the core was critical to within $0.2 \% \Delta \mathrm{k} / \mathrm{k}$. Figure 9 shows the blade position for over the course of the twelve cores, and the BOC and end of cycle (EOC) control blade position for these cores is listed in Table 6. The blade positions are given in terms of the distance withdrawn from full insertion. When fully inserted the bottom of the borated stainless steel control material is $2.38 \mathrm{~cm}$ above the bottom of the fuel meat. Full control blade withdrawal is $53.34 \mathrm{~cm}$ (21 inches). 


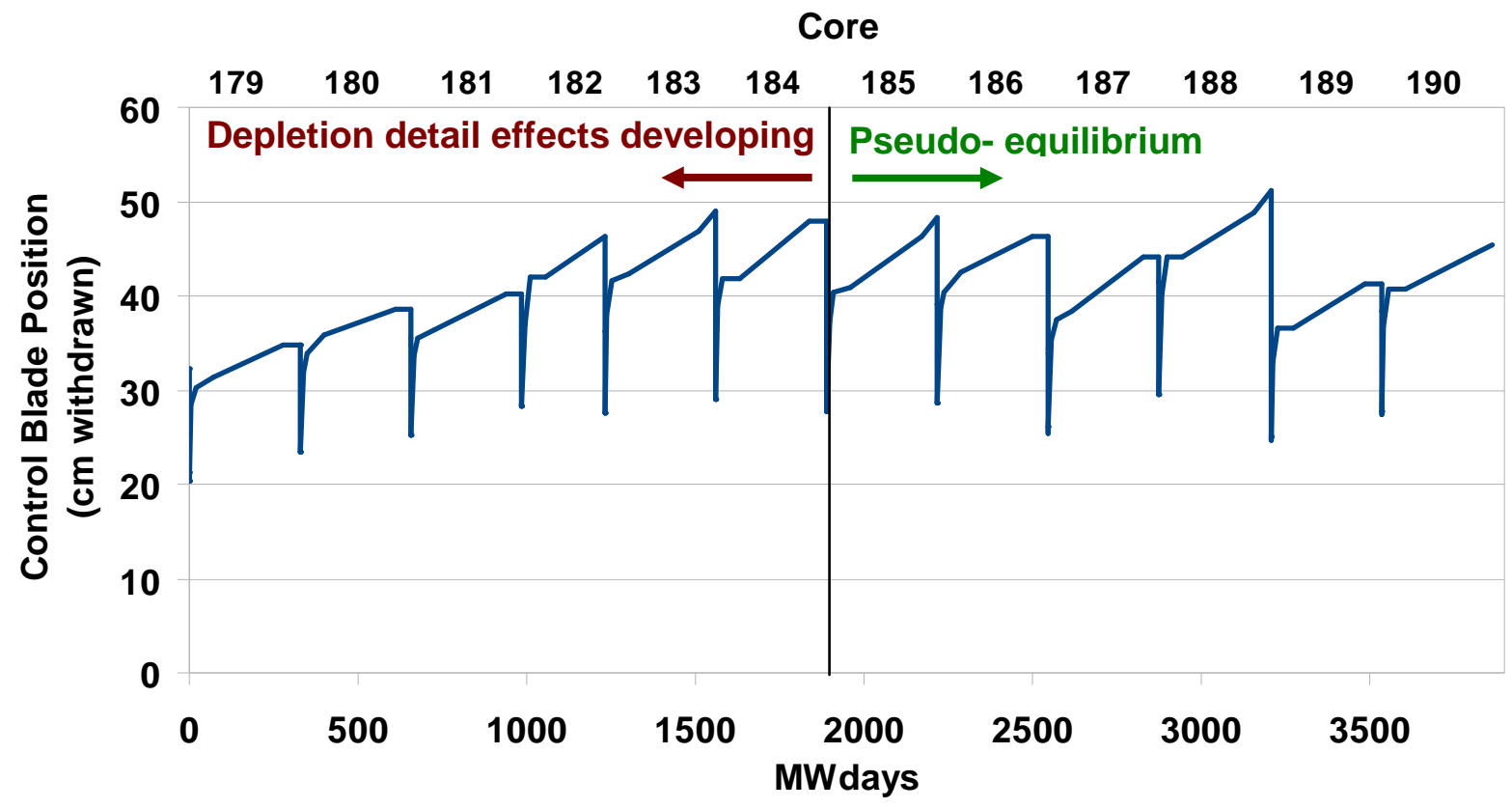

Figure 9. Critical control blade position throughout the depletion of LEU Cores 179-190.

LEU blade heights are seen to transition during the first cores as both burnup shape and reactivity impacts of the 47 day LEU cycle are established in the modeling. The first core state (Core 179) is generated by matching element average burnup from a separate depletion generated without control blades inserted. Control blades withdrawn were considered to better represent an average state for an initialization depletion (without shuffling) since elements are often reoriented by flipping, and MITR cores are on average operated with control blades considerably (70\%) withdrawn. As a consequence, power distributions from the second half of the LEU cores series are considered representative. Thus Cores 185-190 are pseudo-equilibrium power distributions used for thermal hydraulic analyses.

Table 6. Control blade position in MITR fresh and depleted LEU cores.

\begin{tabular}{|c|c|c|c|}
\hline & $\begin{array}{l}\text { LEU } \\
\text { Core }\end{array}$ & $\begin{array}{c}\text { BOC Control } \\
\text { Blades } \\
\text { (cm withdrawn) }\end{array}$ & $\begin{array}{c}\text { EOC Control } \\
\text { Blades } \\
\text { (cm withdrawn) }\end{array}$ \\
\hline & LEU Fresh & 20.74 & - \\
\hline \multirow{6}{*}{$\begin{array}{l}\text { Depletion } \\
\text { Detail } \\
\text { Developing in } \\
\text { the Model }\end{array}$} & 179 & 20.41 & 34.81 \\
\hline & 180 & 23.36 & 38.50 \\
\hline & 181 & 25.20 & 40.22 \\
\hline & 182 & 28.36 & 46.27 \\
\hline & 183 & 27.60 & 48.93 \\
\hline & 184 & 28.95 & 47.89 \\
\hline \multirow{6}{*}{$\begin{array}{c}\text { Pseudo- } \\
\text { Equilibrium } \\
\text { Cycles } \\
\text { Representative } \\
\text { of Typical } \\
\text { Operation }\end{array}$} & 185 & 27.73 & 48.37 \\
\hline & 186 & 28.69 & 46.38 \\
\hline & 187 & 26.14 & 44.22 \\
\hline & 188 & 29.61 & 51.11 \\
\hline & 189 & 24.60 & 41.31 \\
\hline & 190 & 27.81 & 45.38 \\
\hline
\end{tabular}


The MCODE depletion was performed with MCNP5 [6] generated flux and reaction rates at 1, 3, 10, 40, and 47 days during each cycle. An exception was LEU Core 182 which was ended at 35 days. This is consistent with HEU Core 182, which had limited excess reactivity, and was run for a significantly shorter time than the other HEU cores.

The twelve LEU cores modeled in this way provide 552 days of full-power $7 \mathrm{MW}$ operation (3864 MWd). Figure 10 shows measurements from the twelve historical HEU cores, which achieved $2327 \mathrm{MWd}$ of burnup. In comparison, the LEU core modeling achieved a significantly higher burnup (66\% greater) as expected due to the higher ${ }^{235} \mathrm{U}$ fuel element loading. These historical HEU cores operated at various powers, which averaged 4.5 MW which was close to the MITR licensed operating power of $5 \mathrm{MW}$ at that time. In 2010 MITR received a license to operate at $6 \mathrm{MW}$. In order to compare the effective full power days (EFPD) for fuel performance to the $7 \mathrm{MW}$ LEU cores, the HEU EFPD in Figure 10 are calculated based upon the current full HEU core power of $6 \mathrm{MW}$ which provides a reference for equivalent performance [7].

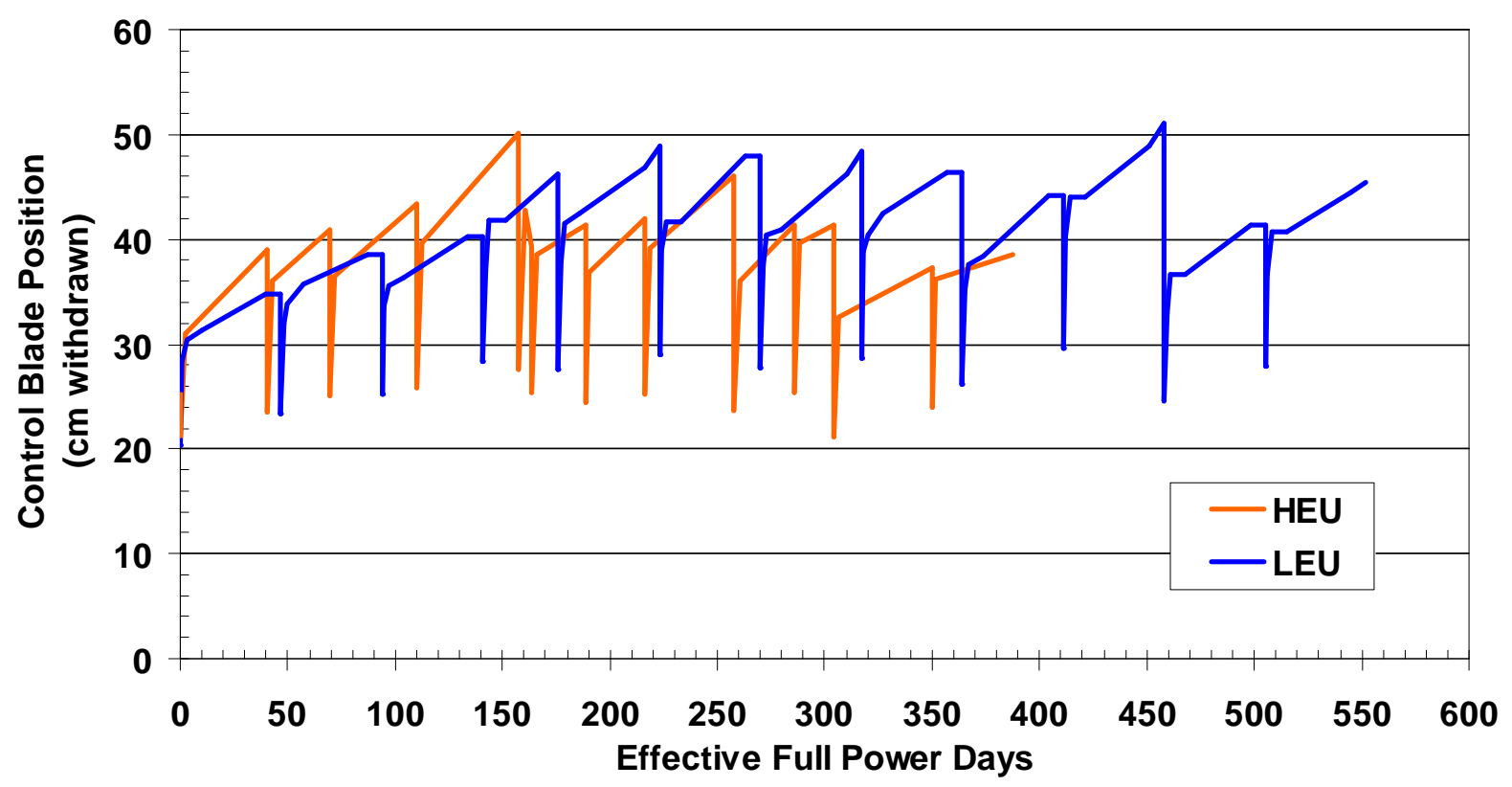

Figure 10. Critical control blade position throughout HEU and LEU Cores 179-190, comparing equivalent performance (EFPD based on full power 6 MW HEU, 7 MW LEU).

Compared to the 552 EFPD from the twelve LEU cores ( $7 \mathrm{MW}$ full power), the HEU cores operated for 338 EFPD (based on 6 MW full power) which is a $42 \%$ increase in EFPD, or a $30 \%$ reduction in fuel element consumption. Fuel performance estimates are approximate, particularly since no attempt was made to match excess reactivity between HEU and the 47 day LEU cycle modeled at the end of Core 190. 


\subsection{Power Distributions of Fresh and Depleted LEU Cores}

Peak heat flux for the twelve depleted LEU Cores 179-190 (24 element cores) are shown in Table 7 at BOC and EOC along with the 22 element all-fresh LEU core. Peaking factors, such as those shown in Table 8, are calculated relative to the average core power. These tables list the peak element, plate, axial, stripe and spot. See also Appendix D.1 for core maps of LEU power distributions, and Appendix D.2 for a discussion of local peaking of various regions such as the stripe heat flux relative to the average heat flux within that same plate. Peaking factors throughout this work, aside from Appendix D.2, are calculated using heat flux for a region normalized by the core average heat flux.

The peak power stripe represents the axial-average within one of the four vertical stripes of a fuel plate, and the peak power axial is an average of the four stripes at each axial level within a plate. Whereas the peaking factors are independent of power, the heat flux and segment power were calculated with a total LEU core power of $7 \mathrm{MW}$. Power distributions were calculated based on modeling with all $7 \mathrm{MW}$ of the fission energy deposited locally within the fuel meat. Thermal hydraulic analyses separately incorporate factors for deposition within various core regions outside of the fuel meat [8]. Table 8 includes the power peaking of the fresh LEU core, though a direct comparison should be based upon the heat flux since the 22 element fresh core has a higher average power density and flow per element than the 24 element depleted cores. The stripe with the highest power peaking factor of 2.12 was found in LEU Core $189 \mathrm{EOC}$, and corresponds to a peak stripe-average heat flux of $57.2 \mathrm{~W} / \mathrm{cm}^{2}$ of foil. Various maximum peak power regions in MITR fresh and depleted 7 MW LEU cores are summarized in Table 9.

Core peak locations from Tables 7-8 are noted in Table 10 and shown in Figure 11. In Figure 11 each peak location is labeled and plate orientation is illustrated by the parallel lines. Locations are designated by element, plate, stripe, and axial. For example element 27, plate 18, stripe 4, bottom axial is designated by $27 \mathrm{P} 18 \mathrm{~S} 4 \mathrm{Ax} 18$. In order to provide a reference to the alphanumeric location commonly used in MITR documentation, the ring order designation is displayed in Figure 11. For example, above the element number designation "27", is the ring designation "C-15". All peaks were found to be located in an outer stripe (stripe 1 or 4 ) of an end plate (plate 1, HEU plate 15 , or LEU plate 18 ). The power was axially peaked between the center and bottom due to the partial insertion of control blades. 
Table 7. Peak heat flux in MITR fresh and depleted LEU 7 MW cores.

\begin{tabular}{|c|c|c|c|c|c|c|}
\hline $\begin{array}{c}\text { Heat Flux } \\
\text { (W/cm } \mathrm{cm}^{2} \text { of foil) }\end{array}$ & $\begin{array}{c}\text { Pseudo- } \\
\text { Equilibrium }\end{array}$ & $\begin{array}{l}\text { Peak } \\
\text { Spot }\end{array}$ & $\begin{array}{l}\text { Peak } \\
\text { Stripe }\end{array}$ & $\begin{array}{l}\text { Peak } \\
\text { Axial }\end{array}$ & $\begin{array}{l}\text { Peak } \\
\text { Plate }\end{array}$ & $\begin{array}{c}\text { Peak } \\
\text { Element }\end{array}$ \\
\hline $\begin{array}{c}\text { LEU Fresh Core } 2 \\
\text { (22 element) }\end{array}$ & all-fresh & 85.6 & 52.9 & 76.1 & 49.4 & 39.1 \\
\hline LEU Core 179 BOC & no & 76.2 & 51.6 & 68.9 & 48.5 & 37.0 \\
\hline LEU Core 180 BOC & no & 73.2 & 49.8 & 69.4 & 46.9 & 36.2 \\
\hline LEU Core 181 BOC & no & 76.6 & 50.9 & 69.1 & 45.6 & 35.6 \\
\hline LEU Core 182 BOC & no & 76.1 & 53.0 & 69.0 & 45.2 & 35.1 \\
\hline LEU Core 183 BOC & no & 78.3 & 53.6 & 71.5 & 45.4 & 36.2 \\
\hline LEU Core 184 BOC & no & 74.6 & 52.0 & 68.0 & 44.5 & 35.5 \\
\hline LEU Core 185 BOC & yes & 71.6 & $50.4^{\mathrm{a}}$ & 65.3 & 47.9 & 35.4 \\
\hline LEU Core 186 BOC & yes & 70.6 & 48.6 & 67.1 & 46.4 & 34.7 \\
\hline LEU Core 187 BOC & yes & 74.3 & 50.1 & 70.8 & 46.2 & 34.3 \\
\hline LEU Core 188 BOC & yes & 73.5 & 49.5 & 70.3 & 44.9 & 33.6 \\
\hline LEU Core 189 BOC & yes & $76.6^{a}$ & 49.7 & 68.5 & 44.4 & 35.7 \\
\hline LEU Core 190 BOC & yes & 73.5 & 50.2 & 66.8 & 43.2 & 35.1 \\
\hline LEU Core 179 EOC & no & 74.6 & 54.7 & 69.8 & 49.3 & 34.7 \\
\hline LEU Core 180 EOC & no & 72.0 & 54.5 & 67.9 & 49.5 & 34.1 \\
\hline LEU Core 181 EOC & no & 73.0 & 57.5 & 66.4 & 50.1 & 33.6 \\
\hline LEU Core 182 EOC & no & 72.6 & 59.7 & 65.1 & 52.4 & 33.2 \\
\hline LEU Core 183 EOC & no & 73.0 & 61.2 & 66.4 & 54.4 & 33.9 \\
\hline LEU Core 184 EOC & no & 69.3 & 58.0 & 63.3 & 51.6 & 33.5 \\
\hline LEU Core 185 EOC & yes & 66.6 & 56.3 & 61.0 & 50.1 & 33.2 \\
\hline LEU Core 186 EOC & yes & 66.0 & 54.3 & 62.6 & 48.6 & 32.8 \\
\hline LEU Core 187 EOC & yes & 71.1 & 56.2 & 67.0 & 51.7 & 32.3 \\
\hline LEU Core 188 EOC & yes & 66.7 & 54.4 & 64.0 & 51.9 & 31.7 \\
\hline LEU Core 189 EOC & yes & 72.2 & $57.2^{\mathrm{a}}$ & 65.9 & 50.3 & 33.6 \\
\hline LEU Core 190 EOC & yes & 68.8 & 56.5 & 62.6 & 50.1 & 33.1 \\
\hline $\begin{array}{c}\text { Pseudo-Equilibrium } \\
\text { Maximum }\end{array}$ & & 76.6 & 57.2 & 70.8 & 54.4 & 35.7 \\
\hline
\end{tabular}

${ }^{\mathrm{a}}$ Indicates that this region has been evaluated thermal hydraulically in section 4.2. 
Table 8. Power peaking versus core average in MITR fresh and depleted LEU cores.

\begin{tabular}{|c|c|c|c|c|c|c|}
\hline $\begin{array}{c}\text { Power Peaking } \\
\text { vs. Core Average }\end{array}$ & $\begin{array}{c}\text { Pseudo- } \\
\text { Equilibrium }\end{array}$ & $\begin{array}{c}\text { Peak } \\
\text { Spot }\end{array}$ & $\begin{array}{c}\text { Peak } \\
\text { Stripe }\end{array}$ & $\begin{array}{c}\text { Peak } \\
\text { Axial }\end{array}$ & $\begin{array}{c}\text { Peak } \\
\text { Plate }\end{array}$ & $\begin{array}{c}\text { Peak } \\
\text { Element }\end{array}$ \\
\hline $\begin{array}{c}\text { LEU Fresh Core 2 } \\
\text { (22 element) }\end{array}$ & all-fresh & 2.91 & 1.80 & 2.59 & 1.68 & 1.33 \\
\hline LEU Core 179 BOC & no & 2.83 & 1.91 & 2.56 & 1.80 & 1.37 \\
\hline LEU Core 180 BOC & no & 2.71 & 1.85 & 2.57 & 1.74 & 1.34 \\
\hline LEU Core 181 BOC & no & 2.84 & 1.89 & 2.57 & 1.69 & 1.32 \\
\hline LEU Core 182 BOC & no & 2.82 & 1.97 & 2.56 & 1.68 & 1.30 \\
\hline LEU Core 183 BOC & no & 2.90 & 1.99 & 2.65 & 1.69 & 1.34 \\
\hline LEU Core 184 BOC & no & 2.77 & 1.93 & 2.52 & 1.65 & 1.32 \\
\hline LEU Core 185 BOC & yes & 2.66 & $1.87^{\mathrm{a}}$ & 2.42 & 1.78 & 1.31 \\
\hline LEU Core 186 BOC & yes & 2.62 & 1.80 & 2.49 & 1.72 & 1.29 \\
\hline LEU Core 187 BOC & yes & 2.76 & 1.86 & 2.63 & 1.71 & 1.27 \\
\hline LEU Core 188 BOC & yes & 2.73 & 1.84 & 2.61 & 1.67 & 1.25 \\
\hline LEU Core 189 BOC & yes & $2.84^{\mathrm{a}}$ & 1.85 & 2.54 & 1.65 & 1.33 \\
\hline LEU Core 190 BOC & yes & 2.73 & 1.86 & 2.48 & 1.60 & 1.30 \\
\hline LEU Core 179 EOC & no & 2.77 & 2.03 & 2.59 & 1.83 & 1.29 \\
\hline LEU Core 180 EOC & no & 2.67 & 2.02 & 2.52 & 1.84 & 1.26 \\
\hline LEU Core 181 EOC & no & 2.71 & 2.13 & 2.46 & 1.86 & 1.25 \\
\hline LEU Core 182 EOC & no & 2.69 & 2.21 & 2.41 & 1.95 & 1.23 \\
\hline LEU Core 183 EOC & no & 2.71 & 2.27 & 2.46 & 2.02 & 1.26 \\
\hline LEU Core 184 EOC & no & 2.57 & 2.15 & 2.35 & 1.91 & 1.24 \\
\hline LEU Core 185 EOC & yes & 2.47 & 2.09 & 2.26 & 1.86 & 1.23 \\
\hline LEU Core 186 EOC & yes & 2.45 & 2.01 & 2.32 & 1.80 & 1.22 \\
\hline LEU Core 187 EOC & yes & 2.64 & 2.09 & 2.48 & 1.92 & 1.20 \\
\hline LEU Core 188 EOC & yes & 2.47 & 2.02 & 2.37 & 1.93 & 1.17 \\
\hline LEU Core 189 EOC & yes & 2.68 & $2.12^{\mathrm{a}}$ & 2.44 & 1.87 & 1.25 \\
\hline LEU Core 190 EOC & yes & 2.55 & 2.10 & 2.32 & 1.86 & 1.23 \\
\hline Pseudo-Equilibrium & & $\mathbf{2 . 8 4}$ & $\mathbf{2 . 1 2}$ & $\mathbf{2 . 6 3}$ & $\mathbf{1 . 9 3}$ & $\mathbf{1 . 3 3}$ \\
\hline Maximum & & & & & \\
\hline
\end{tabular}

${ }^{a}$ Indicates that this region has been evaluated thermal hydraulically in section 4.2.

Table 9. Peak power regions in MITR fresh and depleted 7 MW LEU cores.

\begin{tabular}{|c|c|c|c|c|c|}
\hline $\begin{array}{c}\text { Regions of } \\
\text { Maximum Heat } \\
\text { Flux }\end{array}$ & Elements & Core & $\begin{array}{c}\text { Peak Spot } \\
\text { Location }\end{array}$ & $\begin{array}{c}\text { Peaking } \\
\text { Factor } \\
\text { vs. Core } \\
\text { Average }\end{array}$ & $\begin{array}{c}\text { Heat Flux } \\
\text { (W/cm } \\
\text { of foil) }\end{array}$ \\
\hline $\begin{array}{c}\text { Fresh LEU } \\
\text { Peak Spot }\end{array}$ & 22 & LEU Fresh Core 2 & 27P01S1 Ax 18 & 2.91 & 85.6 \\
\hline $\begin{array}{c}\text { LEU Depleted Peak } \\
\text { Spot }\end{array}$ & 24 & LEU Core 189 BOC & 27P01S1 Ax 18 & 2.84 & 76.6 \\
\hline LEU Peak Stripe & 24 & LEU Core 189 EOC & 27P01S1 & 2.12 & 57.2 \\
\hline $\begin{array}{c}\text { LEU Depleted Inner } \\
\text { Ring Peak Stripe }\end{array}$ & 24 & LEU Core 185 BOC & 12P18S4 & 1.87 & 50.4 \\
\hline
\end{tabular}


Table 10. Peak power locations in MITR fresh and depleted LEU cores.

\begin{tabular}{|c|c|c|c|c|c|}
\hline Peak Locations & Peak Spot & $\begin{array}{l}\text { Peak } \\
\text { Stripe }\end{array}$ & Peak Axial & $\begin{array}{l}\text { Peak } \\
\text { Plate }\end{array}$ & $\begin{array}{c}\text { Peak } \\
\text { Element\# }\end{array}$ \\
\hline LEU Fresh Core 2 & 27P01S1 Ax 18 & 01P01S1 & 27P01 Ax 18 & 01P01 & 1 \\
\hline LEU Core 179 BOC & 27P01S1 Ax 18 & $12 \mathrm{P} 18 \mathrm{~S} 4$ & 25P01 Ax 14 & $12 \mathrm{P} 18$ & 2 \\
\hline LEU Core 180 BOC & 27P01S1 Ax 18 & 12P18S4 & 21P01 Ax 13 & 09P18 & 2 \\
\hline LEU Core $181 \mathrm{BOC}$ & 13P18S1 Ax 18 & 13P18S1 & 13P18 Ax 13 & $12 \mathrm{P} 18$ & 2 \\
\hline LEU Core 182 BOC & 13P18S1 Ax 13 & 13P18S1 & 13P18 Ax 13 & $12 \mathrm{P} 18$ & 2 \\
\hline LEU Core 183 BOC & 27P01S1 Ax 13 & 27P01S1 & 27P01 Ax 13 & 02P18 & 2 \\
\hline LEU Core 184 BOC & 27P01S1 Ax 13 & 27P01S1 & 27P01 Ax 13 & 02P18 & 2 \\
\hline LEU Core 185 BOC & 27P01S1 Ax 14 & 12P18S4 & 27P01 Ax 13 & $12 \mathrm{P} 18$ & 2 \\
\hline LEU Core 186 BOC & 14P18S1 Ax 13 & 12P18S4 & 14P18 $\mathrm{Ax} 13$ & $12 \mathrm{P} 18$ & 2 \\
\hline LEU Core 187 BOC & 25P01S4 Ax 13 & 25P01S4 & 24P18 Ax 13 & $12 \mathrm{P} 18$ & 2 \\
\hline LEU Core 188 BOC & 24P18S1 Ax 13 & 25P18S4 & 24P18 Ax 13 & $12 \mathrm{P} 18$ & 2 \\
\hline LEU Core 189 BOC & 27P01S1 Ax 18 & 27P01S1 & 27P01 Ax 13 & 02P01 & 2 \\
\hline LEU Core $190 \mathrm{BOC}$ & 27P01S1 Ax 13 & 27P01S1 & 27P01 Ax 13 & 02P01 & 2 \\
\hline LEU Core 179 EOC & 25P01S4 Ax 12 & 25P01S4 & 25P01 Ax 11 & 25P01 & 2 \\
\hline LEU Core 180 EOC & 25P01S4 Ax 11 & 27P01S1 & 21P01 Ax 11 & $25 \mathrm{P} 01$ & 2 \\
\hline LEU Core 181 EOC & 13P18S1 Ax 12 & 13P18S1 & 13P18 Ax 11 & $13 \mathrm{P} 18$ & 2 \\
\hline LEU Core 182 EOC & 13P18S1 Ax 9 & 13P18S1 & 13P18 Ax 11 & $13 \mathrm{P} 18$ & 2 \\
\hline LEU Core 183 EOC & 27P01S1 Ax 11 & 27P01S1 & 27P01 Ax 11 & 27P01 & 2 \\
\hline LEU Core 184 EOC & 27P01S1 Ax 11 & 27P01S1 & 27P01 Ax 11 & 27P01 & 2 \\
\hline LEU Core 185 EOC & 27P01S1 Ax 11 & 27P01S1 & 27P01 Ax 11 & 27P01 & 2 \\
\hline LEU Core 186 EOC & 14P18S1 Ax 11 & 27P01S1 & 14P18 Ax 10 & $14 \mathrm{P} 18$ & 2 \\
\hline LEU Core 187 EOC & 25P01S4 Ax 11 & 25P01S4 & 24P18 Ax 11 & 25P01 & 2 \\
\hline LEU Core 188 EOC & 24P18S1 Ax 10 & 24P18S1 & 24P18 Ax 10 & 24P18 & 2 \\
\hline LEU Core 189 EOC & 27P01S1 Ax 11 & 27P01S1 & 27P01 Ax 11 & 27P01 & 2 \\
\hline LEU Core 190 EOC & 27P01S1 Ax 11 & 27P01S1 & 27P01 Ax 11 & 27P01 & 2 \\
\hline
\end{tabular}




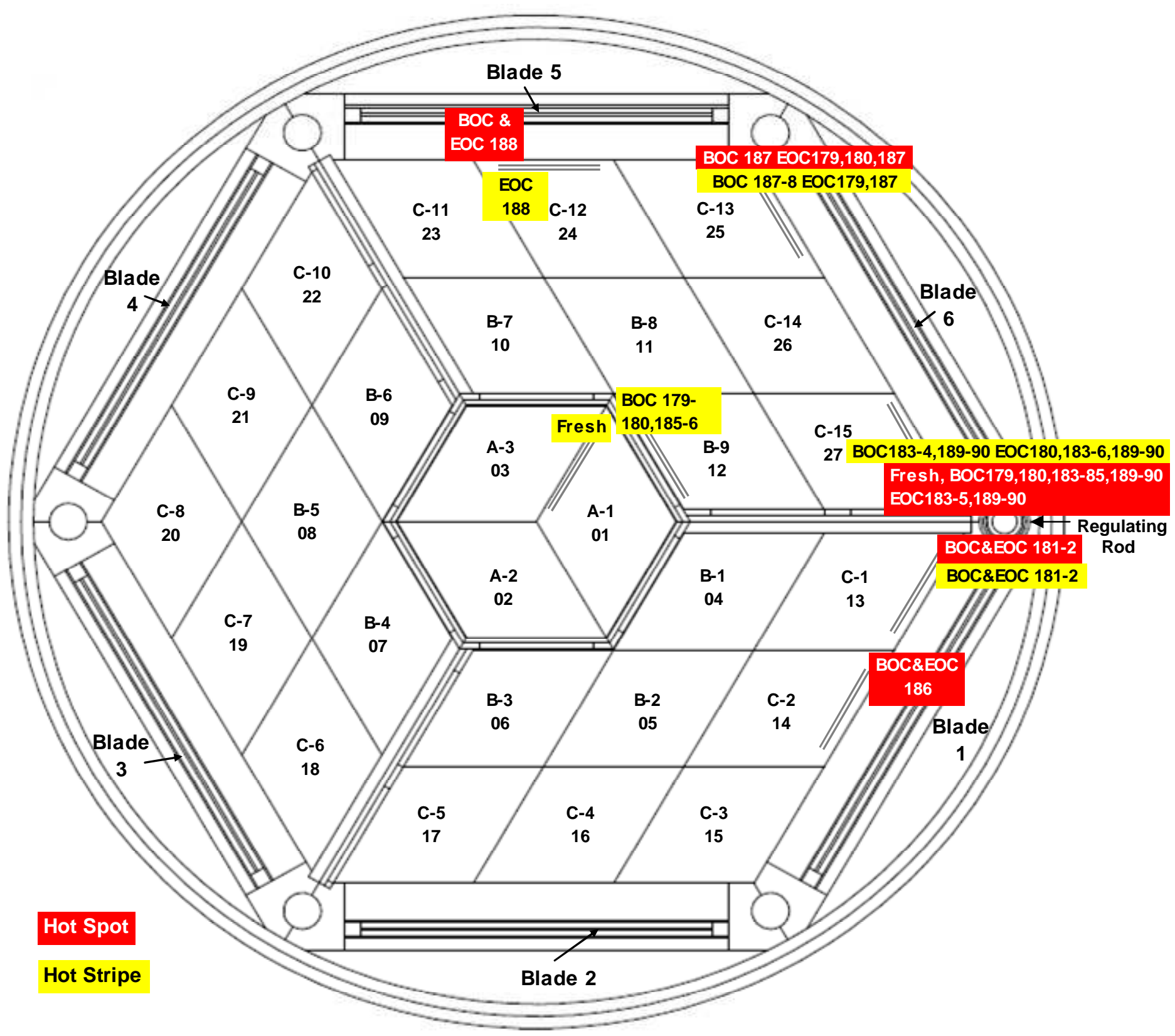

Figure 11. Peak locations of LEU fresh and depleted cores at BOC and EOC. 


\subsection{Peak Power Regions (among all cores)}

The work above describes power distributions across a range of LEU core configurations, including both all-fresh and depleted, which are available to be used in calculations for the thermal hydraulic performance of MITR LEU cores. Since the current methodology used for thermal hydraulic analysis cannot evaluate each of the over $10^{4}$ channel power distributions which are available, the remainder of this report focuses on summarizing a limited number of plates representing various extrema of heat flux modeled.

Figure 12 shows the axial heat flux profile of LEU cores with maximum heat flux for various regions listed in Table 9. The fresh LEU core consisting of 22 elements contains the single spot (a fuel meat area $1.32 \mathrm{~cm}$ laterally $\mathrm{cm}$ by $3.16 \mathrm{~cm}$ axially as discussed in section 3.1 ) with the highest heat flux of any spot among fresh or depleted cores and so is referred to as the fresh LEU peak spot. The peak stripe of all the cores considered, inclusive of the all-fresh 22 element core as well as the 24 element pseudo-equilibrium cores, is found in Core 189 EOC 27P01S1. Since loading an all-fresh LEU core is not currently planned for the conversion of the MITR reactor [9], the peak power spot (Core 189 BOC 27P01S1 Ax 18) among the depleted cores should be considered for thermal hydraulic analysis.

In addition to these core-wide regions of peak heat flux, the peak stripe among the inner ring elements (A and B-ring) was also considered. Prior analysis has found a uniform power shape particularly limiting [8], and so the inner ring peak stripe where power distribution is more axially uniform is also a useful candidate for thermal hydraulic evaluation. The inner ring peak stripe, as shown in Figure 12, is found in Core 185 BOC 12P18S4. Though an all-fresh LEU core is not planned, the results are included in the event they are useful in the future. Tables 11 and 12 list the heat flux and power, respectively, for the stripes shown in Figure 12.

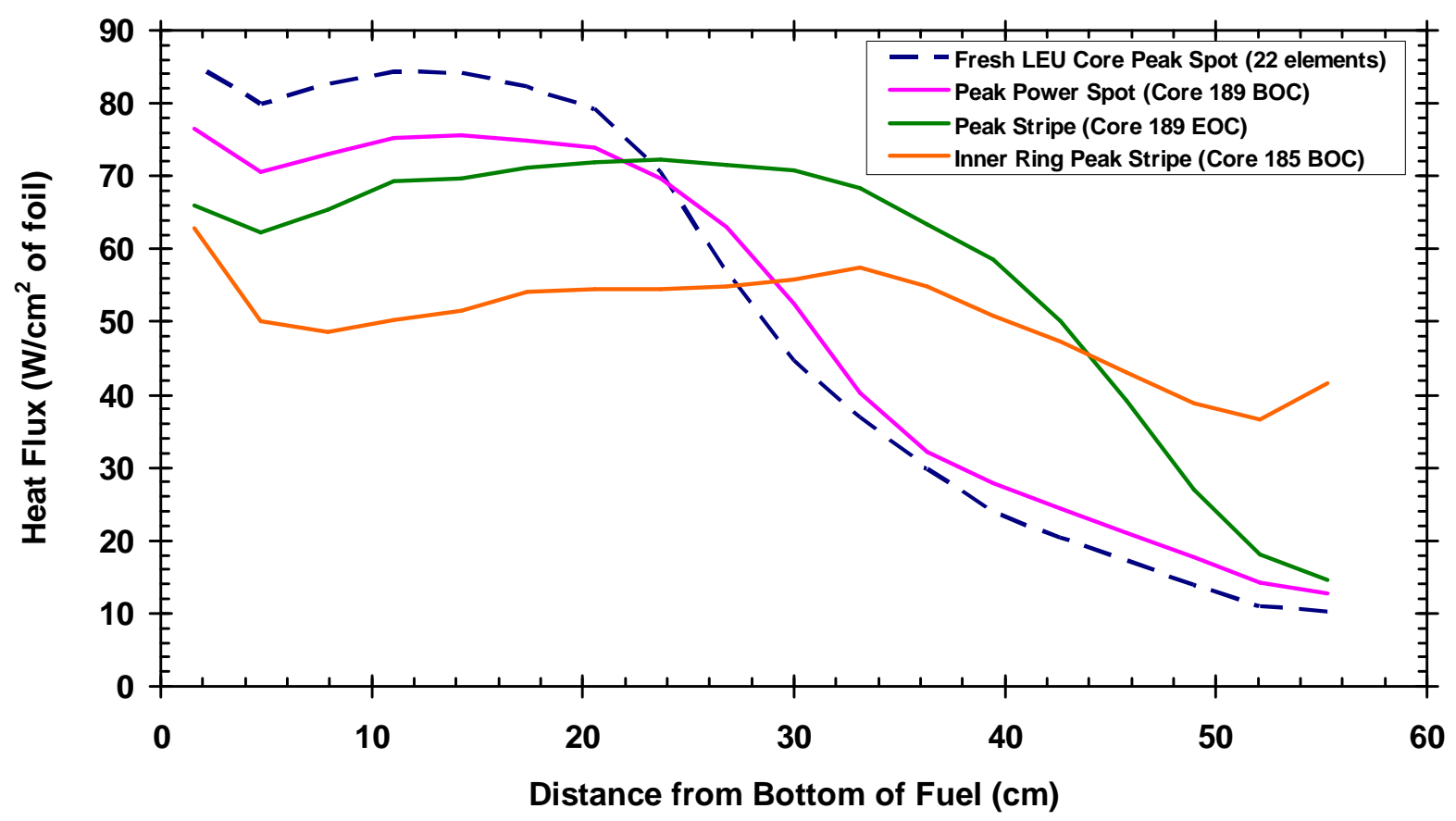

Figure 12. Axial heat flux profile of LEU cores at locations of maximum heat flux. 
Table 11. Axial heat flux distributions of 7 MW LEU cores with locations of maximum power.

\begin{tabular}{|c|c|c|c|c|c|}
\hline Axial Node & $\begin{array}{c}\text { Distance of } \\
\text { Axial Node } \\
\text { Center from } \\
\text { Bottom of Fuel }\end{array}$ & $\begin{array}{c}\text { Fresh LEU Core } \\
\text { Peak Spot }\end{array}$ & $\begin{array}{c}\text { Inner Ring } \\
\text { Peak Stripe } \\
(\text { Core 185 BOC })\end{array}$ & $\begin{array}{c}\text { Peak Spot } \\
(\text { Core 189 BOC })\end{array}$ & $\begin{array}{c}\text { Peak Stripe } \\
(\text { Core 189 EOC })\end{array}$ \\
\hline 1 & $(\mathrm{~cm})$ & $\left(\mathrm{W} / \mathrm{cm}^{2}\right.$ of foil $)$ & $\left(\mathrm{W} / \mathrm{cm}^{2}\right.$ of foil $)$ & $\left(\mathrm{W} / \mathrm{cm}^{2}\right.$ of foil $)$ & $\left(\mathrm{W} / \mathrm{cm}^{2}\right.$ of foil $)$ \\
\hline 2 & 55.3 & 10.4 & 41.5 & 12.8 & 14.6 \\
\hline 3 & 52.1 & 11.2 & 36.6 & 14.2 & 18.2 \\
\hline 4 & 48.9 & 14.1 & 38.9 & 17.7 & 27.1 \\
\hline 5 & 45.8 & 17.4 & 43.1 & 21.0 & 39.1 \\
\hline 6 & 42.6 & 20.5 & 47.2 & 24.4 & 50.0 \\
\hline 7 & 39.5 & 24.1 & 50.8 & 28.0 & 58.6 \\
\hline 8 & 36.3 & 29.9 & 54.9 & 32.1 & 63.3 \\
\hline 9 & 33.2 & 37.0 & 57.5 & 40.2 & 68.5 \\
\hline 10 & 30.0 & 44.8 & 55.9 & 52.4 & 70.9 \\
\hline 11 & 26.8 & 56.9 & 54.9 & 63.1 & 72.6 \\
\hline 12 & 23.7 & 70.6 & 54.6 & 69.6 & 71.9 \\
\hline 13 & 20.5 & 79.3 & 54.6 & 73.9 & 71.1 \\
\hline 14 & 17.4 & 82.5 & 54.1 & 74.8 & 69.7 \\
\hline 15 & 11.2 & 84.2 & 51.6 & 75.7 & 65.3 \\
\hline 16 & 7.9 & 84.5 & 50.2 & 75.3 & 62.3 \\
\hline 17 & 4.7 & 80.1 & 58.6 & 73.0 & 66.0 \\
\hline 18 & 1.6 & 85.6 & 62.8 & 70.6 & 57.2 \\
\hline $\begin{array}{l}\text { Stripe Average } \\
\text { (W/cm } 2 \text { of foil) }\end{array}$ & - & 50.9 & 50.4 & 46.6 & 2.12 \\
\hline $\begin{array}{l}\text { Stripe to Core } \\
\text { Average Ratio }\end{array}$ & - & 1.89 & 1.87 & 1.85 & \\
\hline & & & & & \\
\hline
\end{tabular}


Table 12. Axial power distributions of 7 MW LEU cores with locations of maximum power. ${ }^{\text {a }}$

\begin{tabular}{|c|c|c|c|c|c|}
\hline Axial Node & $\begin{array}{c}\text { Distance of Axial } \\
\text { Node Center from } \\
\text { Bottom of Fuel }\end{array}$ & $\begin{array}{c}\text { Fresh LEU } \\
\text { Core Peak } \\
\text { Spot }\end{array}$ & $\begin{array}{c}\text { Inner Ring } \\
\text { Peak Stripe } \\
\text { (Core 185 } \\
\text { BOC) }\end{array}$ & $\begin{array}{c}\text { Peak Spot } \\
\text { (Core 189 } \\
\text { BOC) }\end{array}$ & $\begin{array}{c}\text { Peak Stripe } \\
\text { (Core 189 } \\
\text { EOC) }\end{array}$ \\
\hline 1 & $(\mathrm{~cm})$ & $\begin{array}{c}\text { W in foil } \\
\text { stripe })\end{array}$ & $\begin{array}{c}\text { (W in foil } \\
\text { stripe) }\end{array}$ & $\begin{array}{c}\text { (W in foil } \\
\text { stripe) }\end{array}$ & $\begin{array}{c}\text { (W in foil } \\
\text { stripe) }\end{array}$ \\
\hline 2 & 55.3 & 86.5 & 346.6 & 106.9 & 122.2 \\
\hline 3 & 52.1 & 93.1 & 305.7 & 118.8 & 151.8 \\
\hline 4 & 48.9 & 117.8 & 324.5 & 147.5 & 226.0 \\
\hline 5 & 45.8 & 145.2 & 359.8 & 175.3 & 326.4 \\
\hline 6 & 42.6 & 170.9 & 394.2 & 203.7 & 417.4 \\
\hline 7 & 39.5 & 201.1 & 424.3 & 233.6 & 489.0 \\
\hline 8 & 36.3 & 249.7 & 458.6 & 267.7 & 528.6 \\
\hline 9 & 33.2 & 308.7 & 479.7 & 335.9 & 571.6 \\
\hline 10 & 30.0 & 373.7 & 466.3 & 437.9 & 591.5 \\
\hline 11 & 26.8 & 474.8 & 458.0 & 526.6 & 597.6 \\
\hline 12 & 23.7 & 589.4 & 455.4 & 580.9 & 603.0 \\
\hline 13 & 20.5 & 662.3 & 455.8 & 616.9 & 600.4 \\
\hline 14 & 17.4 & 688.8 & 451.9 & 624.6 & 593.5 \\
\hline 15 & 14.2 & 702.8 & 431.1 & 631.6 & 581.6 \\
\hline 16 & 11.1 & 705.1 & 419.0 & 628.7 & 578.9 \\
\hline 17 & 7.9 & 690.6 & 406.1 & 609.8 & 546.7 \\
\hline 18 & 4.7 & 668.8 & 417.6 & 589.1 & 520.3 \\
\hline $\begin{array}{c}\text { Stripe Average } \\
\text { (W in foil stripe) }\end{array}$ & 1.6 & 714.4 & 524.5 & 639.1 & 550.7 \\
\hline $\begin{array}{c}\text { Stripe to Core } \\
\text { Average Ratio }\end{array}$ & - & 424.7 & 421.1 & 415.3 & 477.6 \\
\hline & - & 1.89 & 1.87 & 1.85 & 2.12 \\
\hline
\end{tabular}

${ }^{\text {a }}$ Power in each spot is from a fuel meat region $0.212 \mathrm{~cm}^{3}$ in volume $\left(4.17 \mathrm{~cm}^{2}\right.$ area by $0.0508 \mathrm{~cm}$ thick). Power in each stripe is from a fuel meat region $3.82 \mathrm{~cm}^{3}$ in volume $\left(75.1 \mathrm{~cm}^{2}\right.$ area by $0.0508 \mathrm{~cm}$ thick). Heat from these fuel meat regions is conducted through both surfaces of the 2-sided fuel plate. 
Table 13 gives the burnup state of the peak spot and peak stripe among the depleted cores which occurred for Core 189 BOC and EOC, respectively. The plate containing the inner ring peak stripe was a freshly inserted element during Core 185 , and so was unirradiated at the BOC. While burnup data is provided as a reference to the elemental burnup core maps in Appendix D, these values represent burnup at the time of peak power. Burnup data presented in this report does not reflect the maximum levels of burnup anticipated for MITR LEU fuel, which are anticipated to be well in excess of $50 \%{ }^{235} \mathrm{U}$ burnup at peak locations.

Table 13. Axial power distribution of LEU cores with maximum heat flux locations.

\begin{tabular}{|c|c|c|c|}
\hline Axial & $\begin{array}{c}\text { Distance of Axial } \\
\text { Node Center from } \\
\text { Bottom of Fuel }\end{array}$ & $\begin{array}{c}\text { Core 189 BOC } \\
\text { Peak stripe }\end{array}$ & $\begin{array}{c}\text { Core 189 EOC } \\
\text { Peak stripe }\end{array}$ \\
\hline 1 & $\mathbf{( c m )}$ & ${ }^{\mathbf{2 3 5} \text { U Burnup \% }}$ & ${ }^{\mathbf{2 3 5} \mathbf{U} \text { Burnup \% }}$ \\
\hline 2 & 55.3 & 6.2 & 7.2 \\
\hline 3 & 52.1 & 6.2 & 7.2 \\
\hline 4 & 48.9 & 6.2 & 7.2 \\
\hline 5 & 45.8 & 8.3 & 10.9 \\
\hline 6 & 42.6 & 8.3 & 10.9 \\
\hline 7 & 39.5 & 8.3 & 10.9 \\
\hline 8 & 36.3 & 10.2 & 14.5 \\
\hline 9 & 33.2 & 10.2 & 14.5 \\
\hline 10 & 30.0 & 10.2 & 15.6 \\
\hline 11 & 26.8 & 10.6 & 15.6 \\
\hline 12 & 23.7 & 10.6 & 15.6 \\
\hline 13 & 20.5 & 10.6 & 14.4 \\
\hline 14 & 17.4 & 9.7 & 14.4 \\
\hline 15 & 14.2 & 9.7 & 12.9 \\
\hline 16 & 11.1 & 9.7 & 12.9 \\
\hline 17 & 7.9 & 8.5 & 12.9 \\
\hline 18 & 4.7 & 8.5 & 8.5 \\
\hline
\end{tabular}


Figure 13 shows a compilation of data presented in previous figures by integrating the Core 189 BOC and EOC axial heat flux distribution, relative to shim bank position and burnup. The relationship between the power profile and the control blade is seen in the heavily bottom-skewed BOC power distribution. The EOC power is closer to a symmetric chopped-cosine shape; however, the control blade is only withdrawn into the upper axial region of the fuel, and so a majority of power remains in the lower half of the fuel.

Burnup shape more closely resembles the power shape at EOC than BOC. This is consistent with the short time that MITR operates with control blades near fully inserted before significant blade withdrawal during initial Xe and other fission product build-up. In the series of depleted cores modeled here, the distance travelled by the control blades during LEU operation was limited, particularly when excluding the first day of each core's operation. From one day after startup until the end of cycle blade height travel averaged $9 \mathrm{~cm}$. This is less than $20 \%$ of the 53.3 $\mathrm{cm}$ total control blade travel available.

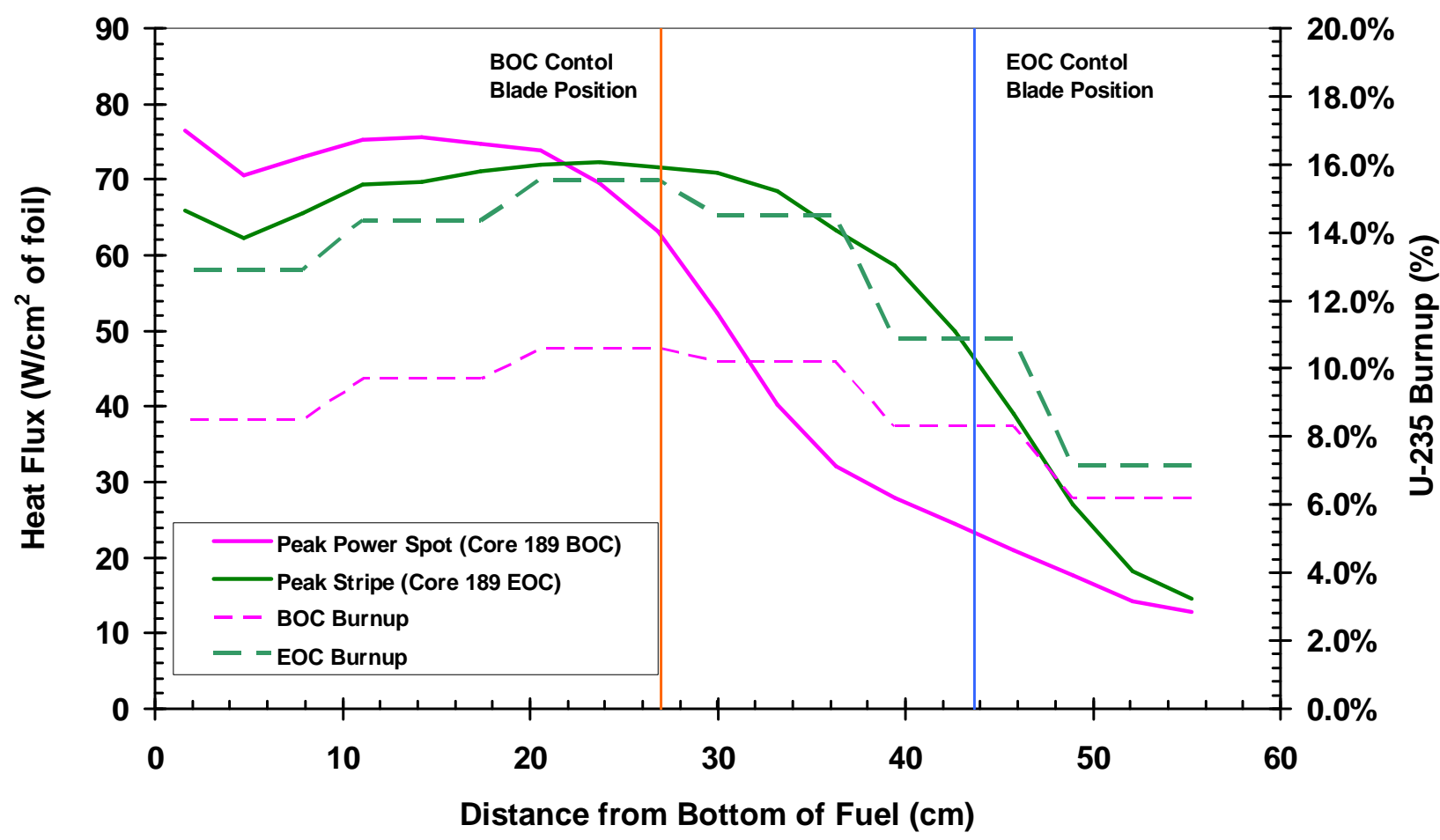

Figure 13. Heat flux and burnup vs. axial position with control blade shim bank position depicted for element 27 plate 1 of LEU Core 189. 


\subsection{Uncertainties in Power Distributions}

Uncertainties in power distributions arise from uncertainties in the calculation method as well as uncertainties in the as-built core. The as-built core differs from calculational models since geometry and materials represent a nominal state or specification. As-built geometry impacts power distributions due to deviation from nominal (component tolerances), as well as the freedom various components may have to move. As-built geometry affects not only power but also flow, where the impact on flow (thermal hydraulic calculation of flow area, etc.) is in addition to the impact on power, and so thermal hydraulic calculations of course include separate flow uncertainties (see section 2.2.1).

\subsubsection{Fuel loading}

Fuel loading is a significant uncertainty in power calculations and is comprised of uncertainties in the differences in both geometry and material composition between the nominal fuel considered and the range of fuel loaded into fabricated plates. Although loading is a major single component, the overall impact of all uncertainties in power are combined together to be used in thermal hydraulic calculations, as discussed in section 3.5.3. This section deals only with the factors affecting fuel loading, as summarized in Table 14, as one component that will be a part of a combined overall power uncertainty.

Table 14. Fuel overloading factors for a foil at the upper limits of thickness and ${ }^{235} \mathrm{U}$ content.

\begin{tabular}{|c|c|c|c|}
\hline Parameters $^{\text {a }}$ & Nominal & $\begin{array}{c}\text { Fuel Overload } \\
\text { Condition }\end{array}$ & $\begin{array}{c}\text { Multiplicative } \\
\text { Factor for }{ }^{235} \mathbf{U}\end{array}$ \\
\hline $\begin{array}{c}\text { Fuel overload } \\
\text { from foil thickness }\end{array}$ & $20 \mathrm{mil}$ & $21 \mathrm{mil}$ & 1.050 \\
\hline $\begin{array}{c}\text { Mo wt\% in } \\
\text { UMo Fuel }\end{array}$ & $10 \%$ & $9 \%$ & 1.011 \\
\hline $\begin{array}{c}\text { Enrichment } \\
\text { wt }{ }^{235} \mathrm{U}\end{array}$ & $19.75 \%$ & $19.95 \%$ & 1.001 \\
\hline $\begin{array}{c}\text { Plate }{ }^{235} \mathrm{U} \text { mass } \\
\text { Plate }{ }^{238} \mathrm{U} \text { mass }\end{array}$ & $46.2 \mathrm{~g}$ & $49.1 \mathrm{~g}{ }^{\mathrm{b}}$ & 1.063 \\
\hline
\end{tabular}

${ }^{a}$ Fuel fabrication requirements used in the safety basis.

b Number shows entire plate mass overloaded out of specification. Hot stripe analysis was performed with only a single hot stripe overloaded. Portions of the plate, such as stripes, being overloaded and underloaded would meet ${ }^{235} \mathrm{U}$ plate loading specifications [3].

Variation in UMo fuel foil thickness is assumed specified to not exceed 20 mil \pm 1 mil at any location on the foil [3]. Since this specification is assumed as a requirement for fuel fabrication, this could at most lead to a 5\% increase in ${ }^{235} \mathrm{U}$ (assuming a stripe could be overloaded at every point up to +1 mil, while other stripes are underloaded so that the plate would still meet overall loading specifications). Additional ${ }^{235} \mathrm{U}$ loading is possible in a thick plate if there is less than 10 wt\% Mo in the foil, and also if the ${ }^{235} \mathrm{U}$ enrichment varies significantly. Table 14 shows a 
combination of these fuel overload factors that would lead to a $6.3 \%$ increase in the ${ }^{235} \mathrm{U}$ content in the foil. This is derived by multiplicatively combining the overload parameters for thickness, Mo content and enrichment. Due to self-shielding, an increased loading will not increase power to quite the same degree, and so an overloaded hot stripe was modeled in MCNP. The power distribution from a $6.3 \%$ increase in ${ }^{235} \mathrm{U}$ in a hot stripe yielded a $4.7 \%$ increase in stripe power. Thus the factor to consider for actual power increase due to differences in fuel loading is taken as 5\%. The parameters in Table 14 are assumed as a part of the safety analyses, and must be set for fuel specification requirements for fuel fabrication. Local, small-scale variations of factors may be more pronounced; however on the size scale of thermal interest, these effects should not be significant, or are accounted for in the separate neutronics calculation uncertainties considered below.

\subsubsection{Additional power distribution uncertainties}

Neutronic power calculations are assumed accurate to within $10 \%$ in addition to fuel loading uncertainties discussed above. Table 15 contains fuel loading and neutronic uncertainties combined. Although the thickness variation of the UMo foil is assumed to be the single most dominant factor, many other components also contribute to variation in power that are included in the overall power density calculation uncertainty. The as-built core geometry (core structures, element and plate location, etc.) and materials vary from those used in modeling.

Also, neutronic power uncertainties arise from methods of calculation. While statistical uncertainties have been minimized during the generation of power distributions to a small fraction of the total uncertainty, typically less than $1 \%$, additional uncertainties remain due to convergence and fundamental data (e.g. ENDF/B-VII cross-sections).

\subsubsection{Combined uncertainties in power distributions}

For thermal hydraulic calculations, Table 15 lists combined fuel loading uncertainties and neutronic power calculation uncertainties for various thermal hydraulic conditions, where these factors have been combined multiplicatively. Since all parameters in Table 15 are dependent upon the core power level, a power measurement uncertainty of 5\% is included in each [8].

Table 15. Combined power distribution uncertainties.

\begin{tabular}{|c|c|c|c|c|c|}
\hline Parameter & $\begin{array}{c}\text { Fuel } \\
\text { Loading, } \\
\text { Plate 1 }\end{array}$ & $\begin{array}{c}\text { Fuel } \\
\text { Loading, } \\
\text { Plate 2 }\end{array}$ & $\begin{array}{c}\text { Power } \\
\text { Calculation }\end{array}$ & $\begin{array}{c}\text { Power } \\
\text { Measurement }\end{array}$ & $\begin{array}{c}\text { Combined RMS } \\
\text { Power Uncertainty } \\
\text { Factor }\end{array}$ \\
\hline Film temperature & 1.05 & - & 1.10 & 1.05 & 1.122 \\
\hline Heat flux & 1.05 & - & 1.10 & 1.05 & 1.122 \\
\hline $\begin{array}{c}\text { Enthalpy rise, } \\
\text { Interior channel }\end{array}$ & 1.025 & 1.0 & 1.10 & 1.05 & 1.115 \\
\hline $\begin{array}{c}\text { Enthalpy rise, } \\
\text { End channel }\end{array}$ & 1.05 & 1.0 & 1.10 & 1.05 & 1.122 \\
\hline $\begin{array}{c}\text { Core Power } \\
\text { Measurement }\end{array}$ & - & - & - & 1.05 & 1.05 \\
\hline
\end{tabular}

${ }^{\text {a }}$ For example if $1^{\text {st }}$ plate at maximum nominal power plus 5\% fuel overload contributes half of enthalpy rise; $2^{\text {nd }}$ plate at maximum nominal power.

b Core power uncertainty may be combined. Alternatively, since a whole core parameter, it may be useful to treat core power measurement separately from other uncertainties. 


\section{Thermal Hydraulic Determination of Limiting Power Distributions}

Thermal hydraulic calculations were made to address issues related to generating and selecting appropriate neutronic power distributions for use in future detailed thermal hydraulics analyses. Firstly, prior to generating final power distributions it was necessary to determine the number of lateral stripes per plate required for a conservative treatment of lateral variations in power density across a plate. A second issue was to determine which of the peak stripe axial power profiles discussed in Section 3.4 is most limiting for the margin to onset of nucleate boiling (ONB). A third issue was the question of whether the most limiting coolant channel is an interior channel or an end channel. This is an issue since as shown in Chapter 3 peak plate powers are in end plates, and an end plate is in contact with an interior coolant channel on one side and an end coolant channel on the other side.

\subsection{Lateral Heat Conduction Basis for Lateral Power Segmentation}

The impact of lateral conduction on steady-state temperatures in a MITR LEU fuel plate was determined by multi-stripe calculations with the RELAP5-3D code. 1-stripe, 4-stripe, 8-stripe and 16-stripe results, with and without lateral conduction in the plate, were compared. Also, the impact of adding axial conduction, as well as lateral conduction, through the plate was investigated.

\subsubsection{Power Shapes}

Power shapes used in this RELAP5 calculation were obtained from the all-fresh LEU core. The peak power stripe (1/16 $6^{\text {th }}$ of a plate) was found to be in the outer plate of element C-5 facing the core housing. The axial power shapes for 16 stripes in the plate are shown in Figure 14. The power was peaked at the edge of the LEU foil, near the side plate (side plate placed next to the arm). The power was also peaked toward the bottom because the control blades were partially inserted.

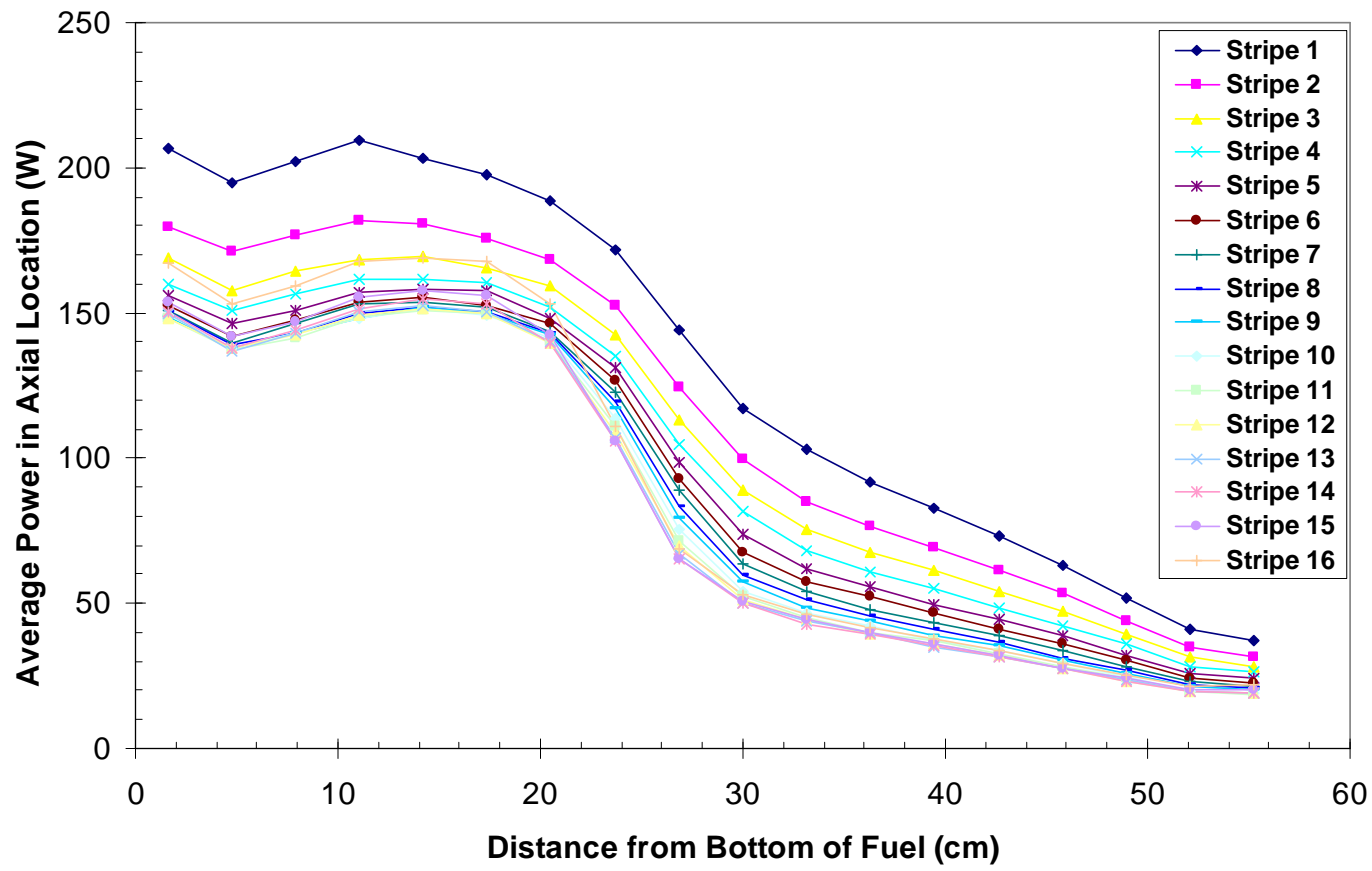

Figure 14. Axial power shapes for 16 stripes, 18 axial nodes, in the plate with the hottest stripe. 
The stripe peaking factor impact of using various numbers of stripes for an LEU fresh core peak stripe is shown in Table 16.

Table 16. Stripe peaking factor for various numbers of stripes.

\begin{tabular}{|c|c|}
\hline Number of stripes per plate & $\begin{array}{c}\text { Peak stripe power/core average } \\
\text { stripe power }\end{array}$ \\
\hline 1 & 1.449 \\
\hline 4 & 1.758 \\
\hline 8 & 1.981 \\
\hline 16 & 2.055 \\
\hline
\end{tabular}

\subsubsection{RELAP5 Model}

The RELAP5 model used for the 16 stripe cases for an end plate and end channel is shown schematically in Figure 15. Shown are 18 channels. Channels 0 and 17 are the side channels beyond the ends of the fuel. These channels contain no fuel and have no heat source. Channels 1 to 16 are the 16 equally fueled stripes. The channels represent half of the thickness of the plate plus the end coolant channel. Each fueled channel starts at the center of the fuel and contains half of the thickness of the fuel, the clad and fins on one side of the plate and the coolant. Coolant cross-flow and lateral mixing between adjacent coolant channels were not accounted for. Also, there was no lateral conduction through the water between adjacent coolant channels. Zero heat flux boundary conditions were used at the middle of the fuel thickness and at the surface of the side plate of the adjacent assembly.

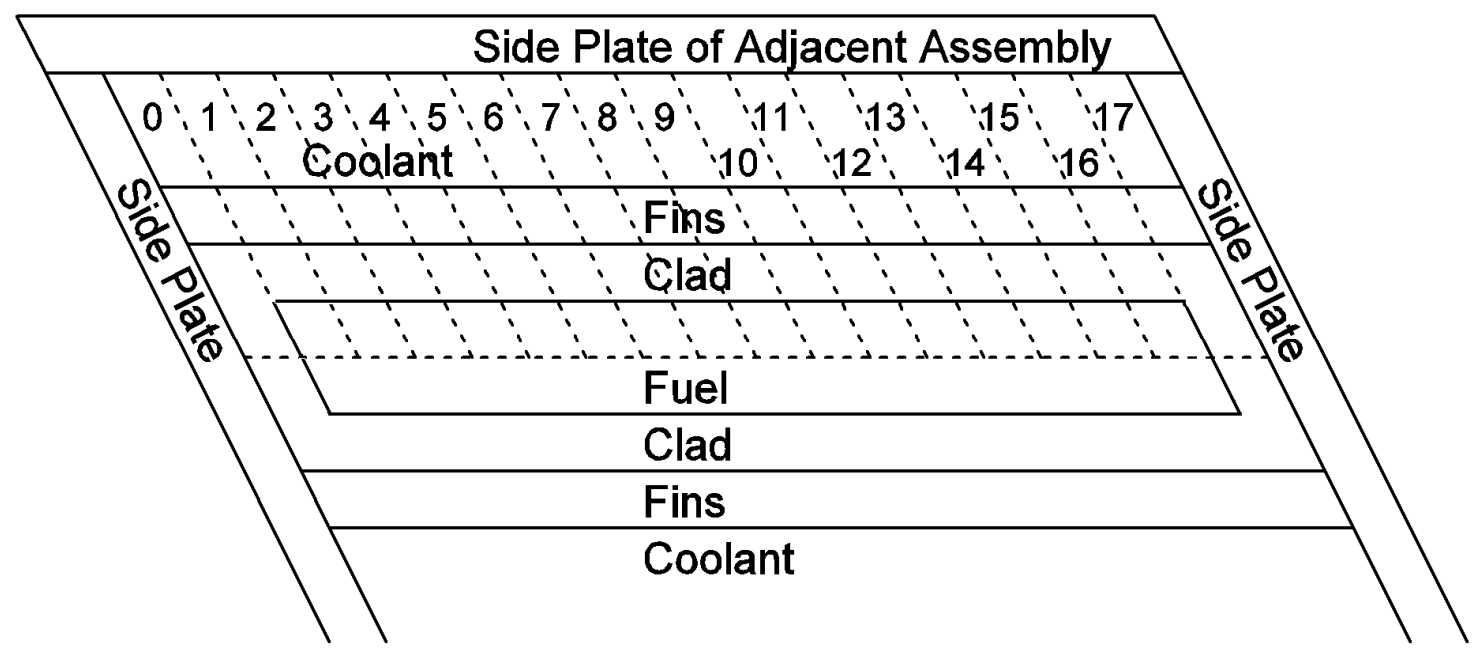

Figure 15. Sixteen stripe model for an end plate (schematic; not to scale).

The treatment of the fins in the calculation was a special matter, since RELAP5 contains no explicit fin model. The effective plate surface area was adjusted to account for an effective fin surface area factor of 0.9 . Also, $90 \%$ of the coolant flow area between fins was included in the coolant channel flow area. 
The main thermal hydraulic parameters used for the 16 stripe cases are listed in Table 17 . The thermal conductivities used for lateral heat conduction were $17 \mathrm{~W} / \mathrm{m}-\mathrm{K}$ for the fuel and $180 \mathrm{~W} / \mathrm{m}-\mathrm{K}$ for the aluminum. A similar model was used for the 8 stripe case, with the stripes twice as wide in the fueled region.

Table 17. Thermal hydraulic parameters for the 16 stripe case.

\begin{tabular}{|l|l|}
\hline Stripe width, stripes 1-16 & $\begin{array}{l}2.082 \text { inch } / 16=0.1301 \text { inch }= \\
0.003305 \mathrm{~m}\end{array}$ \\
\hline Stripe width, stripes 0 and 17 (side channels) & 0.113 inch $=0.00287 \mathrm{~m}$ \\
\hline Finned width, stripes 0 and 17 & 0.059 inch $=0.001499 \mathrm{~m}$ \\
\hline Unfinned width, stripes 0 and 17 & 0.054 inch $=0.001372 \mathrm{~m}$ \\
\hline $\begin{array}{l}\text { Coolant channel thickness (height), fin tip to } \\
\text { side plate of adjacent assembly }\end{array}$ & $38 \mathrm{mil}=0.000965 \mathrm{~m}$ \\
\hline Coolant flow area, stripes 1-16 & $3.568 \times 10^{-6} \mathrm{~m}^{2}$ \\
\hline Coolant flow area, stripes 0 and 17 & $2.942 \times 10^{-6} \mathrm{~m}^{2}$ \\
\hline Hydraulic diameter, stripes 1-16 & $0.001440 \mathrm{~m}$ \\
\hline Hydraulic diameter, stripes 0 and 17 & $0.001434 \mathrm{~m}$ \\
\hline Fuel thickness & $20 \mathrm{mil}=0.000508 \mathrm{~m}$ \\
\hline Clad thickness & $10 \mathrm{mil}=0.000254 \mathrm{~m}$ \\
\hline Fin depth & $10 \mathrm{mil}=0.000254 \mathrm{~m}$ \\
\hline Fin width & $10 \mathrm{mil}=0.000254 \mathrm{~m}$ \\
\hline Gap between fins & $10 \mathrm{mil}=0.000254 \mathrm{~m}$ \\
\hline Side plate thickness & 0.188 inch $=0.004775 \mathrm{~m}$ \\
\hline Fueled length of the plate & 22.375 inch $=0.5683 \mathrm{~m}$ \\
\hline
\end{tabular}

RELAP5 does not have a direct solution for the steady-state temperatures and coolant flow rates, and so initial conditions were required for these calculations. Therefore, the initial conditions that were supplied for the runs were a pump flow rate of $112.5 \mathrm{~kg} / \mathrm{s}$, approximate initialization flows for the rest of the coolant flow rates, a temperature of $43.45{ }^{\circ} \mathrm{C}$ for the coolant channel inlet temperature and temperatures between $43.45{ }^{\circ} \mathrm{C}$ and $60{ }^{\circ} \mathrm{C}$ for the rest of the coolant and the plates. Then a transient was run. The power was held at 7.4 MW and the pump flow was held at $112.5 \mathrm{~kg} / \mathrm{s}$ for 100 seconds while flow redistribution and temperatures were calculated. Within 12 seconds the flows redistributed on the basis of hydraulic parameters. The temperatures had reached stable steady-state values by the end of the 100 second transient. After the flows redistributed the total core flow rate was $103 \mathrm{~kg} / \mathrm{s}$. For the 16 stripe end channel, the flow in each side channel was $0.004971 \mathrm{~kg} / \mathrm{s}$. The flow in each fueled stripe channel was $0.006152 \mathrm{~kg} / \mathrm{s}$. 


\subsubsection{Results, Lateral Conduction}

The calculated coolant outlet temperatures and peak clad temperatures are shown in Figures 16 and 17. In Figure 16 the stripe -1 and stripe 17 temperatures are the side plate temperatures. Because the thermal neutron flux peaks near the sides of the plates, beyond the fueled region, the power peaks fairly strongly in a narrow region at each edge of the fuel region. If lateral heat conduction in the fuel plate is ignored, then the coolant outlet temperature and the peak clad temperature also peak at the edges of the fuel region; and using more (and narrower) stripes results in higher peaks at the edges.

Accounting for lateral heat conduction greatly reduces the temperature peaks. With lateral heat conduction, the highest temperatures predicted with 16 stripes are about the same as those with 8 stripes. Lateral heat conduction removes some of the heat produced in stripe 1, the highest power stripe; and moves it to stripe 0 , the side channel, where it is removed by the side channel coolant flow. Also, heat is conducted from the highest power stripes near the edges of the fuel to the lower power stripes in the middle of the fuel.

The maximum temperatures calculated with a 4 stripe treatment without lateral conduction approximate those calculated with 8 or 16 stripes with lateral conduction. Thus a 4 stripe treatment without lateral conduction would be considered sufficient.

\subsubsection{Results, Axial Conduction}

The impact of axial conduction in the fuel plates was evaluated for the 8 stripe case. The axial treatment used the 18 axial nodes in the fueled part of the plate plus short un-powered axial nodes above and below the fueled part to account for the unfueled ends of the plate. The case was run with lateral conduction. Then the same case was run with both lateral conduction and axial conduction. Adding the axial conduction made very little difference: the peak coolant outlet temperature changed by $0.003{ }^{\circ} \mathrm{C}$ and the peak clad temperature changed by $0.005{ }^{\circ} \mathrm{C}$. Because the effect of axial conduction is so small, it was not included in the 16 stripe cases. Also, axial conduction is not included in the 8 stripe results shown in Figures 16 and 17. 


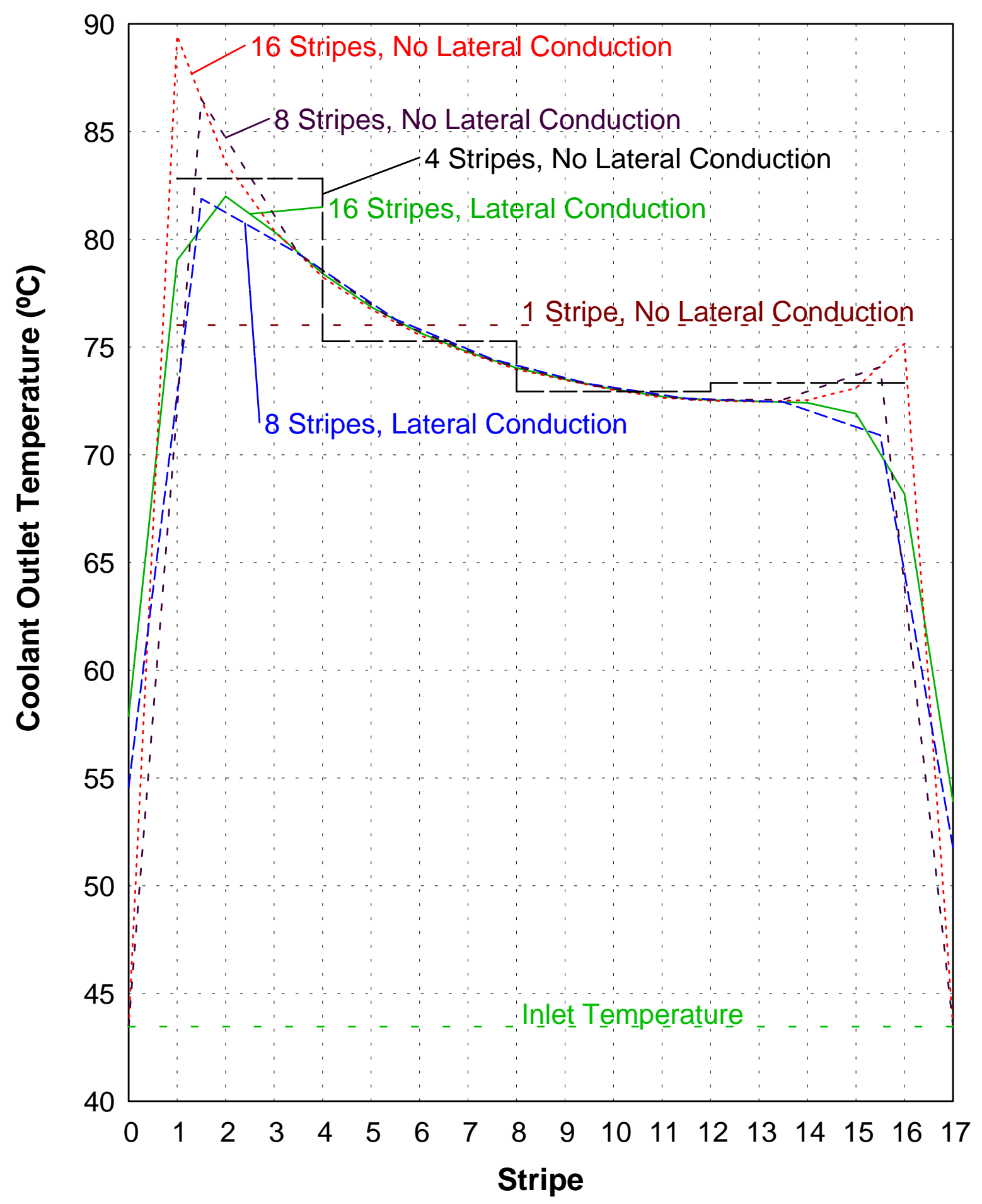

Figure 16. Coolant outlet temperatures, in degrees Celsius, by stripe. 


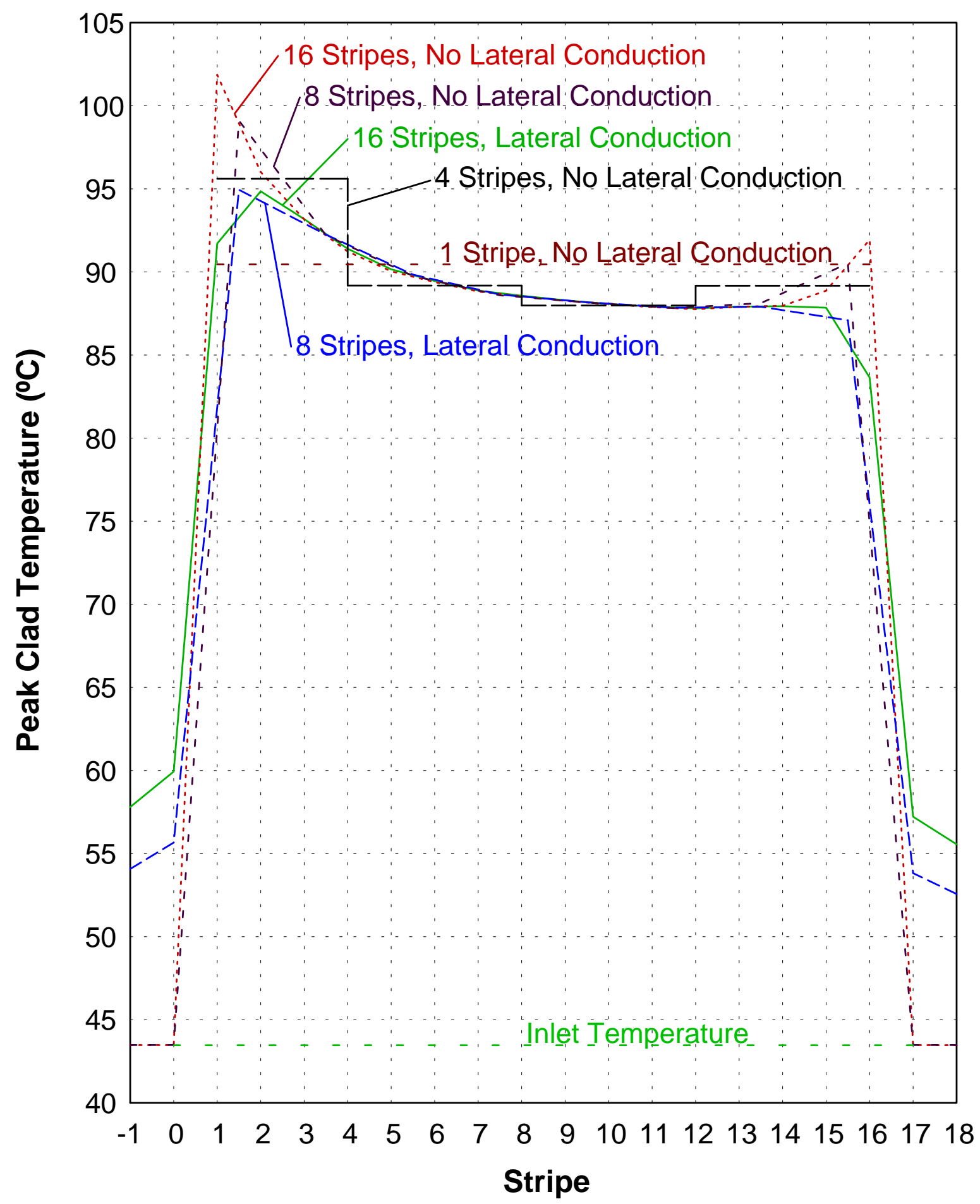

Figure 17. Peak clad temperature, in degrees Celsius, by stripe. 


\subsubsection{Conclusions, Lateral and Axial Conduction}

The results including lateral conduction for cases with 8 and 16 stripes in the fuel plate show that a 4 stripe treatment without lateral conduction is conservative. Axial conduction has a negligible impact on the results.

This also implies that for all future thermal hydraulic safety analyses using 4 fuel stripes for power distributions, that the heat flux should be calculated based on the LEU foil width of 2.082 inch $(0.052883 \mathrm{~m})$ rather than the physical channel width of 2.308 inch $(0.058623 \mathrm{~m})$.

\subsection{Determination of Limiting Power Distribution and Comparison of End Channel to Interior Channels}

In order to address both the determination of the limiting power distribution and the comparison of end channel to interior channels, the analysis using engineering hot channel factors described in Sections 2 and 3 of Reference [10] was applied to both interior and end channels using the axial power shapes from Section 3.4 of this report. The shapes presented for the peak stripe (Core 189 EOC), as well for the peak spot (Core 189 BOC) and inner ring peak stripe (Core 185 BOC) are analyzed here.

\subsubsection{Input Parameters Used in the Analytic Analysis Using Engineering Hot Channel Factors}

Table 18 lists the parameters used in these calculations. The statistical uncertainty factors for the interior channel were taken from Table 1 of Reference [10]. The end channel calculation used the same statistical uncertainty factors as the interior channel except for the flow channel tolerances used in the enthalpy rise summation.

It might be expected that the flow channel tolerances used for the film temperature rise summation should also be higher for the end channel, since the tolerances for the end channel gap are larger than those for the interior gap. Such a change would make the end channel more limiting. On the other hand, results from the RELAP5 calculations described in Section 4.3 below indicate that the unmodified Dittus-Boelter film heat transfer coefficient for a 28 mil end gap is almost identical to that for a 38 mil end gap. Similar results would probably be obtained for an interior channel, although this has not been done. The explanation for this result has to do with the fairly strong variation of the water viscosity with temperature. A change in coolant channel gap size leads to a change in coolant channel flow rate, which leads to a change in coolant temperature. The resulting change in viscosity leads to a change in film heat transfer coefficient which is in the opposite direction from the change due only to the change in geometry. For the cases we are interested in, the opposing changes have similar magnitudes. Thus, the actual contribution of the flow channel tolerances to the film temperature rise summation for either an end channel or an interior channel is small compared to the $20 \%$ heat transfer coefficient uncertainty contribution also included in this summation.

Other than the flow channel tolerances, the sub-factors listed in Table 1 of Reference [10] refer to plate powers or total core flow. The interior channel and the end channel are in contact with the same end plate-just on different sides of the plate. Therefore, the same plate power sub-factors should apply to either the interior channel or the end channel. Also, the same total core flow subfactors were applied to both the interior channel and the end channel (i.e., the element to element disparity factor where the loss coefficient due to the entrance nozzle is considered equivalent for all channels whether end or interior). 
Table 18. Parameters used in the analytical statistical approach. ${ }^{\mathrm{a}}$

\begin{tabular}{|c|c|c|}
\hline Parameter & $\begin{array}{l}\text { Interior } \\
\text { Channel }\end{array}$ & $\begin{array}{c}\text { End } \\
\text { Channel }\end{array}$ \\
\hline Fin-fin or fin-wall gap, mil & $72 \pm 4$ & $50.5 \pm 9^{b}$ \\
\hline Coolant flow area, $\mathrm{m}^{2}$ & $1.101 \times 10^{-4}$ & $0.7455 \times 10^{-4}$ \\
\hline Hydraulic diameter, based on wetted perimeter, $\mathrm{m}$ & 0.00208 & 0.00188 \\
\hline Thermal diameter, based on heated perimeter, $\mathrm{m}$ & 0.00208 & 0.00282 \\
\hline Pump flow, kg/s & 111.938 & 111.938 \\
\hline Core flow factor & 0.921 & 0.921 \\
\hline Flow disparity factor & 0.93 & 0.93 \\
\hline Radial power factor & 2.12 & 2.12 \\
\hline Fraction of power in the core & 0.985 & 0.985 \\
\hline Fraction of power in the fuel plate & 0.94 & 0.94 \\
\hline Outlet temperature, ${ }^{\circ} \mathrm{C}$ & 60 & 60 \\
\hline Elements & 24 & 24 \\
\hline Plates/element & 18 & 18 \\
\hline Water height above the core outlet, $\mathrm{m}$ & 3.05 & 3.05 \\
\hline Fuel length, m & 0.5683 & 0.5683 \\
\hline Fuel width, $\mathrm{m}$ & 0.0529 & 0.0529 \\
\hline Flow channel tolerances, for enthalpy rise sum & 1.068 & 1.27 \\
\hline Enthalpy (coolant temperature) rise HCF & 1.173 & 1.360 \\
\hline Film temperature rise $\mathrm{HCF}$ & 1.275 & 1.275 \\
\hline Carnavos heat transfer fin factor & 0.717 & 0.719 \\
\hline Nominal coolant channel flow rate, computed, $\mathrm{kg} / \mathrm{s}$ & 0.2219 & 0.1403 \\
\hline
\end{tabular}

a Parameters and methodology may not reflect final LEU assumptions for thermal hydraulic analyses; values are used as a starting point for comparison for interior and end channels.

${ }^{\mathrm{b}}$ Used as a starting point for comparison of interior and end channels. See section 2.2 for discussion of end channel tolerances which may exceed these values.

\subsubsection{Results for 3 Axial Power Shapes for Interior Channels and End Channels}

Results from these calculations for 3 power shapes from Section 3.4 are shown in Table 19. The all fresh LEU case was not considered, since there is no intention to operate with such a core.

Table 19. Analytic LSSS results. ${ }^{a}$

\begin{tabular}{|c|c|c|}
\hline Power Shape & \multicolumn{2}{|c|}{ LSSS power, MW } \\
\hline & Inner Channel & End Channel \\
\hline Peak stripe, 189 EOC & 8.21 & 7.79 \\
\hline Peak spot, 189 BOC & 9.43 & 8.62 \\
\hline Inner ring peak stripe, 185 BOC & 9.39 & 9.34 \\
\hline
\end{tabular}

${ }^{a}$ Results are based on parameters and methodology may not reflect final LEU assumptions for thermal hydraulic analyses; values are used as a starting point for comparison for interior and end channel limiting power distribution analysis. 
The peak stripe 189EOC power shape is clearly more limiting for either the interior channel or the end channel. For the peak stripe 189EOC power shape the end channel is more limiting by about $5 \%$. 


\subsection{Additional Comparison of End Channel to Interior Channels}

In addition to the approach described in Section 4.2, an alternate approach was taken to address the question of whether the interior channel or the end channel will be more limiting, and to obtain some indication of the consequences of varying the end channel gap size. The interior channel nominal gap size and the manufacturing tolerance on this gap size are reasonably well known. On the other hand, the end channel nominal gap size and its uncertainties are less well known at this point.

To address this issue a three channel RELAP5 model was set up. The first channel represents 862 average half-plates and their half coolant channels, and so is called the core average lumped channel. The second channel represents half of the end plate with the highest power quarter stripe plus the end coolant channel. The third channel represents the other half of the end plate with the highest power quarter stripe plus half of its interior coolant channel. Even though the full width of the end plate was represented in channels 2 and 3, the power density in these channels was based on that in the hot stripe. Consistent with traditional hot channel analysis, in all three channels a zero heat flux boundary condition was imposed at the middle of the plate. A number of cases were run with the interior coolant channel gap in channel 3 held constant at its minimum value (nominal - tolerance). The end channel gap in channel 2 was varied to find the value of the end channel gap at which the peak clad surface temperatures in channels 2 and 3 are the same. For smaller minimum end channel gaps the end channel would be limiting, and for larger minimum end channel gaps the interior channel with a minimum gap size would be limiting.

These cases were all run with the 189EOC axial power shape and a reactor power of $7 \mathrm{MW}$. Table 20 lists some of the input parameters used in four of the cases where the Dittus-Boelter heat transfer coefficient was used. Figure 18 shows the results of the calculations. If the end gap size is larger than $43.3 \mathrm{mil}$, then the interior channel is more limiting. Otherwise, the end channel is more limiting. For an end gap size of $50.5 \pm 9$ mil, the minimum gap size would be $41.5 \mathrm{mil}$, and the end channel would be more limiting by about $2{ }^{\circ} \mathrm{C}$. This result is consistent with the results obtained in Section 4.3.

Table 20. Channel input parameters.

\begin{tabular}{|c|c|c|c|c|c|}
\hline & $\begin{array}{c}\text { Core } \\
\text { Average } \\
\text { Lumped } \\
\text { Channel }\end{array}$ & \multicolumn{2}{|c|}{ Hot End Channel } & $\begin{array}{c}\text { Hot } \\
\text { Interior } \\
\text { Channel }\end{array}$ \\
\hline $\begin{array}{c}\text { Channel gap, fin tip to fin } \\
\text { tip or fin tip to core barrel } \\
\text { (mil) }\end{array}$ & 72 & 38 & 43 & 48 & 68 \\
\hline $\begin{array}{c}\text { Channel width, width of } \\
\text { fuel (m) }\end{array}$ & 0.05288 & 0.05288 & 0.05288 & 0.05288 & 0.05288 \\
\hline $\begin{array}{c}\text { Coolant flow area }\left(\mathrm{m}^{2}\right) \\
\text { Wetted perimeter }(\mathrm{m})\end{array}$ & 0.04747 & $5.776 \times 10^{-5}$ & $6.447 \times 10^{-5}$ & $7.119 \times 10^{-5}$ & $5.238 \times 10^{-5}$ \\
\hline Heated perimeter ${ }^{\mathrm{a}}$ & 86.607 & 0.1004 & 0.1004 & 0.1004 & 0.10047 \\
\hline $\begin{array}{c}\text { Hydraulic diameter }(\mathrm{m}) \\
\text { Thermal diameter }=4 \mathrm{x} \\
\text { area/heated perimeter }(\mathrm{m})\end{array}$ & 0.002083 & 0.001457 & 0.001626 & 0.001795 & 0.001981 \\
\hline
\end{tabular}


${ }^{\mathrm{a}} \mathrm{A}$ fin effectiveness of 1.9 was used in computing the heated perimeter in all cases.

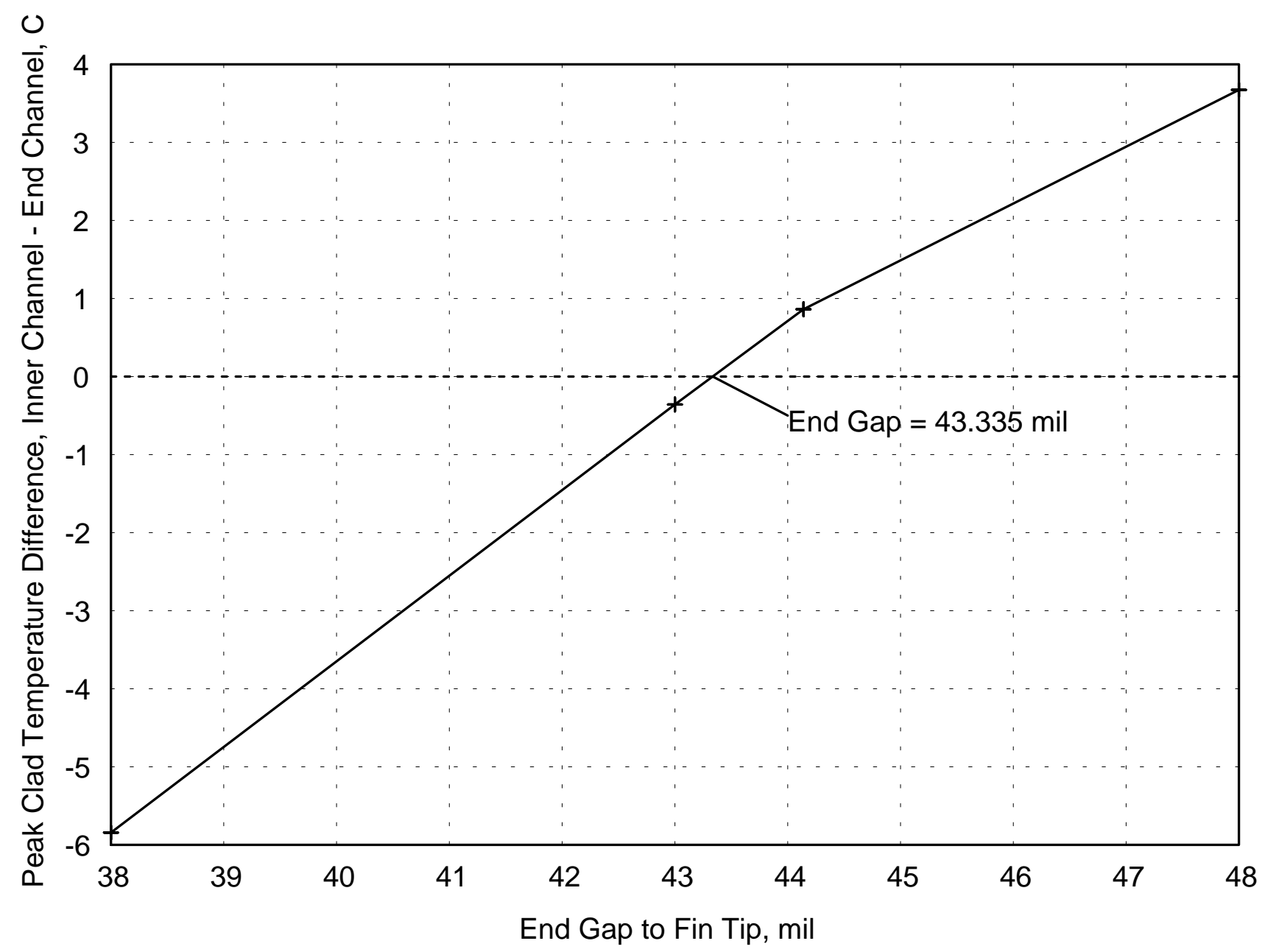

Figure 18. Influence of end channel gap size on peak clad temperature. 


\section{Conclusions}

Power distributions using specific three dimensional power shape (individual core, element, and stripe within a plate) have been calculated for MITR cores. The power distributions across a range of LEU core configurations, including both all-fresh and depleted, have been modeled and peak power shapes presented which may be used in calculations for the thermal hydraulic performance of MITR LEU cores. In addition to channels selected representing various extrema of heat flux modeled, thermal hydraulic evaluation of these distributions indicates that the limiting distribution is the axial profile obtained for the peak stripe in Core 189 EOC. Thermal hydraulic cases were used in order to determine stripe discretization, and for comparison of interior to end channels. Stripe discretization was based on modeling conductive cooling through the portions of the channel along the plate width $(2.308 \mathrm{inch}, 0.058623 \mathrm{~m})$ and side plate. For thermal hydraulic analysis without explicit modeling of conduction, a 4-stripe power distribution was found to be sufficient. Since the stripe width accounts for lateral heat conduction, all future thermal hydraulic safety analyses using the 4-stripe foil power distributions in this report would not otherwise account for conduction. This also requires using a channel one quarter of the foil width of 2.082 inch $(0.052883 \mathrm{~m})$ as the thermal hydraulic channel when applying the heat fluxes reported.

Due to the locations of peak power in the outer plate of each fuel element, consideration of both the first interior coolant channel and the end channel has been performed. Based upon preliminary tolerance assumptions, the end channel LSSS power was found to be more limiting by $5 \%$. Since this result was derived with a very optimistic element tolerance for the end channel (fuel plate fin-tip to nozzle dimension tolerance $50.5 \pm 4 \mathrm{mil}$ ), the end channel would be more limiting in all cases with more realistic fabrication tolerance assumptions. As discussed in the geometry of the end channel, the proposed fuel element would directly specify the fin-tip to nozzle dimension. Calculation of the uncertainties with this direct specification assumes a $50.5 \pm 8$ mil fin-tip to nozzle outer dimension, which would be required of fuel fabrication specifications since it is used in the analysis of the safety basis.

Power distribution uncertainties were also summarized, including assumed calculation uncertainties, and fuel loading. Loading tolerance assumptions for the fuel, yet to be fabricated, are also used in the calculation of the safety basis, and so fabrication specifications must meet or exceed these tolerances.

Together, channel geometries, power distributions, and uncertainties with both are required for thermal hydraulic safety analyses for LEU conversion of MITR. While safety analyses are ongoing the conversion of MITR depends upon successful qualification and demonstration of monolithic UMo $10 \mathrm{wt} \%$ fuel suitable for use in MITR. 


\section{References}

[1] E.H. Wilson, T.H. Newton, Jr., A. Bergeron, N. Horelik, and J.G. Stevens, "Comparison and Validation of HEU and LEU Modeling Results to HEU Experimental Benchmark Data for the Massachusetts Institute of Technology MITR Reactor," ANL-RERTR-TM-10-41, Argonne National Laboratory, December, 2010.

[2] MITR-II "Fuel Element Assembly," drawing R3F-201-4, MIT Nuclear Reactor Laboratory, Massachusetts Institute of Technology, Cambridge, Massachusetts.

[3] Lin-wen Hu, T.H. Newton, E.H. Wilson, J.G. Stevens, "Preliminary Safety Analysis Report Methodologies and Scenarios for LEU Fuel Conversion of the MITR Reactor," MITNRL-1101, MIT Nuclear Reactor Laboratory, Massachusetts Institute of Technology, Cambridge, Massachusetts, April, 2011.

[4] Z. Xu, P. Hejzlar, and M.S. Kazimi, "MCODE, Version 2.2 - An MCNP-ORIGEN Depletion Program," Center for Advanced Nuclear Systems, Massachusetts Institute of Technology, Cambridge, Massachusetts, April 2006.

[5] A.G. Croff, "A User's Manual for the ORIGEN2 Computer Code," ORNL/TM-7175, Oak Ridge National Laboratory (1980).

[6] "MCNP - A General Monte Carlo N-Particle Transport Code, Version 5 User's Guide Manual,” X-5 Monte Carlo Team, LA-UR-03-1987, Los Alamos National Laboratory, April, 2003.

[7] T.H. Newton, Jr., T.H. Newton, Jr., L-W Hu, G. E. Kohse, E. E. Pilat, B. Forget, P. K. Romano, Y-C Ko, S. Wong, and Y. Wang, B. Dionne, J. Thomas, and A. Olson "Completion of Feasibility Studies on using LEU Fuel in the MIT Reactor," Proceedings of the RERTR Conference, Beijing, China, November, 2009.

[8] MITR Staff, “Safety Analysis Report for the MIT Research Reactor (MITR-II),"MIT Nuclear Reactor Laboratory, October, 2010.

[9] T.H. Newton, Jr., L-W Hu, B. Forget, N.E. Horelik, H.M. Connaway, T. Gerrity, K.E. Plumer, E.H. Wilson, and J.G. Stevens, "Fuel Management and Safety Analysis for LEU Conversion of the MIT Nuclear Reactor," Proceedings of the RERTR Conference, Santiago, Chile, October, 2011.

[10]Keng-Yen Chiang, Lin-wen Hu and Benoit Forget, "Evaluation of Thermal Hydraulic Limits Based on Statistical Propagation of Parametric Uncertainties", Proceedings of the RERTR Conference, Santiago, Chile, October, 2011. 


\section{APPENDIX A HYDRAULIC GEOMETRIES OF CHANNELS}

The interior and end channel geometries are listed for various configurations in Table A-1 (based on units as-specified) and Table A-2 (SI units). Table 4 is used as the basis for the nominal and element off-center with tolerances. The assumption made is that the exterior plate fin-tip to nozzle outer dimension $50.5 \pm 8$ mil (assumed in this report pending confirmation when fuel fabrication has been performed).

Hydraulic diameters were calculated based upon four times the flow area divided by the wetted perimeter. For simplicity, wetted perimeter is assumed to include the two lengths ends of the channel, but not the channel gap. The fin depth and width of $10 \mathrm{mil}$, and one groove every 20 mil, was used in the calculations. The 2.082 inch meat length is used as the basis of the parameters in Tables A-1 and A-2, and so the tables would only be suitable for use in the calculation of the hot channel with the power distribution of a plate.

Since the power distributions are presented in terms of a quarter stripe of a plate, Tables A-3 and A-4 present the hydraulic geometries of a quarter stripe hot channel (0.5205 inch, $1.322 \mathrm{E}-2 \mathrm{~m}$ ) in units as-specified and SI units, respectively. 
Table A-1. Interior and end channel hydraulic geometry.

\begin{tabular}{|c|c|c|c|c|c|c|c|c|c|c|c|c|c|c|}
\hline \multirow[b]{2}{*}{$\begin{array}{l}\text { Fig } 7 . \\
\text { Label }\end{array}$} & \multirow[b]{2}{*}{ Channel Configuration } & \multicolumn{4}{|c|}{ Channel Dimension from fin-tip (mil) } & \multirow{2}{*}{$\begin{array}{c}\text { Effective } \\
\text { Channel } \\
\text { Dimension } \\
\text { (mil) }\end{array}$} & \multicolumn{5}{|c|}{ Nominal Channel Parameters } & \multicolumn{3}{|c|}{ Minimum Channels } \\
\hline & & Nominal & $\begin{array}{c}\text { Element } \\
\text { Off- } \\
\text { Center } \\
\end{array}$ & $\begin{array}{c}\text { Element } \\
\text { Off-Center } \\
\text { with Grid } \\
\text { Tolerances } \\
\end{array}$ & $\begin{array}{l}\text { Element Off- } \\
\text { center with } \\
\text { Tolerances } \\
\end{array}$ & & \begin{tabular}{|l} 
Finned \\
Plates
\end{tabular} & $\begin{array}{c}\text { Heated } \\
\text { Perimeter } \\
\text { (inch) }\end{array}$ & $\begin{array}{c}\text { Wetted } \\
\text { Perimeter } \\
\text { (inch) }\end{array}$ & $\begin{array}{c}\text { Flow Area, } \\
\text { Nominal } \\
\left(\text { inch }^{2}\right)\end{array}$ & $\begin{array}{c}\text { Hydraulic } \\
\text { Diameter, } \\
\text { Nominal } \\
\text { (mil) } \\
\end{array}$ & $\begin{array}{c}\text { Tolerance } \\
\text { on Fins } \\
\text { (mil) }\end{array}$ & $\begin{array}{c}\text { Flow Area, } \\
\text { Minimum } \\
\left(\text { inch }^{2}\right)\end{array}$ & $\begin{array}{c}\text { Hydraulic } \\
\text { Diameter, } \\
\text { Minimum } \\
\text { (mil) }\end{array}$ \\
\hline & Interior Channels & 72 & 72 & 72 & 68 & 78 & 2 & 8.328 & 8.328 & 0.1707 & 82 & 2 & 0.1582 & 76 \\
\hline (a) & $\begin{array}{l}\text { End channel facing } \\
\text { adjacent element } \\
\text { end channel, A-ring }\end{array}$ & 101 & 101 & 101 & 85 & 95 & 2 & 8.328 & 8.328 & 0.2311 & 111 & 2 & 0.1936 & 93 \\
\hline (b) & $\begin{array}{c}\text { End channel facing } \\
\text { adjacent element } \\
\text { end channel, B/C ring }\end{array}$ & 111 & 101 & 101 & 85 & 95 & 2 & 8.328 & 8.328 & 0.2519 & 121 & 2 & 0.1936 & 93 \\
\hline (c) & $\begin{array}{l}\text { End channel facing } \\
\text { adjacent element } \\
\text { side plate, A-ring } \\
\end{array}$ & 65.5 & 65.5 & 65.5 & 47.5 & 52.5 & 1 & 4.164 & 6.246 & 0.1468 & 94 & 2 & 0.1072 & 68.7 \\
\hline (d) & $\begin{array}{l}\text { End channel facing } \\
\text { adjacent element } \\
\text { side plate, B/C-ring } \\
\end{array}$ & 75.5 & 65.5 & 65.5 & 47.5 & 52.5 & 1 & 4.164 & 6.246 & 0.1676 & 107.3 & 2 & 0.1072 & 68.7 \\
\hline (f) & $\begin{array}{l}\text { End channel facing } \\
\text { inner hex (B-ring) }\end{array}$ & 67.5 & 54.5 & 50.5 & 37.5 & 42.5 & 1 & 4.164 & 6.246 & 0.1509 & 96.7 & 2 & 0.0864 & 55.3 \\
\hline (g) & End channel facing Arm & 55.5 & 50.5 & 50.5 & 37.5 & 42.5 & 1 & 4.164 & 6.246 & 0.1260 & 80.7 & 2 & 0.0864 & 55.3 \\
\hline (h) & $\begin{array}{c}\text { End channel facing } \\
\text { outer hex }\end{array}$ & 65.5 & 52.5 & 50.5 & 37.5 & 42.5 & 1 & 4.164 & 6.246 & 0.1468 & 94 & 2 & 0.0864 & 55.3 \\
\hline
\end{tabular}


Table A-2. Interior and end channel hydraulic geometry (SI units).

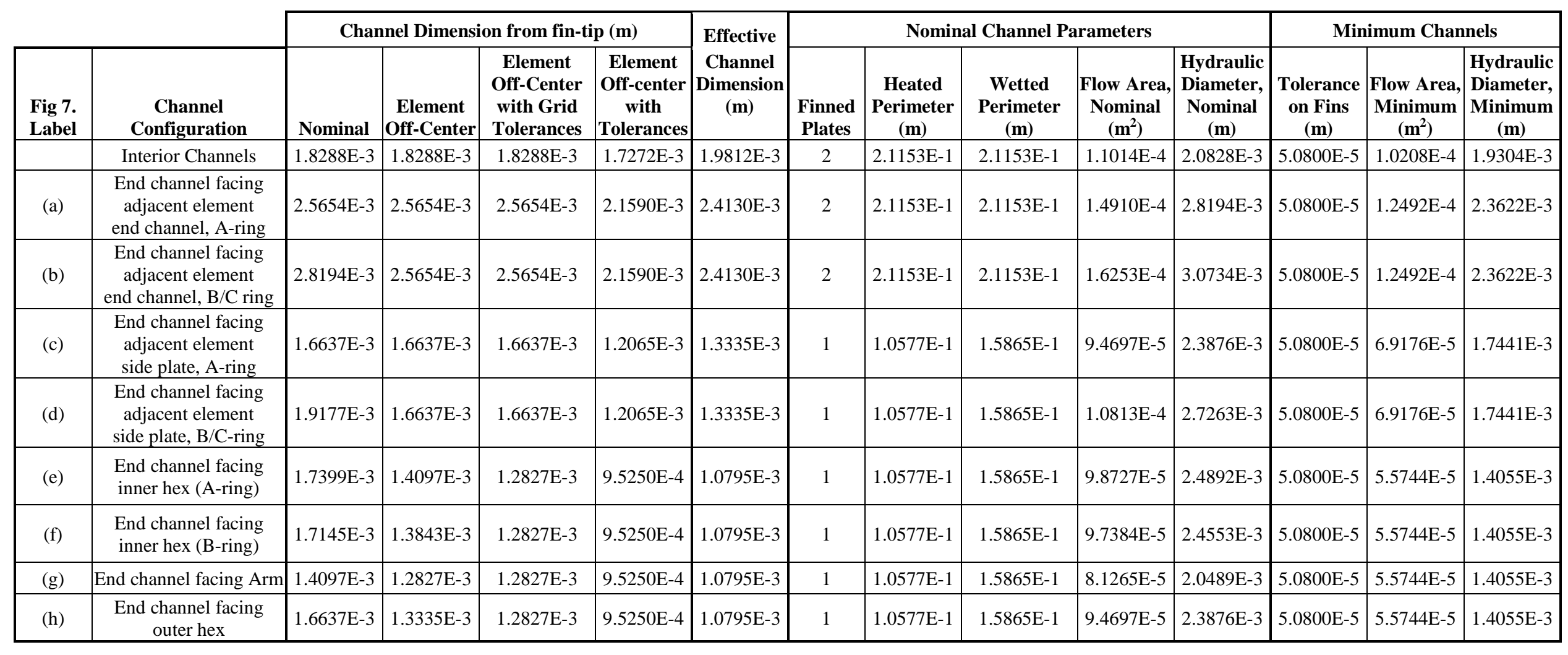


Table A-3. Stripe of interior and end channel hydraulic geometry.

\begin{tabular}{|c|c|c|c|c|c|c|c|c|c|c|c|c|c|c|}
\hline \multirow[b]{2}{*}{$\begin{array}{l}\text { Fig } 7 . \\
\text { Label }\end{array}$} & \multirow[b]{2}{*}{ Channel Configuration } & \multicolumn{4}{|c|}{ Channel Dimension from fin-tip (mil) } & \multirow{2}{*}{$\begin{array}{c}\text { Effective } \\
\text { Channel } \\
\text { Dimension } \\
\text { (mil) }\end{array}$} & \multicolumn{5}{|c|}{ Nominal Channel Parameters } & \multicolumn{3}{|c|}{ Minimum Channel } \\
\hline & & Nominal & \begin{tabular}{|c|} 
Element \\
Off- \\
Center \\
\end{tabular} & \begin{tabular}{|c|} 
Element \\
Off-Center \\
with Grid \\
Tolerances \\
\end{tabular} & \begin{tabular}{|c|} 
Element Off- \\
center with \\
Tolerances \\
\end{tabular} & & $\begin{array}{l}\text { Finned } \\
\text { Plates } \\
\end{array}$ & \begin{tabular}{|c|} 
Heated \\
Perimeter \\
(inch)
\end{tabular} & $\begin{array}{c}\text { Wetted } \\
\text { Perimeter } \\
\text { (inch) }\end{array}$ & $\begin{array}{c}\text { Flow Area, } \\
\text { Nominal } \\
\left(\text { inch }^{2}\right)\end{array}$ & \begin{tabular}{|c|} 
Hydraulic \\
Diameter, \\
Nominal \\
$($ mil $)$
\end{tabular} & $\begin{array}{c}\text { Tolerance } \\
\text { on Fins } \\
\text { (mil) }\end{array}$ & $\begin{array}{c}\text { Flow Area, } \\
\text { Minimum } \\
\left(\text { inch }^{2}\right)\end{array}$ & \begin{tabular}{|c|} 
Hydraulic \\
Diameter, \\
Minimum \\
(mil) \\
\end{tabular} \\
\hline & Interior Channels & 72 & 72 & 72 & 68 & 78 & 2 & 2.082 & 2.082 & 0.0427 & 82 & 2 & 0.0396 & 76 \\
\hline (a) & $\begin{array}{l}\text { End channel facing } \\
\text { adjacent element } \\
\text { end channel, A-ring }\end{array}$ & 101 & 101 & 101 & 85 & 95 & 2 & 2.082 & 2.082 & 0.0578 & 111 & 2 & 0.0484 & 93 \\
\hline (b) & $\begin{array}{c}\text { End channel facing } \\
\text { adjacent element } \\
\text { end channel, B/C ring }\end{array}$ & 111 & 101 & 101 & 85 & 95 & 2 & 2.082 & 2.082 & 0.0630 & 121 & 2 & 0.0484 & 93 \\
\hline (c) & $\begin{array}{c}\text { End channel facing } \\
\text { adjacent element } \\
\text { side plate, A-ring } \\
\end{array}$ & 65.5 & 65.5 & 65.5 & 47.5 & 52.5 & 1 & 1.041 & 1.5615 & 0.0367 & 94 & 2 & 0.0268 & 68.67 \\
\hline (d) & $\begin{array}{l}\text { End channel facing } \\
\text { adjacent element } \\
\text { side plate, B/C-ring } \\
\end{array}$ & 75.5 & 65.5 & 65.5 & 47.5 & 52.5 & 1 & 1.041 & 1.5615 & 0.0419 & 107.33 & 2 & 0.0268 & 68.67 \\
\hline (f) & $\begin{array}{l}\text { End channel facing } \\
\text { inner hex (B-ring) }\end{array}$ & 67.5 & 54.5 & 50.5 & 37.5 & 42.5 & 1 & 1.041 & 1.5615 & 0.0377 & 96.67 & 2 & 0.0216 & 55.33 \\
\hline$(\mathrm{g})$ & End channel facing Arm & 55.5 & 50.5 & 50.5 & 37.5 & 42.5 & 1 & 1.041 & 1.5615 & 0.0315 & 80.67 & 2 & 0.0216 & 55.33 \\
\hline (h) & $\begin{array}{c}\text { End channel facing } \\
\text { outer hex }\end{array}$ & 65.5 & 52.5 & 50.5 & 37.5 & 42.5 & 1 & 1.041 & 1.5615 & 0.0367 & 94 & 2 & 0.0216 & 55.33 \\
\hline
\end{tabular}


Table A-4. Stripe of interior and end channel hydraulic geometry (SI units).

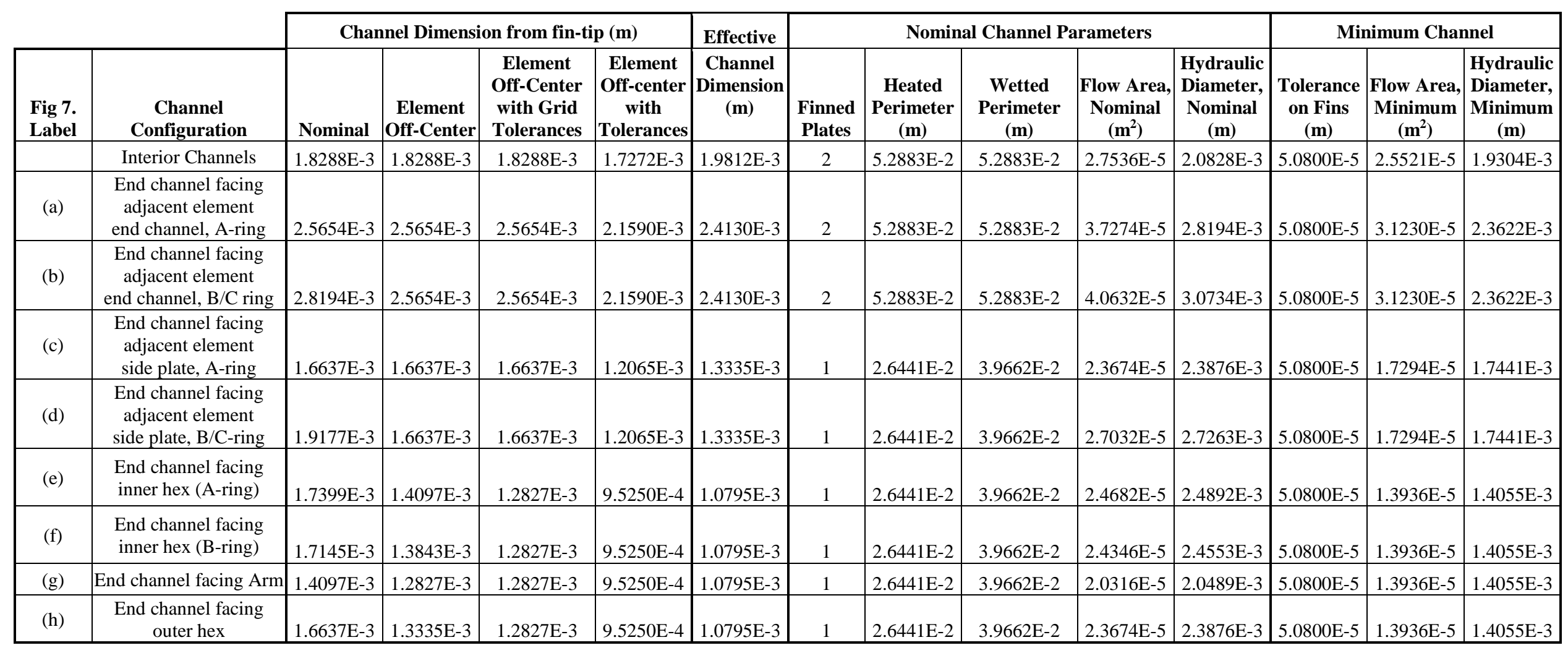




\section{APPENDIX B HEU POWER DISTRIBUTIONS}

In order to characterize power distributions over a range of MITR HEU core configurations, a set of fresh and depleted cores was generated. The HEU depleted cores are a set of historical HEU cores from the years 2007-2009. The depleted HEU cores were previously studied, in addition to the HEU all-fresh Core 2, for comparison and validation of HEU and LEU modeling results to HEU experimental benchmark data [1]. Power distributions of these HEU cores are presented here following the methodology described in Chapter 3.

Peak heat flux for the twelve depleted HEU Cores 179-190 (24 element cores) are shown in Table B-1 at BOC and EOC along with the 22 element all-fresh HEU Core 2. Peaking factors, such as those shown in Table B-2, are calculated relative to the average core power. These tables list the peak element, plate, axial, stripe and spot (see Appendix $\mathrm{C}$ for core maps of HEU power distributions).

The peak power stripe represents the axial-average within one of the four vertical stripes of a fuel plate, and the peak power axial is an average of the four stripes at each axial level within a plate. Whereas the peaking factors are independent of power, the heat flux and segment power were calculated with a total HEU core power of $6 \mathrm{MW}$. Power distributions were calculated based on modeling with all $6 \mathrm{MW}$ of the fission energy deposited locally within the fuel meat. Thermal hydraulic analyses separately incorporate factors for deposition within various core regions outside of the fuel meat [8]. Table B-2 includes the power peaking of the fresh HEU core, though a direct comparison should be based upon the heat flux and flow rate since the 22 element fresh core has a higher average power density and flow per element and than the 24 element depleted cores.

The highest HEU power peaking factors for the peak stripe were 1.81 times the core average, and for the peak spot 2.35 times the core average power. HEU peaking factors are about $20 \%$ lower than those presented for LEU in Chapter 3. The highest HEU heat flux from the depleted cores (peak stripe $50.2 \mathrm{~W} / \mathrm{cm}^{2}$ of meat, peak spot $64.9 \mathrm{~W} / \mathrm{cm}^{2}$ of meat) are $14 \%-18 \%$ lower than the LEU peaking in Chapter 3. However, this comparison is made with the LEU core delivering additional power (LEU at $7 \mathrm{MW}$ vs. HEU at $6 \mathrm{MW}$ ) from additional fueled area (18 LEU plates vs. $15 \mathrm{HEU}$ ) for reasons of equivalent reactor performance.

Core peak locations from Tables B-1 and B-2 are noted in Table B-3 and shown in Figure B-1. In Figure B-1 each peak location is labeled and plate orientation is illustrated by the parallel lines. Locations are designated by element, plate, stripe, and axial. For example element 27, plate 15, stripe 4 , bottom axial is designated by $27 \mathrm{P} 15 \mathrm{~S} 4 \mathrm{Ax} 18$. In order to provide a reference to the alphanumeric location commonly used in MITR documentation, the ring order designation is displayed in Figure B-1. For example, above the element number designation "27", is the ring designation "C-15". As found in the LEU cases, all HEU peaks were found to be located in an outer stripe (stripe 1 or 4 ) of an end plate (plate 1, HEU plate 15, or LEU plate 18). The power was peaked toward the center or bottom due to the partial insertion of control blades. 
Table B-1. Peak heat flux in MITR fresh and depleted HEU 6 MW cores. ${ }^{a}$

\begin{tabular}{|c|c|c|c|c|c|}
\hline $\begin{array}{c}\text { Peak Heat Flux } \\
\text { (W/cm } \text { of meat) }^{2}\end{array}$ & $\begin{array}{c}\text { Peak } \\
\text { Spot }\end{array}$ & $\begin{array}{c}\text { Peak } \\
\text { Stripe }\end{array}$ & $\begin{array}{c}\text { Peak } \\
\text { Axial }\end{array}$ & $\begin{array}{c}\text { Peak } \\
\text { Plate }\end{array}$ & $\begin{array}{c}\text { Peak } \\
\text { Element }\end{array}$ \\
\hline $\begin{array}{c}\text { HEU Fresh Core 2 } \\
\text { (22 element) }\end{array}$ & 71.1 & 48.8 & 64.5 & 45.6 & 39.3 \\
\hline HEU Core 179 BOC & 64.2 & 50.2 & 59.7 & 47.7 & 37.1 \\
\hline HEU Core 180 BOC & 64.9 & 48.5 & 61.6 & 46.1 & 36.3 \\
\hline HEU Core 181 BOC & 63.4 & 47.1 & 59.5 & 44.7 & 35.6 \\
\hline HEU Core 182 BOC & 61.2 & 46.2 & 56.3 & 43.8 & 36.4 \\
\hline HEU Core 183 BOC & 63.6 & 44.4 & 58.8 & 42.4 & 36.2 \\
\hline HEU Core 184 BOC & 63.6 & 44.2 & 58.4 & 42.1 & 36.2 \\
\hline HEU Core 185 BOC & 61.4 & 49.8 & 57.8 & 47.3 & 36.4 \\
\hline HEU Core 186 BOC & 59.3 & 48.7 & 56.1 & 46.1 & 35.4 \\
\hline HEU Core 187 BOC & 62.3 & 47.4 & 59.6 & 45.2 & 34.9 \\
\hline HEU Core 188 BOC & 64.1 & 46.4 & 61.1 & 44.2 & 34.5 \\
\hline HEU Core 189 BOC & 63.1 & 45.5 & 57.6 & 43.4 & 37.4 \\
\hline HEU Core 190 BOC & 60.9 & 43.7 & 56.5 & 41.8 & 36.5 \\
\hline HEU Core 179 EOC & 62.4 & 47.5 & 58.6 & 43.9 & 34.5 \\
\hline HEU Core 180 EOC & 63.0 & 46.7 & 59.8 & 43.2 & 34.1 \\
\hline HEU Core 181 EOC & 59.3 & 45.6 & 56.3 & 42.3 & 33.4 \\
\hline HEU Core 182 EOC & 54.0 & 46.1 & 51.1 & 43.2 & 33.7 \\
\hline HEU Core 183 EOC & 61.6 & 48.0 & 57.0 & 42.7 & 34.7 \\
\hline HEU Core 184 EOC & 59.9 & 47.8 & 55.0 & 42.5 & 34.1 \\
\hline HEU Core 185 EOC & 58.2 & 47.0 & 53.3 & 44.2 & 34.3 \\
\hline HEU Core 186 EOC & 54.5 & 45.5 & 50.6 & 42.9 & 33.2 \\
\hline HEU Core 187 EOC & 59.9 & 46.9 & 57.1 & 43.3 & 32.9 \\
\hline HEU Core 188 EOC & 60.0 & 44.2 & 57.0 & 42.1 & 32.8 \\
\hline HEU Core 189 EOC & 58.4 & 44.2 & 55.8 & 40.4 & 35.0 \\
\hline HEU Core 190 EOC & 57.8 & 45.1 & 54.0 & 40.3 & 34.4 \\
\hline Maximum & 71.1 & 50.2 & 64.5 & 47.7 & 39.3 \\
\hline 18R & & \\
\hline
\end{tabular}

${ }^{\mathrm{a}}$ MITR licensed power level of $5 \mathrm{MW}$ at time of core operation. License for $6 \mathrm{MW}$ HEU operation received in 2010 provides basis for comparison for conversion. 
Table B-2. Power peaking versus core average in MITR fresh and depleted HEU cores.

\begin{tabular}{|c|c|c|c|c|c|}
\hline $\begin{array}{c}\text { Power Peaking } \\
\text { vs. Core Average }\end{array}$ & $\begin{array}{c}\text { Peak } \\
\text { Spot }\end{array}$ & $\begin{array}{c}\text { Peak } \\
\text { Stripe }\end{array}$ & $\begin{array}{c}\text { Peak } \\
\text { Axial }\end{array}$ & $\begin{array}{c}\text { Peak } \\
\text { Plate }\end{array}$ & $\begin{array}{c}\text { Peak } \\
\text { Element }\end{array}$ \\
\hline $\begin{array}{c}\text { HEU Fresh Core 2 } \\
\text { (22 element) }\end{array}$ & 2.35 & 1.61 & 2.13 & 1.51 & 1.30 \\
\hline HEU Core 179 BOC & 2.32 & 1.81 & 2.15 & 1.72 & 1.34 \\
\hline HEU Core 180 BOC & 2.34 & 1.75 & 2.22 & 1.66 & 1.31 \\
\hline HEU Core 181 BOC & 2.29 & 1.70 & 2.15 & 1.61 & 1.28 \\
\hline HEU Core 182 BOC & 2.21 & 1.67 & 2.03 & 1.58 & 1.31 \\
\hline HEU Core 183 BOC & 2.29 & 1.60 & 2.12 & 1.53 & 1.31 \\
\hline HEU Core 184 BOC & 2.29 & 1.59 & 2.10 & 1.52 & 1.30 \\
\hline HEU Core 185 BOC & 2.21 & 1.80 & 2.08 & 1.70 & 1.31 \\
\hline HEU Core 186 BOC & 2.14 & 1.75 & 2.02 & 1.66 & 1.28 \\
\hline HEU Core 187 BOC & 2.25 & 1.71 & 2.15 & 1.63 & 1.26 \\
\hline HEU Core 188 BOC & 2.31 & 1.67 & 2.20 & 1.60 & 1.24 \\
\hline HEU Core 189 BOC & 2.28 & 1.64 & 2.08 & 1.57 & 1.35 \\
\hline HEU Core 190 BOC & 2.20 & 1.58 & 2.04 & 1.51 & 1.32 \\
\hline HEU Core 179 EOC & 2.25 & 1.71 & 2.11 & 1.59 & 1.24 \\
\hline HEU Core 180 EOC & 2.27 & 1.68 & 2.16 & 1.56 & 1.23 \\
\hline HEU Core 181 EOC & 2.14 & 1.65 & 2.03 & 1.53 & 1.20 \\
\hline HEU Core 182 EOC & 1.95 & 1.66 & 1.84 & 1.56 & 1.22 \\
\hline HEU Core 183 EOC & 2.22 & 1.73 & 2.06 & 1.54 & 1.25 \\
\hline HEU Core 184 EOC & 2.16 & 1.73 & 1.98 & 1.53 & 1.23 \\
\hline HEU Core 185 EOC & 2.10 & 1.70 & 1.92 & 1.60 & 1.24 \\
\hline HEU Core 186 EOC & 1.97 & 1.64 & 1.83 & 1.55 & 1.20 \\
\hline HEU Core 187 EOC & 2.16 & 1.69 & 2.06 & 1.56 & 1.19 \\
\hline HEU Core 188 EOC & 2.17 & 1.60 & 2.06 & 1.52 & 1.18 \\
\hline HEU Core 189 EOC & 2.11 & 1.59 & 2.01 & 1.46 & 1.26 \\
\hline HEU Core 190 EOC & 2.08 & 1.63 & 1.95 & 1.45 & 1.24 \\
\hline Maximum & $\mathbf{2 . 3 5}$ & $\mathbf{1 . 8 1}$ & $\mathbf{2 . 2 2}$ & $\mathbf{1 . 7 2}$ & $\mathbf{1 . 3 5}$ \\
\hline
\end{tabular}


Table B-3. Peak power locations in MITR fresh and depleted HEU cores.

\begin{tabular}{|c|c|c|c|c|c|}
\hline Peak Locations & Peak Spot & $\begin{array}{l}\text { Peak } \\
\text { Stripe }\end{array}$ & Peak Axial & $\begin{array}{l}\text { Peak } \\
\text { Plate }\end{array}$ & $\begin{array}{c}\text { Peak } \\
\text { Element\# }\end{array}$ \\
\hline HEU Fresh Core 2 & 27P01S1 Ax14 & 01P01S1 & 27P01 Ax14 & 01P01 & 1 \\
\hline HEU Core 179 BOC & 27P01S1 Ax18 & 12P15S4 & 25P01 Ax14 & 09P15 & 2 \\
\hline HEU Core 180 BOC & 21P01S1 Ax13 & 12P15S4 & 21P01 Ax13 & 09P15 & 2 \\
\hline HEU Core 181 BOC & 13P15S1 Ax18 & 12P15S4 & 21P01 Ax13 & 09P15 & 2 \\
\hline HEU Core 182 BOC & 13P15S1 Ax18 & 12P15S4 & 26P01 Ax13 & $12 \mathrm{P} 15$ & 10 \\
\hline HEU Core 183 BOC & 27P01S1 Ax18 & 12P15S4 & 23P15 Ax13 & $12 \mathrm{P} 15$ & 2 \\
\hline HEU Core 184 BOC & 23P15S1 Ax13 & 12P15S4 & 23P15 Ax13 & $12 \mathrm{P} 15$ & 2 \\
\hline HEU Core 185 BOC & 23P15S1 Ax14 & 12P15S4 & 12P15 Ax18 & $12 \mathrm{P} 15$ & 9 \\
\hline HEU Core 186 BOC & 27P01S1 Ax18 & 12P15S4 & 12P15 Ax18 & $12 \mathrm{P} 15$ & 9 \\
\hline HEU Core 187 BOC & 25P01S4 Ax13 & 12P15S4 & 24P15 Ax13 & $12 \mathrm{P} 15$ & 9 \\
\hline HEU Core 188 BOC & 24P15S1 Ax13 & 12P15S4 & 24P15 Ax13 & $12 \mathrm{P} 15$ & 9 \\
\hline HEU Core 189 BOC & 27P01S1 Ax18 & 12P15S4 & 24P15 Ax14 & 09P15 & 2 \\
\hline HEU Core 190 BOC & 18P15S1 Ax14 & 02P01S1 & 18P15 Ax13 & 09P15 & 2 \\
\hline HEU Core 179 EOC & 25P01S4 Ax11 & 25P01S4 & 25P01 Ax11 & 09P15 & 2 \\
\hline HEU Core 180 EOC & 21P01S1 Ax11 & 25P01S4 & 21P01 Ax11 & 09P15 & 2 \\
\hline HEU Core 181 EOC & 21P01S1 Ax11 & 25P01S4 & 21P01 Ax11 & 21P01 & 2 \\
\hline HEU Core 182 EOC & 25P01S4 Ax11 & 25P01S4 & $25 \mathrm{P} 01 \quad \mathrm{Ax9}$ & $25 \mathrm{P} 01$ & 10 \\
\hline HEU Core 183 EOC & 23P15S1 Ax13 & 23P15S1 & 23P15 Ax11 & 23P15 & 2 \\
\hline HEU Core 184 EOC & 23P15S1 Ax11 & 23P15S1 & 23P15 Ax11 & 23P15 & 2 \\
\hline HEU Core 185 EOC & 23P15S1 Ax9 & 23P15S1 & 23P15 Ax11 & $12 \mathrm{P} 15$ & 9 \\
\hline HEU Core 186 EOC & 23P15S1 Ax9 & 23P15S1 & 09P15 Ax8 & $12 \mathrm{P} 15$ & 9 \\
\hline HEU Core 187 EOC & 25P01S4 Ax11 & 25P01S4 & 24P15 Ax11 & 25P01 & 9 \\
\hline HEU Core 188 EOC & 24P15S1 Ax13 & 24P15S1 & 24P15 Ax11 & $24 \mathrm{P} 15$ & 9 \\
\hline HEU Core 189 EOC & 24P15S1 Ax13 & 22P01S4 & 24P15 Ax13 & 09P15 & 2 \\
\hline HEU Core 190 EOC & 18P15S1 Ax13 & 18P15S1 & 18P15 Ax11 & $18 \mathrm{P} 15$ & 2 \\
\hline
\end{tabular}




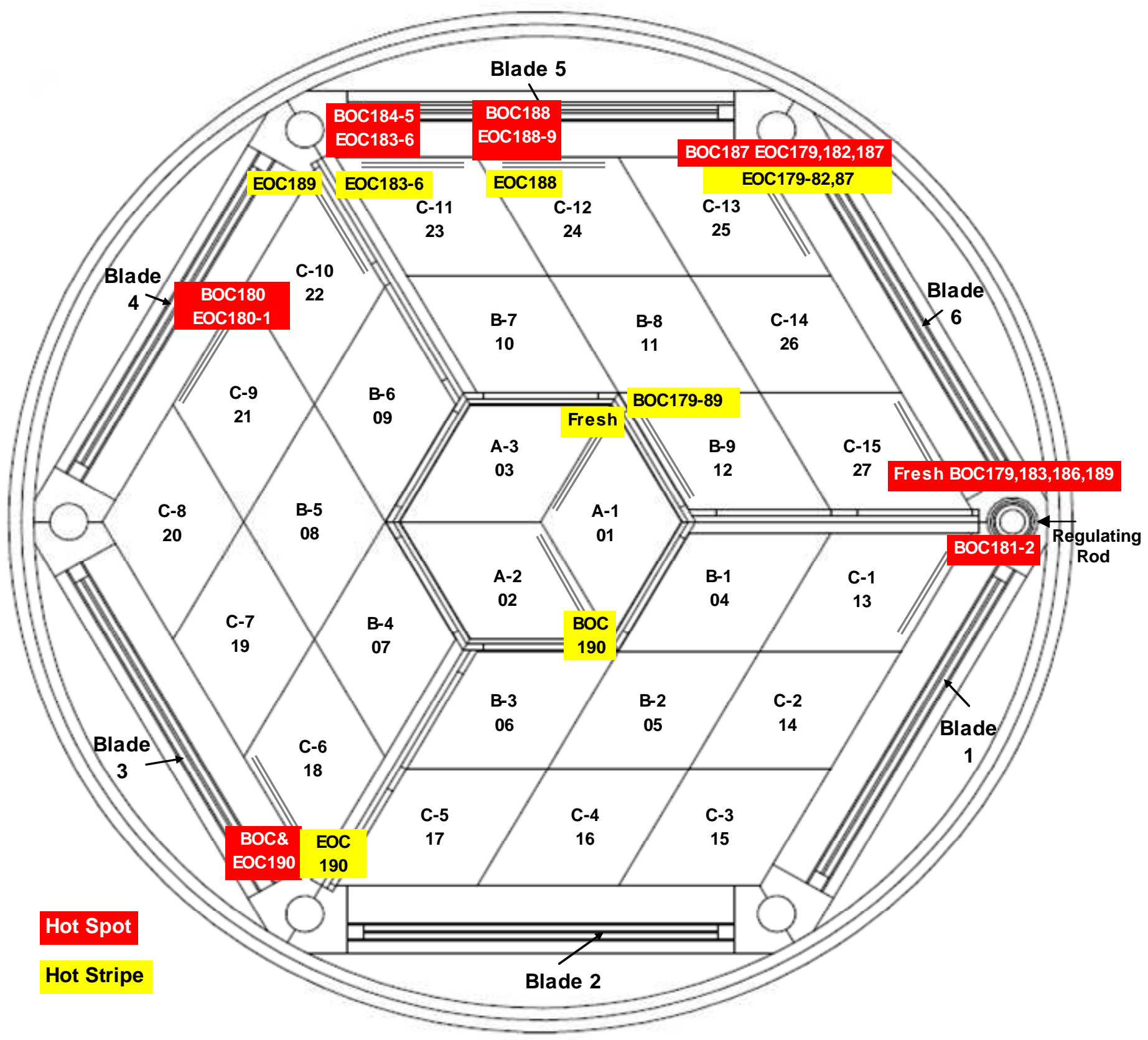

Figure B-1. Peak locations of HEU fresh and depleted cores at BOC and EOC. 


\section{APPENDIX C POWER DISTRIBUTIONS BY HEU CORE LOADING}

Power distributions are shown for the all-fresh HEU Core 2 and depleted HEU Cores 179-190 at BOC and EOC in Tables C-1 and C-2 at BOC and EOC, respectively. The color coding in the tables indicates element power vs. average with $<80 \%$ (green), $80 \%-100 \%$ (yellow), $100 \%-110 \%$ (orange), > 110\% (red). Peaking is illustrated in core maps of element power in Figures C-1 to C-25.

Table C-1. Power peaking by element in HEU fresh and depleted cores at BOC.

\begin{tabular}{|c|c|c|c|c|c|c|c|c|c|c|c|c|c|}
\hline Element & \begin{tabular}{|c|} 
All \\
Fresh
\end{tabular} & \begin{tabular}{|c|}
179 \\
$B O C$ \\
\end{tabular} & $\begin{array}{c}180 \\
B O C\end{array}$ & \begin{tabular}{|c|}
181 \\
$B O C$ \\
\end{tabular} & $\begin{array}{c}182 \\
B O C\end{array}$ & $\begin{array}{c}183 \\
B O C\end{array}$ & $\begin{array}{c}184 \\
B O C\end{array}$ & $\begin{array}{c}185 \\
\text { BOC }\end{array}$ & \begin{tabular}{|c|}
186 \\
$B O C$ \\
\end{tabular} & $\begin{array}{c}187 \\
\text { BOC }\end{array}$ & \begin{tabular}{|c|}
188 \\
$B O C$ \\
\end{tabular} & $\begin{array}{r}189 \\
B O C\end{array}$ & $\begin{array}{c}190 \\
B O C\end{array}$ \\
\hline A-2 $2^{*}$ & 1.30 & 1.34 & 1.31 & 1.28 & 1.27 & 1.31 & 1.30 & 1.29 & 1.27 & 1.24 & 1.23 & 1.35 & 1.32 \\
\hline B-1 & 16 & 1.18 & 1.17 & 1.14 & 1.27 & 1.24 & 1.22 & 1.21 & 1.20 & 1.18 & 1.17 & 1.26 & 1.22 \\
\hline B-2 & 1.09 & 1.11 & 1.10 & 1.08 & 1.08 & 1.09 & 1.08 & 1.07 & 1.05 & 1.16 & 1.14 & 1.13 & 1.11 \\
\hline-4 & .15 & 1.26 & 1.23 & 1.21 & 1.19 & 1.17 & 1.17 & 1.25 & 1.23 & 1.20 & 1.19 & 1.24 & 1.21 \\
\hline-5 & 1.06 & 1.14 & 1.11 & \begin{tabular}{|l|}
1.09 \\
\end{tabular} & 1.20 & 1.17 & 1.16 & 1.15 & 1.14 & 1.18 & 1.17 & 1.17 & 1.15 \\
\hline B-6 & no fuel & 1.32 & 1.28 & 1.25 & 1.24 & 1.21 & 1.22 & 1.31 & 1.28 & 1.26 & 1.24 & 1.24 & 1.20 \\
\hline B-7 & 1.15 & 1.24 & 1.21 & \begin{tabular}{|l|}
1.18 \\
\end{tabular} & 1.31 & 1.28 & 1.28 & 1.27 & 1.24 & 1.22 & 1.21 & 1.31 & 1.27 \\
\hline B-8 & 1.08 & 1.15 & 1.13 & \begin{tabular}{|l|}
1.10 \\
\end{tabular} & 1.10 & 1.14 & 1.13 & 1.12 & 1.10 & 1.21 & 1.19 & 1.18 & 1.14 \\
\hline B-9 & no fuel & 1.29 & 1.26 & 1.23 & 1.23 & 1.20 & 1.19 & 1.28 & 1.25 & 1.25 & 1.23 & 1.21 & 1.18 \\
\hline $\mathrm{C}-1$ & 0.96 & 0.87 & 0.88 & 0.95 & 0.94 & 0.93 & 0.90 & 0.91 & 0.88 & 0.87 & 0.85 & 0.82 & 0.81 \\
\hline $\mathrm{C}-2$ & 0.92 & 0.78 & 0.80 & 0.80 & 0.83 & 0.83 & 0.80 & 0.79 & 0.91 & 0.89 & 0.88 & 0.85 & 0.85 \\
\hline $\mathrm{C}-3$ & 0.93 & 0.79 & 0.89 & 0.90 & 0.91 & 0.90 & 0.87 & 0.80 & 0.80 & 0.77 & 0.83 & 0.79 & 0.80 \\
\hline C-4 & 0.92 & 0.81 & 0.81 & 0.94 & 0.81 & 0.80 & 0.78 & 0.76 & 0.89 & 0.86 & 0.86 & 0.83 & 0.83 \\
\hline $\mathrm{C}-5$ & 0.98 & 0.84 & 0.85 & 0.84 & 0.86 & 0.85 & 0.83 & 0.82 & 0.84 & 0.80 & 0.81 & 0.77 & 0.96 \\
\hline$C-6$ & 0.94 & 0.79 & 0.80 & 0.97 & 0.85 & 0.84 & 0.83 & 0.84 & 0.84 & 0.81 & 0.81 & 0.82 & 0.95 \\
\hline C-7 & 0.89 & 0.92 & 0.92 & 0.83 & 0.81 & 0.80 & 0.92 & 0.92 & 0.91 & 0.87 & 0.87 & 0.84 & 0.85 \\
\hline C-8 & 0.90 & 0.90 & 0.90 & 0.90 & 0.88 & 0.88 & 0.86 & 0.85 & 0.84 & 0.80 & 0.90 & 0.86 & 0.88 \\
\hline C-9 & 0.90 & 0.89 & 0.97 & 0.95 & 0.83 & 0.82 & 0.94 & 0.93 & 0.93 & 0.89 & 0.89 & 0.85 & 0.85 \\
\hline C-10 & 0.97 & \begin{tabular}{|l|}
0.90 \\
\end{tabular} & 0.89 & 0.87 & 0.88 & 0.87 & 0.86 & 0.84 & 0.89 & 0.87 & 0.88 & 0.97 & 0.96 \\
\hline & 0.94 & 0.91 & 0.91 & 0.88 & 0.88 & 1.00 & 1.00 & 0.98 & 0.97 & 0.94 & 0.94 & 0.90 & .89 \\
\hline $\mathrm{C}-12$ & 0.90 & 0.80 & 0.79 & \begin{tabular}{|l|}
0.83 \\
\end{tabular} & 0.84 & 0.83 & 0.90 & 0.88 & 0.87 & 0.97 & 0.97 & 0.93 & 0.92 \\
\hline C-13 & 0.93 & 0.96 & 0.96 & 0.95 & 0.96 & 0.97 & 0.94 & 0.93 & \begin{tabular}{|l|}
0.91 \\
\end{tabular} & 0.95 & 0.95 & 0.90 & 0.90 \\
\hline C-14 & 0.93 & 0.93 & 0.93 & 0.92 & 0.93 & 0.93 & 0.90 & 0.89 & 0.88 & 0.92 & 0.92 & 0.88 & 0.87 \\
\hline $\mathrm{C}-15$ & 1.00 & 0.90 & 0.90 & 0.90 & 0.90 & 0.94 & 0.91 & 0.92 & 0.90 & 0.88 & 0.87 & 0.89 & 0.88 \\
\hline
\end{tabular}

* A-ring element for HEU all-fresh Core 2 is located in MITR gridplate position A-1. 
Table C-2. Power peaking by element in HEU depleted cores at EOC. 


\begin{tabular}{|c|c|c|c|c|c|c|c|c|c|c|c|c|}
\hline Element & $\begin{array}{c}179 \\
\text { EOC }\end{array}$ & $\begin{array}{c}180 \\
\text { EOC }\end{array}$ & $\begin{array}{c}181 \\
\text { EOC }\end{array}$ & $\begin{array}{c}182 \\
\text { EOC }\end{array}$ & $\begin{array}{c}183 \\
\text { EOC }\end{array}$ & $\begin{array}{c}184 \\
\text { EOC }\end{array}$ & $\begin{array}{r}185 \\
\text { EOC }\end{array}$ & $\begin{array}{c}\mathbf{1 8 6} \\
\text { EOC }\end{array}$ & $\begin{array}{c}187 \\
\text { EOC }\end{array}$ & $\begin{array}{c}188 \\
\text { EOC }\end{array}$ & $\begin{array}{c}189 \\
\text { EOC }\end{array}$ & $\begin{array}{c}190 \\
\text { EOC }\end{array}$ \\
\hline A-2 & 1.24 & 1.23 & 1.20 & 1.18 & 1.25 & 1.23 & 1.21 & 1.18 & 1.16 & 1.16 & 1.26 & 1.24 \\
\hline B-1 & 1.11 & 1.10 & 1.08 & 1.18 & 1.19 & 1.16 & 1.14 & 1.12 & 1.11 & 1.10 & 1.18 & 1.16 \\
\hline B-2 & 1.05 & 1.04 & 1.02 & 1.02 & 1.06 & 1.03 & 1.02 & 1.00 & 1.09 & 1.09 & 1.07 & 1.07 \\
\hline B-4 & 1.18 & 1.17 & 1.14 & 1.12 & 1.12 & 1.11 & 1.18 & 1.16 & 1.14 & 1.13 & 1.17 & 1.15 \\
\hline B-5 & 1.07 & 1.06 & 1.04 & 1.12 & 1.13 & 1.11 & 1.10 & 1.07 & 1.11 & 1.11 & 1.11 & 1.10 \\
\hline B-6 & 1.23 & 1.21 & 1.18 & 1.16 & 1.17 & 1.15 & 1.24 & 1.20 & 1.19 & 1.18 & 1.17 & 1.14 \\
\hline B-7 & 1.16 & 1.14 & 1.11 & 1.22 & 1.23 & 1.21 & 1.20 & 1.17 & 1.15 & 1.14 & 1.23 & 1.20 \\
\hline B-8 & 1.08 & 1.07 & 1.04 & 1.03 & 1.10 & 1.07 & 1.07 & 1.04 & 1.14 & 1.13 & 1.12 & 1.09 \\
\hline B-9 & 1.20 & 1.18 & 1.16 & 1.15 & 1.15 & 1.12 & 1.20 & 1.17 & 1.17 & 1.16 & 1.14 & 1.12 \\
\hline $\mathrm{C}-1$ & 0.90 & 0.90 & 0.96 & 0.97 & 0.95 & 0.93 & 0.91 & 0.91 & 0.89 & 0.87 & 0.84 & 0.82 \\
\hline $\mathrm{C}-2$ & 0.82 & 0.83 & 0.83 & 0.88 & 0.85 & 0.83 & 0.82 & 0.95 & 0.93 & 0.91 & 0.88 & 0.88 \\
\hline $\mathrm{C}-3$ & 0.86 & 0.96 & 0.97 & 0.99 & 0.95 & 0.93 & 0.85 & 0.86 & 0.83 & 0.89 & 0.85 & 0.85 \\
\hline $\mathrm{C}-4$ & 0.85 & 0.85 & 0.98 & 0.86 & 0.82 & 0.81 & 0.79 & 0.93 & 0.90 & 0.90 & 0.87 & 0.87 \\
\hline $\mathrm{C}-5$ & 0.88 & 0.88 & 0.87 & 0.90 & 0.87 & 0.86 & 0.86 & 0.87 & 0.84 & 0.83 & 0.80 & 1.00 \\
\hline $\mathrm{C}-6$ & 0.83 & 0.83 & 1.01 & 0.90 & 0.86 & 0.86 & 0.88 & 0.87 & 0.84 & 0.84 & 0.86 & 0.98 \\
\hline $\mathrm{C}-7$ & 0.96 & 0.96 & 0.86 & 0.86 & 0.83 & 0.96 & 0.96 & 0.96 & 0.92 & 0.91 & 0.89 & 0.89 \\
\hline C-8 & 0.98 & 0.97 & 0.96 & 0.96 & 0.92 & 0.92 & 0.91 & 0.90 & 0.86 & 0.96 & 0.93 & 0.93 \\
\hline C-9 & 0.94 & 1.01 & 1.00 & 0.87 & 0.84 & 0.98 & 0.98 & 0.97 & 0.93 & 0.93 & 0.90 & 0.89 \\
\hline C-10 & 0.94 & 0.92 & 0.91 & 0.91 & 0.89 & 0.88 & 0.87 & 0.93 & 0.91 & 0.91 & 1.01 & 0.99 \\
\hline $\mathrm{C}-11$ & 0.95 & 0.94 & 0.92 & 0.92 & 1.03 & 1.03 & 1.02 & 1.00 & 0.98 & 0.98 & 0.94 & 0.92 \\
\hline $\mathrm{C}-12$ & 0.84 & 0.83 & 0.87 & 0.88 & 0.86 & 0.93 & 0.93 & 0.91 & 1.02 & 1.01 & 0.98 & 0.96 \\
\hline $\mathrm{C}-13$ & 1.04 & 1.03 & 1.02 & 1.04 & 1.02 & 1.00 & 1.00 & 0.98 & 1.02 & 1.01 & 0.97 & 0.95 \\
\hline C-14 & 0.97 & 0.96 & 0.95 & 0.97 & 0.95 & 0.93 & 0.93 & 0.92 & 0.96 & 0.95 & 0.92 & 0.90 \\
\hline C-15 & 0.93 & 0.92 & 0.91 & 0.93 & 0.97 & 0.94 & 0.93 & 0.92 & 0.91 & 0.90 & 0.92 & 0.90 \\
\hline
\end{tabular}




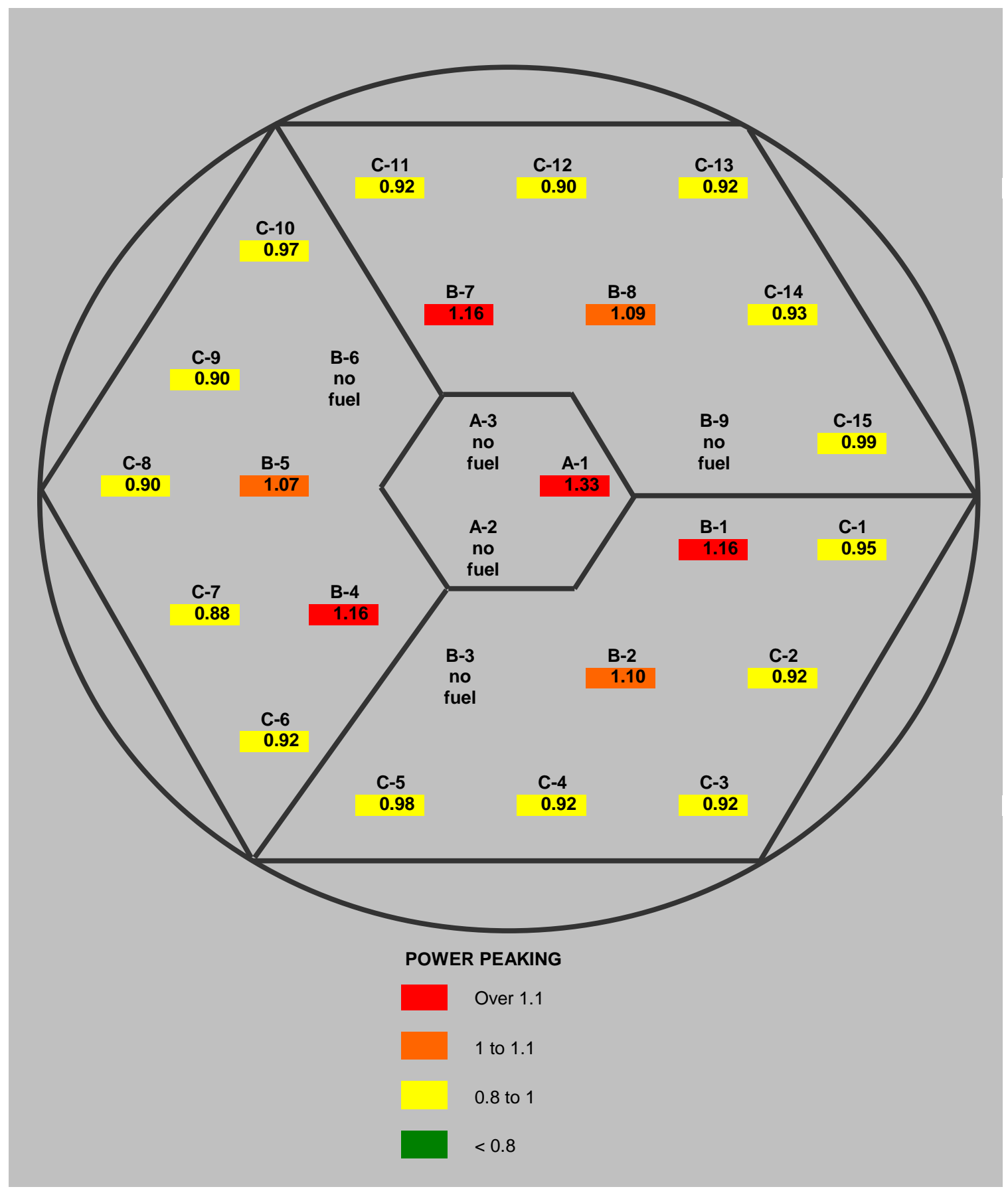

Figure C-1. Elemental power distribution in the all-fresh HEU Core 2. 


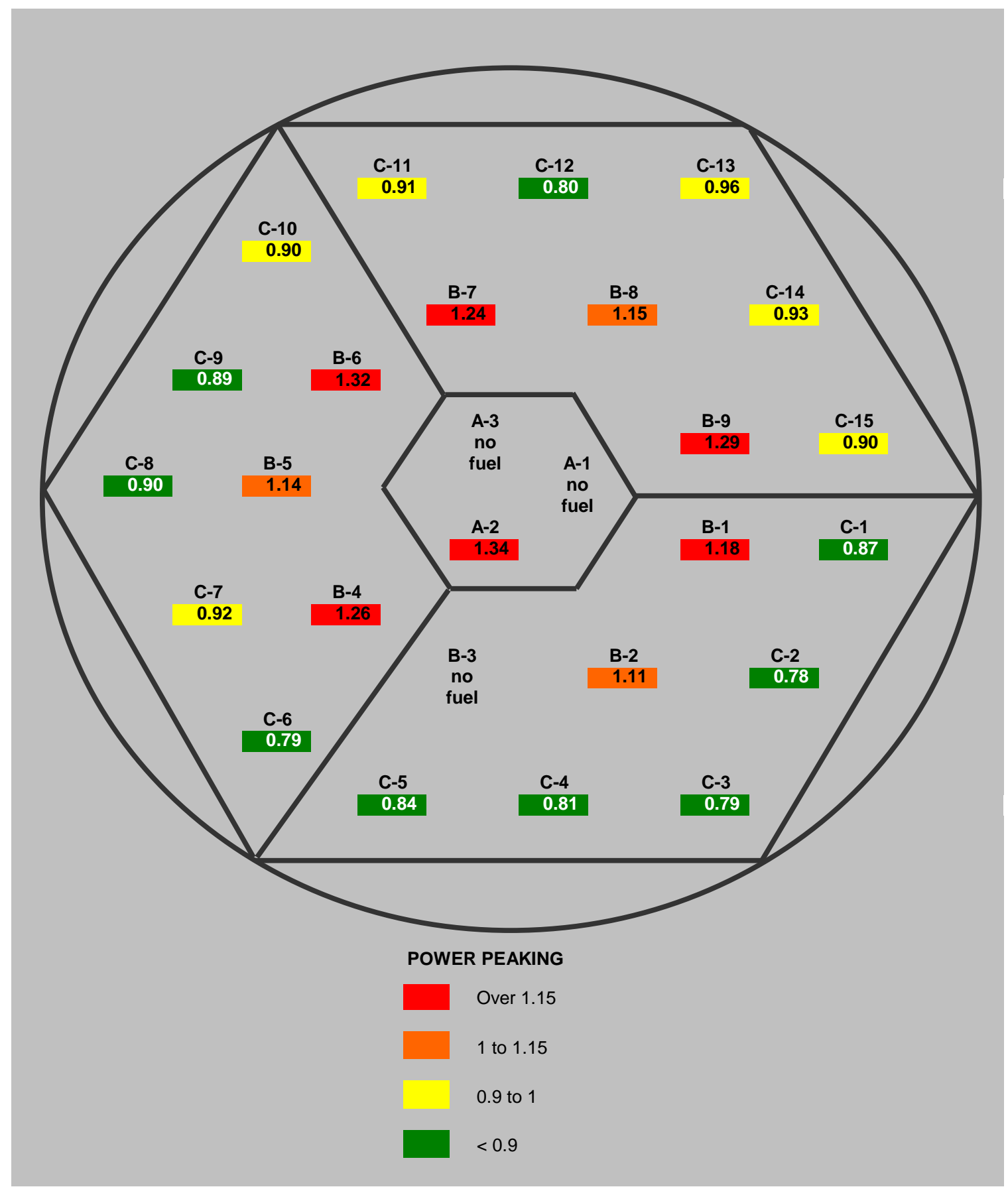

Figure C-2. Elemental power distribution in HEU depleted Core 179 at BOC. 


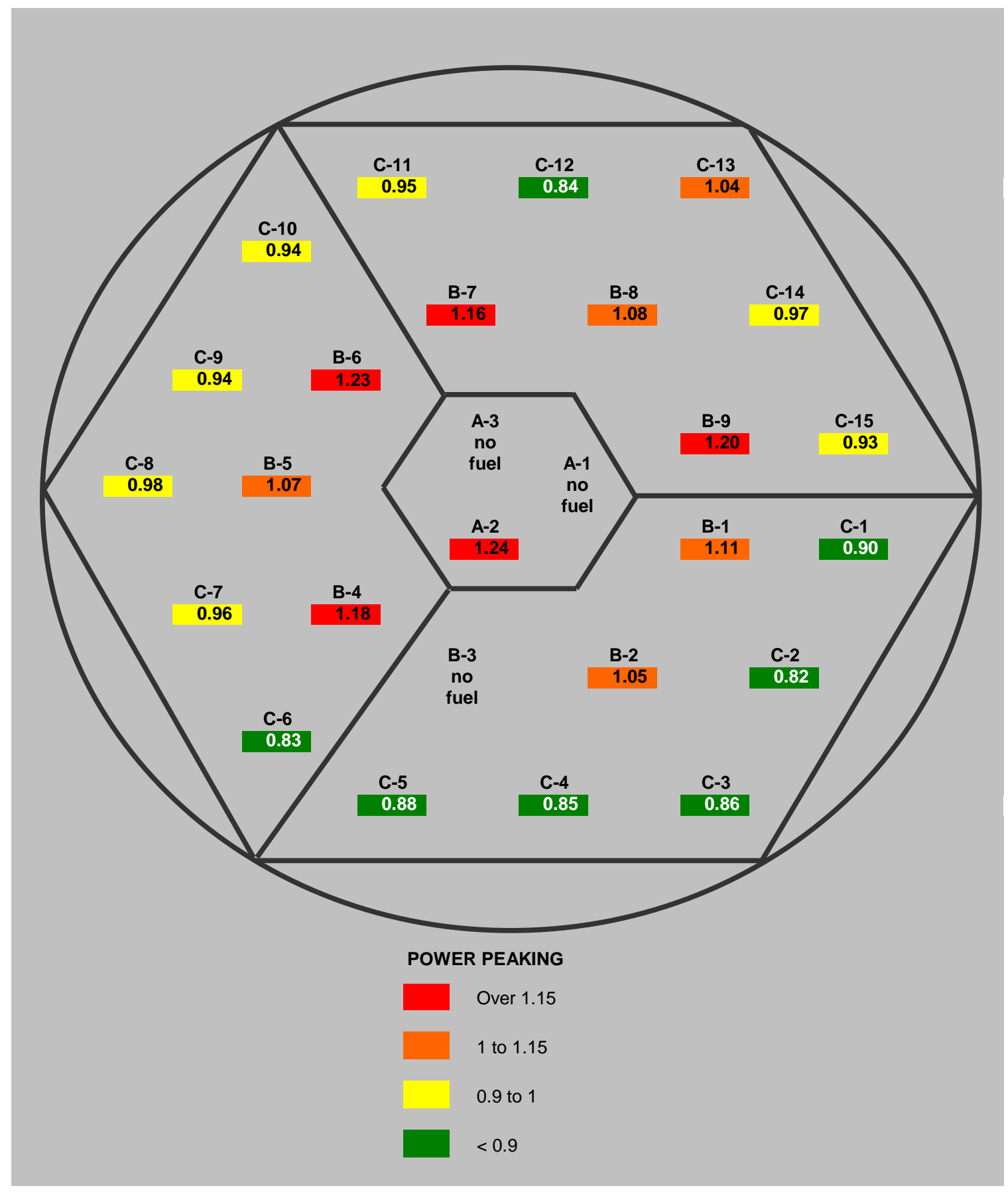

Figure C-3. Elemental power distribution in HEU depleted Core 179 at EOC. 


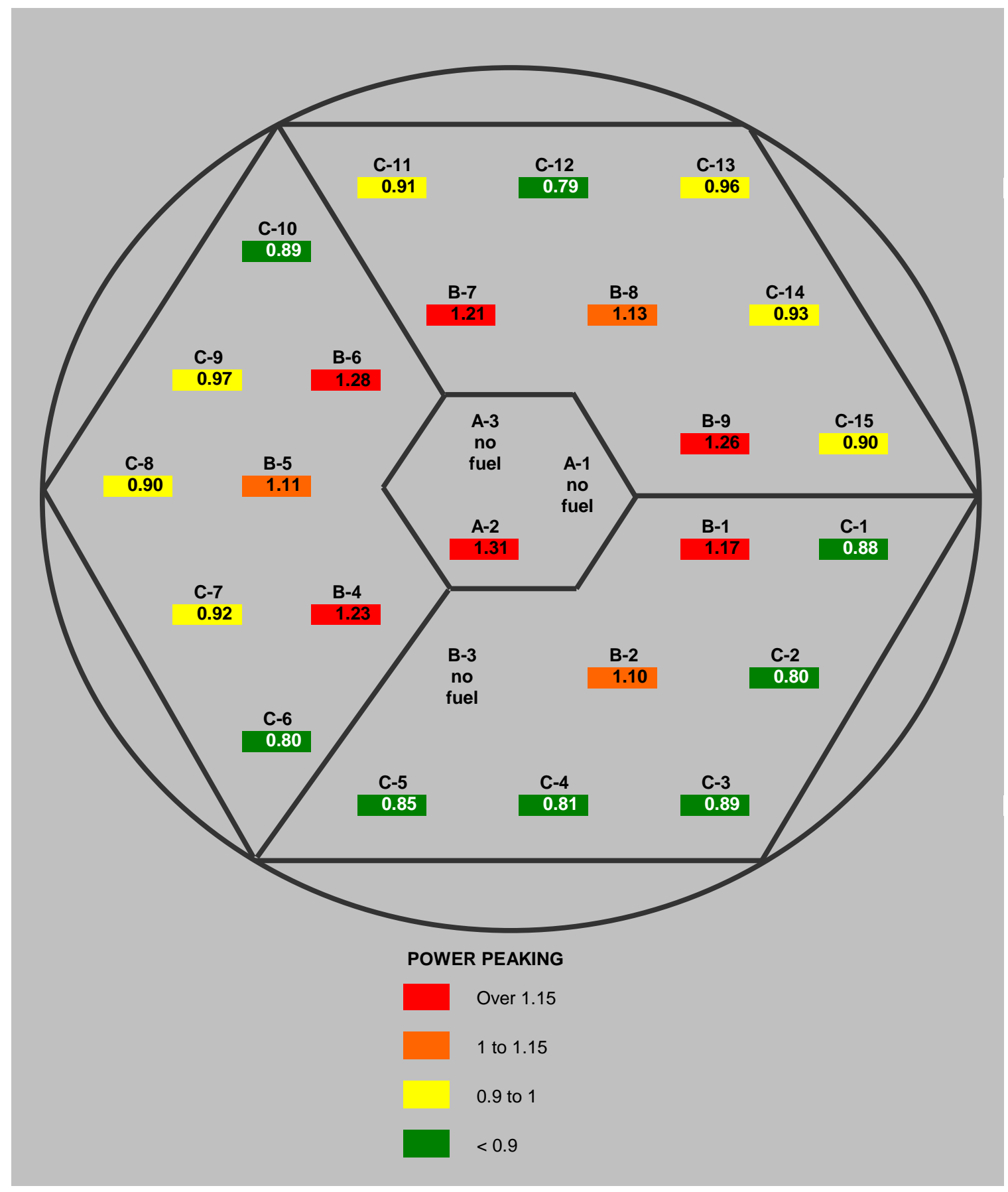

Figure C-4. Elemental power distribution in HEU depleted Core 180 at BOC. 


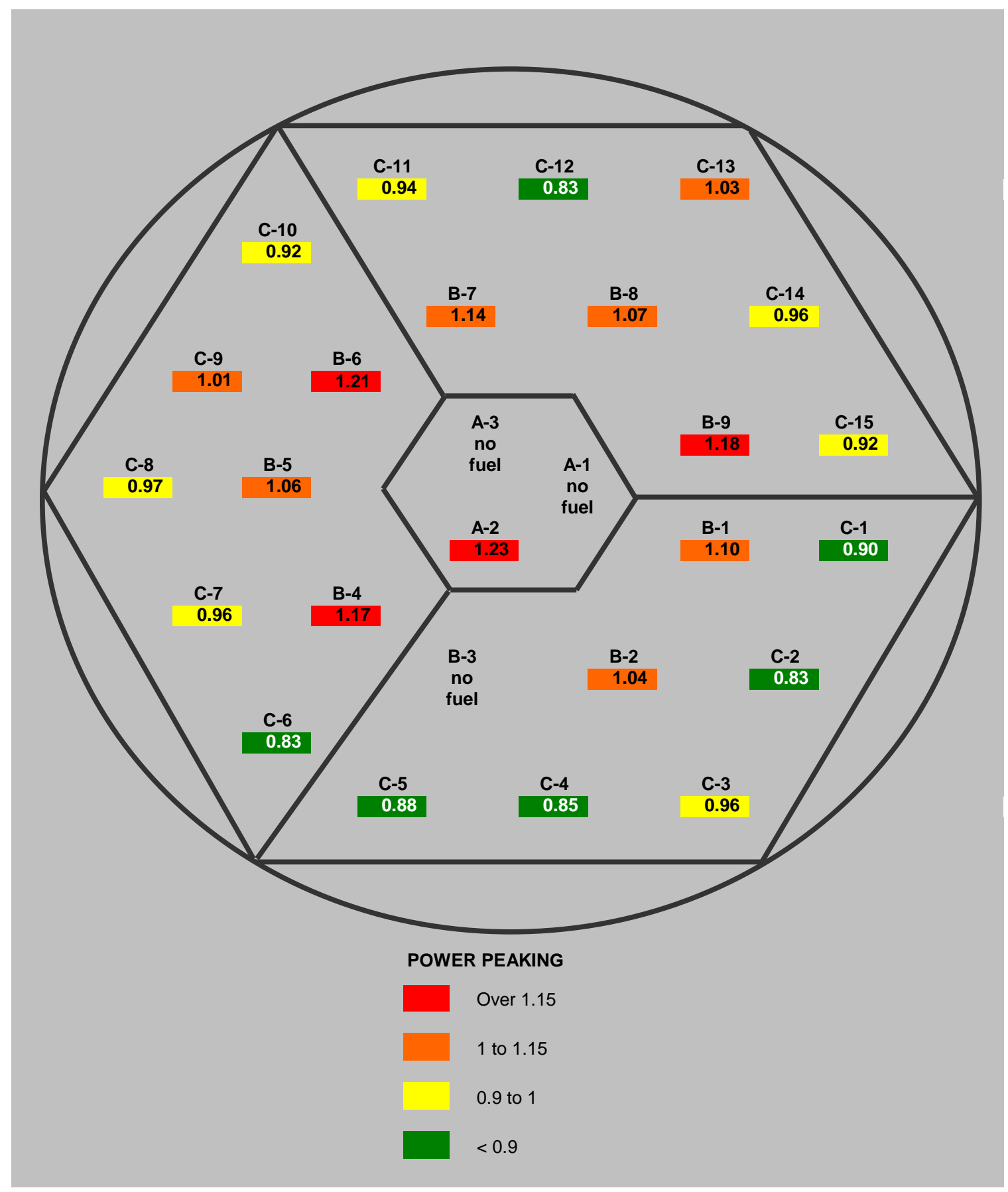

Figure C-5. Elemental power distribution in HEU depleted Core 180 at EOC. 


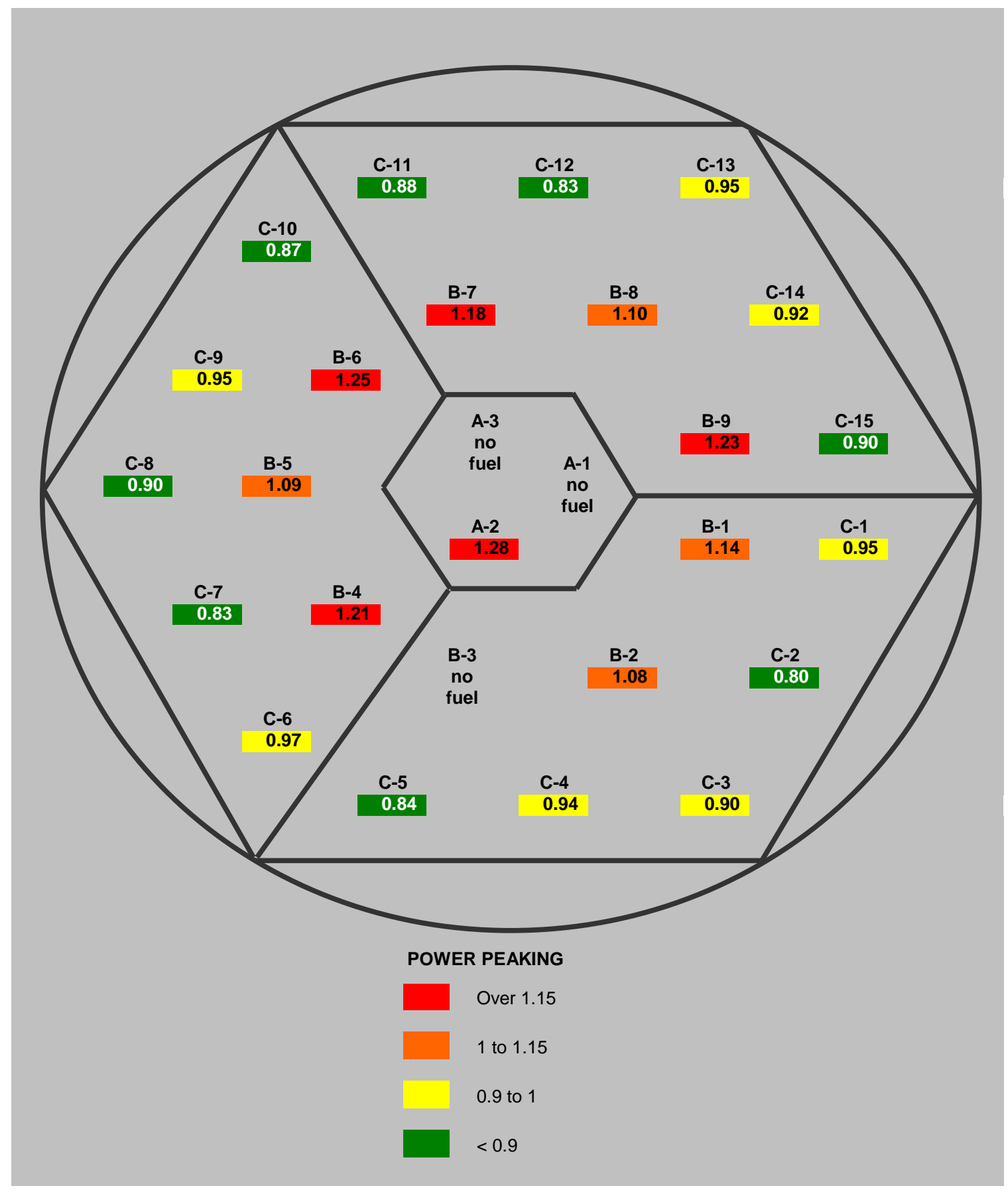

Figure C-6. Elemental power distribution in HEU depleted Core 181 at BOC. 


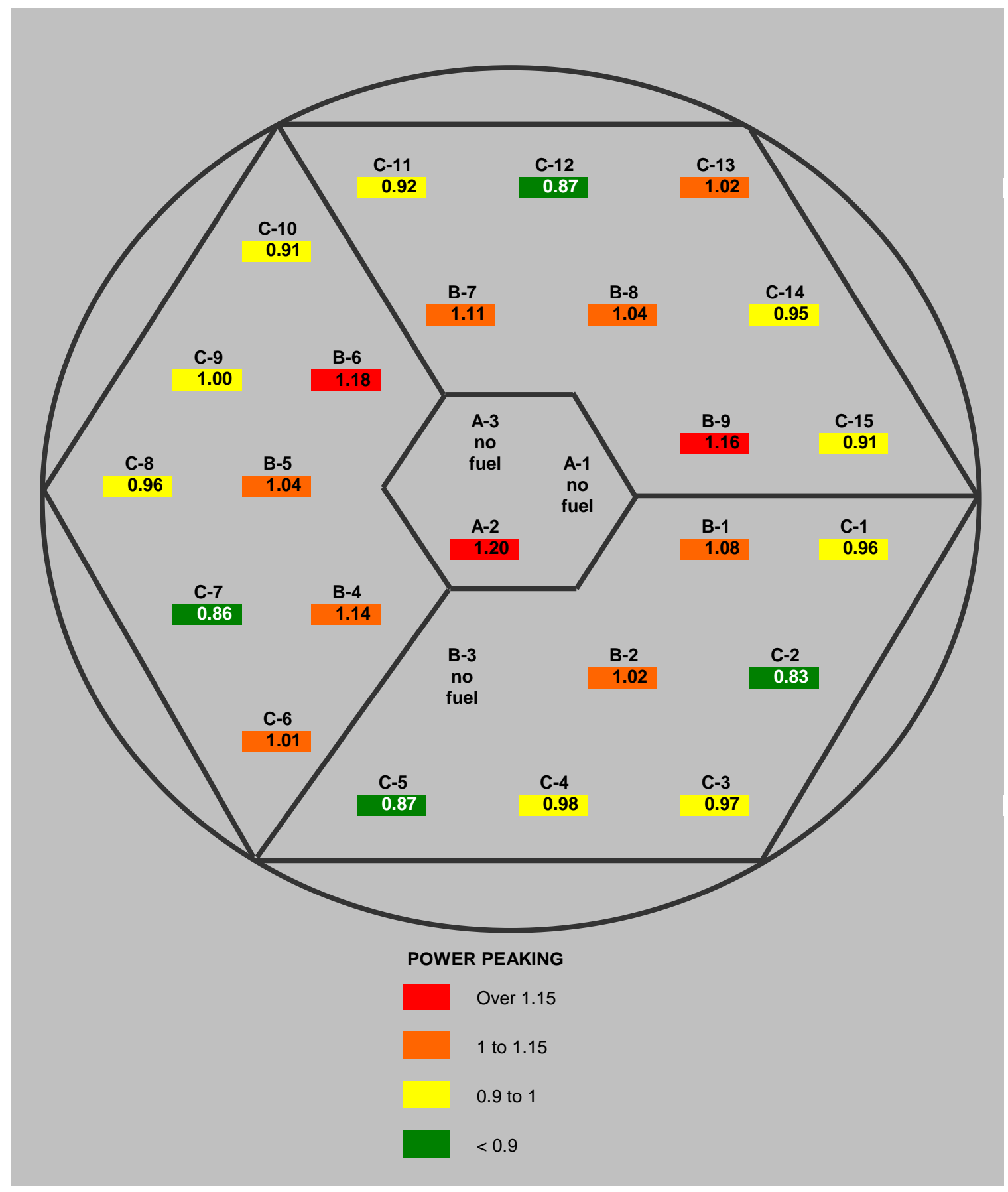

Figure C-7. Elemental power distribution in HEU depleted Core 181 at EOC. 


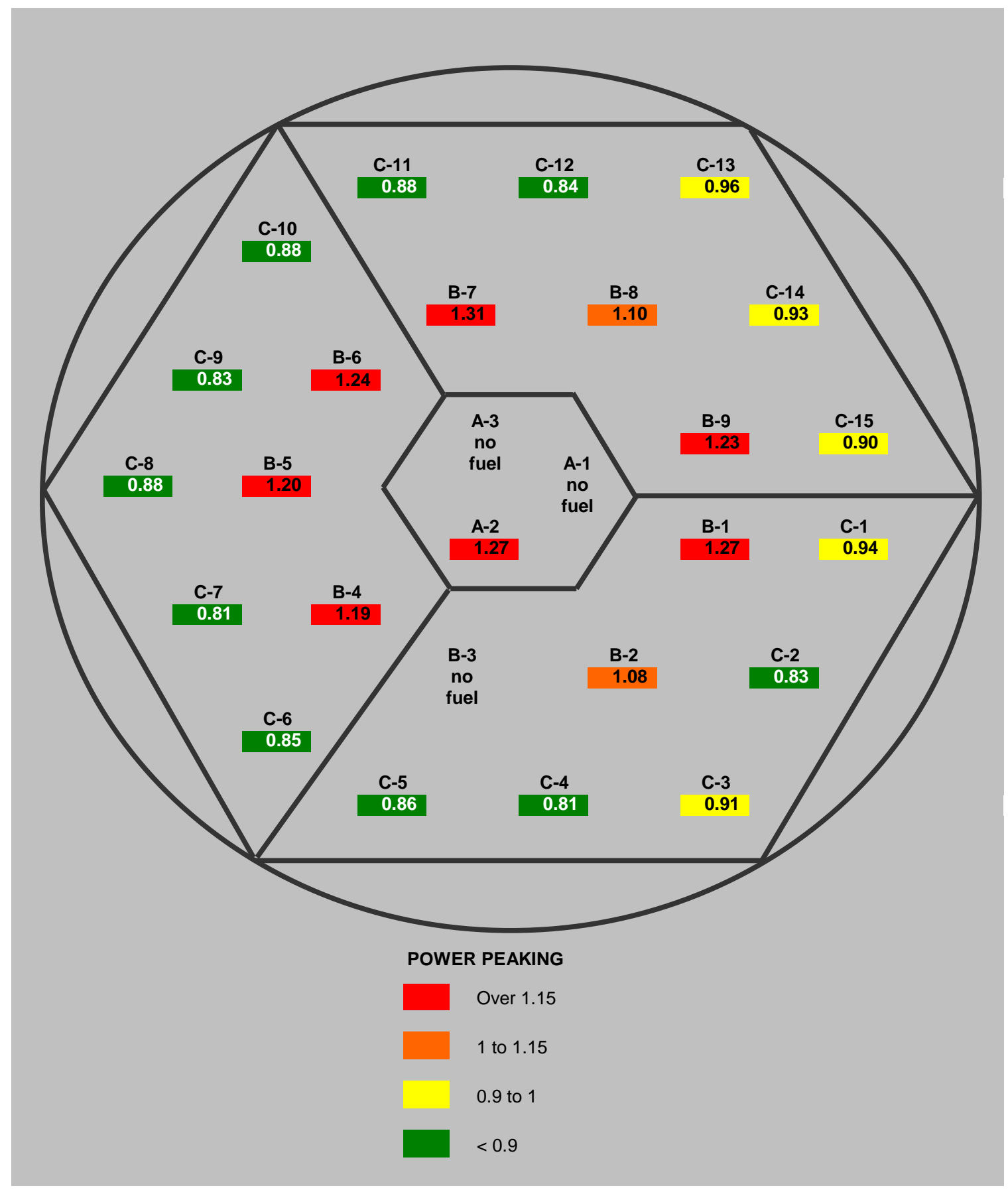

Figure C-8. Elemental power distribution in HEU depleted Core 182 at BOC. 


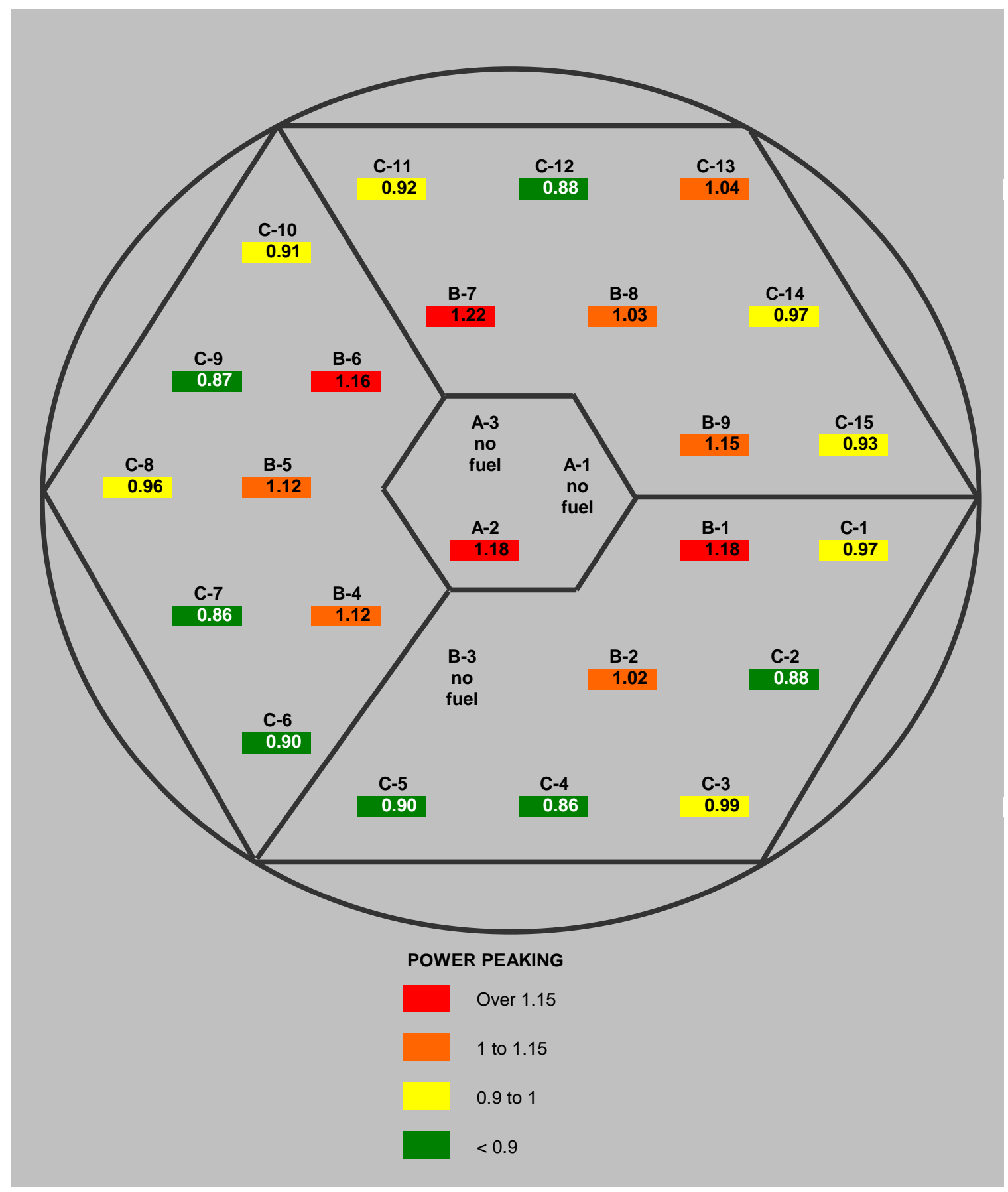

Figure C-9. Elemental power distribution in HEU depleted Core 182 at EOC. 


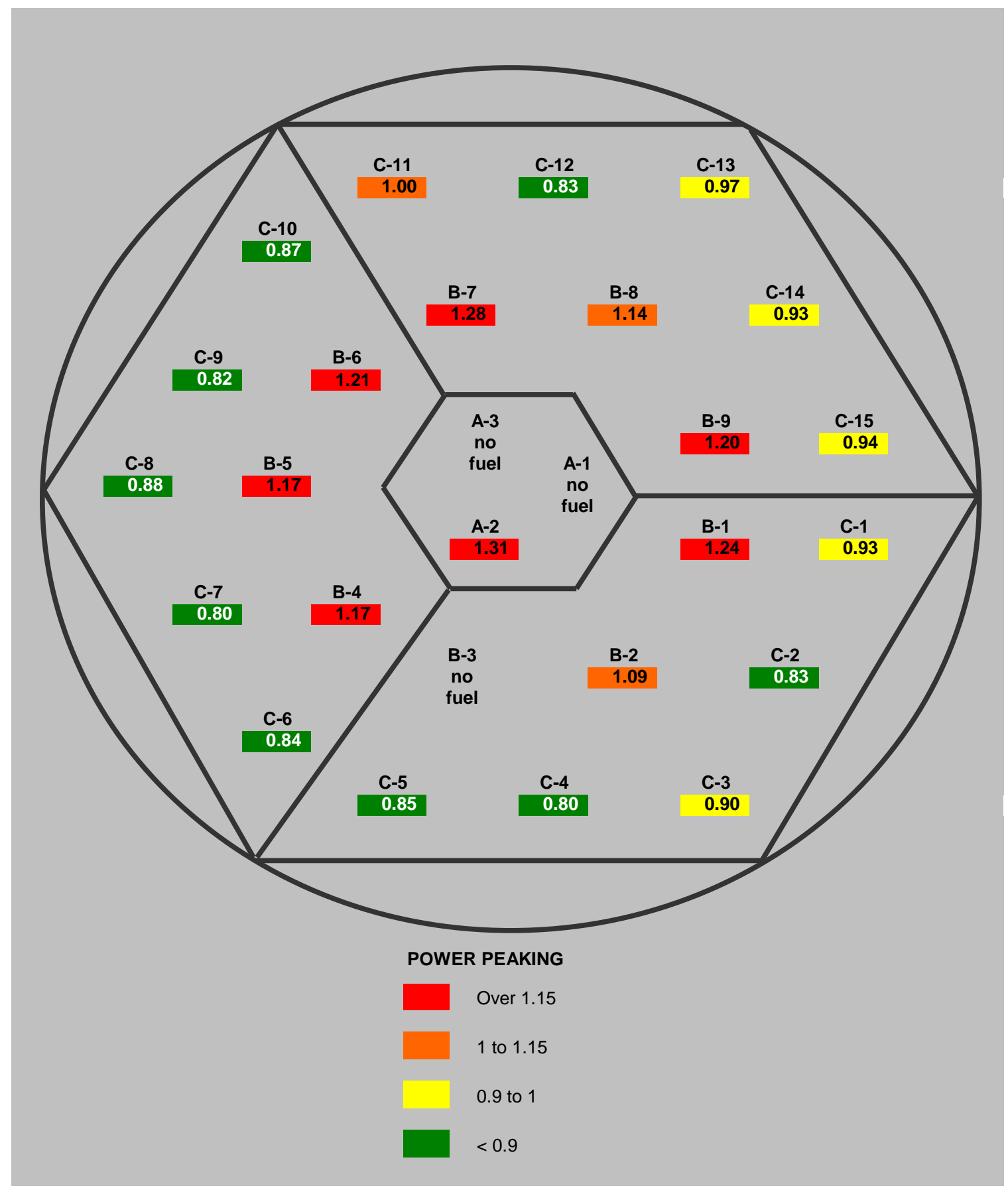

Figure C-10. Elemental power distribution in HEU depleted Core 183 at BOC. 


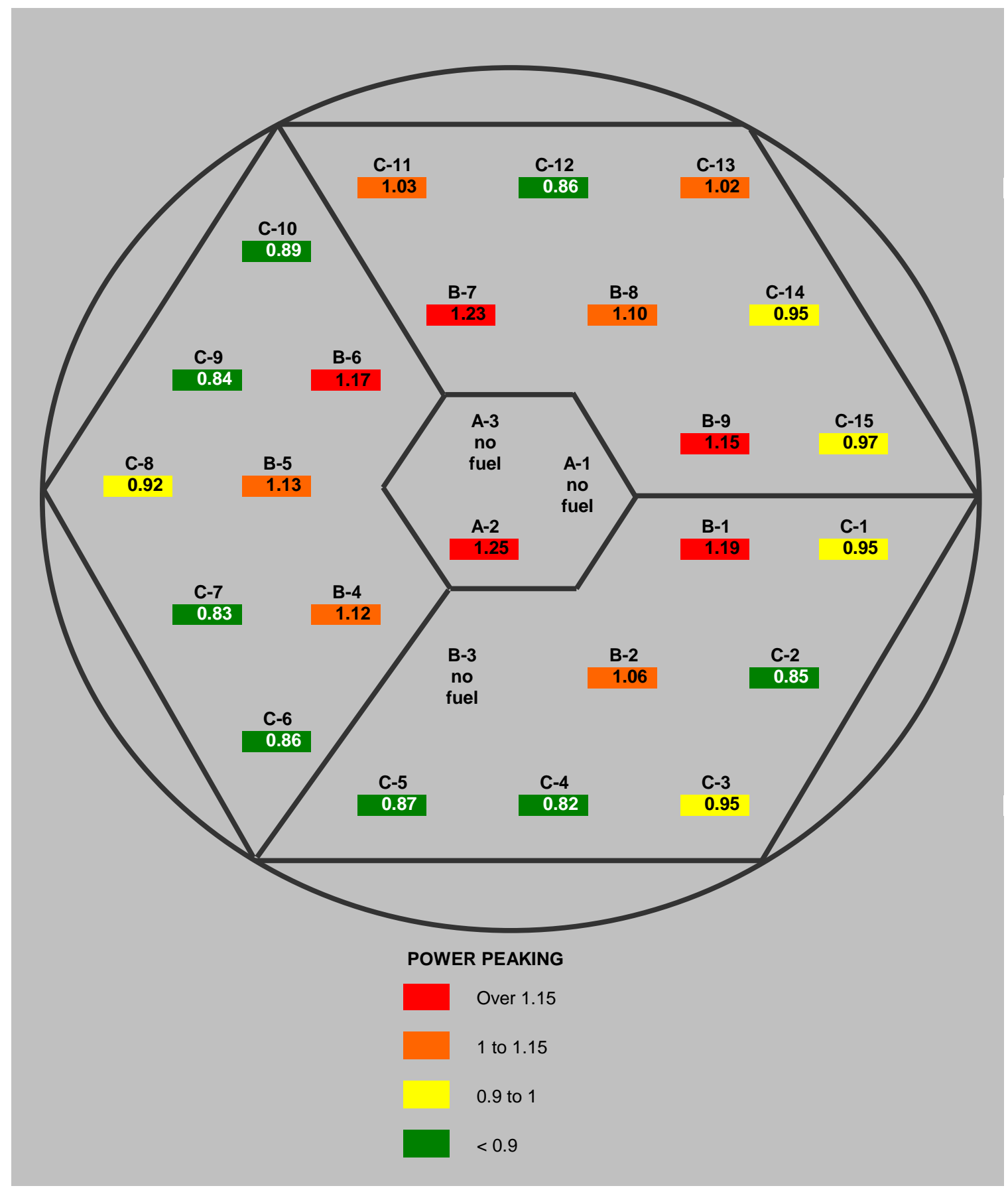

Figure C-11. Elemental power distribution in HEU depleted Core 183 at EOC. 


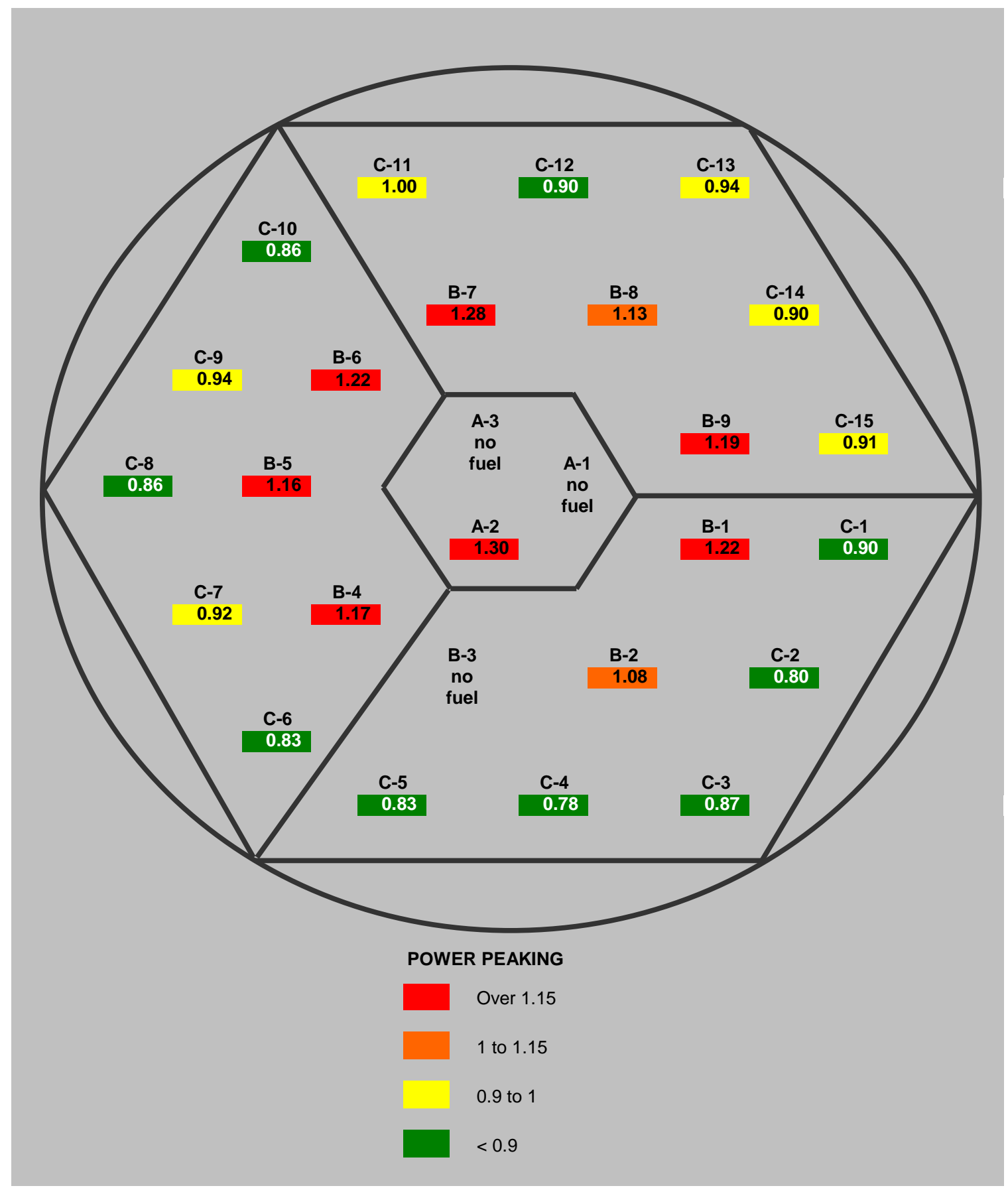

Figure C-12. Elemental power distribution in HEU depleted Core 184 at BOC. 


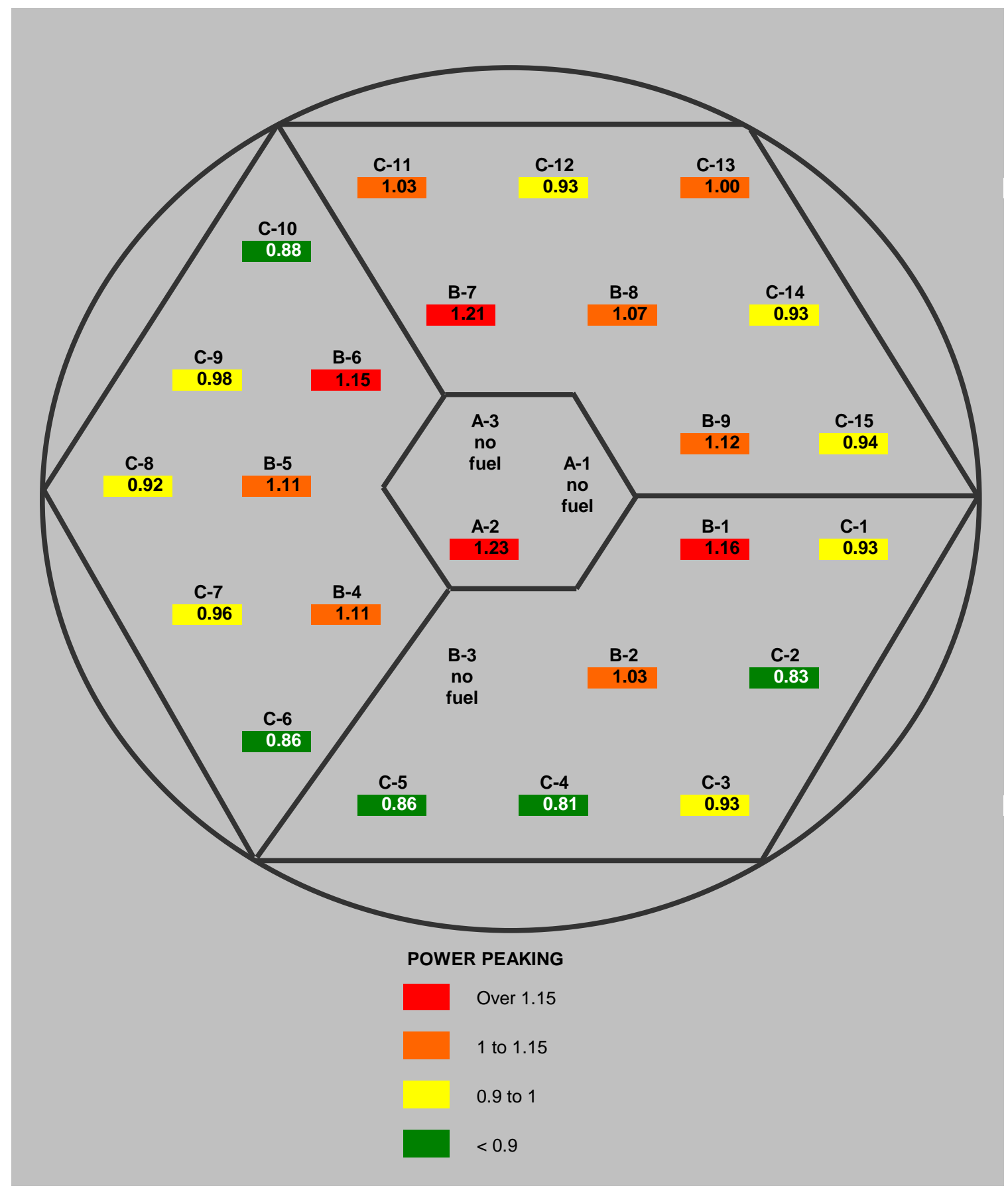

Figure C-13. Elemental power distribution in HEU depleted Core 184 at EOC. 


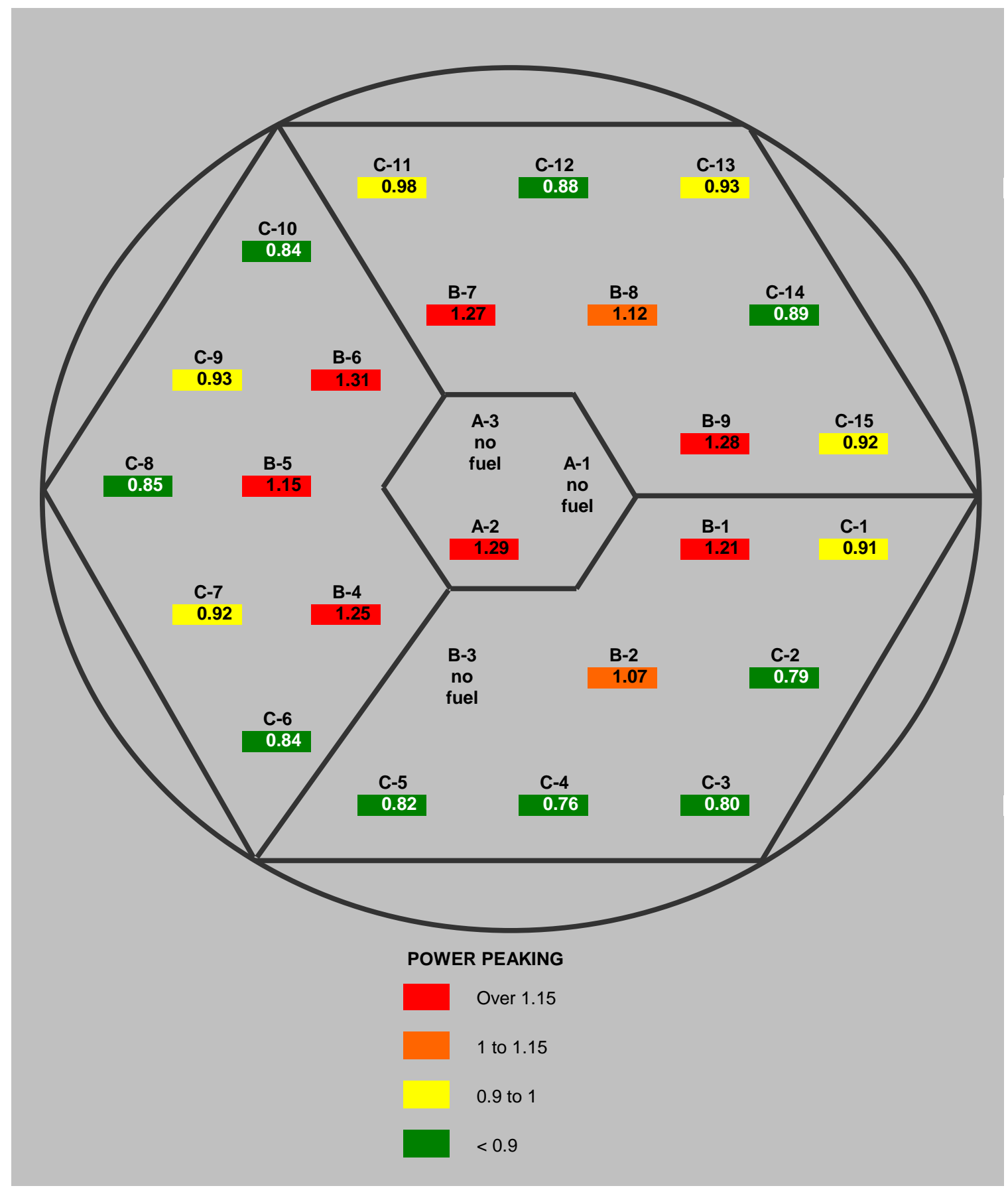

Figure C-14. Elemental power distribution in HEU depleted Core 185 at BOC. 


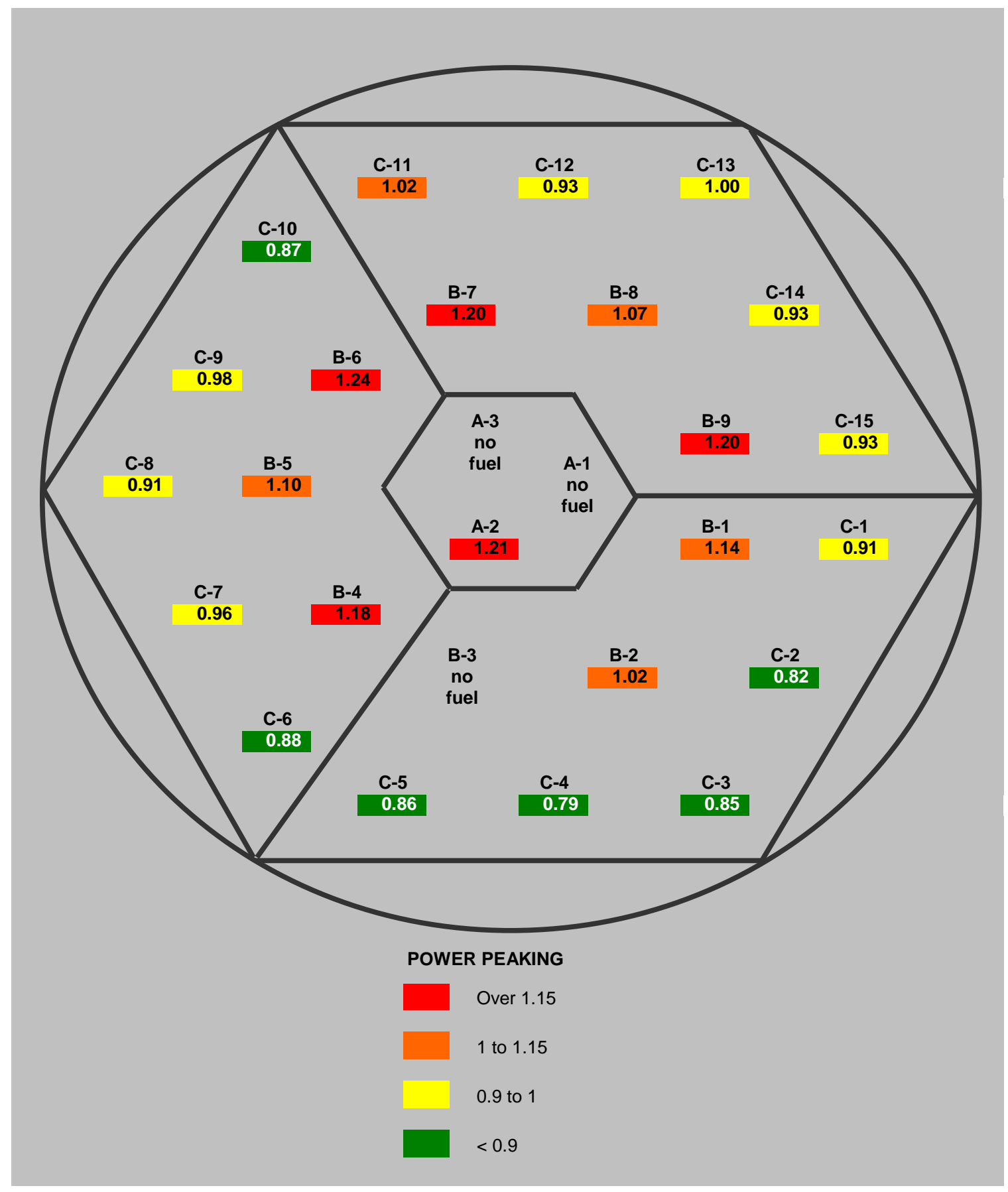

Figure C-15. Elemental power distribution in HEU depleted Core 185 at EOC. 


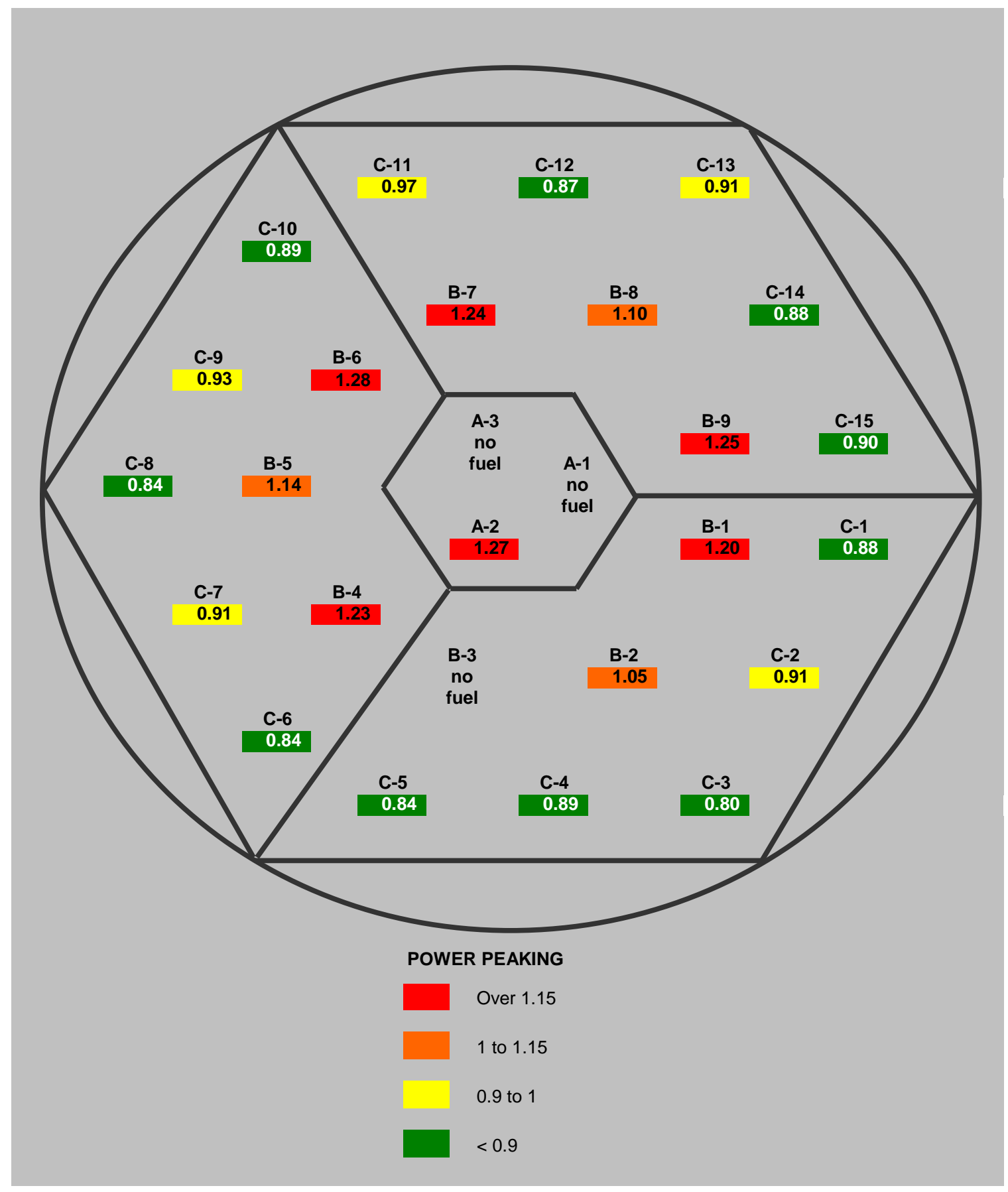

Figure C-16. Elemental power distribution in HEU depleted Core 186 at BOC. 


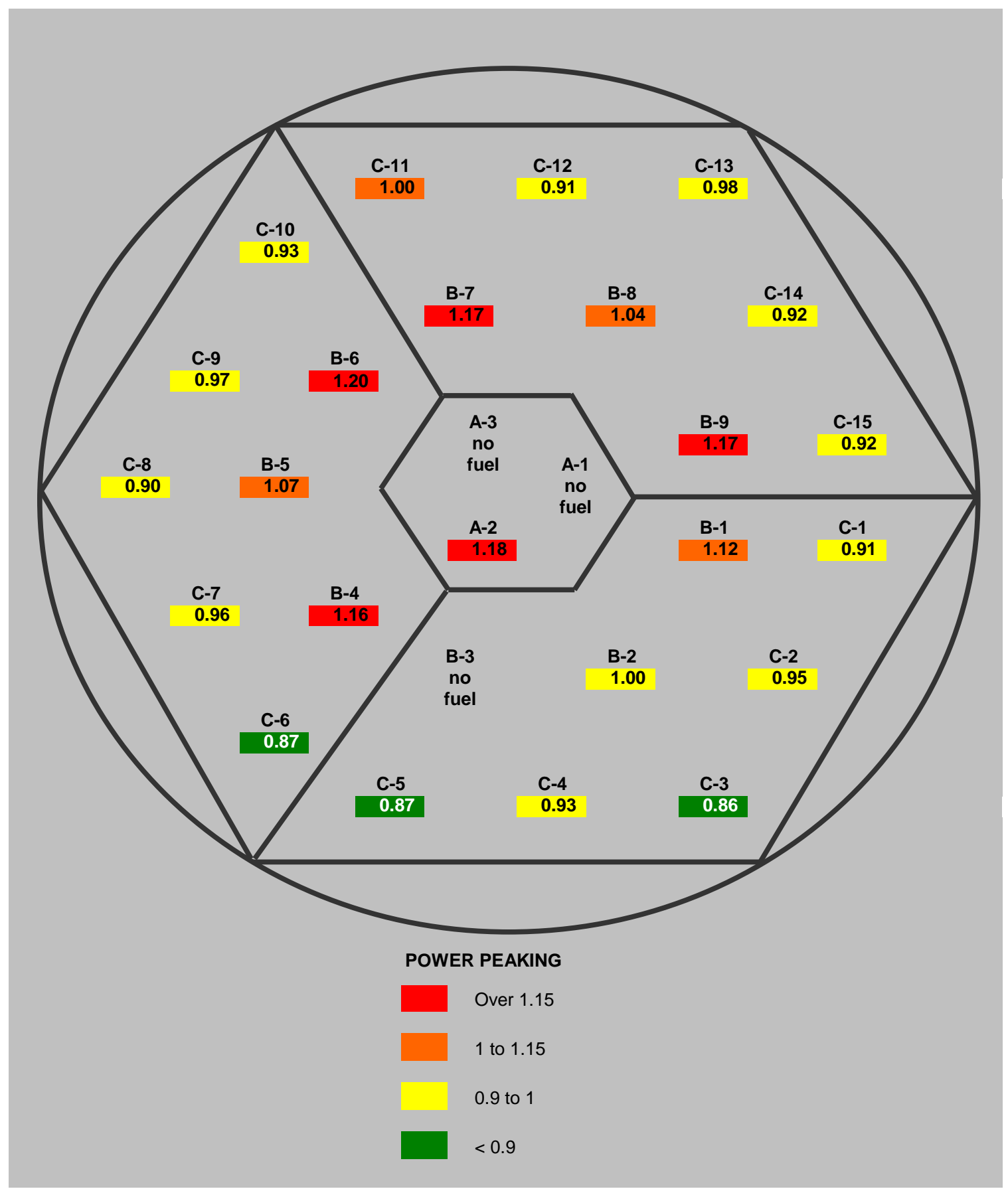

Figure C-17. Elemental power distribution in HEU depleted Core 186 at EOC. 


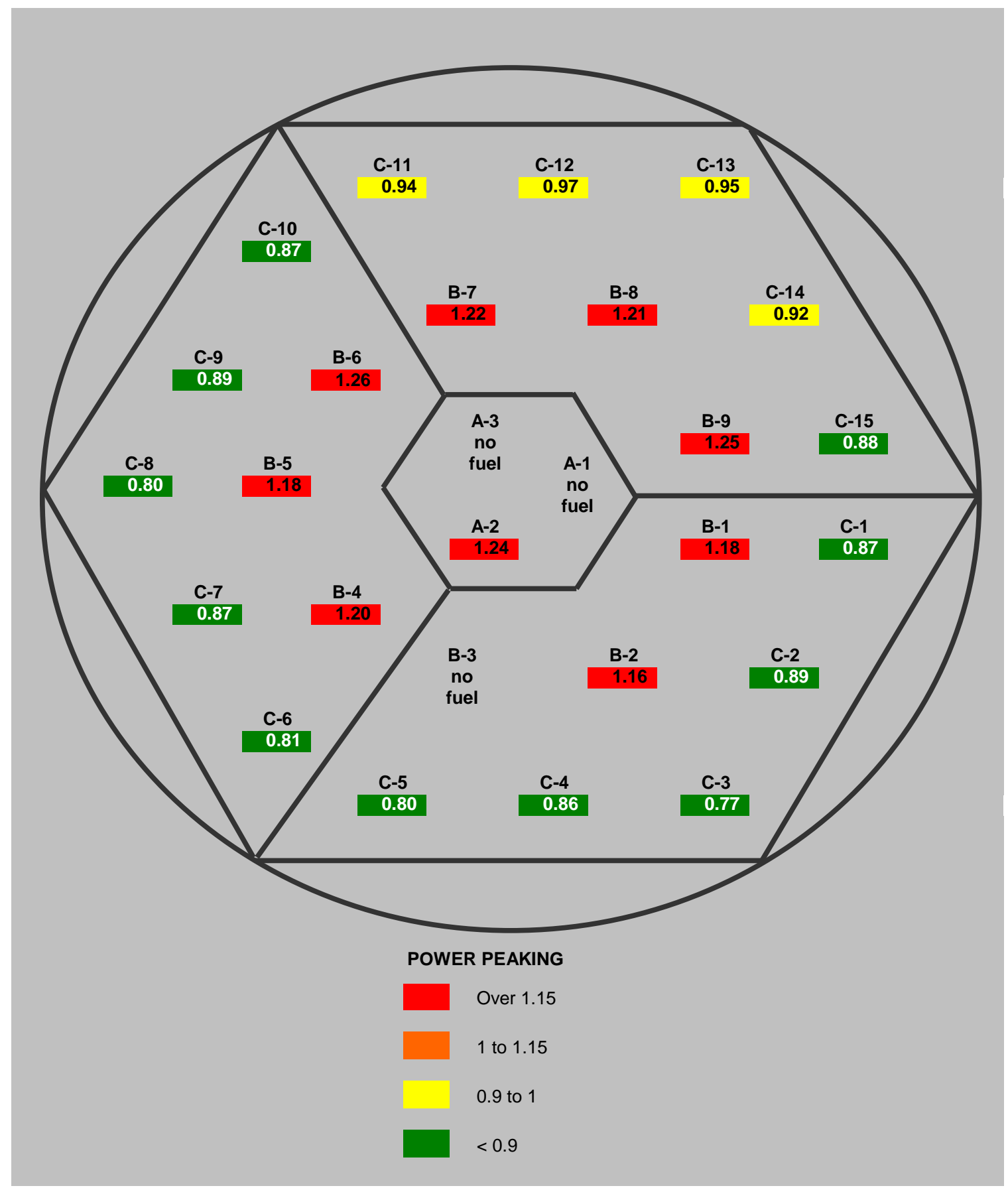

Figure C-18. Elemental power distribution in HEU depleted Core 187 at BOC. 


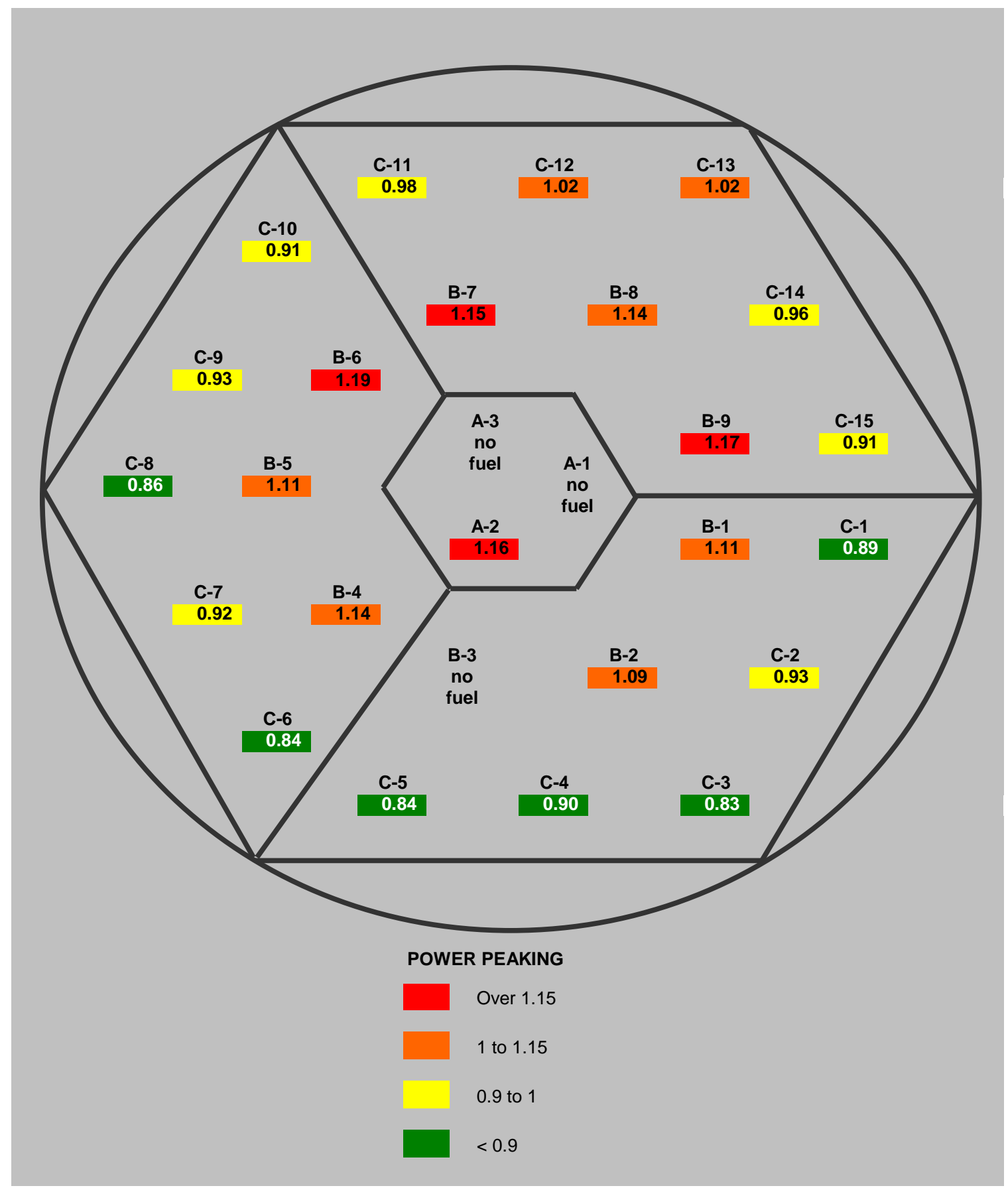

Figure C-19. Elemental power distribution in HEU depleted Core 187 at EOC. 


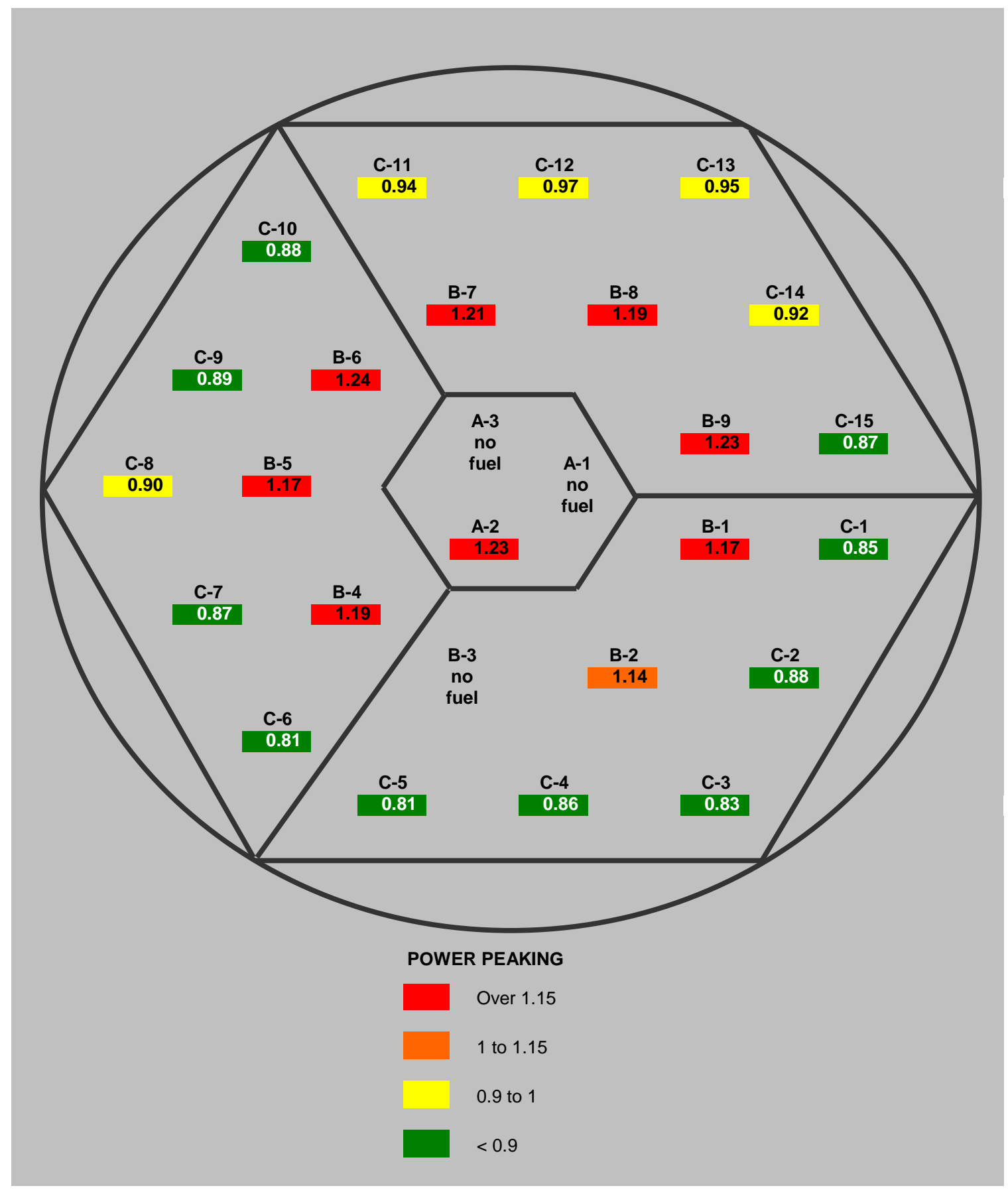

Figure C-20. Elemental power distribution in HEU depleted Core 188 at BOC. 


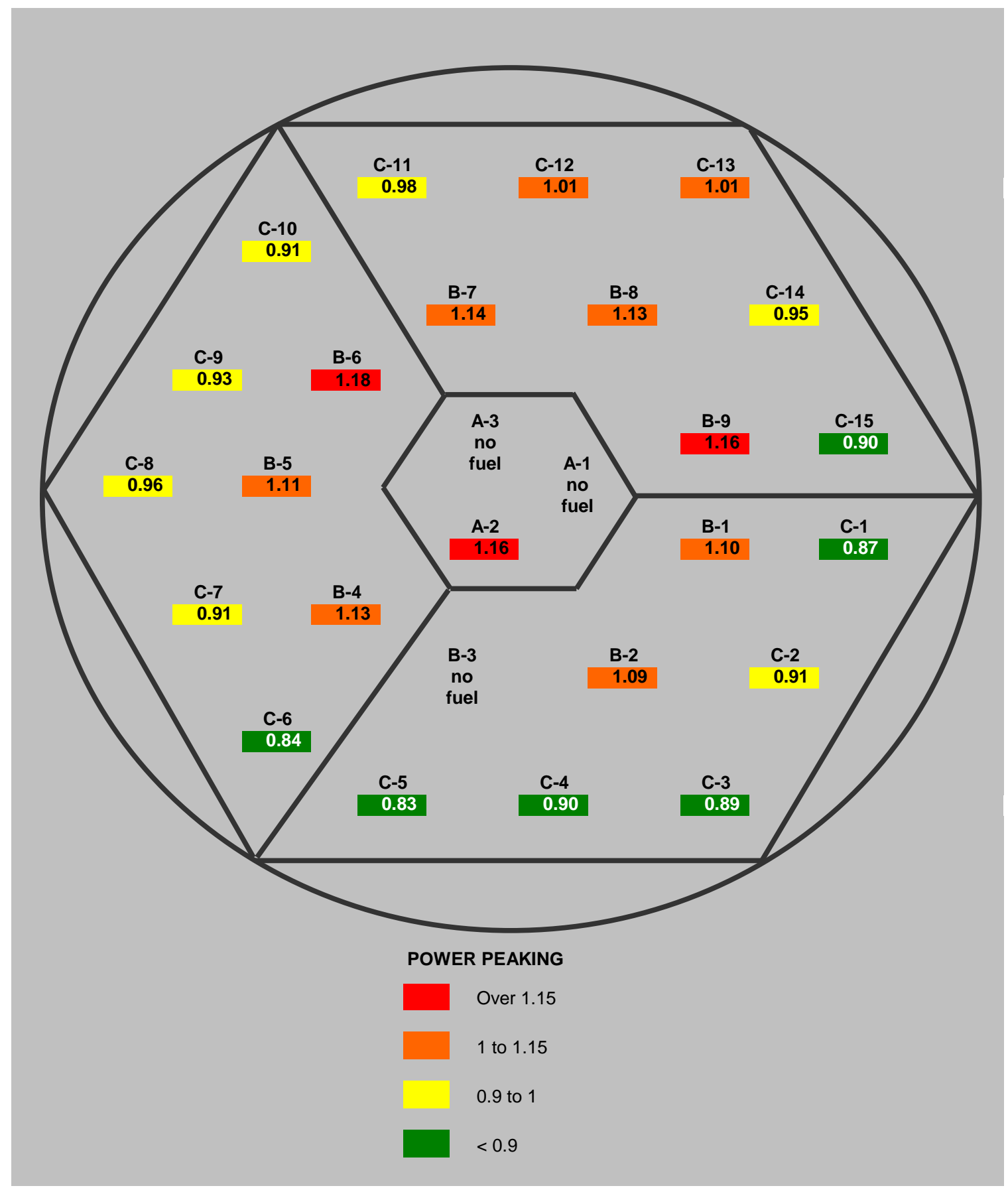

Figure C-21. Elemental power distribution in HEU depleted Core 188 at EOC. 


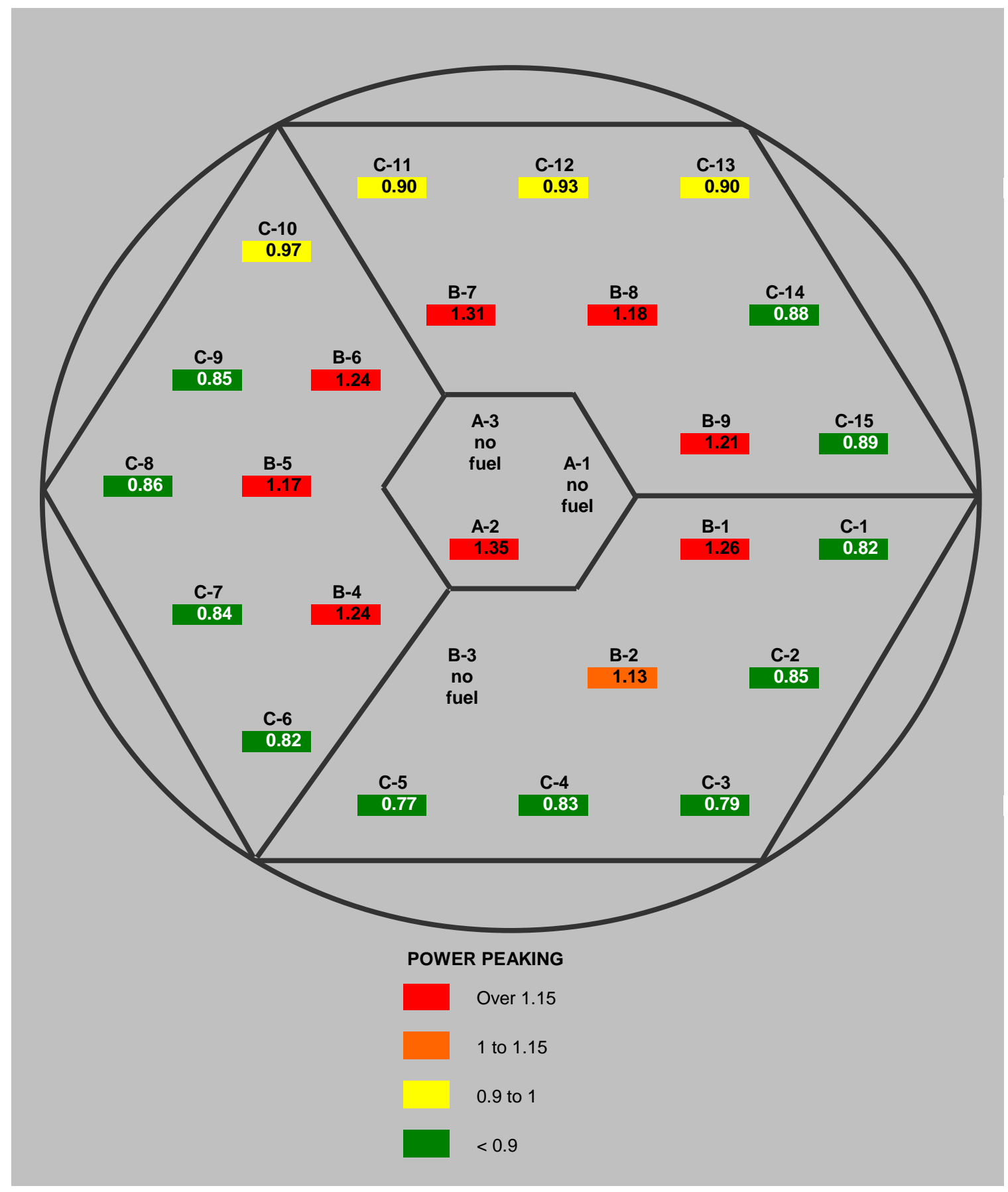

Figure C-22. Elemental power distribution in HEU depleted Core 189 at BOC. 


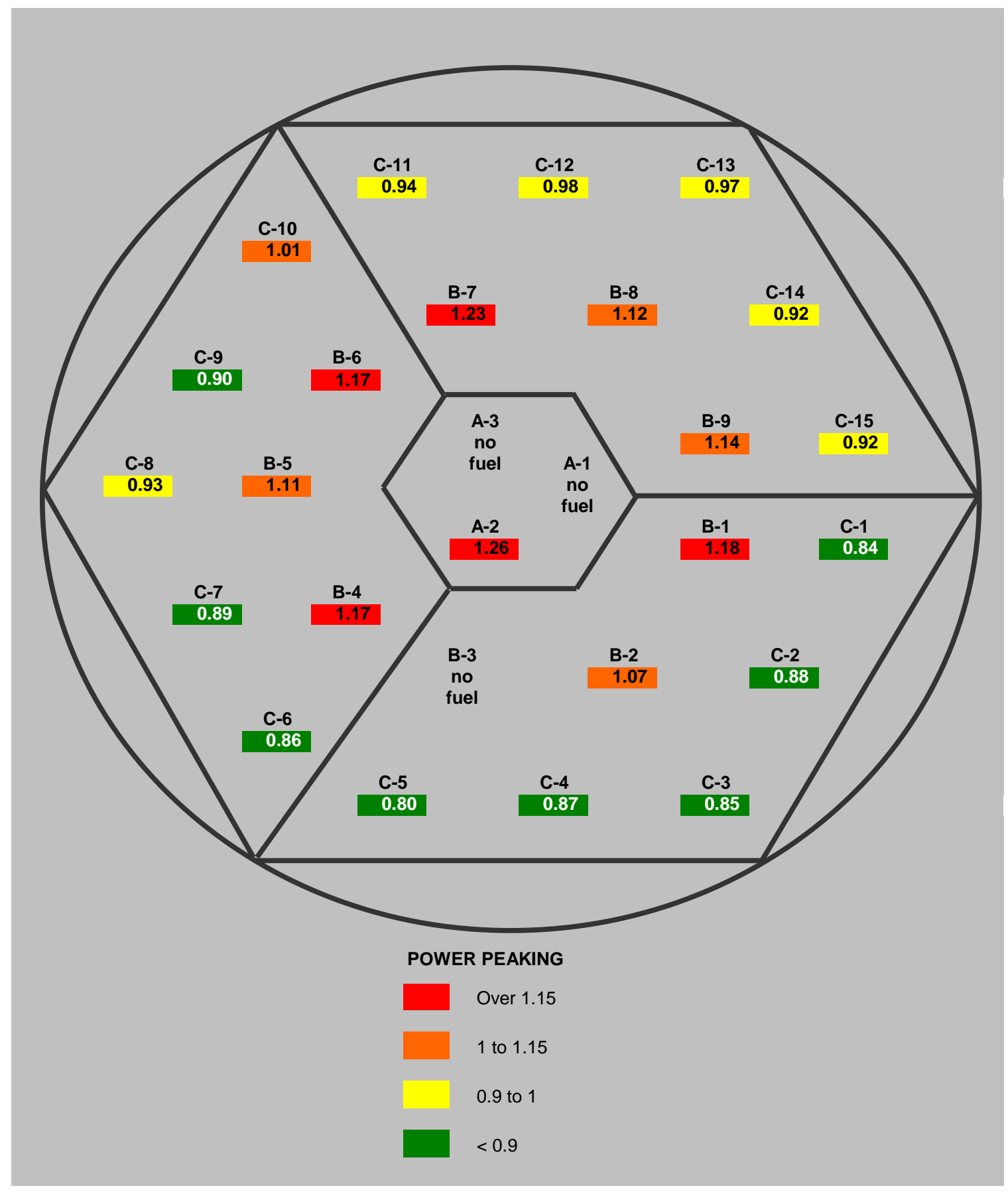

Figure C-23. Elemental power distribution in HEU depleted Core 189 at EOC. 


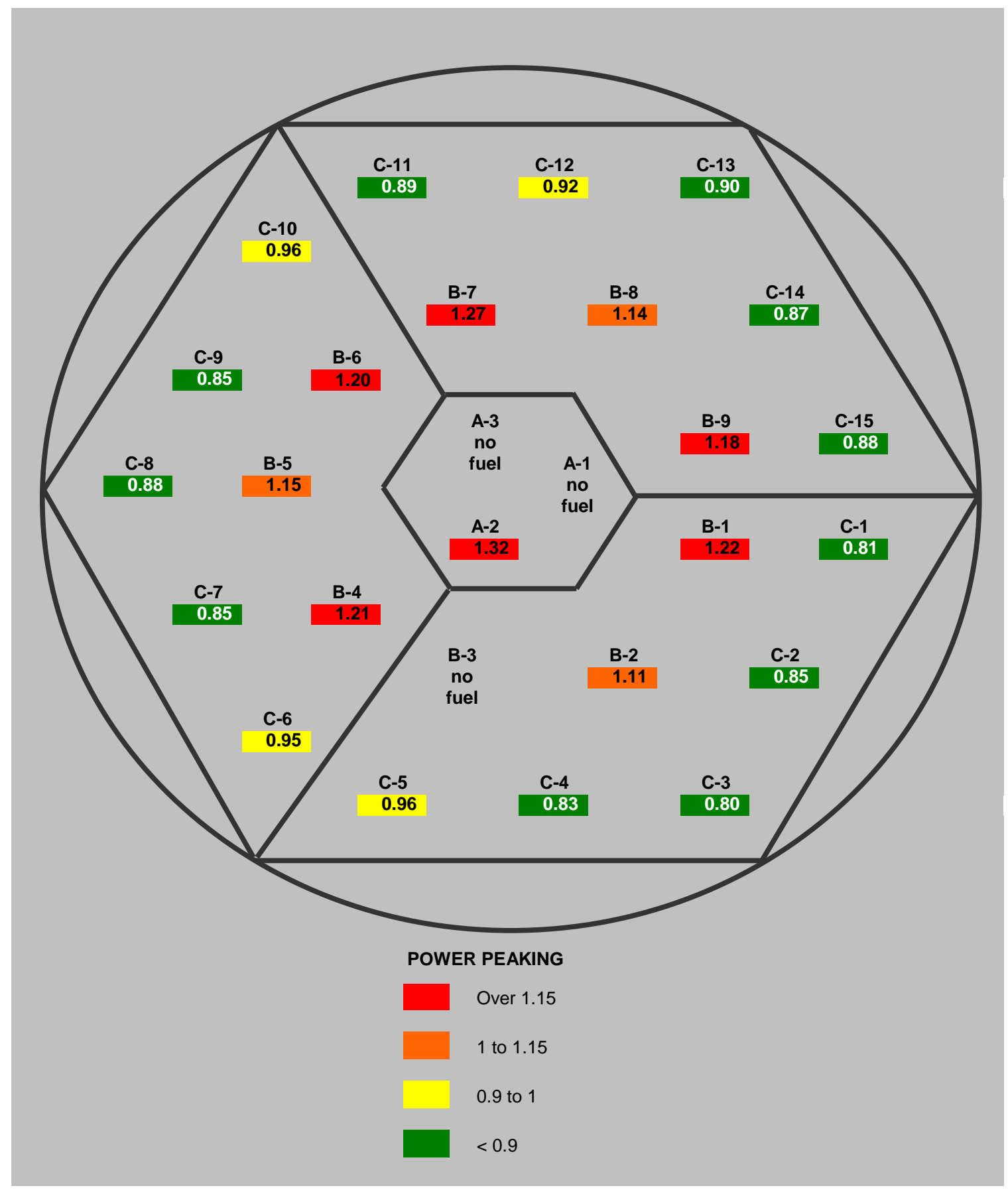

Figure C-24. Elemental power distribution in HEU depleted Core 190 at BOC. 


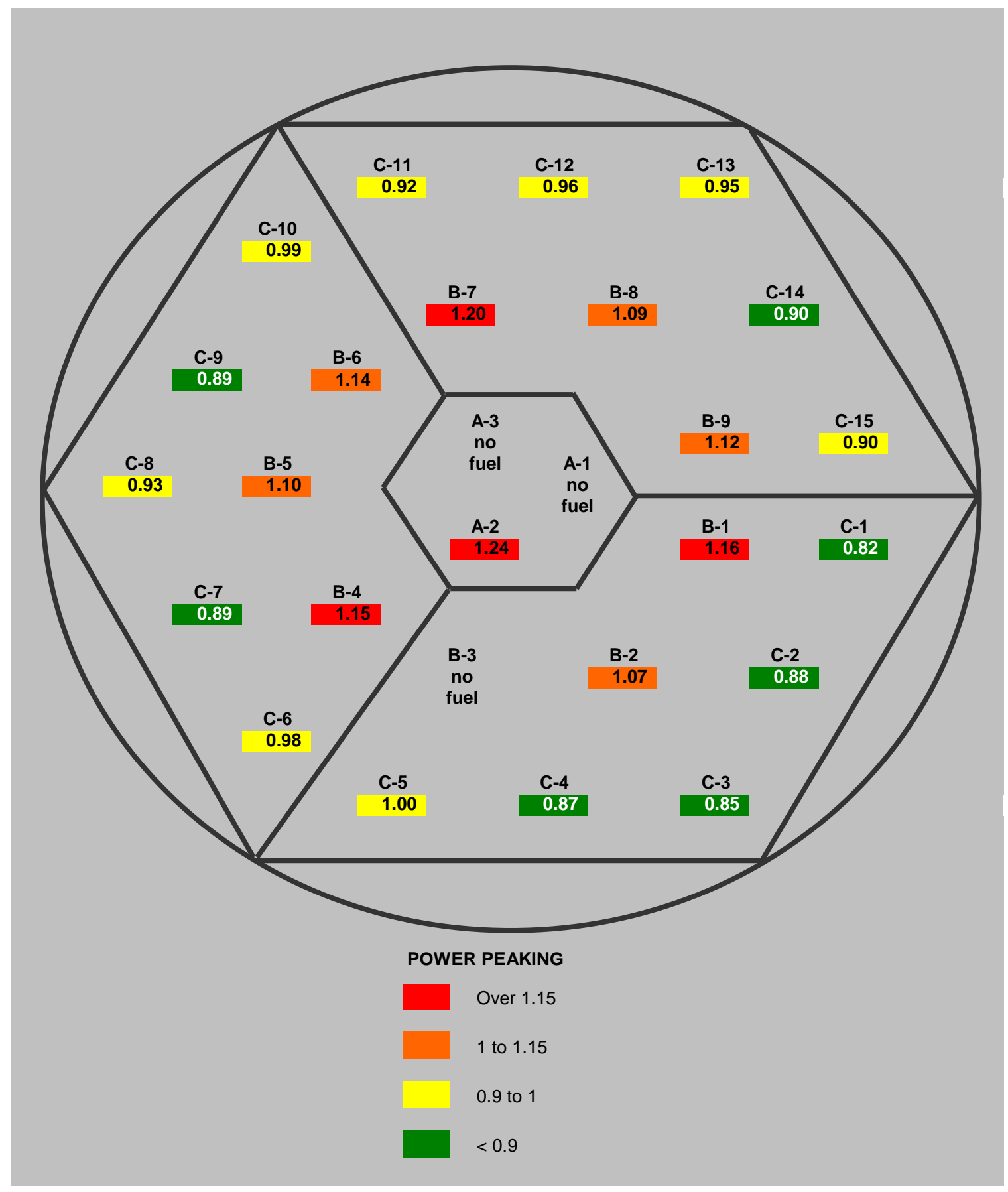

Figure C-25. Elemental power distribution in HEU depleted Core 190 at EOC. 


\section{APPENDIX D POWER DISTRIBUTIONS BY LEU CORE LOADING}

\section{D.1 LEU Power Peaking by Element}

Power distributions are shown for the all-fresh LEU Core 2 and depleted LEU Cores 179190 at BOC and EOC in Tables D-1 and D-2 at BOC and EOC, respectively. The color coding in the tables indicates element power vs. average with <90\% (green), 90\%-100\% (yellow), 100\%-115\% (orange), > 115\% (red). Peaking is illustrated in core maps of element power in Figures D-1 to D-25.

Table D-1. Power peaking by element in LEU fresh and depleted cores at BOC.

\begin{tabular}{|c|c|c|c|c|c|c|c|c|c|c|c|c|c|}
\hline Element & $\begin{array}{c}\text { All } \\
\text { Fresh }\end{array}$ & $\begin{array}{c}179 \\
B O C\end{array}$ & $\begin{array}{c}180 \\
\text { BOC }\end{array}$ & $\begin{array}{c}181 \\
\text { BOC } \\
\end{array}$ & $\begin{array}{c}182 \\
B 0 C\end{array}$ & $\begin{array}{c}183 \\
\text { BOC }\end{array}$ & $\begin{array}{c}184 \\
B O C\end{array}$ & $\begin{array}{c}185 \\
\text { BOC } \\
\end{array}$ & \begin{tabular}{|c|}
186 \\
$B O C$
\end{tabular} & $\begin{array}{c}187 \\
\text { BOC }\end{array}$ & \begin{tabular}{|c|}
188 \\
BOC
\end{tabular} & $\begin{array}{r}189 \\
B O C\end{array}$ & \begin{tabular}{|c|}
190 \\
BOC \\
\end{tabular} \\
\hline $\mathrm{A}-2^{*}$ & 1.33 & \begin{tabular}{|l|}
1.37 \\
\end{tabular} & 1.34 & 1.32 & 1.30 & 1.34 & 1.32 & 1.31 & 1.29 & 1.27 & 1.25 & 1.33 & 1.30 \\
\hline B-1 & 1.16 & 1.21 & 1.18 & 1.17 & 1.23 & 1.21 & 1.17 & 1.16 & 1.15 & 1.14 & 1.12 & 1.22 & 1.18 \\
\hline & 1.10 & 1.10 & 1.09 & 1.09 & 1.08 & 1.08 & 1.05 & 1.04 & 1.04 & 1.10 & 1.08 & 1.08 & 1.07 \\
\hline B-4 & 16 & 1.20 & 1.17 & 1.15 & 1.13 & 1.12 & 1.11 & 1.19 & 1.16 & 1.14 & 1.13 & 1.18 & 1.16 \\
\hline $\mathrm{B}$ & 1.07 & 1.15 & 1.12 & 1.09 & 1.12 & 1.10 & 1.10 & 1.10 & 1.07 & 1.12 & 1.10 & 1.10 & 1.08 \\
\hline B-6 & no fuel & 1.26 & 1.24 & 1.20 & 1.19 & 1.18 & 1.17 & 1.26 & 1.21 & 1.20 & 1.18 & 1.20 & \begin{tabular}{|l|}
1.17 \\
\end{tabular} \\
\hline B-7 & 1.16 & 1.25 & 1.22 & 1.19 & 1.25 & 1.24 & 1.22 & 1.21 & 1.18 & 1.17 & 1.15 & 1.26 & 1.22 \\
\hline B-8 & 1.09 & 1.16 & 1.13 & 1.10 & 1.11 & 1.14 & 1.10 & 1.10 & \begin{tabular}{|l|}
1.07 \\
\end{tabular} & 1.16 & 1.12 & 1.12 & 1.09 \\
\hline B-9 & no fuel & 1.26 & 1.22 & 1.20 & 1.20 & 1.19 & 1.15 & 1.23 & 1.20 & 1.21 & 1.18 & 1.18 & 1.15 \\
\hline $\mathrm{C}-1$ & 0.95 & 0.89 & 0.90 & 0.97 & 1.00 & 0.99 & 0.97 & 0.94 & 0.95 & 0.92 & 0.90 & 0.87 & 0.87 \\
\hline $\mathrm{C}-2$ & 92 & 0.79 & 0.81 & \begin{tabular}{|l|}
0.83 \\
\end{tabular} & 0.88 & 0.86 & 0.84 & 0.82 & 0.94 & 0.92 & 0.91 & 0.87 & 0.88 \\
\hline $\mathrm{C}-3$ & 0.92 & 0.78 & 0.87 & 0.90 & 0.92 & 0.90 & 0.88 & 0.82 & 0.85 & 0.82 & 0.87 & 0.82 & 0.84 \\
\hline C-4 & 0.92 & 0.80 & 0.81 & 0.93 & 0.83 & 0.82 & 0.80 & 0.78 & 0.91 & 0.88 & 0.89 & 0.86 & 0.87 \\
\hline C. & 0.98 & 0.86 & 0.87 & 0.88 & 0.88 & 0.86 & 0.86 & 0.86 & 0.90 & 0.87 & 0.88 & 0.84 & 0.94 \\
\hline $\mathrm{C}$ & 92 & 0.83 & 0.84 & 0.95 & 0.85 & 0.84 & 0.85 & \begin{tabular}{|l|}
0.87 \\
\end{tabular} & 0.87 & 0.84 & 0.85 & \begin{tabular}{|l}
0.85 \\
\end{tabular} & 0.93 \\
\hline C-7 & 88 & 0.90 & 0.90 & 0.82 & 0.82 & 0.80 & 0.92 & 0.92 & \begin{tabular}{|l|}
0.91 \\
\end{tabular} & 0.88 & 0.89 & 0.85 & 0.87 \\
\hline C-8 & 0.90 & 0.88 & 0.90 & 0.89 & 0.88 & 0.86 & 0.90 & 0.88 & 0.86 & 0.83 & 0.94 & 0.89 & 0.91 \\
\hline C-9 & 0.90 & 0.88 & 0.95 & 0.93 & 0.84 & 0.83 & 0.94 & 0.93 & 0.92 & 0.89 & 0.91 & 0.88 & 0.88 \\
\hline C-10 & 97 & 0.89 & 0.88 & \begin{tabular}{|l|l}
0.87 \\
\end{tabular} & \begin{tabular}{|l|l|}
0.87 \\
\end{tabular} & 0.87 & 0.88 & 0.87 & 0.90 & \begin{tabular}{|l|l|}
0.88 \\
\end{tabular} & 0.89 & 0.97 & \begin{tabular}{|l}
0.97 \\
\end{tabular} \\
\hline & 0.92 & 0.89 & 0.89 & 0.87 & 0.88 & 0.98 & 0.98 & 0.97 & 0.96 & 0.94 & 0.95 & 0.92 & 0.91 \\
\hline C-12 & 0.90 & 0.84 & 0.84 & 0.84 & 0.86 & 0.86 & 0.91 & 0.89 & 0.87 & 0.98 & \begin{tabular}{|l|l}
0.99 \\
\end{tabular} & 0.95 & 0.95 \\
\hline C-13 & 0.92 & 0.95 & 0.96 & 0.95 & 0.98 & 0.98 & 0.98 & \begin{tabular}{|l|}
0.95 \\
\end{tabular} & \begin{tabular}{|l|}
0.93 \\
\end{tabular} & \begin{tabular}{|l}
0.96 \\
\end{tabular} & \begin{tabular}{|l|}
0.97 \\
\end{tabular} & 0.92 & 0.92 \\
\hline C-14 & 0.93 & 0.93 & 0.93 & 0.93 & 0.95 & 0.96 & 0.94 & 0.92 & 0.90 & 0.95 & 0.95 & 0.91 & 0.91 \\
\hline C-15 & 0.99 & 0.93 & 0.93 & 0.93 & 0.96 & 0.99 & 0.97 & 0.95 & 0.94 & 0.92 & 0.91 & 0.94 & 0.94 \\
\hline
\end{tabular}

* A-ring element for LEU all-fresh Core 2 is located in MITR gridplate position A-1. 
Table D-2. Power peaking by element in LEU depleted cores at EOC.

\begin{tabular}{|c|c|c|c|c|c|c|c|c|c|c|c|c|}
\hline Element & $\begin{array}{c}179 \\
\text { EOC }\end{array}$ & $\begin{array}{c}180 \\
\text { EOC }\end{array}$ & $\begin{array}{c}181 \\
\text { EOC }\end{array}$ & $\begin{array}{c}182 \\
\text { EOC }\end{array}$ & $\begin{array}{c}183 \\
\text { EOC }\end{array}$ & $\begin{array}{c}184 \\
\text { EOC }\end{array}$ & $\begin{array}{r}185 \\
\text { EOC }\end{array}$ & $\begin{array}{c}186 \\
\text { EOC }\end{array}$ & $\begin{array}{c}187 \\
\text { EOC }\end{array}$ & $\begin{array}{c}188 \\
\text { EOC }\end{array}$ & $\begin{array}{r}189 \\
\text { EOC }\end{array}$ & $\begin{array}{c}190 \\
\text { EOC }\end{array}$ \\
\hline A-2 & 1.29 & 1.26 & 1.25 & 1.23 & 1.26 & 1.24 & 1.23 & 1.22 & 1.20 & 1.17 & 1.25 & 1.23 \\
\hline B-1 & 1.14 & 1.12 & 1.11 & 1.16 & 1.14 & 1.12 & 1.10 & 1.10 & 1.09 & 1.07 & 1.15 & 1.12 \\
\hline B-2 & 1.05 & 1.04 & 1.04 & 1.03 & 1.03 & 1.01 & 0.99 & 1.00 & 1.05 & 1.03 & 1.03 & 1.02 \\
\hline B-4 & 13 & 1.11 & 1.10 & 1.08 & 1.06 & 1.06 & 1.12 & 1.11 & 1.08 & 1.07 & 1.11 & 1.10 \\
\hline B-5 & 1.08 & 1.07 & 1.04 & 1.06 & 1.04 & 1.04 & 1.04 & 1.02 & 1.05 & 1.05 & 1.05 & 1.03 \\
\hline B-6 & 1.19 & 1.17 & 1.14 & 1.13 & 1.11 & 1.11 & 1.18 & 1.15 & 1.13 & 1.12 & 1.13 & 1.11 \\
\hline B-7 & 1.18 & 1.16 & 1.13 & 1.18 & 1.17 & 1.16 & 1.15 & 1.12 & 1.11 & 1.09 & 1.18 & 1.16 \\
\hline B-8 & 1.10 & 1.07 & 1.05 & 1.06 & 1.08 & 1.05 & 1.04 & 1.02 & 1.09 & 1.07 & 1.07 & 1.04 \\
\hline $\mathrm{E}$ & 1.18 & 1.16 & 1.14 & 1.14 & 1.12 & 1.09 & 1.16 & 1.14 & 1.15 & 1.12 & 1.11 & 1.09 \\
\hline $\mathrm{C}-1$ & 0.92 & 0.93 & 1.00 & 1.04 & 1.03 & 0.99 & 0.98 & 0.97 & 0.96 & 0.92 & 0.90 & 0.89 \\
\hline $\mathrm{C}-2$ & 0.83 & 0.84 & 0.86 & 0.92 & 0.91 & 0.88 & 0.86 & 0.98 & 0.95 & 0.94 & 0.91 & 0.91 \\
\hline C-3 & 0.84 & 0.94 & 0.96 & 0.98 & 0.97 & 0.94 & 0.88 & 0.90 & 0.87 & 0.93 & 0.88 & 0.89 \\
\hline $\mathrm{C}-4$ & 0.84 & 0.85 & 0.97 & 0.86 & 0.85 & 0.83 & 0.82 & 0.94 & 0.91 & 0.93 & 0.89 & 0.90 \\
\hline $\mathrm{C}-5$ & 0.89 & 0.89 & 0.91 & 0.90 & 0.89 & 0.88 & 0.88 & 0.93 & 0.90 & 0.91 & 0.87 & 0.97 \\
\hline $\mathrm{C}-\mathrm{E}$ & 0.86 & 0.86 & 0.98 & 0.88 & 0.86 & 0.87 & 0.90 & 0.89 & 0.86 & 0.87 & 0.88 & 0.96 \\
\hline C-7 & 0.93 & 0.94 & 0.85 & 0.85 & 0.84 & 0.95 & 0.96 & 0.94 & 0.91 & 0.93 & 0.89 & 0.90 \\
\hline C-8 & 0.95 & 0.96 & 0.94 & 0.93 & 0.92 & 0.95 & 0.93 & 0.91 & 0.88 & 1.00 & 0.95 & 0.97 \\
\hline $\mathrm{C}-9$ & 0.92 & 0.98 & 0.96 & 0.87 & 0.86 & 0.97 & 0.96 & 0.95 & 0.92 & 0.94 & 0.91 & 0.91 \\
\hline C-10 & 0.93 & 0.91 & 0.89 & 0.89 & 0.89 & 0.90 & 0.90 & 0.93 & 0.91 & 0.92 & 1.00 & 1.00 \\
\hline C-11 & 0.92 & 0.91 & 0.89 & 0.91 & 1.01 & 1.01 & 1.00 & 0.98 & 0.98 & 0.98 & 0.95 & 0.94 \\
\hline $\mathrm{C}-12$ & 0.87 & 0.87 & 0.86 & 0.89 & 0.89 & 0.94 & 0.93 & 0.90 & 1.02 & 1.02 & 0.99 & 0.98 \\
\hline $\mathrm{C}-13$ & 1.02 & 1.02 & 1.01 & 1.04 & 1.05 & 1.03 & 1.02 & 0.99 & 1.03 & 1.02 & 0.98 & 0.97 \\
\hline C-14 & 0.97 & 0.97 & 0.96 & 0.99 & 1.00 & 0.97 & 0.96 & 0.94 & 0.99 & 0.98 & 0.95 & 0.94 \\
\hline C-15 & 0.96 & 0.96 & 0.96 & 0.99 & 1.03 & 1.00 & 0.99 & 0.97 & 0.96 & 0.94 & 0.98 & 0.97 \\
\hline
\end{tabular}


Table D-3. Burnup at peak power locations in MITR depleted LEU cores.

\begin{tabular}{|c|c|c|c|c|c|c|c|c|c|c|}
\hline Peak Power Location & Peak Spot & $\begin{array}{c}{ }^{235} \mathrm{U} \\
\text { Burnup }\end{array}$ & Peak Stripe & $\begin{array}{c}{ }^{235} \mathrm{U} \\
\text { Burnup }\end{array}$ & Peak Axial & $\begin{array}{c}{ }^{235} \mathrm{U} \\
\text { Burnup }\end{array}$ & $\begin{array}{l}\text { Peak } \\
\text { Plate }\end{array}$ & $\begin{array}{c}{ }^{235} \mathrm{U} \\
\text { Burnup }\end{array}$ & $\begin{array}{c}\text { Peak } \\
\text { Element\# }\end{array}$ & $\begin{array}{c}{ }^{235} \mathrm{U} \\
\text { Burnup }\end{array}$ \\
\hline LEU Core 179 BOC & 27P01S1 Ax 18 & $8.5 \%$ & 12P18S4 & $0.0 \%$ & $25 \mathrm{P} 01 \quad \mathrm{Ax} 14$ & $1.8 \%$ & $12 \mathrm{P} 18$ & $0.0 \%$ & 2 & $5.3 \%$ \\
\hline LEU Core 180 BOC & 27P01S1 Ax 18 & $12.9 \%$ & 12P18S4 & $3.5 \%$ & $21 \mathrm{P} 01 \quad \mathrm{Ax} 13$ & $3.6 \%$ & 09P18 & $3.5 \%$ & 2 & $8.0 \%$ \\
\hline LEU Core 181 BOC & 13P18S1 Ax 18 & $6.4 \%$ & 13P18S1 & $7.5 \%$ & 13P18 Ax 13 & $7.9 \%$ & $12 \mathrm{P} 18$ & $6.9 \%$ & 2 & $10.6 \%$ \\
\hline LEU Core 182 BOC & 13P18S1 Ax 13 & $12.5 \%$ & 13P18S1 & $11.1 \%$ & $13 \mathrm{P} 18$ Ax 13 & $12.5 \%$ & $12 \mathrm{P} 18$ & $10.2 \%$ & 2 & $13.1 \%$ \\
\hline LEU Core 183 BOC & 27P01S1 Ax 13 & $9.9 \%$ & 27P01S1 & $9.2 \%$ & 27P01 Ax 13 & $9.9 \%$ & 02P18 & $7.4 \%$ & 2 & $6.7 \%$ \\
\hline LEU Core 184 BOC & 27P01S1 Ax 13 & $14.5 \%$ & 27P01S1 & $13.1 \%$ & 27P01 Ax 13 & $14.5 \%$ & 02P18 & $10.7 \%$ & 2 & $9.3 \%$ \\
\hline LEU Core 185 BOC & 27P01S1 Ax 14 & $19.0 \%$ & $12 \mathrm{P} 18 \mathrm{~S} 4$ & $0.0 \%$ & 27P01 Ax 13 & $19.0 \%$ & $12 \mathrm{P} 18$ & $0.0 \%$ & 2 & $11.8 \%$ \\
\hline LEU Core 186 BOC & 14P18S1 Ax 13 & $9.5 \%$ & 12P18S4 & $3.5 \%$ & $14 \mathrm{P} 18 \quad \mathrm{Ax} 13$ & $9.5 \%$ & $12 \mathrm{P} 18$ & $3.5 \%$ & 2 & $14.3 \%$ \\
\hline LEU Core 187 BOC & 25P01S4 Ax 13 & $11.6 \%$ & 25P01S4 & $10.9 \%$ & 24P18 Ax 13 & $7.0 \%$ & $12 \mathrm{P} 18$ & $6.9 \%$ & 2 & $16.7 \%$ \\
\hline LEU Core 188 BOC & 24P18S1 Ax 13 & $7.7 \%$ & 25P18S4 & $18.6 \%$ & 24P18 Ax 13 & $7.7 \%$ & $12 \mathrm{P} 18$ & $10.2 \%$ & 2 & $19.1 \%$ \\
\hline LEU Core 189 BOC & 27P01S1 Ax 18 & $8.5 \%$ & 27P01S1 & $8.9 \%$ & 27P01 Ax 13 & $9.7 \%$ & 02P01 & $10.6 \%$ & 2 & $10.3 \%$ \\
\hline LEU Core 190 BOC & 27P01S1 Ax 13 & $14.4 \%$ & 27P01S1 & $12.6 \%$ & 27P01 Ax 13 & $14.4 \%$ & 02P01 & $13.7 \%$ & 2 & $12.8 \%$ \\
\hline LEU Core 179 EOC & 25P01S4 Ax 12 & $7.2 \%$ & $25 \mathrm{P} 01 \mathrm{~S} 4$ & $5.4 \%$ & 25P01 Ax 11 & $7.2 \%$ & $25 \mathrm{P} 01$ & $5.4 \%$ & 2 & $8.0 \%$ \\
\hline LEU Core 180 EOC & 25P01S4 Ax 11 & $12.2 \%$ & 27P01S1 & $15.9 \%$ & $21 \mathrm{P} 01 \mathrm{Ax} 11$ & $9.2 \%$ & $25 \mathrm{P} 01$ & $9.1 \%$ & 2 & $10.6 \%$ \\
\hline LEU Core 181 EOC & 13P18S1 Ax 12 & $13.5 \%$ & 13P18S1 & $11.1 \%$ & 13P18 Ax 11 & $13.5 \%$ & $13 \mathrm{P} 18$ & $11.1 \%$ & 2 & $13.1 \%$ \\
\hline LEU Core 182 EOC & 13P18S1 Ax 9 & $15.5 \%$ & 13P18S1 & $13.8 \%$ & $13 \mathrm{P} 18$ Ax 11 & $17.1 \%$ & $13 \mathrm{P} 18$ & $13.8 \%$ & 2 & $14.9 \%$ \\
\hline LEU Core 183 EOC & 27P01S1 Ax 11 & $15.8 \%$ & 27P01S1 & $13.1 \%$ & $27 \mathrm{P} 01 \quad \mathrm{Ax} 11$ & $15.8 \%$ & $27 \mathrm{P} 01$ & $13.1 \%$ & 2 & $9.3 \%$ \\
\hline LEU Core 184 EOC & 27P01S1 Ax 11 & $20.4 \%$ & 27P01S1 & $16.9 \%$ & 27P01 Ax 11 & $20.4 \%$ & $27 \mathrm{P} 01$ & $16.9 \%$ & 2 & $11.8 \%$ \\
\hline LEU Core 185 EOC & 27P01S1 Ax 11 & $24.8 \%$ & 27P01S1 & $20.4 \%$ & 27P01 Ax 11 & $24.8 \%$ & $27 \mathrm{P} 01$ & $20.4 \%$ & 2 & $14.3 \%$ \\
\hline LEU Core 186 EOC & 14P18S1 Ax 11 & $15.6 \%$ & 27P01S1 & $23.7 \%$ & $14 \mathrm{P} 18 \quad \mathrm{Ax} 10$ & $15.6 \%$ & $14 \mathrm{P} 18$ & $13.1 \%$ & 2 & $16.7 \%$ \\
\hline LEU Core 187 EOC & 25P01S4 Ax 11 & $17.6 \%$ & $25 \mathrm{P} 01 \mathrm{~S} 4$ & $14.6 \%$ & $24 \mathrm{P} 18$ Ax 11 & $12.9 \%$ & $25 \mathrm{P} 01$ & $14.6 \%$ & 2 & $19.1 \%$ \\
\hline LEU Core 188 EOC & 24P18S1 Ax 10 & $15.1 \%$ & 24P18S1 & $12.4 \%$ & $24 \mathrm{P} 18 \quad \mathrm{Ax} 10$ & $15.1 \%$ & $24 \mathrm{P} 18$ & $12.4 \%$ & 2 & $21.4 \%$ \\
\hline LEU Core 189 EOC & 27P01S1 Ax 11 & $15.6 \%$ & 27P01S1 & $12.6 \%$ & $27 \mathrm{P} 01 \quad \mathrm{Ax} 11$ & $15.6 \%$ & $27 \mathrm{P} 01$ & $12.6 \%$ & 2 & $12.8 \%$ \\
\hline LEU Core 190 EOC & 27P01S1 Ax 11 & $20.3 \%$ & 27P01S1 & $16.2 \%$ & 27P01 Ax 11 & $20.3 \%$ & $27 \mathrm{P} 01$ & $16.2 \%$ & 2 & $15.2 \%$ \\
\hline
\end{tabular}




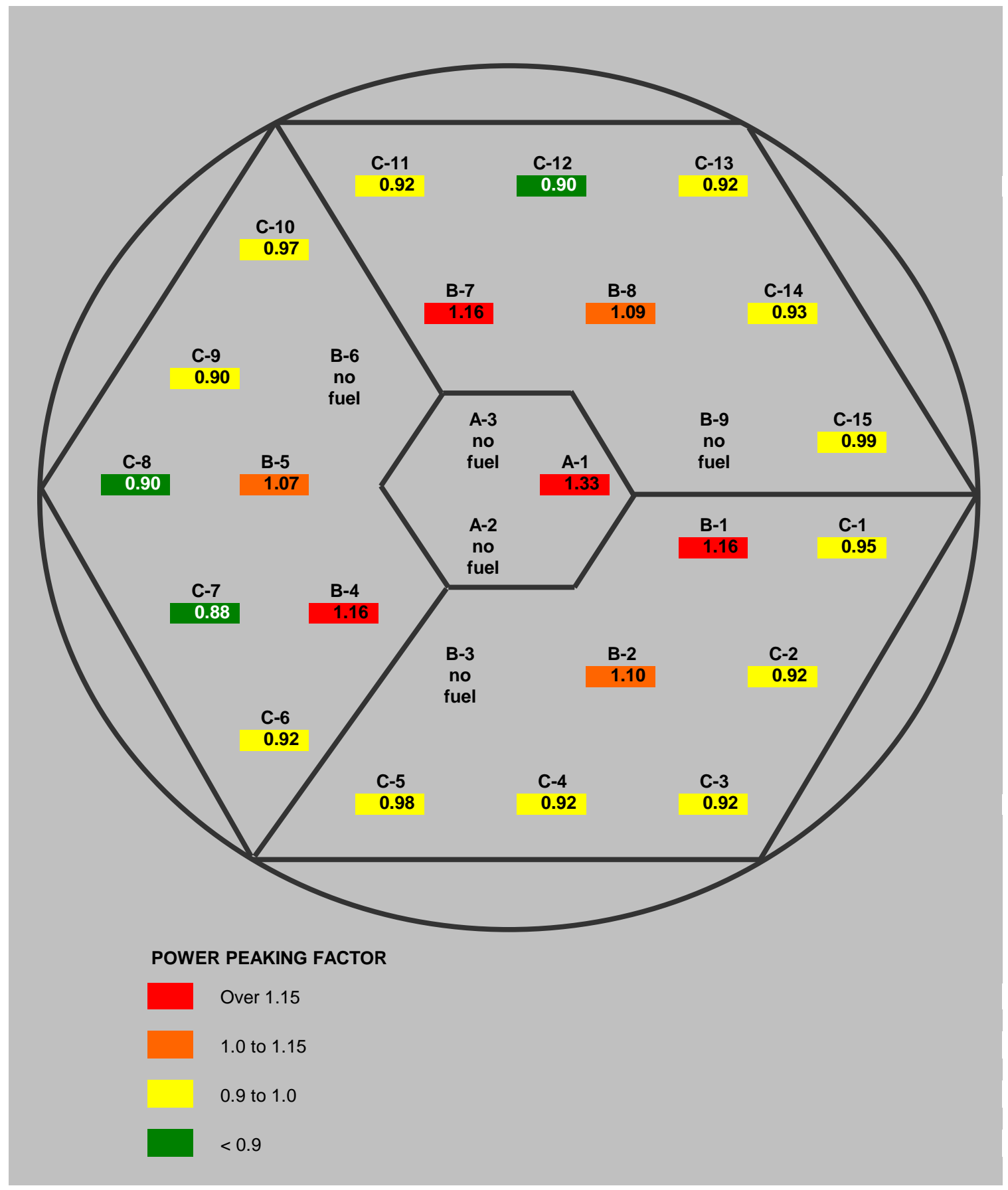

Figure D-1. Elemental power and burnup distribution in the all-fresh LEU Core 2. 


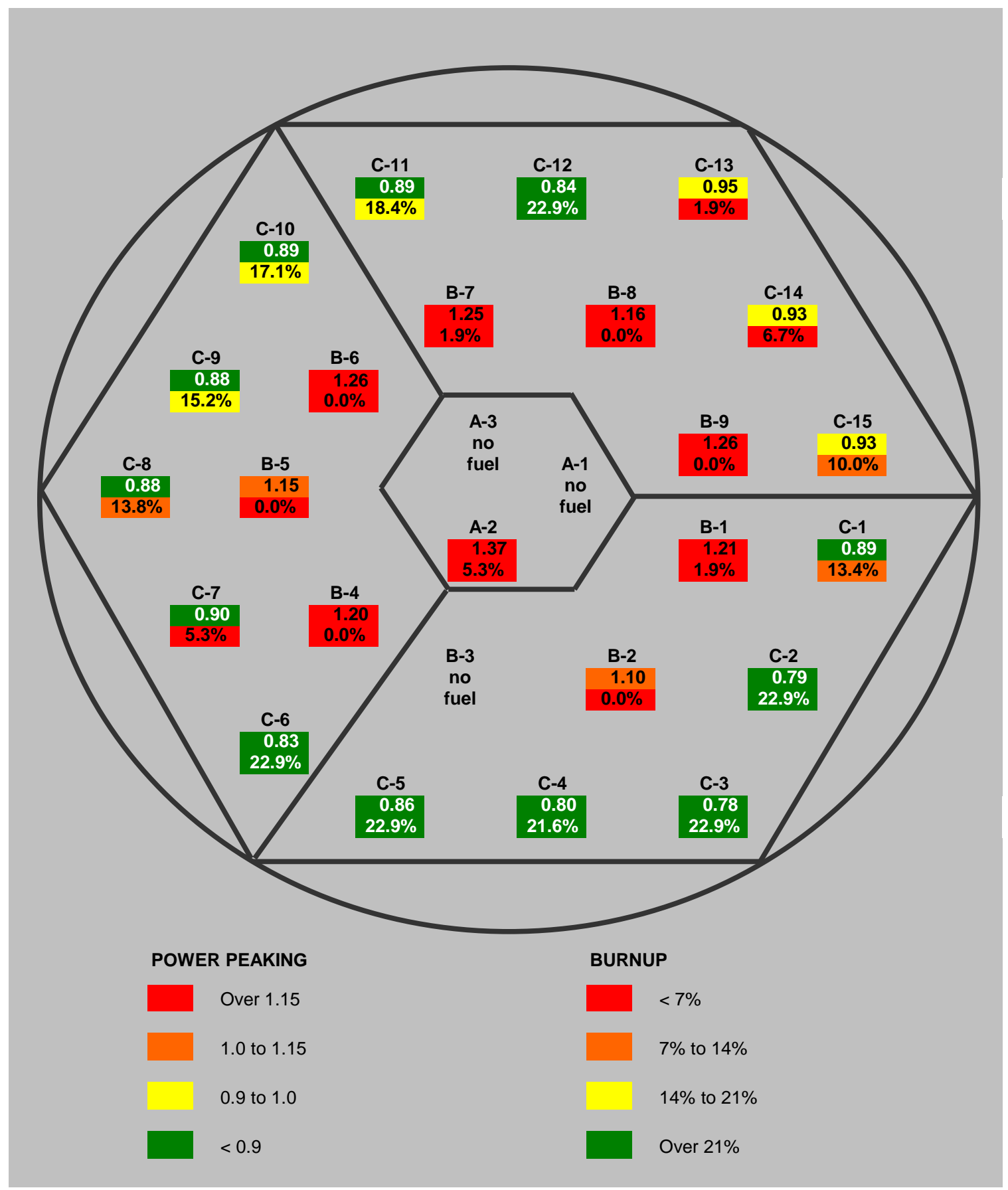

Figure D-2. Elemental power and burnup distribution in LEU depleted Core 179 at BOC. 


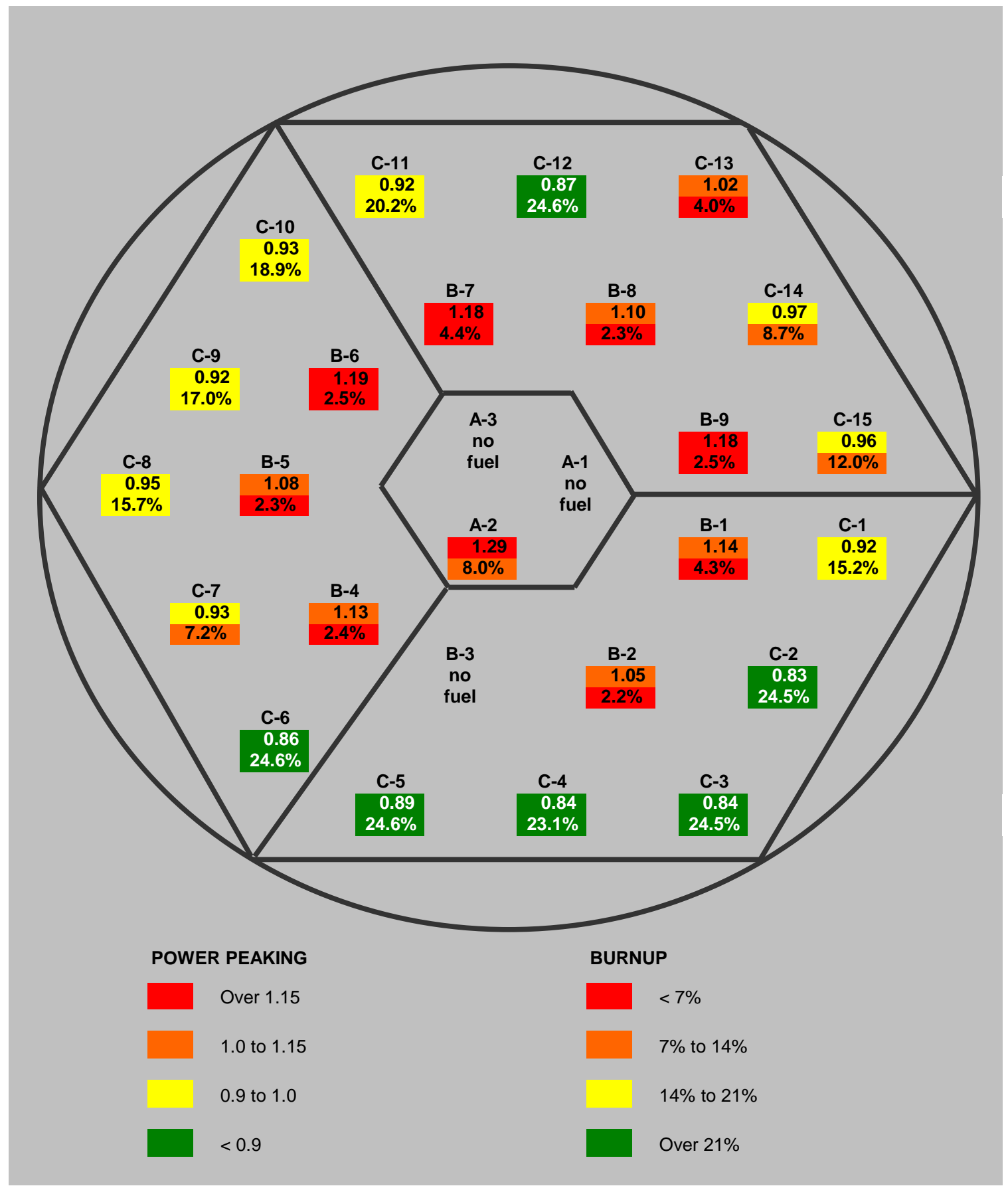

Figure D-3. Elemental power and burnup distribution in LEU depleted Core 179 at EOC. 


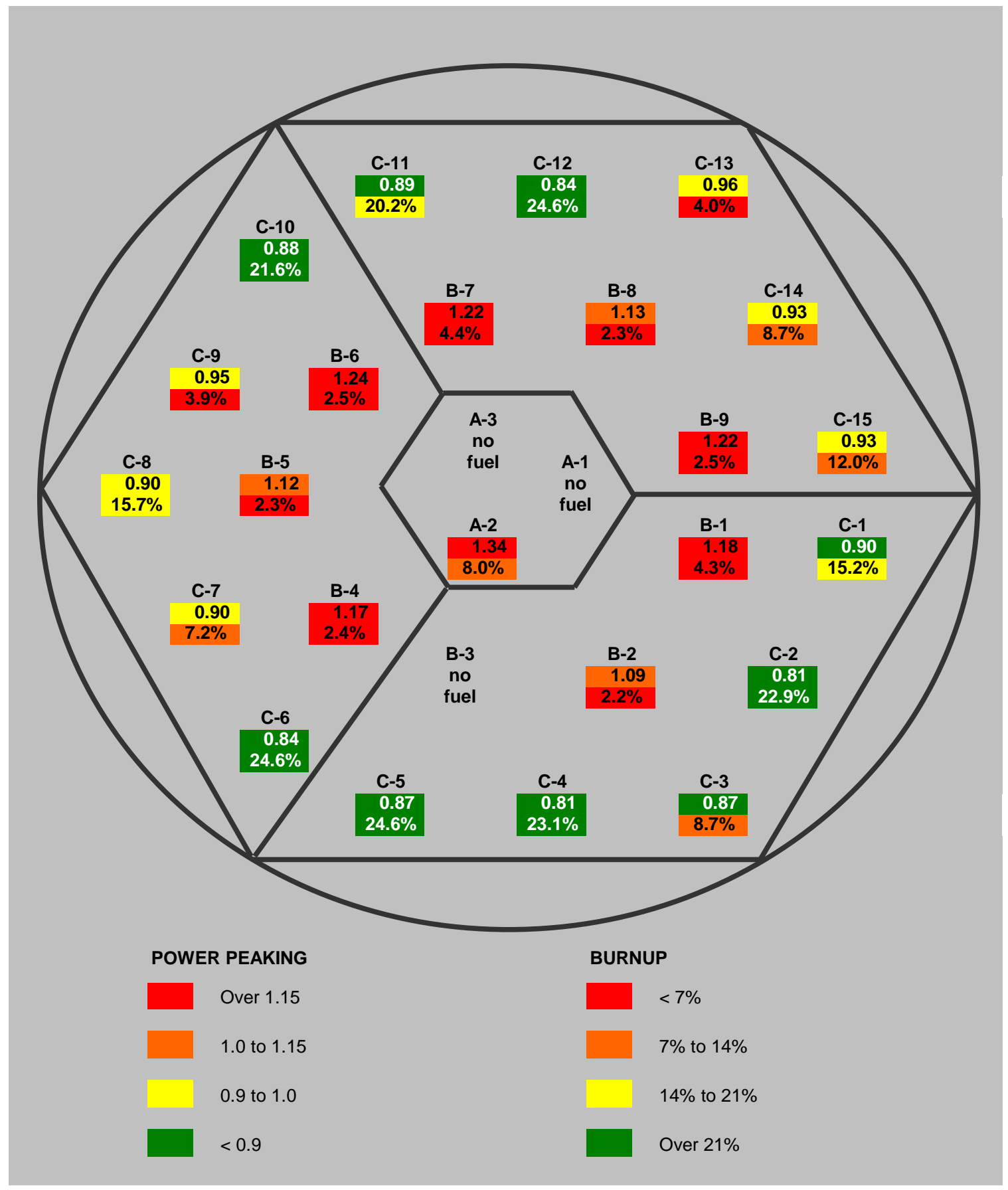

Figure D-4. Elemental power and burnup distribution in LEU depleted Core 180 at BOC. 


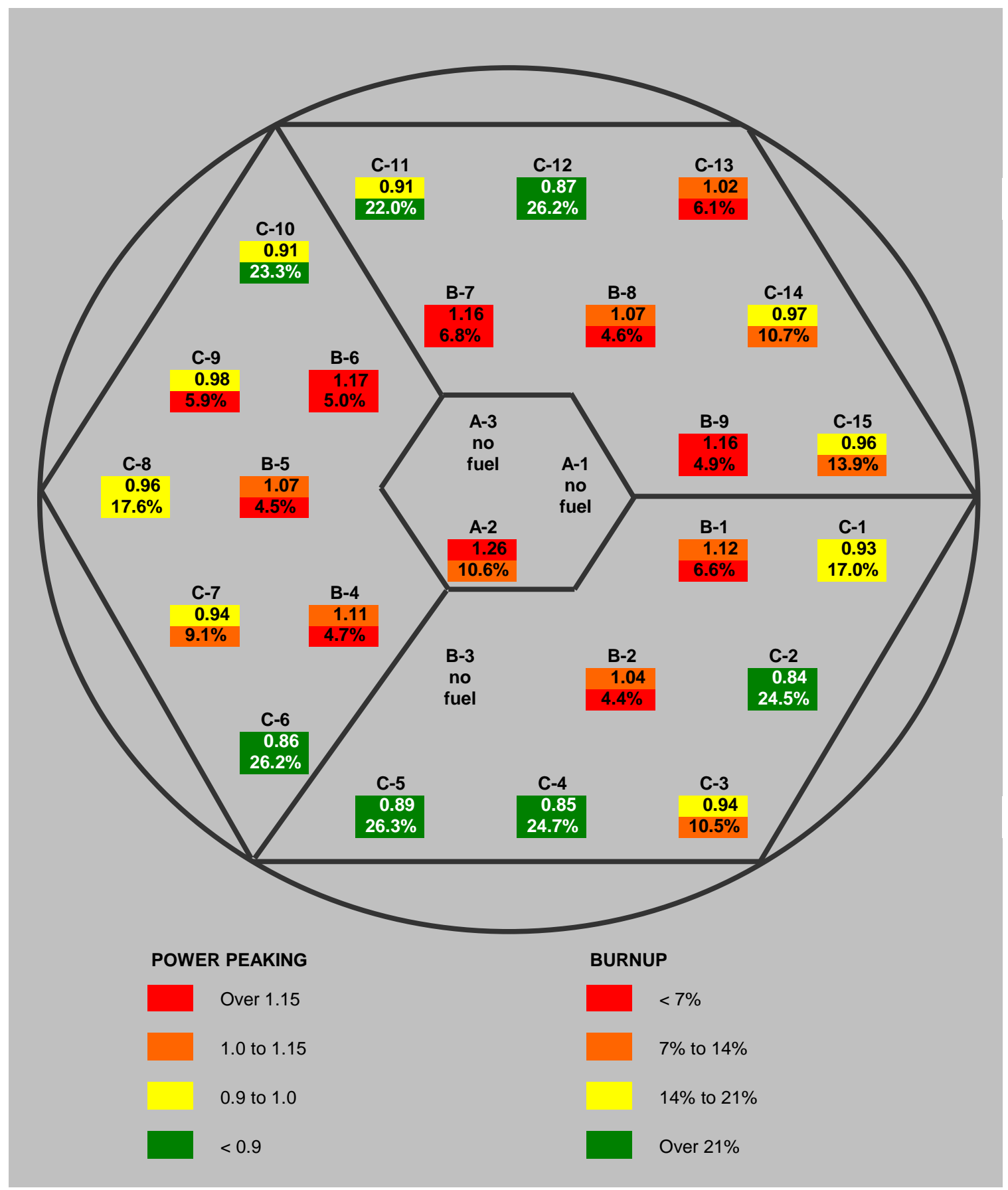

Figure D-5. Elemental power and burnup distribution in LEU depleted Core 180 at EOC. 


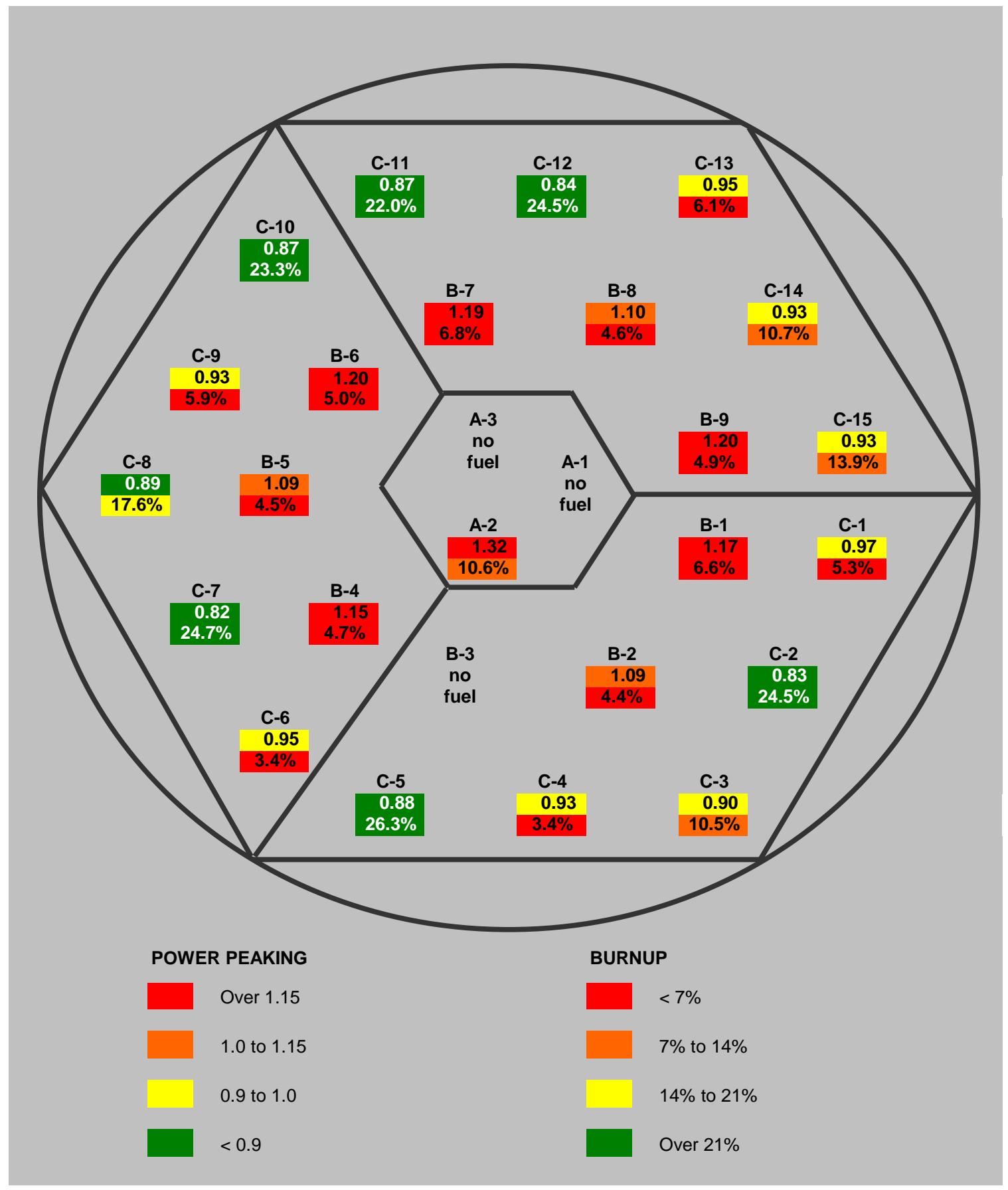

Figure D-6. Elemental power and burnup distribution in LEU depleted Core 181 at BOC. 


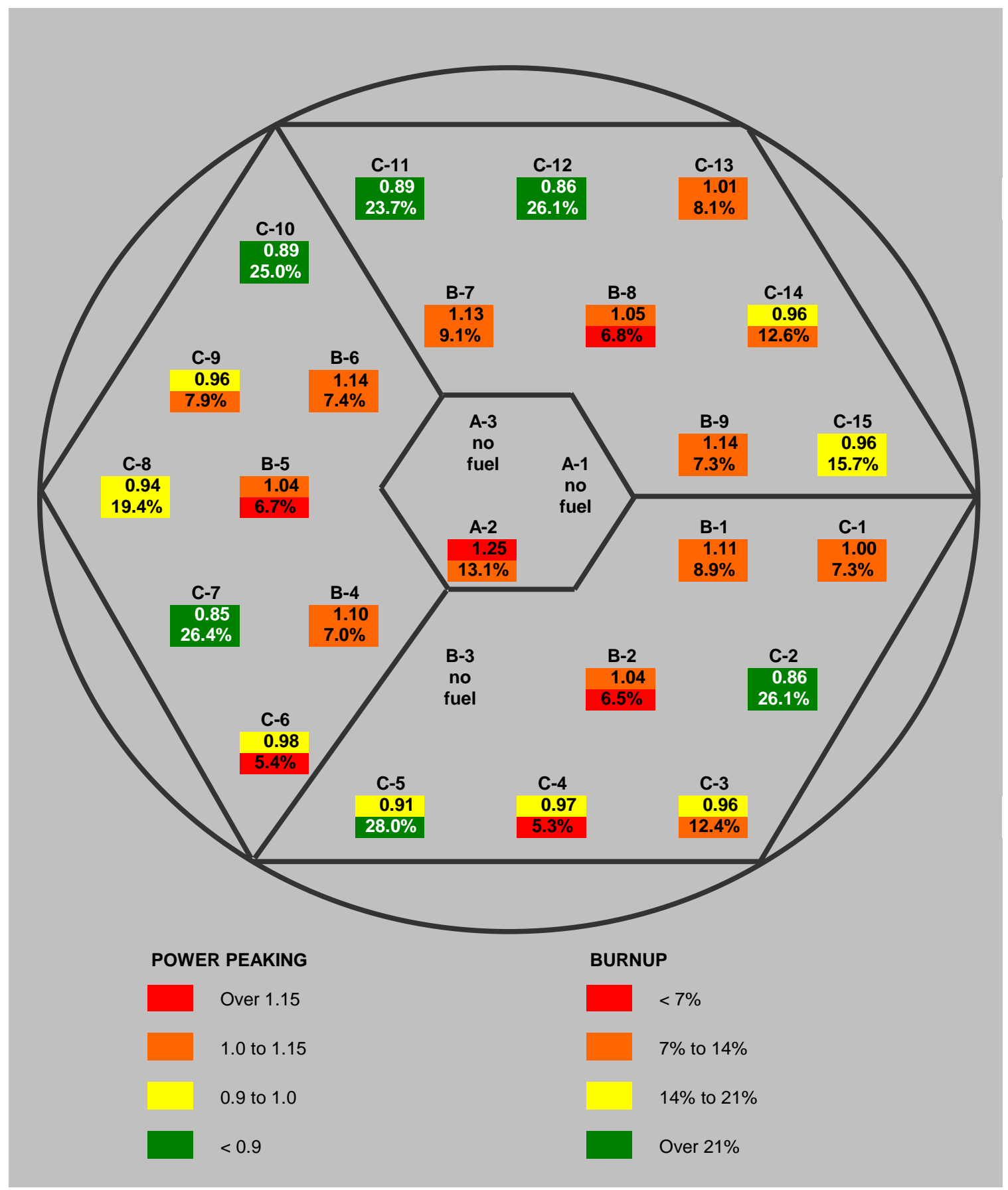

Figure D-7. Elemental power and burnup distribution in LEU depleted Core 181 at EOC. 


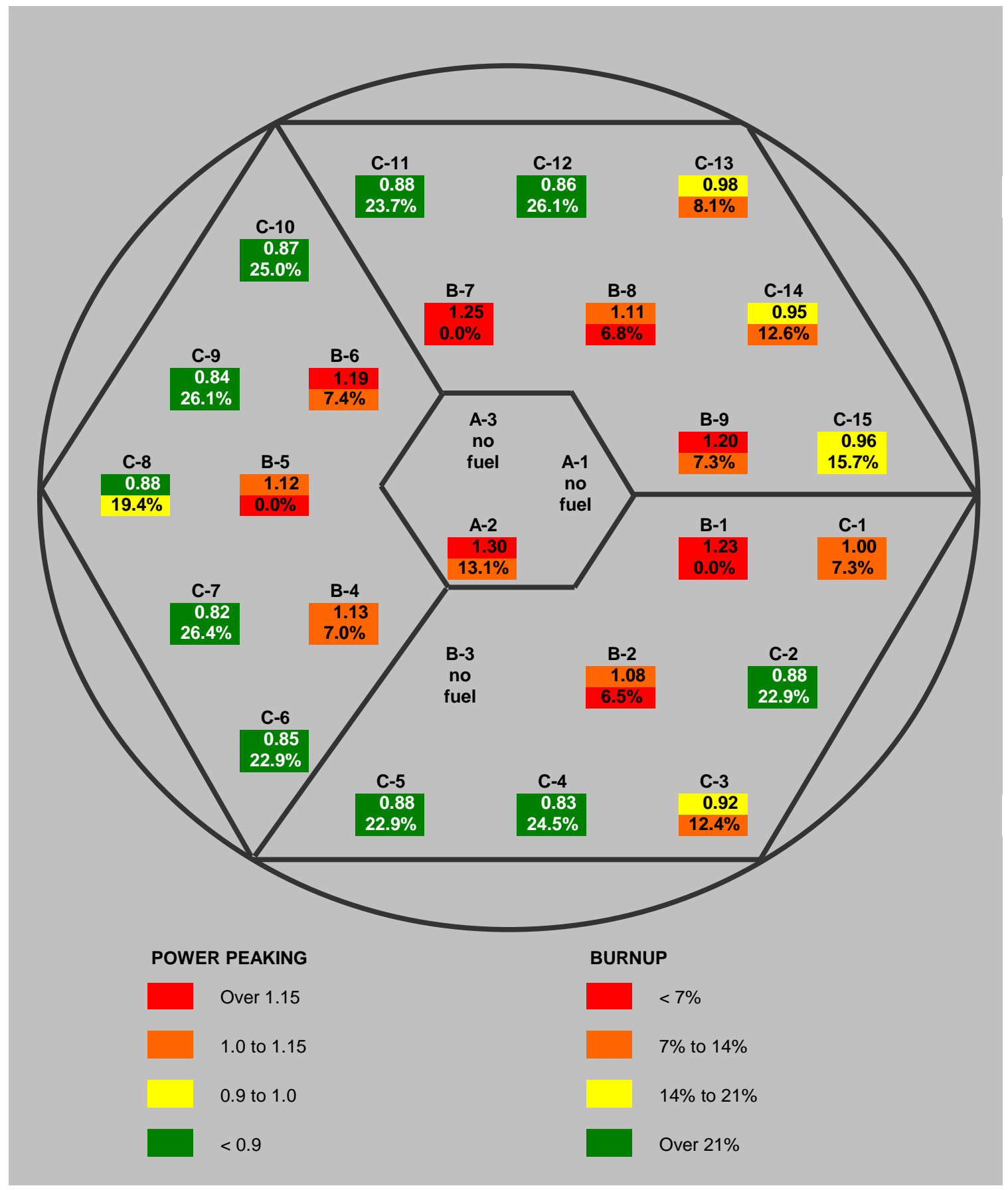

Figure D-8. Elemental power and burnup distribution in LEU depleted Core 182 at BOC. 


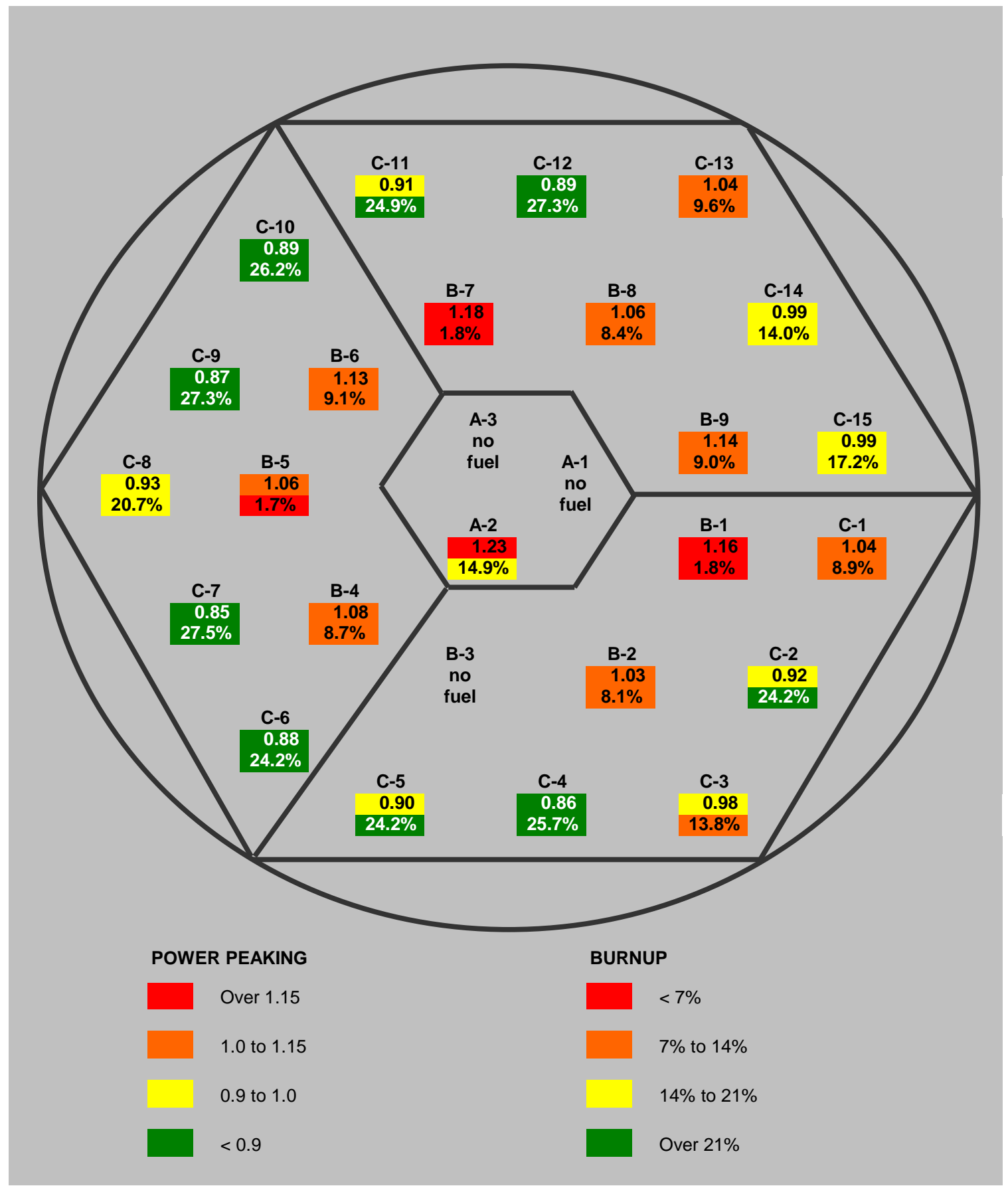

Figure D-9. Elemental power and burnup distribution in LEU depleted Core 182 at EOC. 


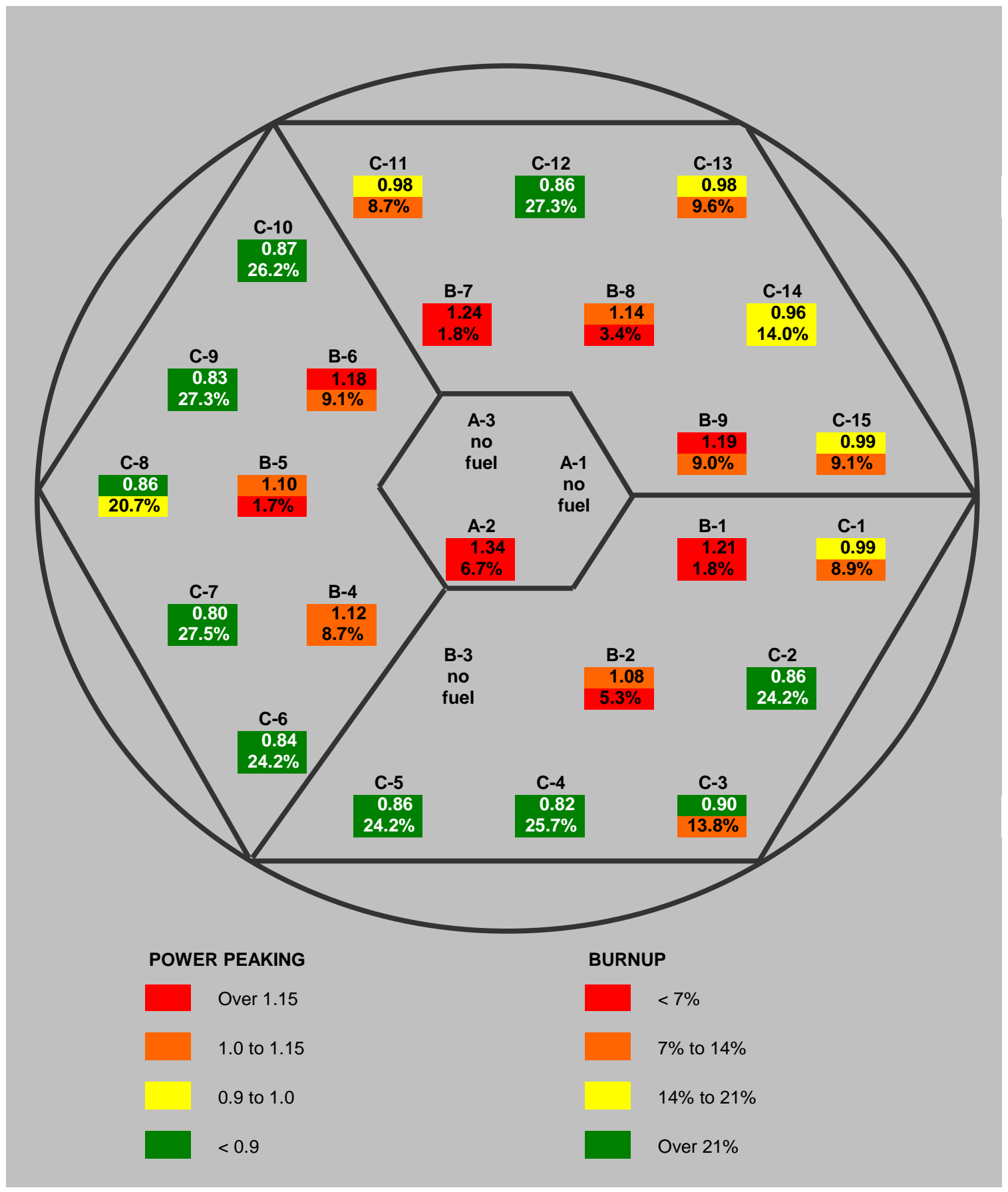

Figure D-10. Elemental power and burnup distribution in LEU depleted Core 183 at BOC. 


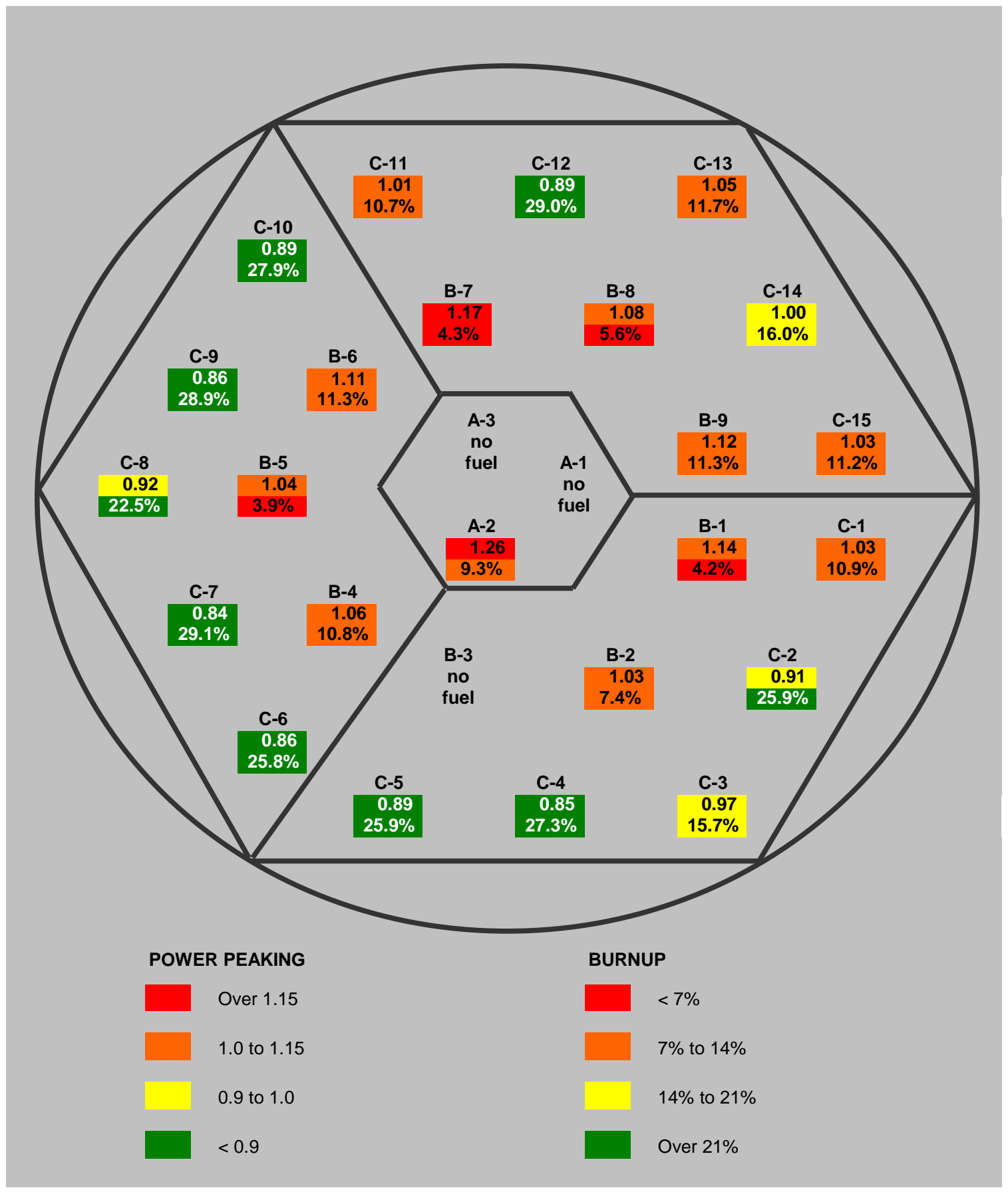

Figure D-11. Elemental power and burnup distribution in LEU depleted Core 183 at EOC. 


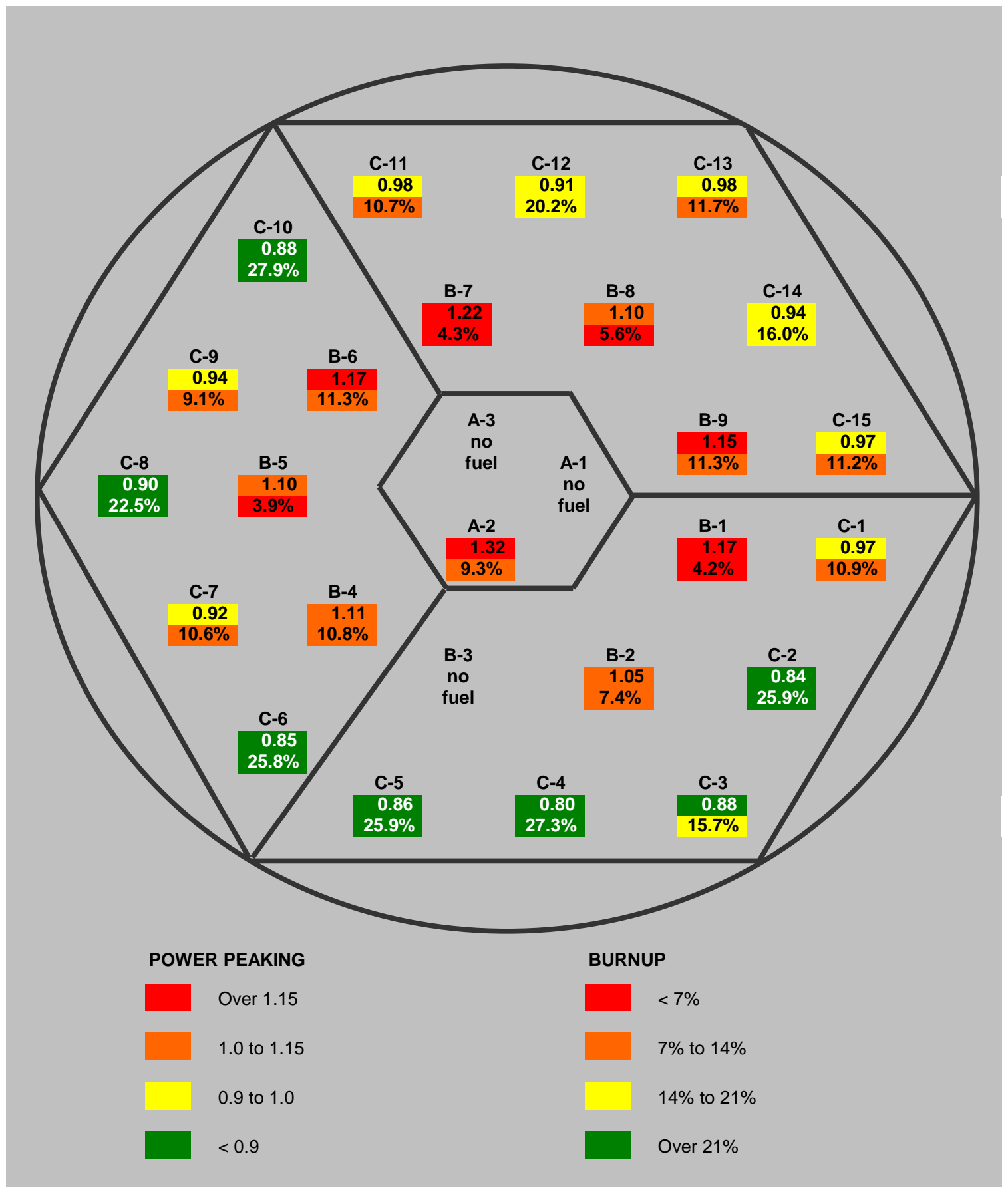

Figure D-12. Elemental power and burnup distribution in LEU depleted Core 184 at BOC. 


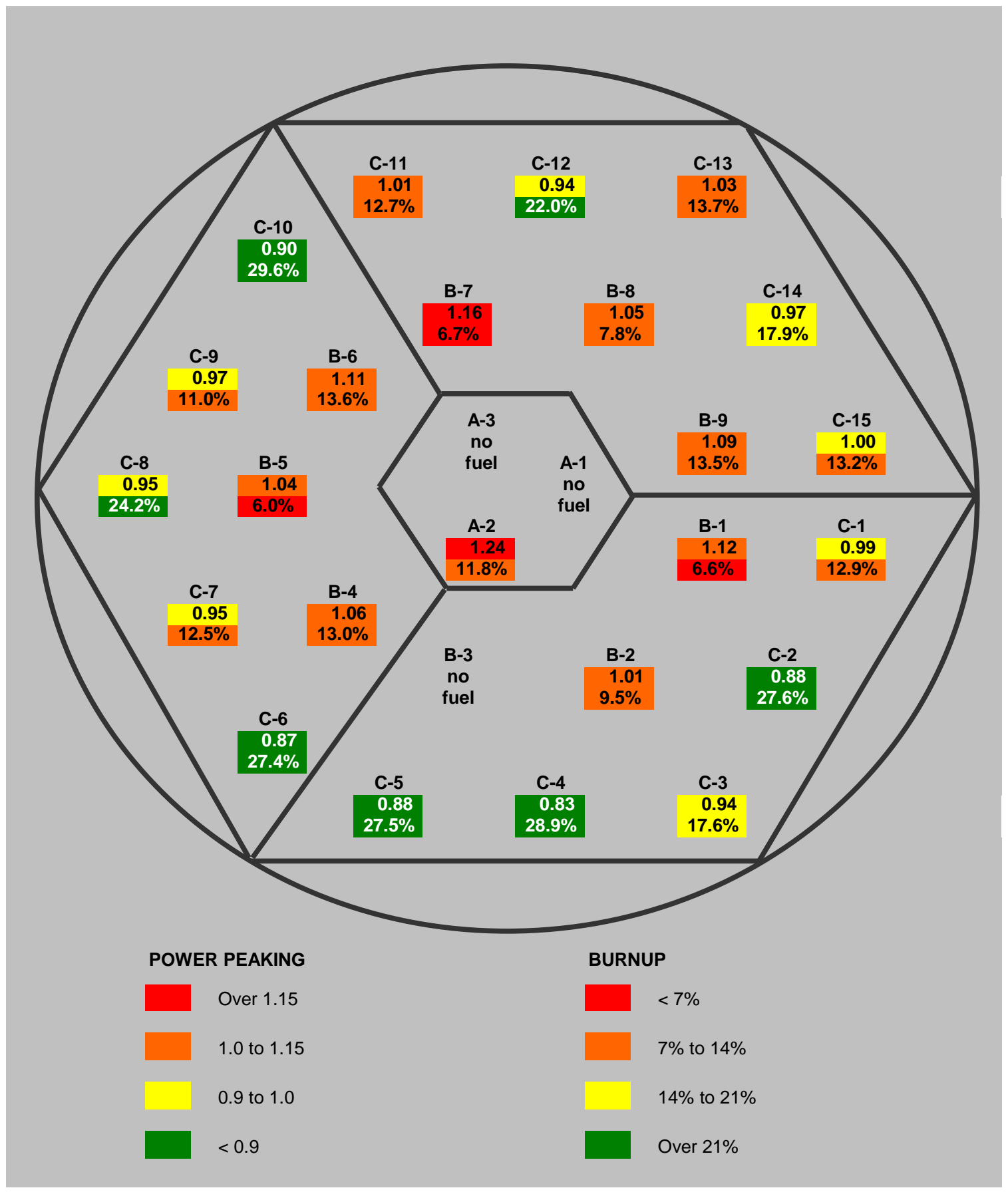

Figure D-13. Elemental power and burnup distribution in LEU depleted Core 184 at EOC. 


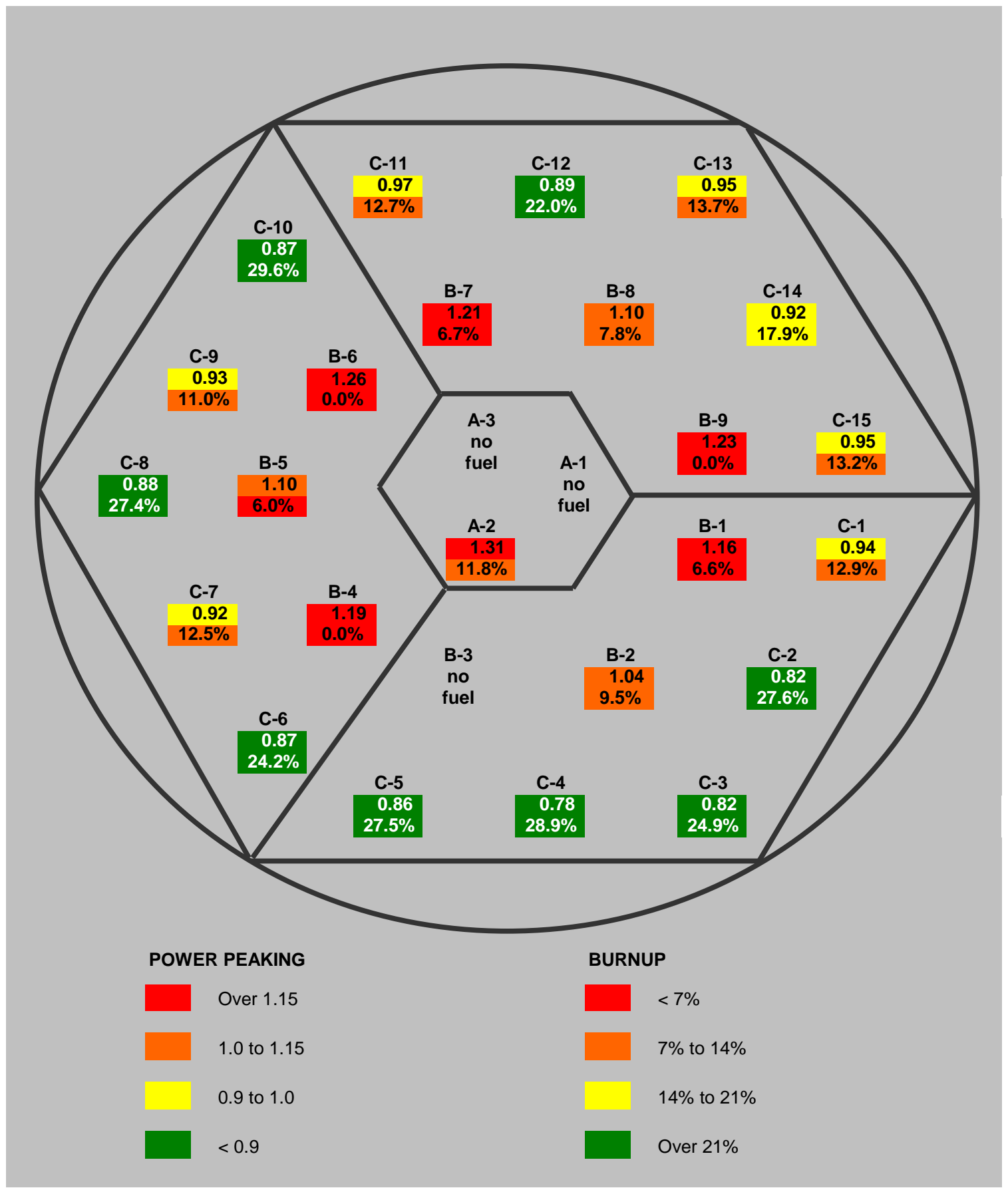

Figure D-14. Elemental power and burnup distribution in LEU depleted Core 185 at BOC. 


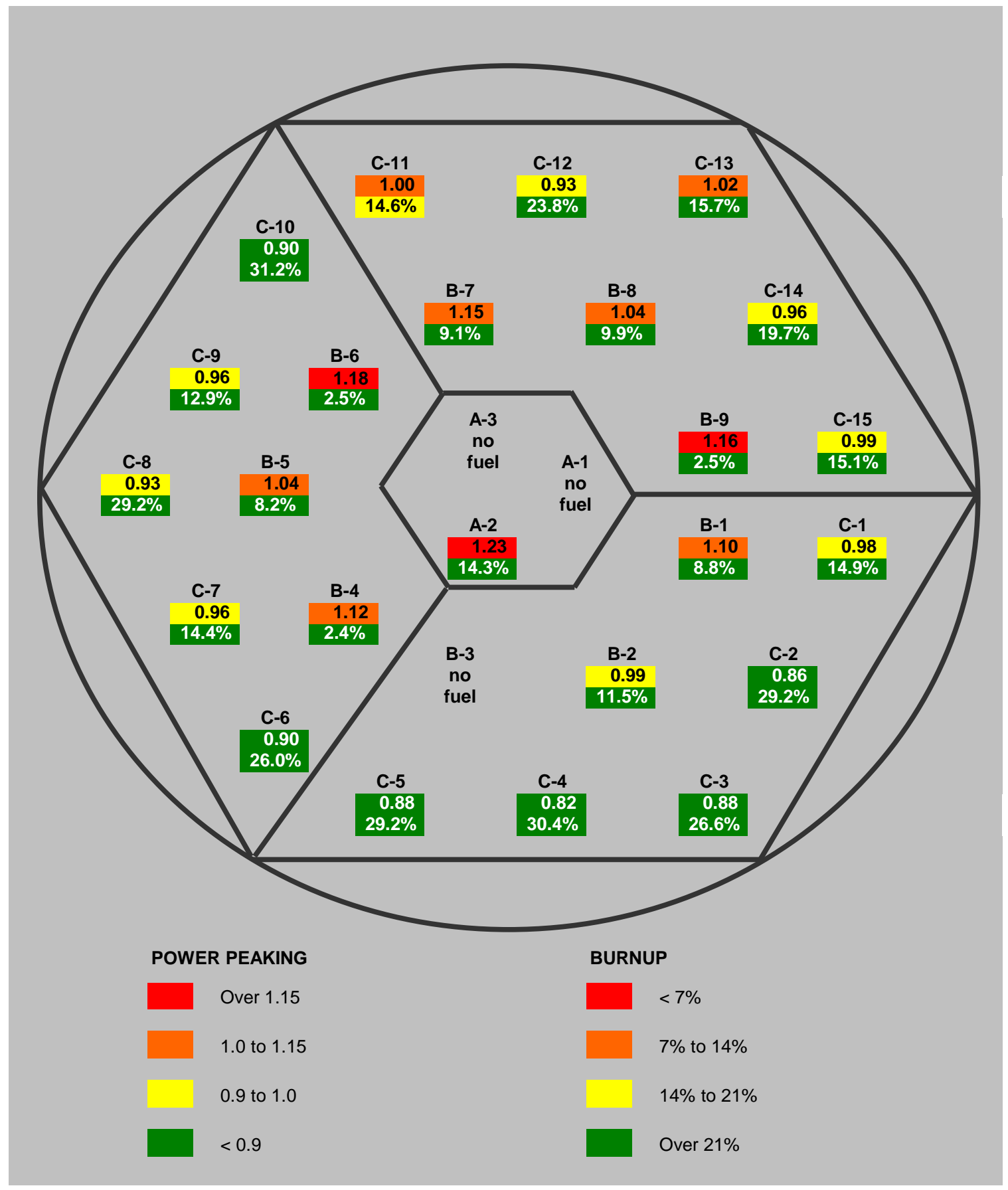

Figure D-15. Elemental power and burnup distribution in LEU depleted Core 185 at EOC. 


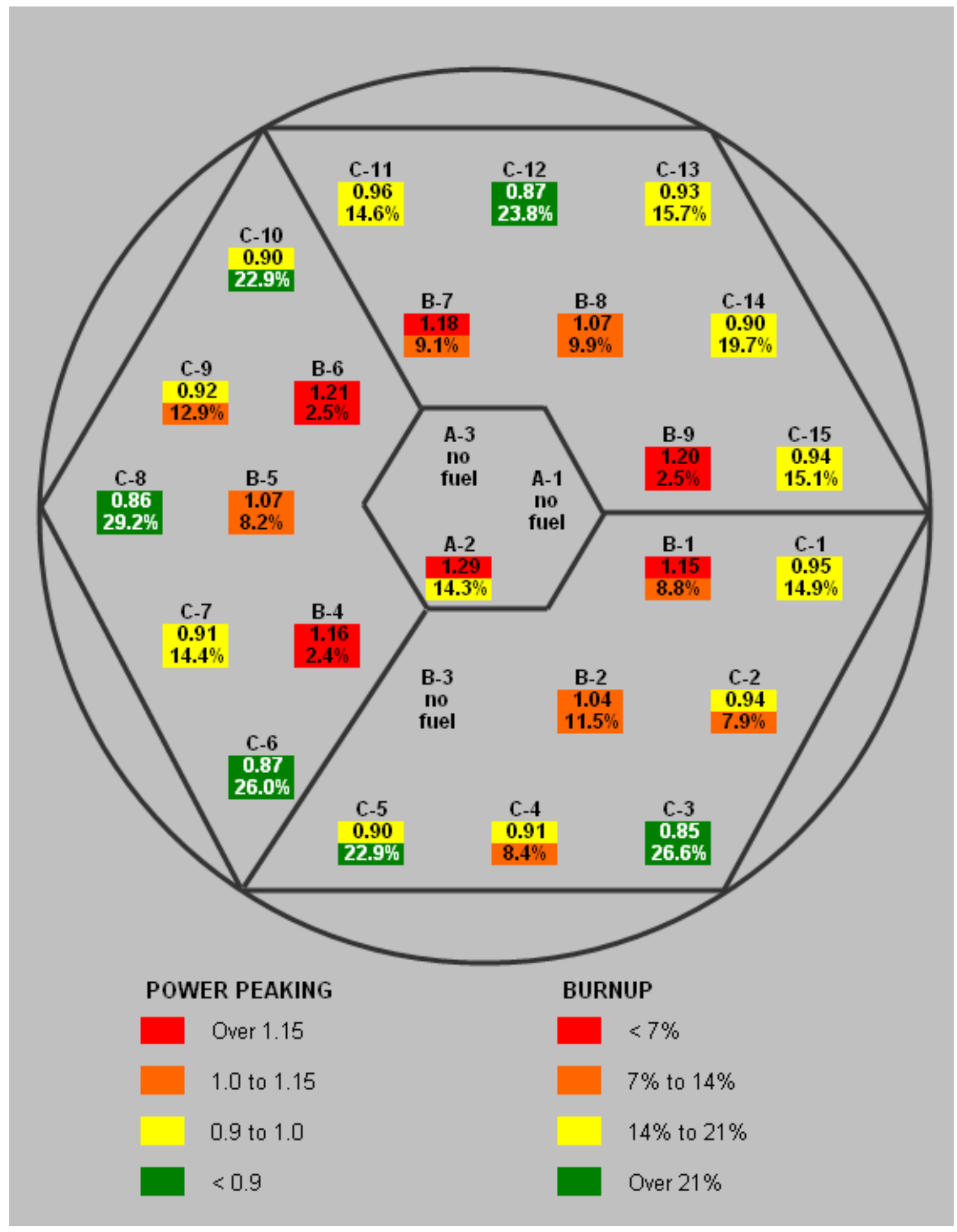

Figure D-16. Elemental power and burnup distribution in LEU depleted Core 186 at BOC. 


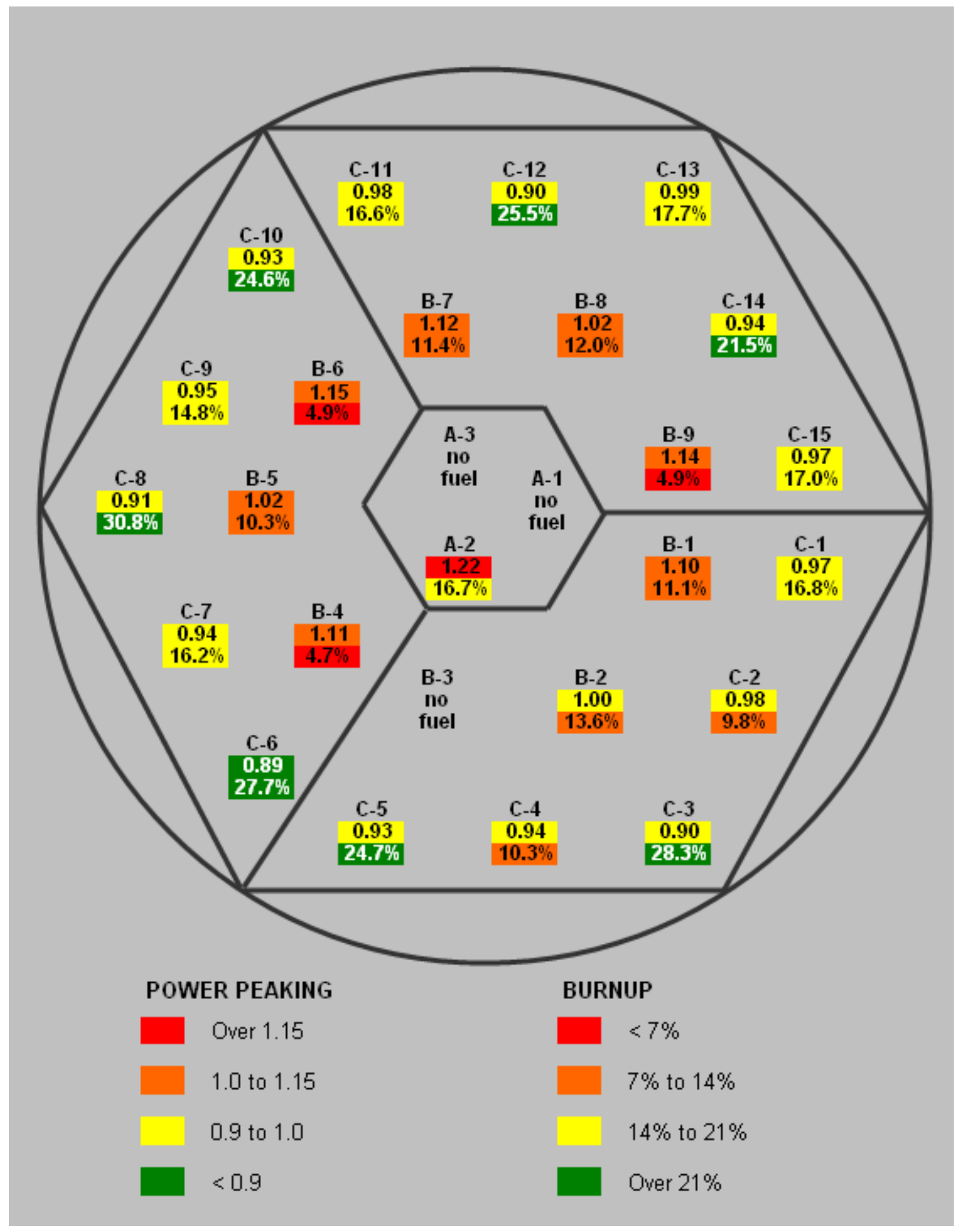

Figure D-17. Elemental power and burnup distribution in LEU depleted Core 186 at EOC. 


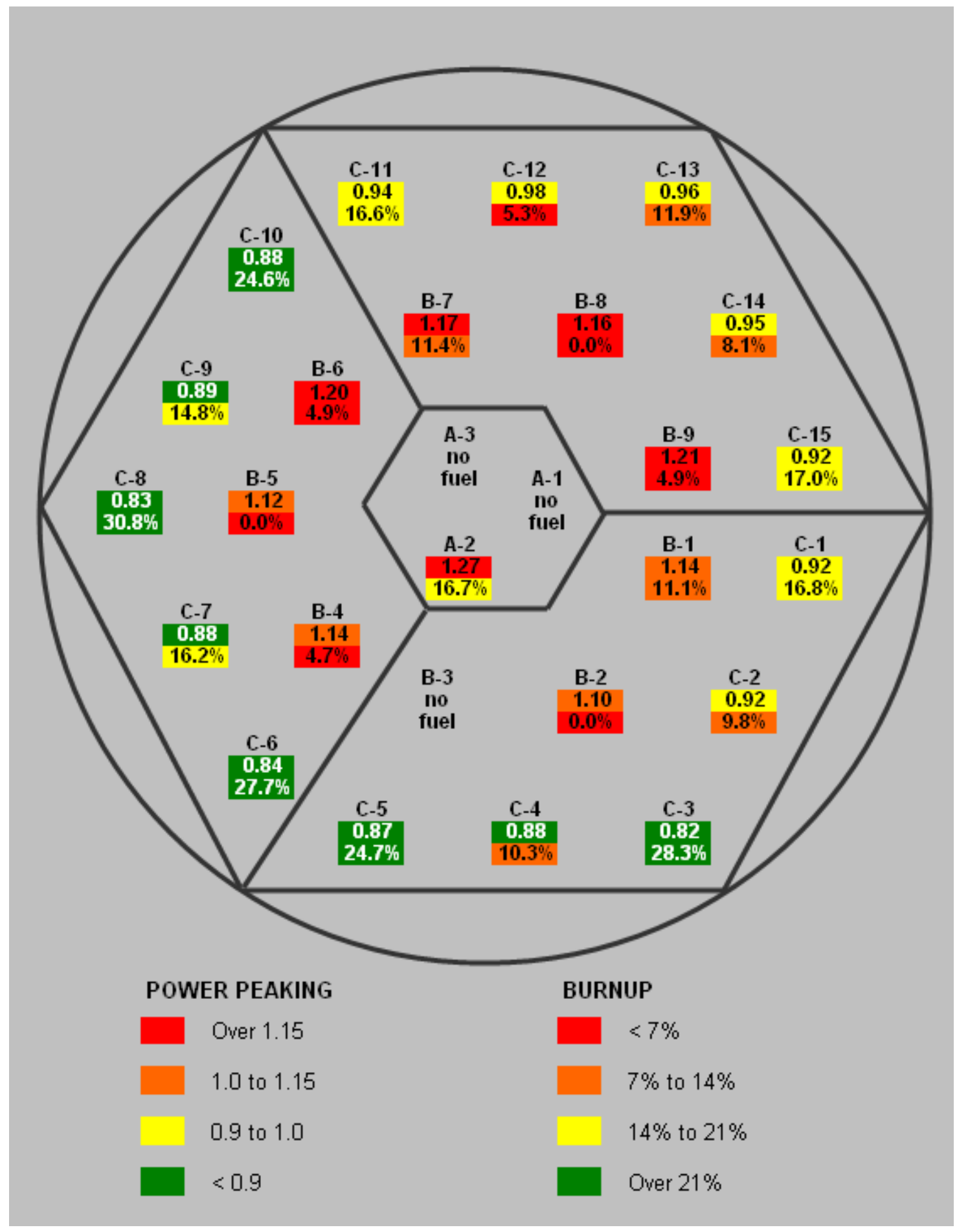

Figure D-18. Elemental power and burnup distribution in LEU depleted Core 187 at BOC. 


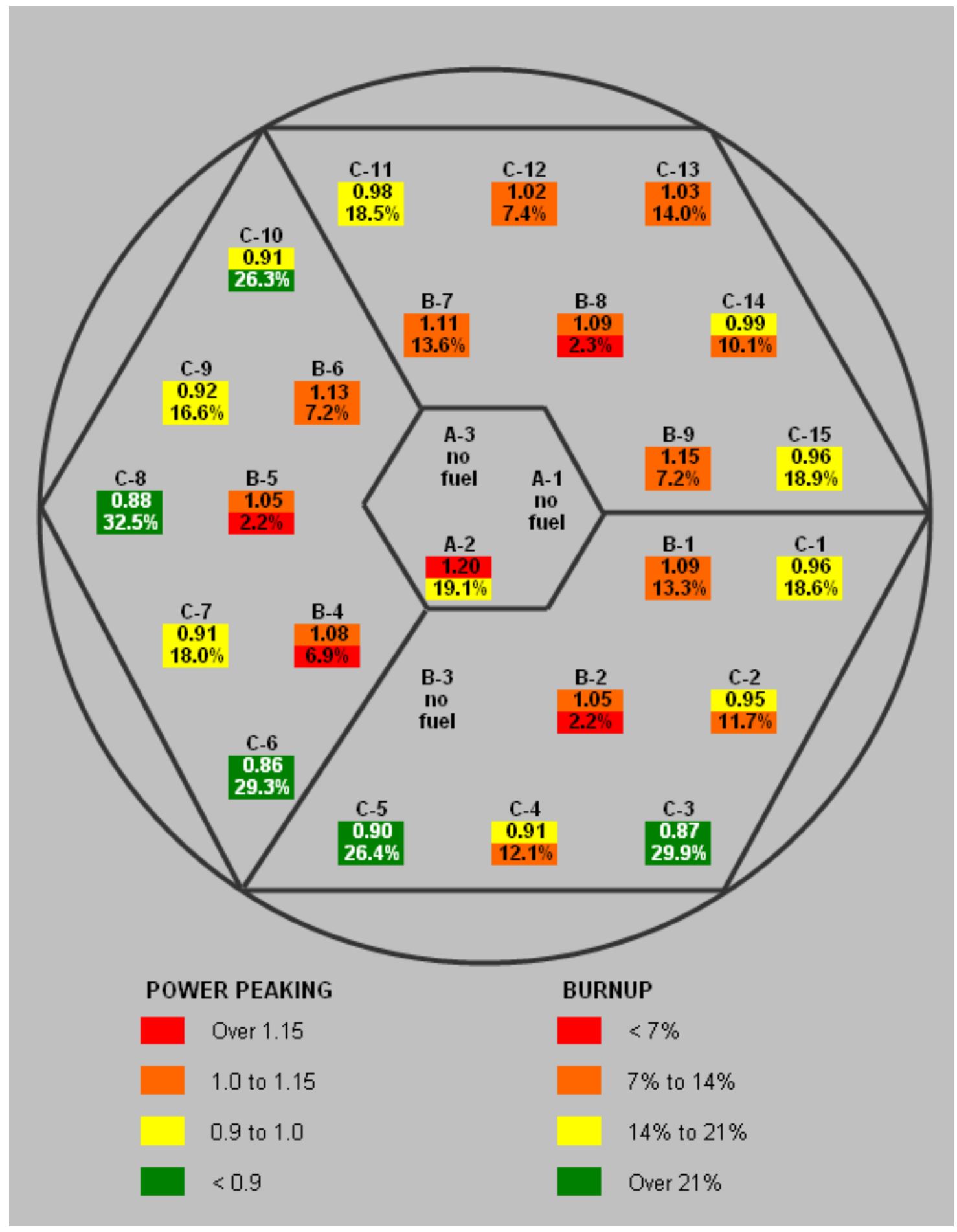

Figure D-19. Elemental power and burnup distribution in LEU depleted Core 187 at EOC. 


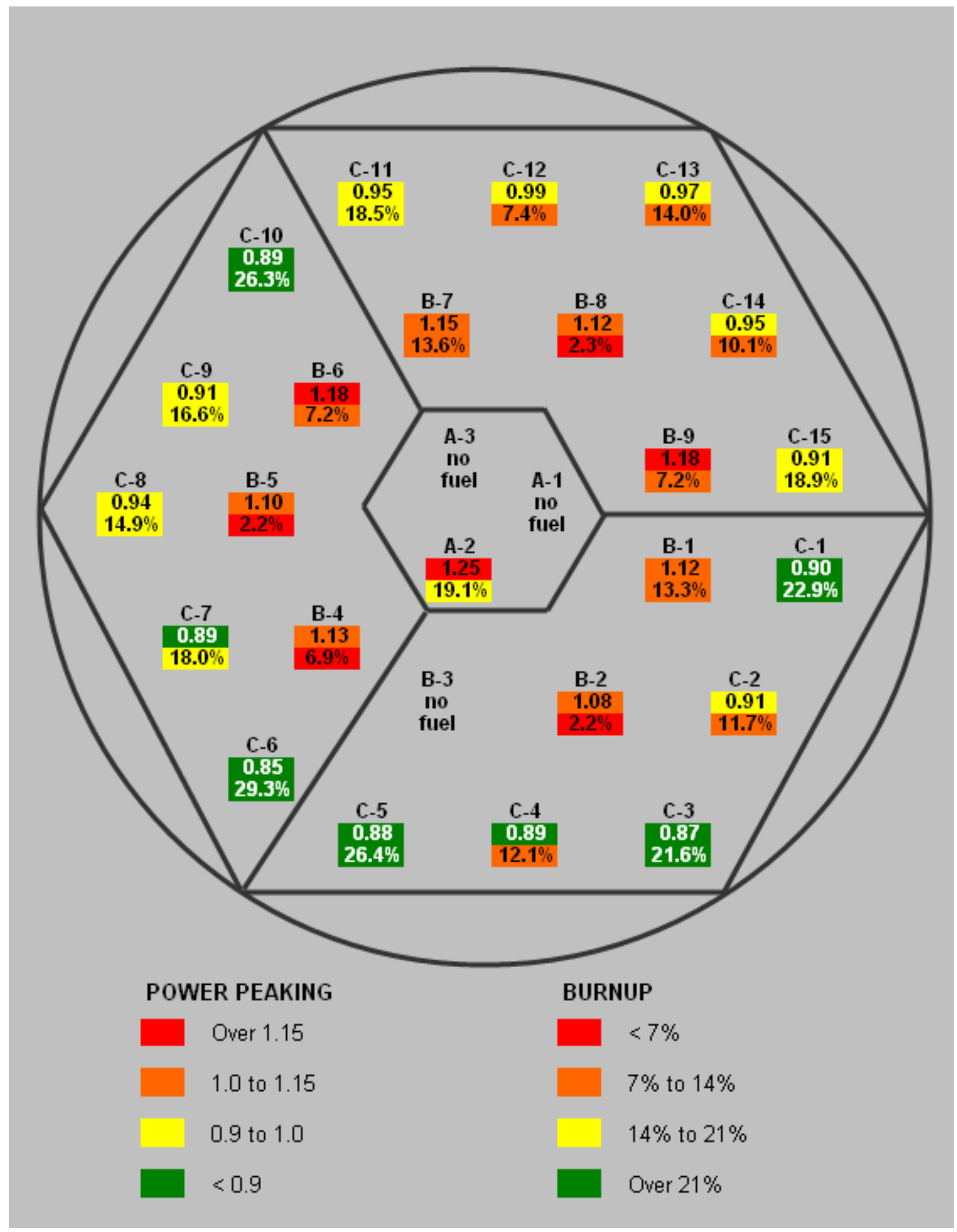

Figure D-20. Elemental power and burnup distribution in LEU depleted Core 188 at BOC. 


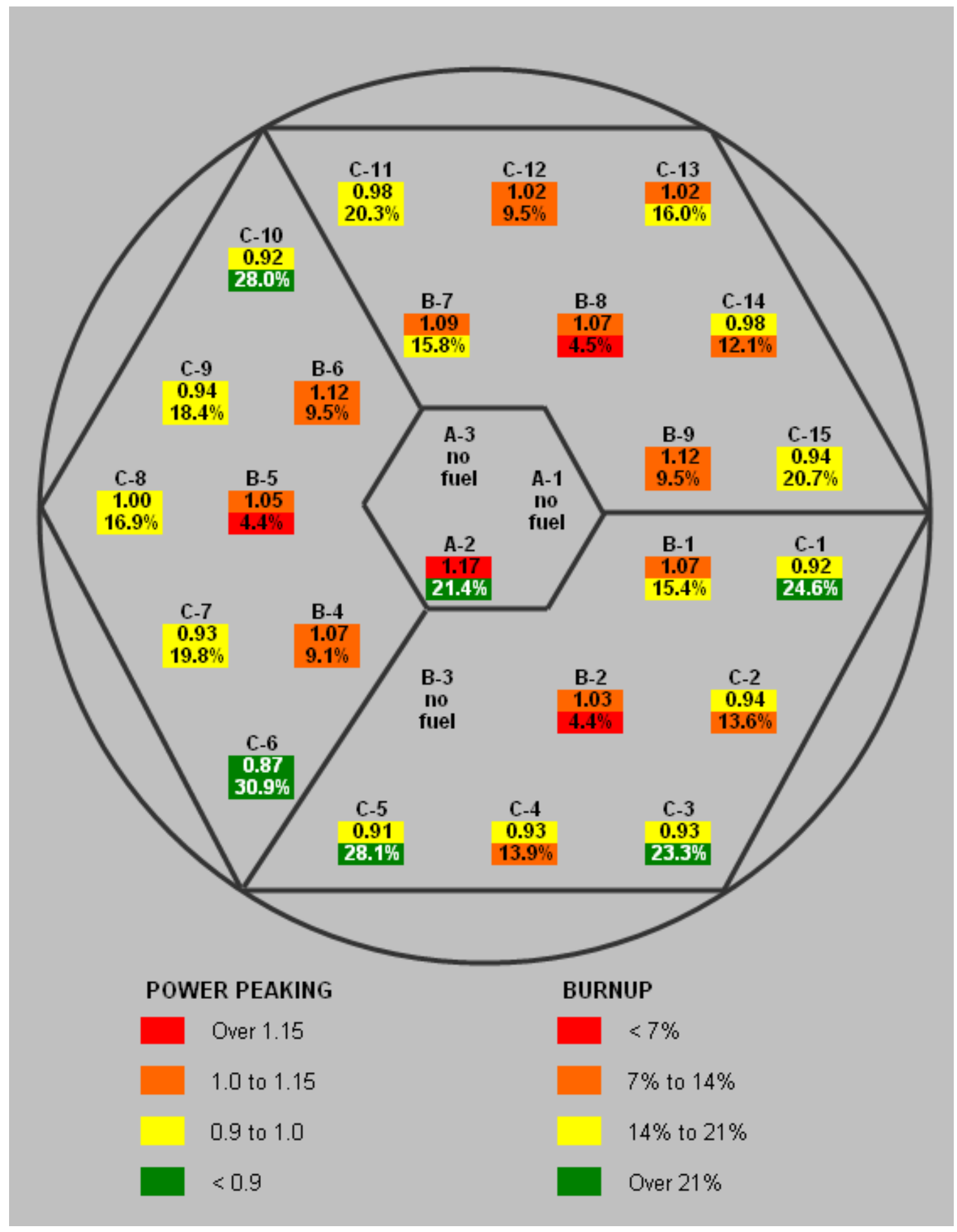

Figure D-21. Elemental power and burnup distribution in LEU depleted Core 188 at EOC. 


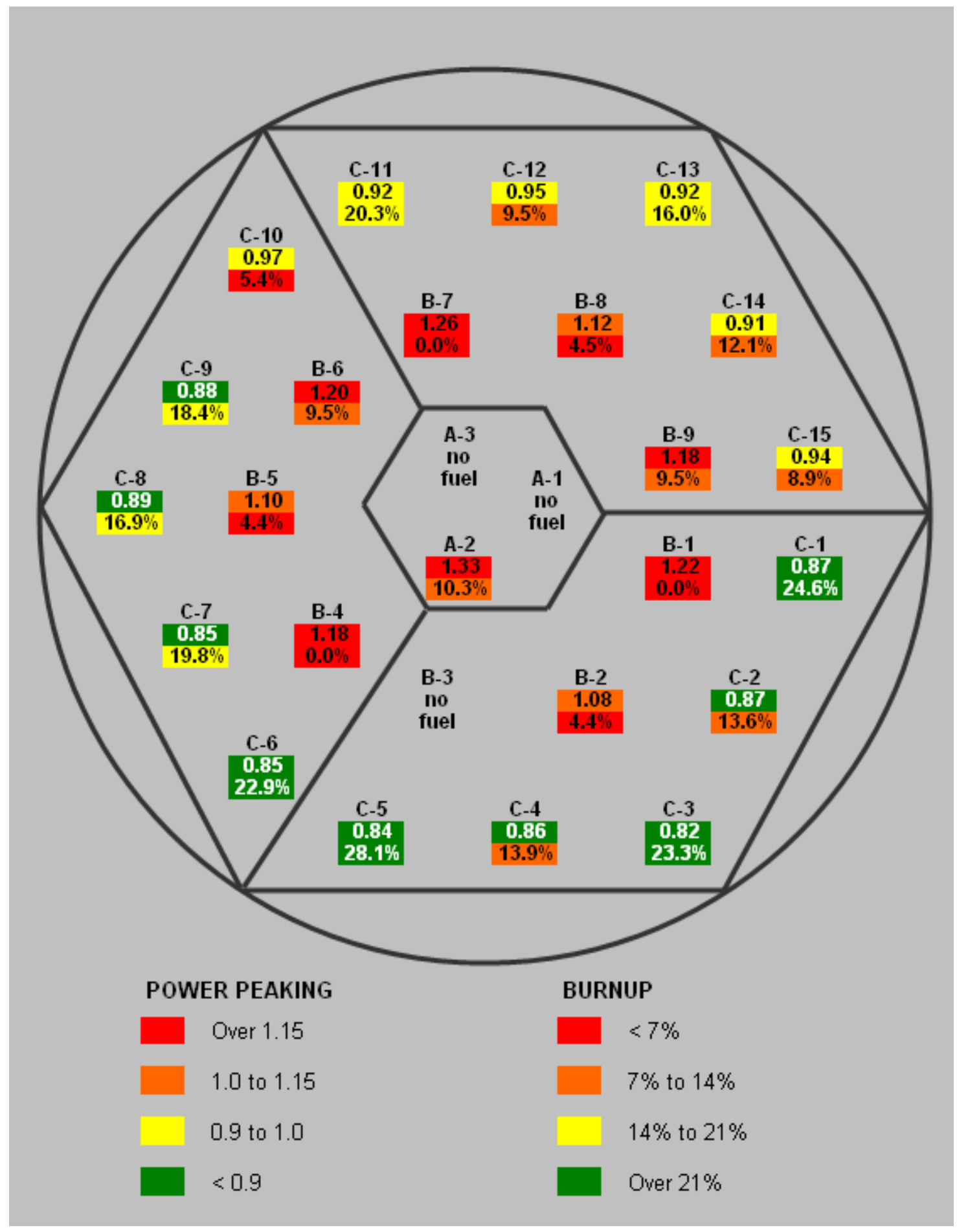

Figure D-22. Elemental power and burnup distribution in LEU depleted Core 189 at BOC. 


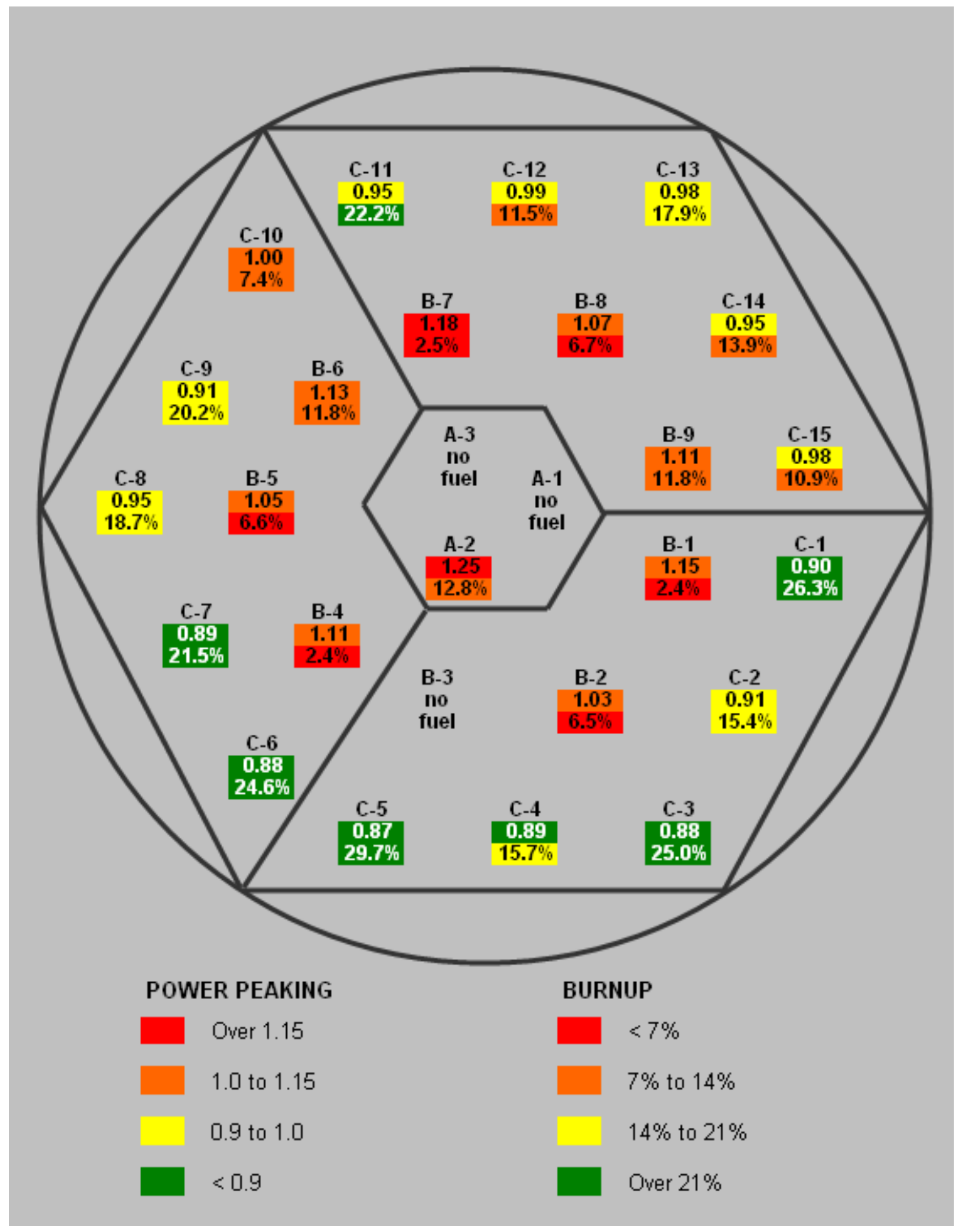

Figure D-23. Elemental power and burnup distribution in LEU depleted Core 189 at EOC. 


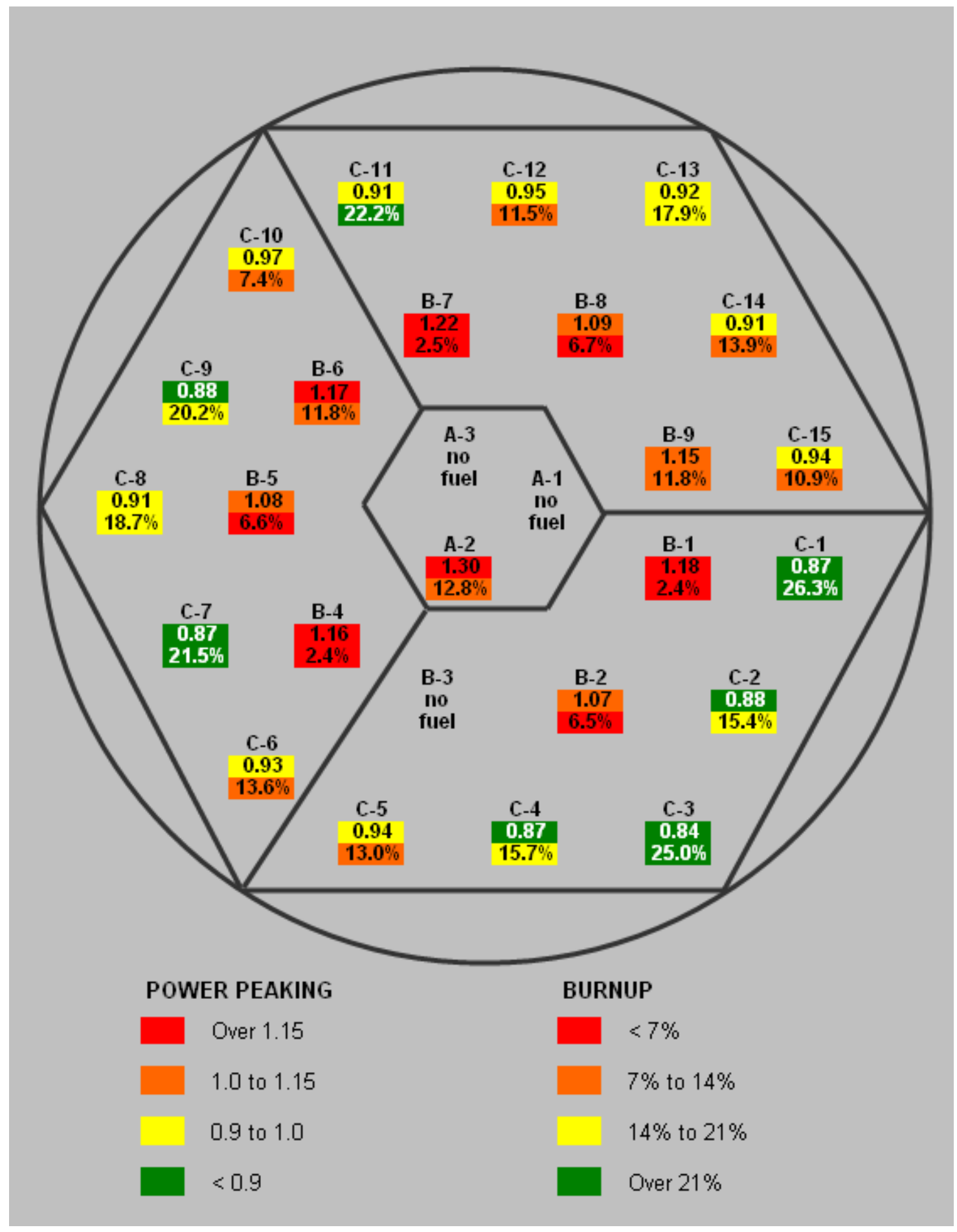

Figure D-24. Elemental power and burnup distribution in LEU depleted Core 190 at BOC. 


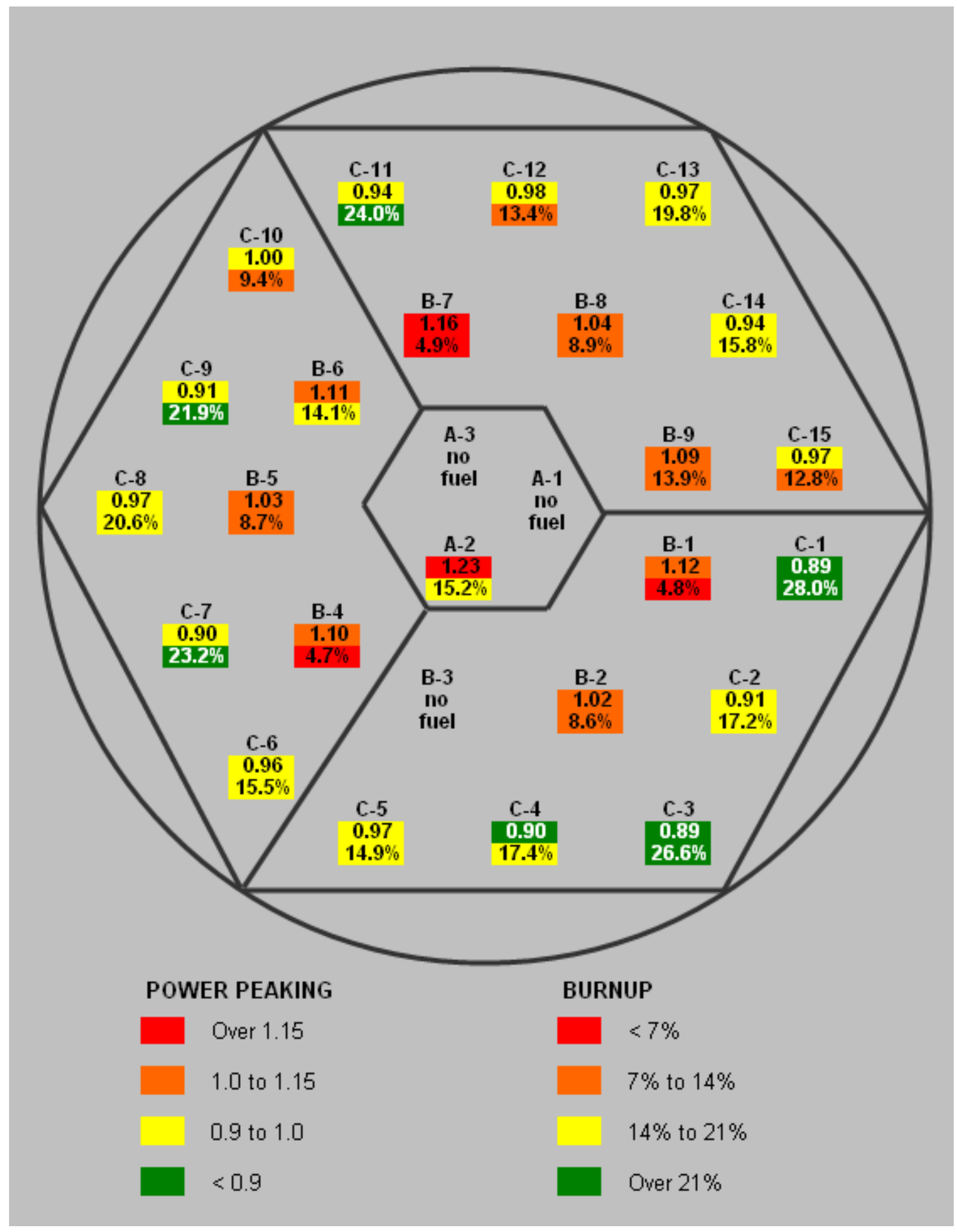

Figure D-25. Elemental power and burnup distribution in LEU depleted Core 190 at EOC. 


\section{D.2 LEU Power Peaking within Elements}

The peak stripe for each pseudo-equilibrium core, at both BOC and EOC, is shown in Figure D-26 as a plot of heat flux vs. axial position. Particularly limiting profiles among this set were chosen and analyzed in Chapters 3 and 4 . It can be seen that these power distributions bound various parameters of power such as that the highest power profile which exhibits a flatter (less bottom peaked) profile is found in Core 185 BOC (inner ring peak stripe). As well, the highest single power point is observed in Core 189 BOC (peak power spot). As shown in Chapter 4, among these cases, the most limiting is the stripe with the highest average power which occurs in Core 189 EOC (peak stripe). Throughout this report, heat flux is based on the area of the fuel foil, without accounting for fin area, assuming a total LEU reactor power of 7 MW is produced within the fuel meat.

The elements which contain these peak stripe are of interest, particularly in the event that something other than a half-channel thermal hydraulic analysis is performed in the future. Various parametric power distributions are shown for these peak stripes, with a focus on the Core 185, and Core 189 peak stripes. The plate-average heat flux for each plate within elements containing the peak stripe of each core is shown in Figure D-27 for the pseudo-equilibrium LEU Cores 185-190. The element number containing the peak stripe for each core state is also denoted alongside the core number and BOC/EOC state. The effect of self-shielding and moderation can be seen in the lower power for interior plates. The effect is less pronounced for the inner ring elements where the two B-ring elements which contain the peak stripe for the core are seen to be markedly flatter (Cores 185 and 186 at BOC). Notably, in these cases the plates with the peak power are located adjacent to an interior plate with significantly less power since the power rises considerably in the exterior plate, which is located adjacent to the inner hex structural wall. The remaining cores experience power peaking in the outer plate of the element in the C-ring where for these LEU cores the hot stripe for the core is located adjacent and parallel to the heavy water reflector (against the core housing structural wall). Due to the symmetry in the MITR, Figures 11 and B-1 are used to illustrate the locations of these peak stripes, and the directions which the plates face.

The effects of moderation and self-shielding are also important in the lateral direction of the MITR fuel plates. The lateral direction is used to denote the direction parallel with the fuel plates, which may face in various directions which are neither purely azimuthal nor radial. Figures D-28 through D-33 illustrate the impact of this on lateral peaking by showing the axial power distribution of each of the four stripes within a plate for the core states considered previously. Figure D-28 shows the inner ring peak stripe among all LEU core (Core 185 BOC element 12 plate 18 stripe 4). The degree of stripe peaking is lower in Figure D-28 than in Figures D-29 to D-33, which may be due to the overall core power shape which concentrates more power in the core interior at BOC, and moves a greater share of power to the C-ring as the control blades surrounding the exterior of the core are withdrawn (See Figures D-1 to D-25). The peaking of the hot stripe in Figure D-29 shows this same plate at Core 185 EOC. In this case depletion of the Core 185 element 12 would not contribute to lateral peaking at BOC since this element was fresh.

Figure D-31 shows the axial power distribution of stripes within plate containing the single peak spot among all LEU cores (Core 189 BOC element 27 plate 1 stripe 1). This same plate and stripe is the peak stripe among all LEU cores at the Core 189 EOC state, as shown in Figure D-32. Both BOC and EOC exhibit a similar degree of lateral peaking as the EOC, where the Core 189 EOC peak stripe has a $14 \%$ higher power than the average for that plate. 


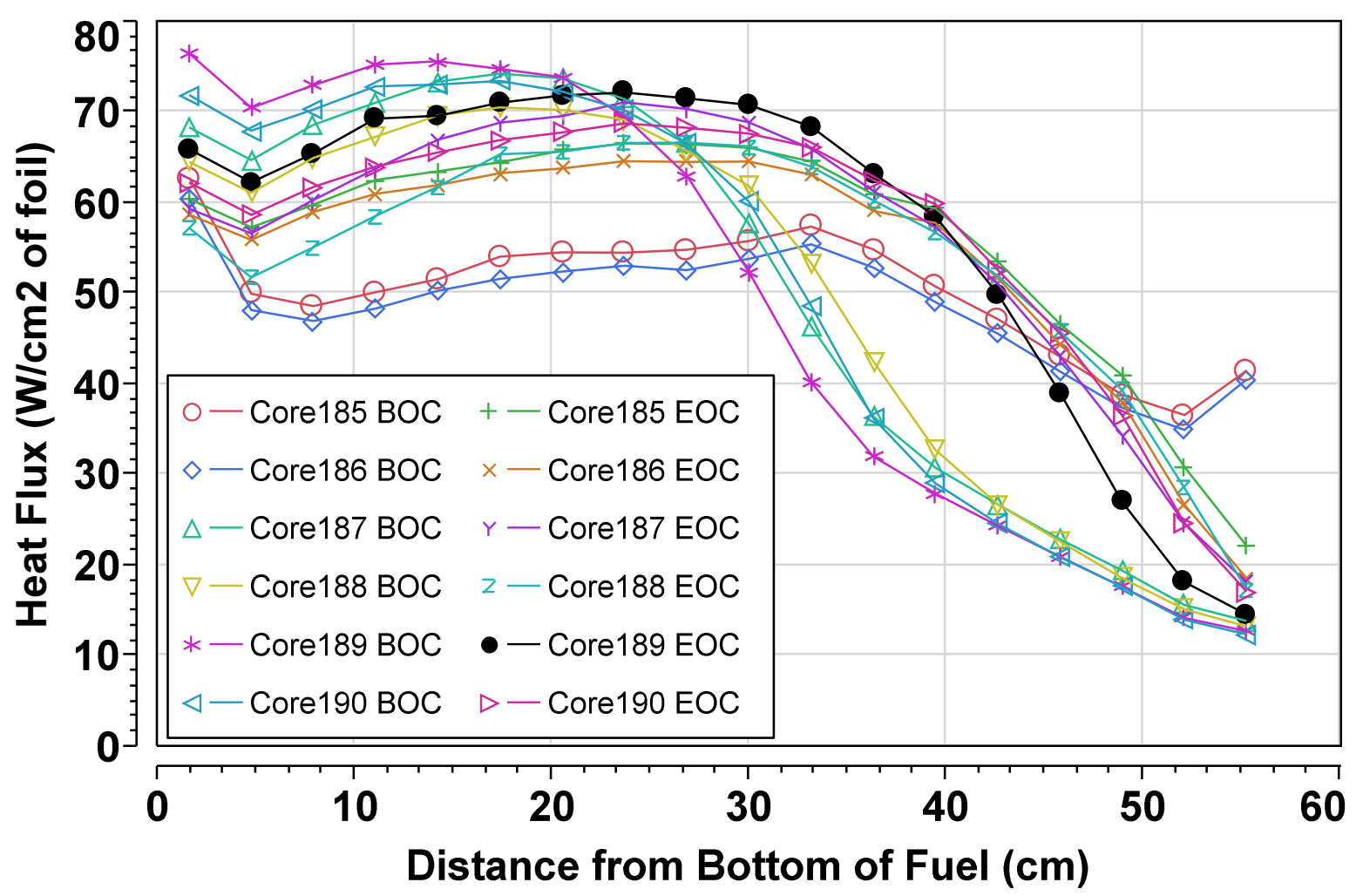

Figure D-26. Axial power distribution of stripes with peak heat flux by pseudo-equilibrium core.

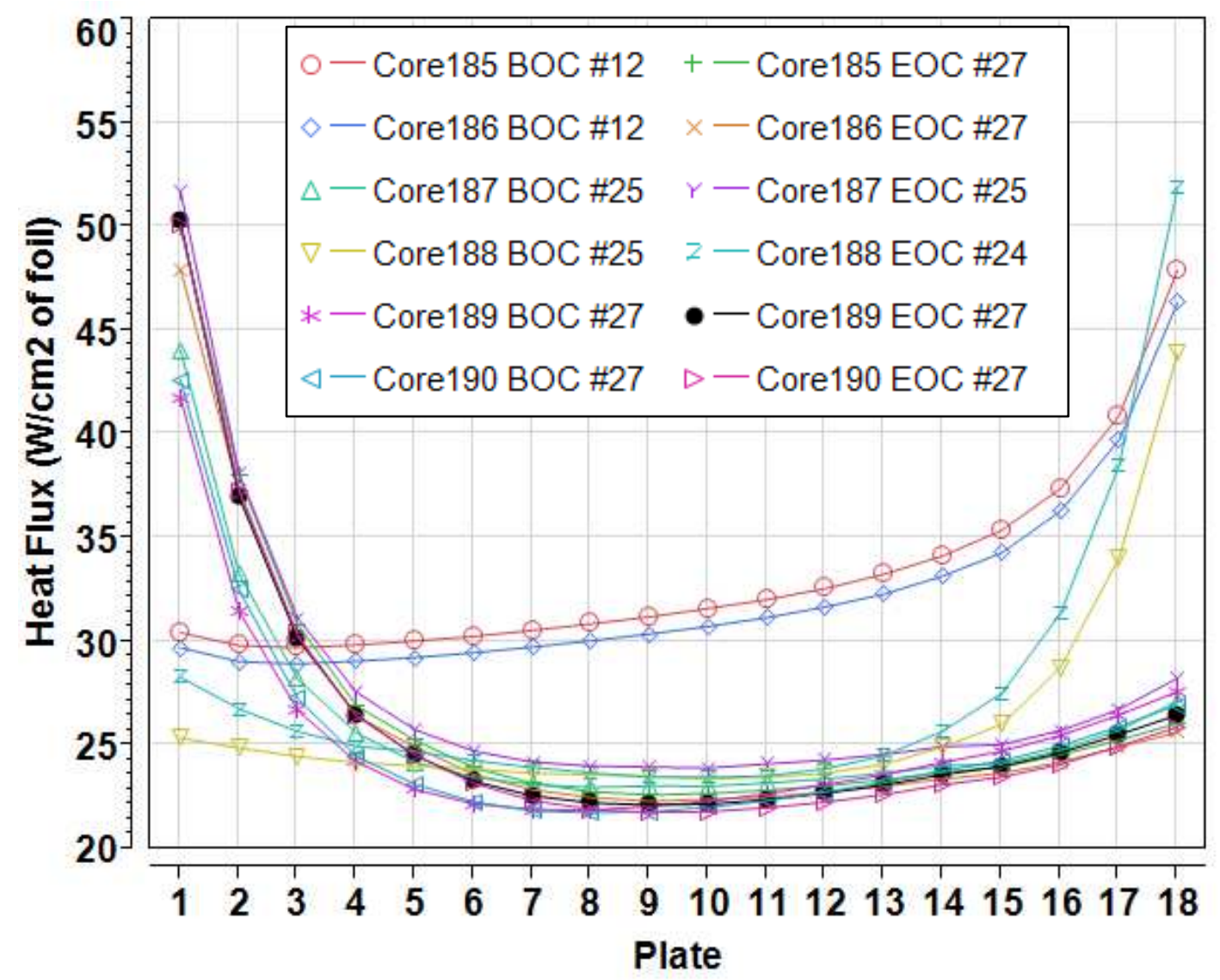

Figure D-27. Plate-average heat flux for elements containing peak stripes in pseudoequilibrium 7 MW LEU cores (with element \# noted). 


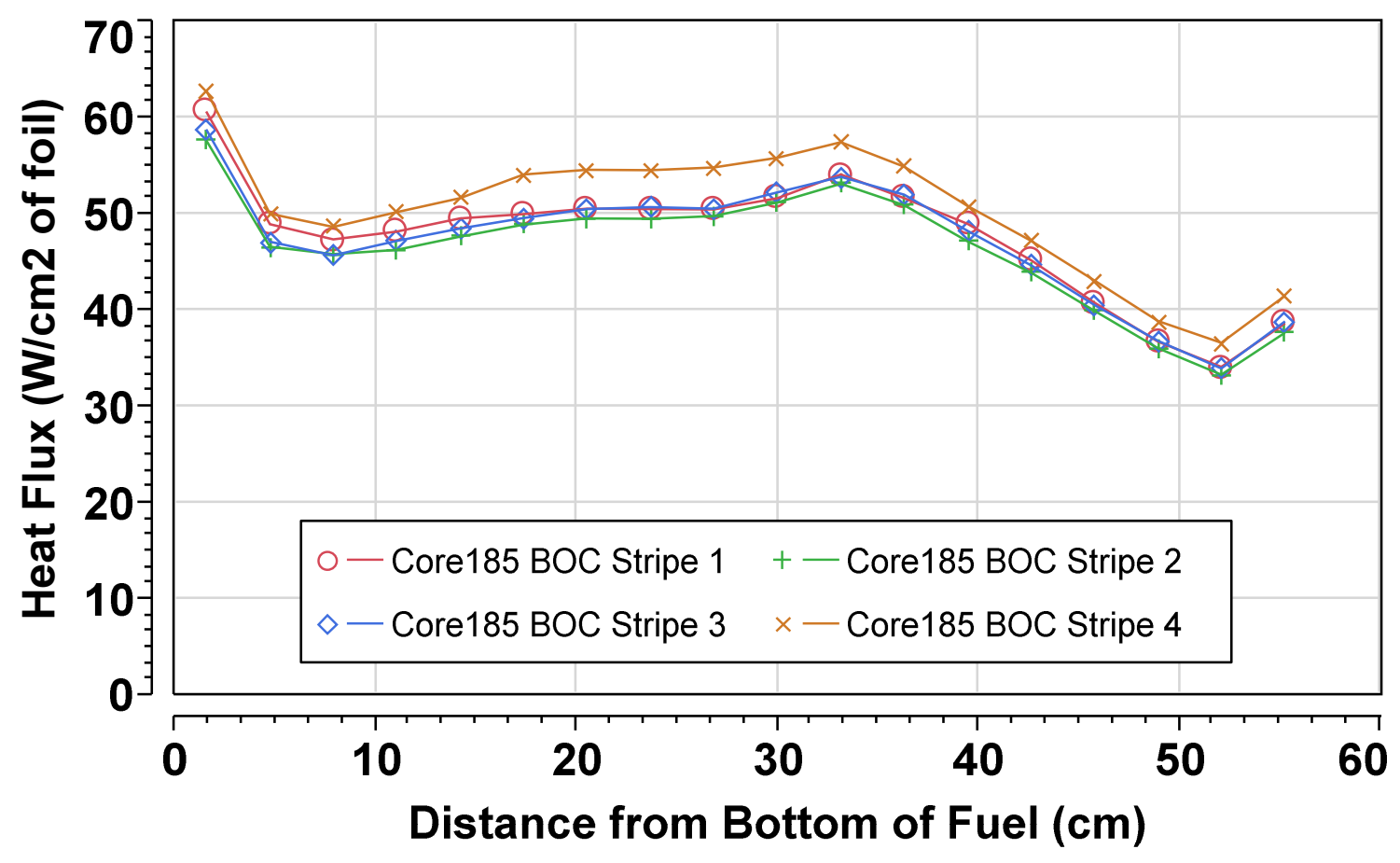

Figure D-28. Axial power distribution of stripes within plate containing inner ring peak stripe among all cores (7MW LEU Core 185 BOC element 12 plate 18 stripe 4).

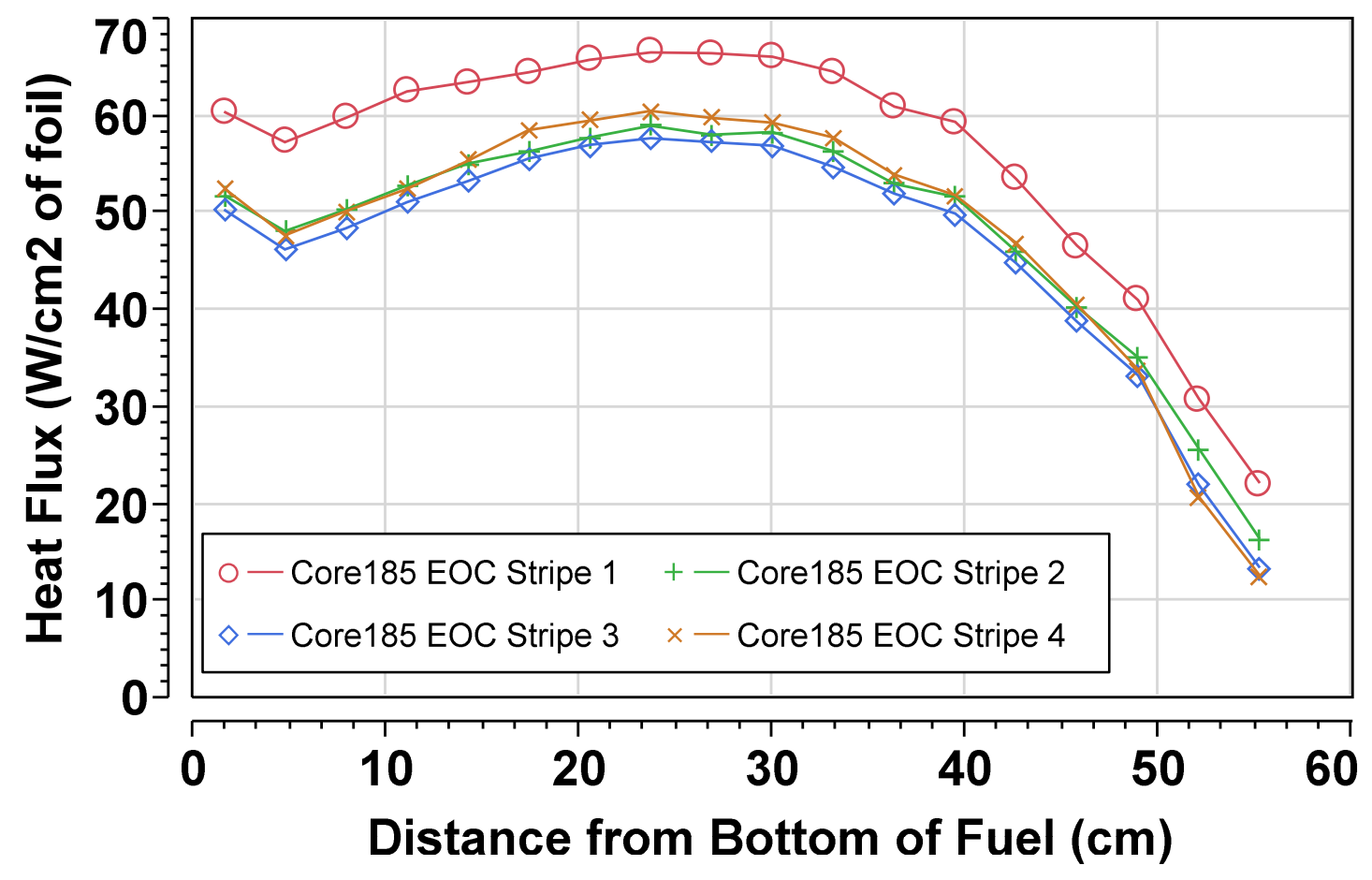

Figure D-29. Axial power distribution of stripes within plate for 7 MW LEU Core 185 EOC element 12 plate 18 stripe 4. 


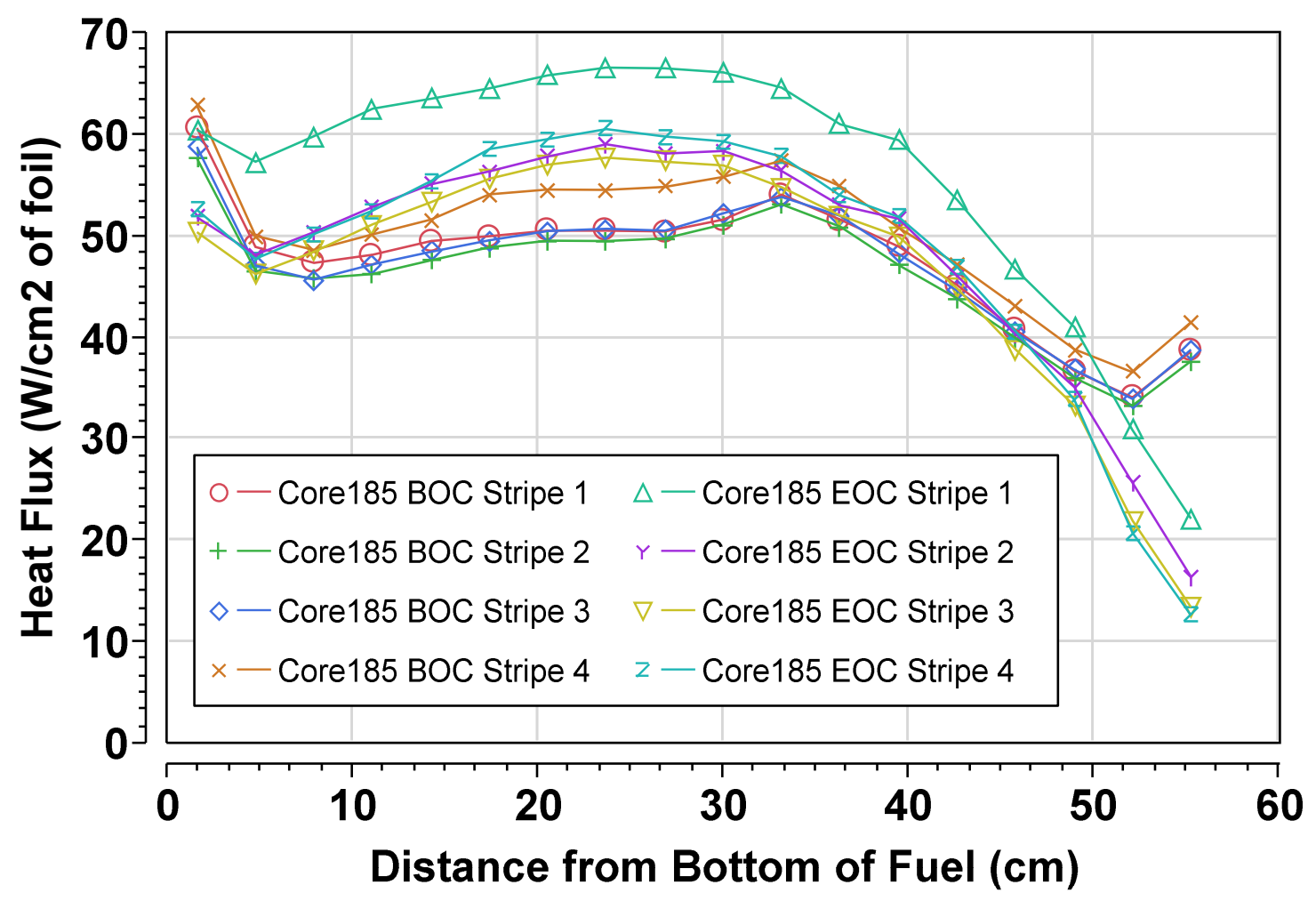

Figure D-30. Axial power distribution of stripes within plate containing inner ring peak stripe among all cores (7 MW LEU Core 185 BOC element 12 plate 18 stripe 4) shown at BOC and EOC. 


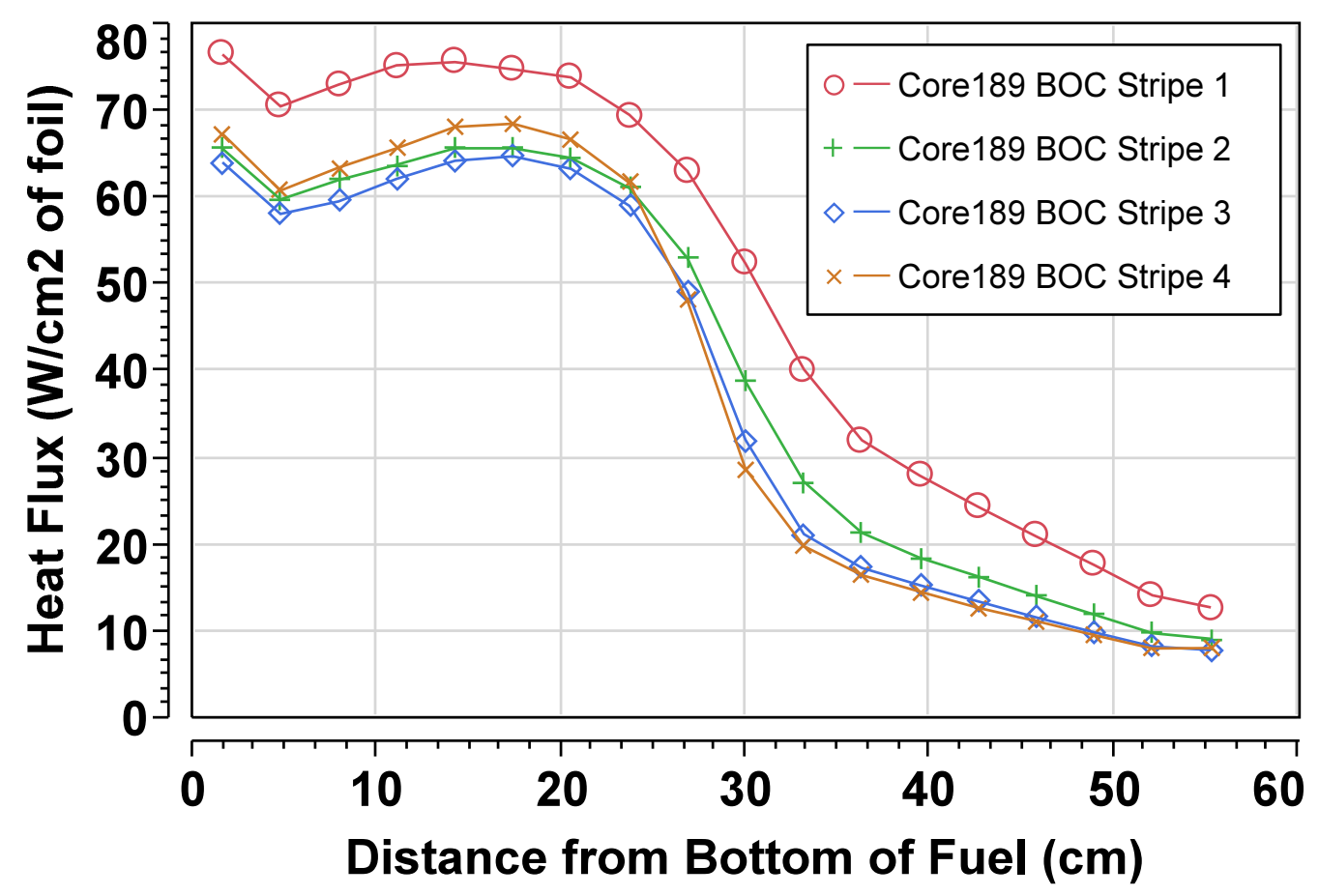

Figure D-31. Axial power distribution of stripes within plate containing peak stripe among all cores (7 MW LEU Core 189 EOC element 27 plate 1 stripe 1) shown at BOC.

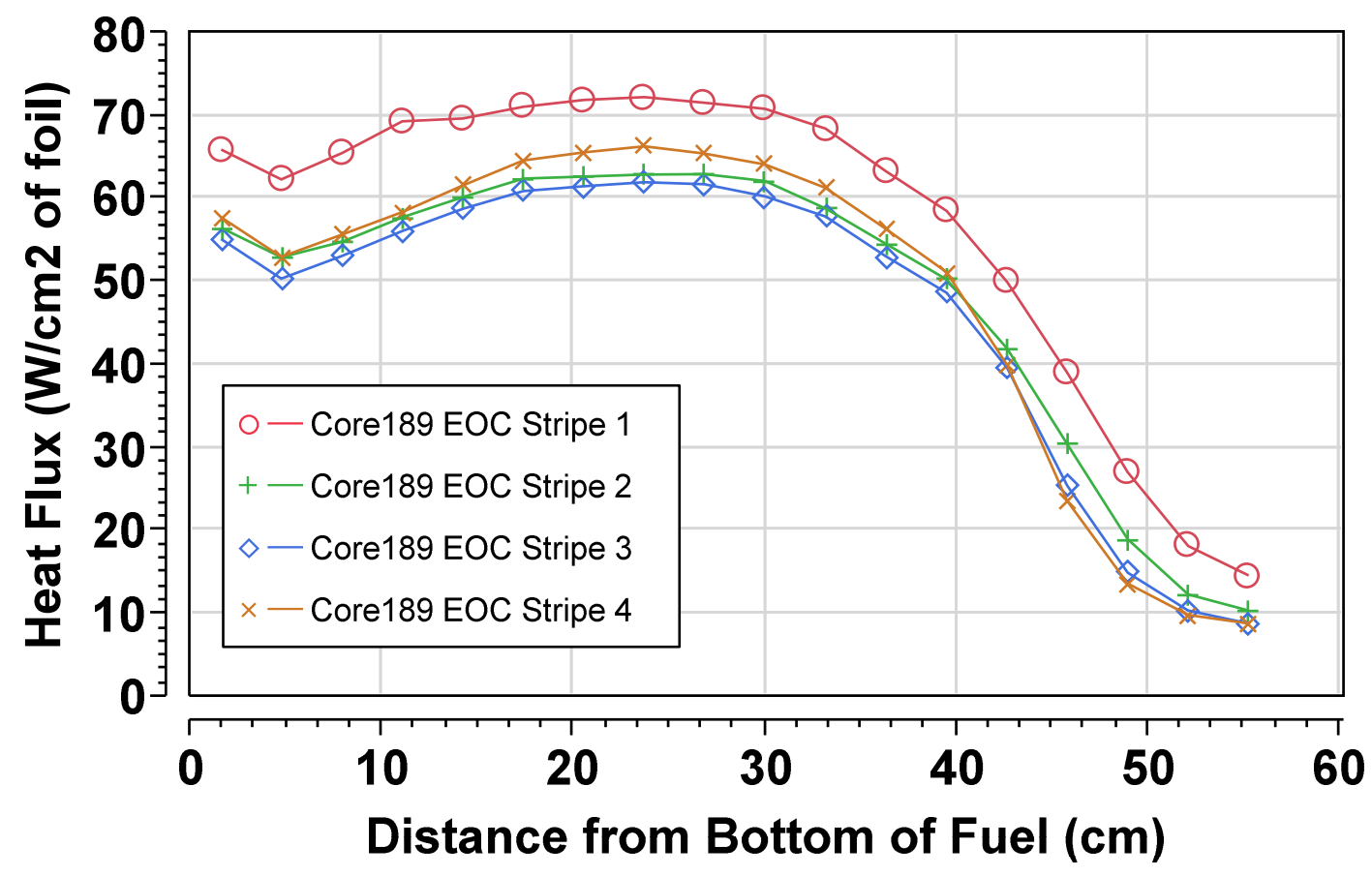

Figure D-32. Axial power distribution of stripes within plate containing peak stripe among all cores (7 MW LEU Core 189 EOC element 27 plate 1 stripe 1) shown at EOC. 


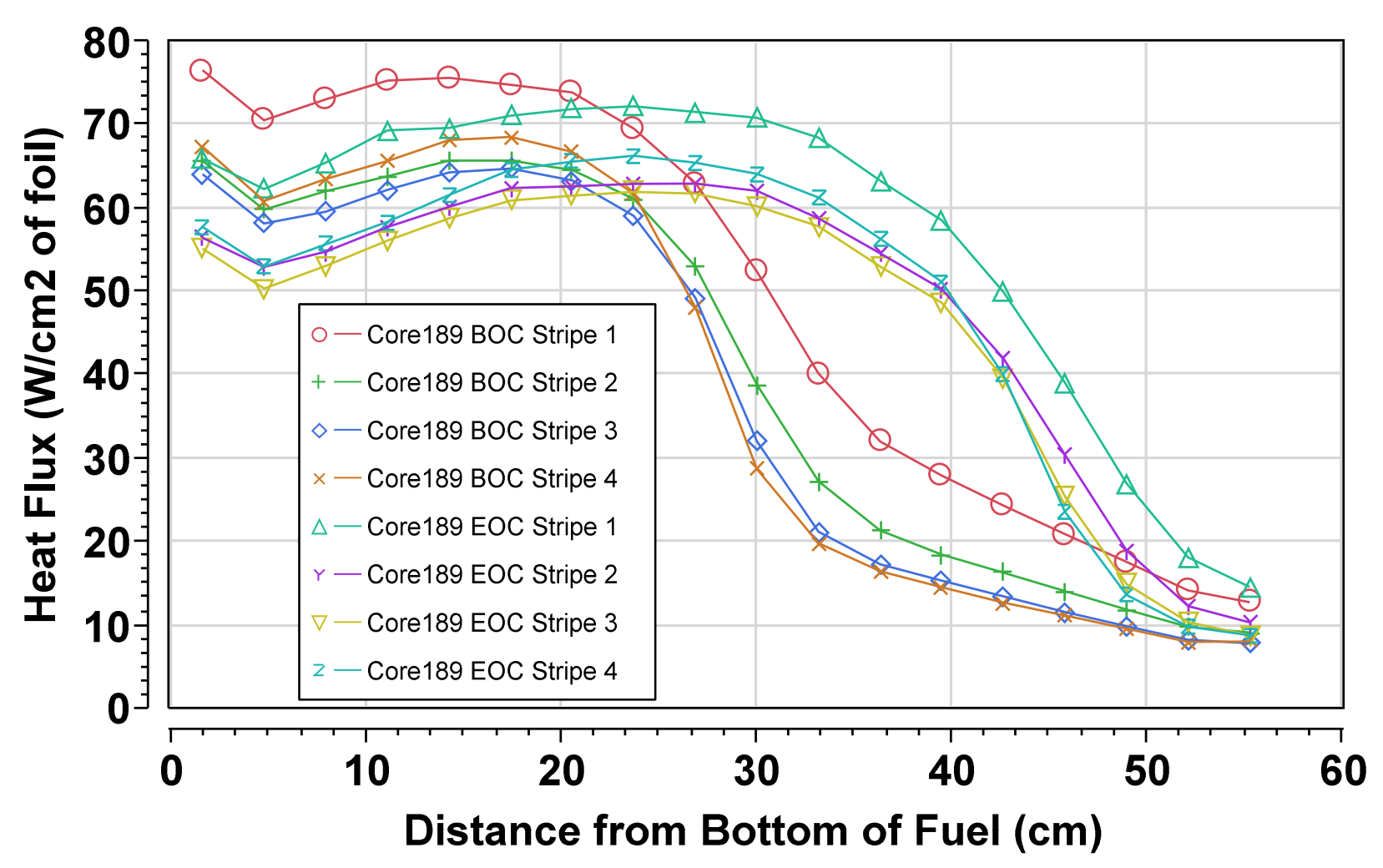

Figure D-33. Axial power distribution of stripes within plate containing peak stripe and peak spot among all cores (7 MW LEU Core 189 element 27 plate 1 stripe 1) shown at BOC and EOC.

In addition to the lateral peaking of the stripe, which to the degree that coolant channel does not mix is important to the analysis another factor impacting the thermal hydraulic conditions in the coolant channel is the plate on the opposite end of the (interior) coolant channel. Figure D-34 shows the axial power distribution of plate 1 and plate 2 for the most limiting case found in Chapter 4 (Core 189 EOC element 27 plate 1 stripe 1), which is the peak stripe among all cores. A thermal hydraulic analysis based upon the half channel would not require information on this second, less limiting, plate. However, it is presented here and noted that there is substantially lower power on stripe of the fuel plate on the opposite side of the interior coolant channel from the limiting stripe. This stripe power is $33 \%$ lower than the power in the limiting stripe which demonstrates how significantly conservative the assumption of a half channel analysis is.

Figure D-35 shows the outer plates on the opposite side of this same assembly which are seen to have significantly lower heat flux and less peaking from stripe to stripe or plate to plate since these plate are located at the boundary between the C-ring and B-ring. Certainly it is seen that the peaking of the element facing the reflector is much higher than the other positions modeled in this core series. 


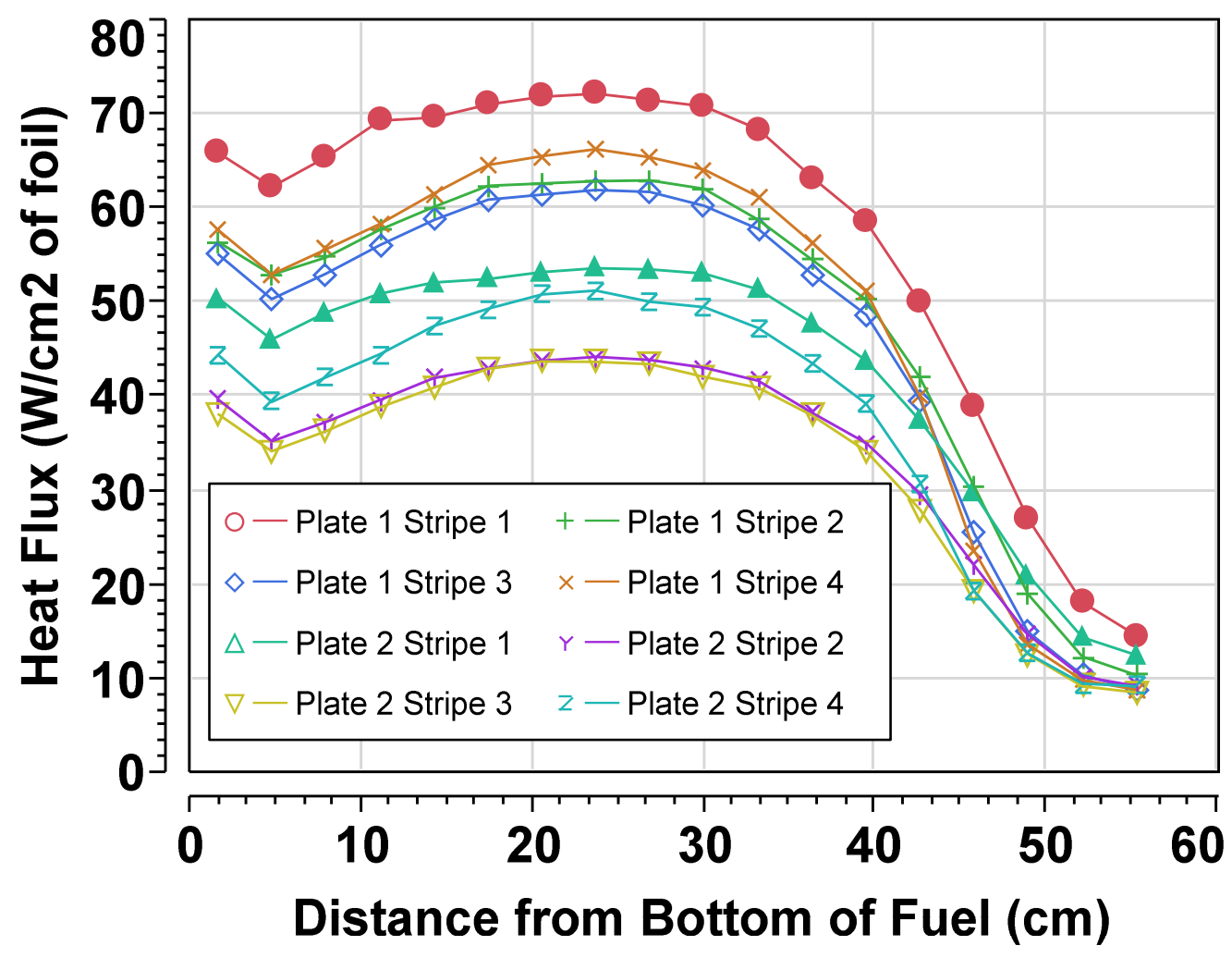

Figure D-34. Axial power distribution of stripes within plate containing peak stripe among all cores and adjacent plate (7 MW LEU Core 189 EOC element 27).

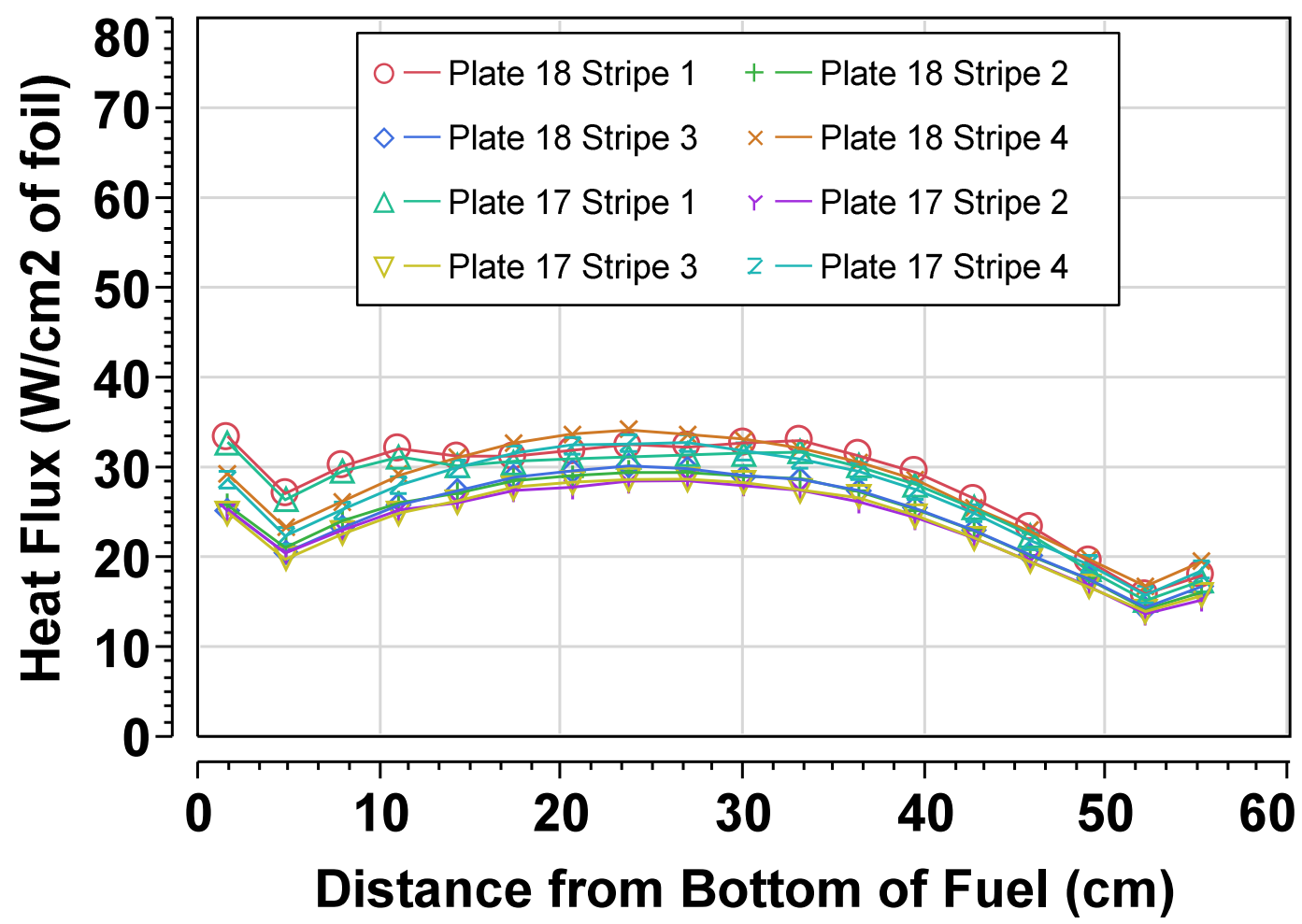

Figure D-35. Axial power distribution of outer two plates on opposite end of element containing peak stripe among all cores (7 MW LEU Core 189 EOC element 27). 
In order to present a better present the whole core power shape, Figure D-36 shows the heat flux in each axial segment of each plate for LEU Core 189 EOC. The same trends of flatter power shape in the core interior (elements 2 through 12) are observed. Notable are the flatter distributions in C-ring elements 16, 21 and 26. These elements are still peaked since adjacent to the reflector; however, the plate-averaged peaking is significantly lower since these plates are orthogonal (placed at right angle) to the core housing structural wall, and so the peaked stripes adjacent to the reflector are averaged with the entire plate.

Shown in Figure D-37 is the average plate heat flux shown by element for LEU Core 189 EOC. This figure again makes clear that the limiting peak stripe among all cores, contained in element 27 plate 1 is limiting not because of the overall element power which is considerably lower than the remainder of the plates in element 27. Many other elements have a much higher element average power; however it is the proximity to the reflector, particularly at the end of cycle when control blades are further withdrawn that makes Core 189 EOC 27P1S1 the most limiting.

The lateral peaking factor for each plate of each element is shown in Figure D-38 for LEU Core 189 EOC, where the lateral peaking of the peak stripe among all cores is well below peaking found in many other elements. In Figure D-39 the heat flux of the hot stripe of each plate is shown for each element in LEU Core 189 EOC and illustrates the combined peaking in a stripe of an element and plate where the highest value observed is the $57.2 \mathrm{~W} / \mathrm{cm}^{2}$ of foil, as listed in Table 7 in Chapter 3 of this report. 

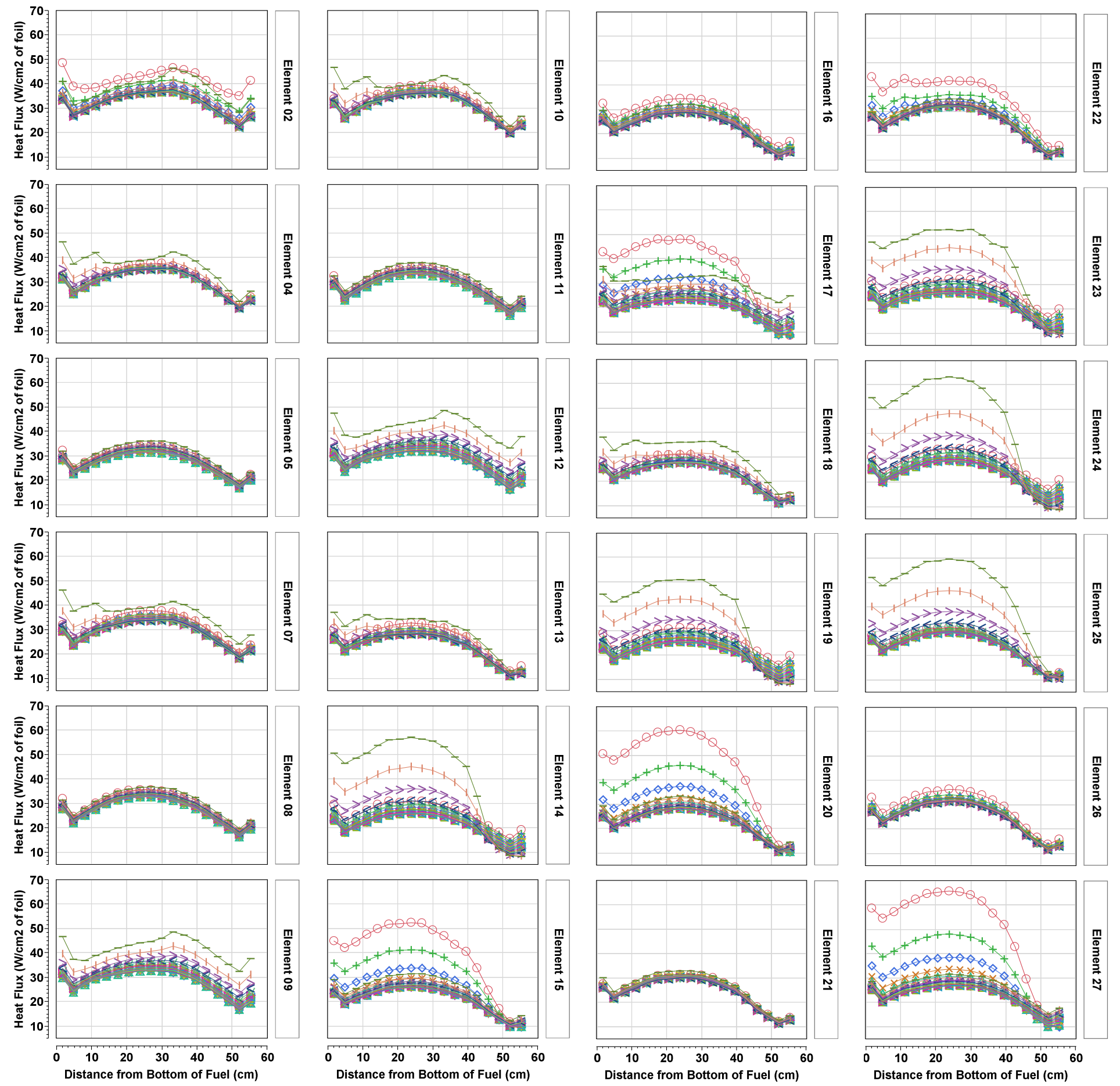

\begin{tabular}{|c|c|c|c|c|c|c|c|}
\hline o-Plate 01 & + -Plate $02 \diamond$-Plate 03 & $\times$ - Plate 04 & $\triangle$-Plate 05 & r-Plate 06 & $\nabla$-Plate 07 & $z$ - Plate 08 & *-Plate 09 \\
\hline 口-Plate 10 & $\triangleleft$-Plate $11 \triangleright$-Plate 12 & $\wedge$ - Plate 13 & $\vee$-Plate 14 & $<$ - Plate 15 & $>$-Plate 16 & | - Plate 17 & 18 \\
\hline
\end{tabular}

Figure D-36. Heat flux in each axial segment of each plate (7 MW LEU Core 189 EOC). 


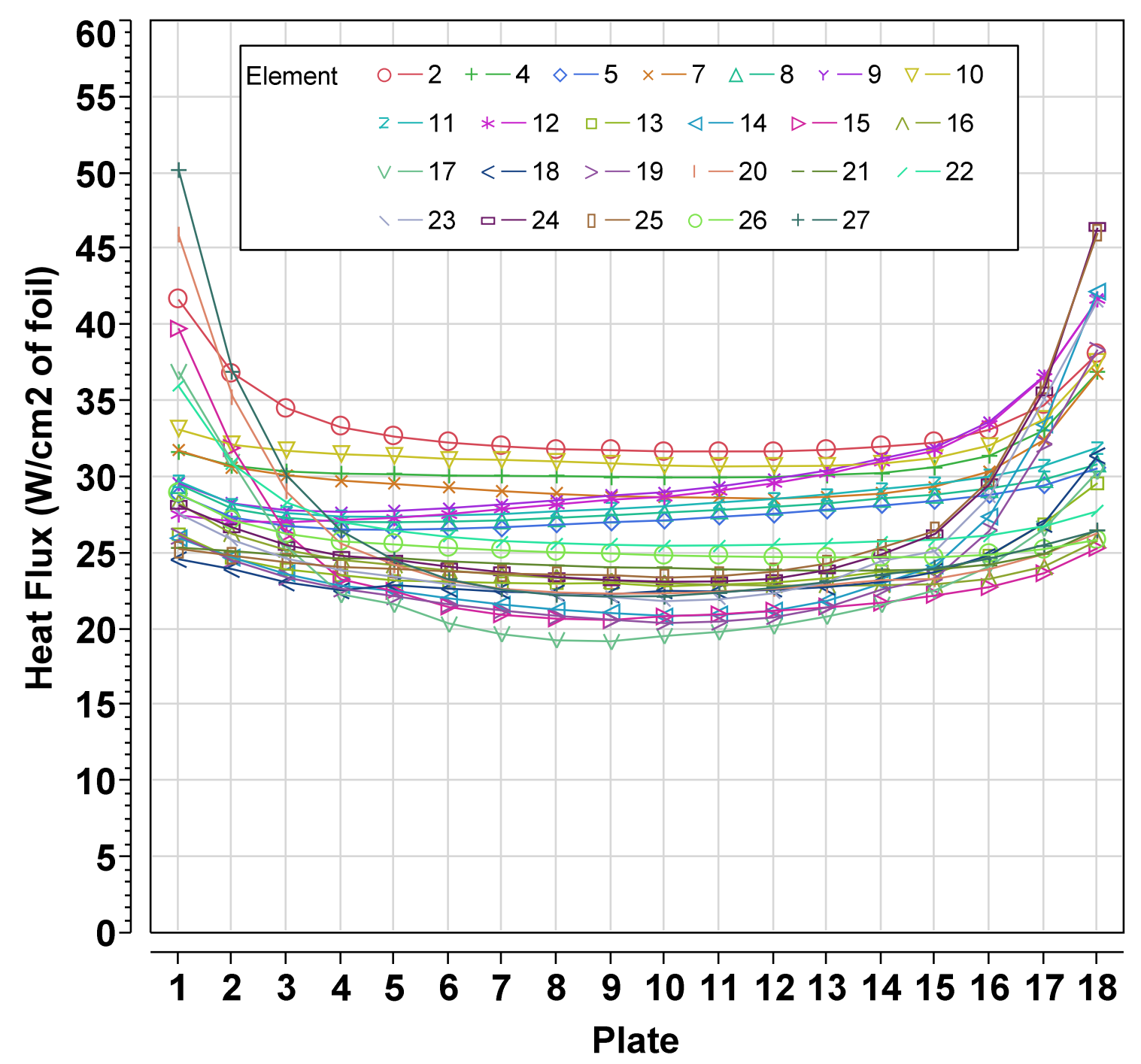

Figure D-37. Average plate heat flux shown by element (7 MW LEU Core 189 EOC). 


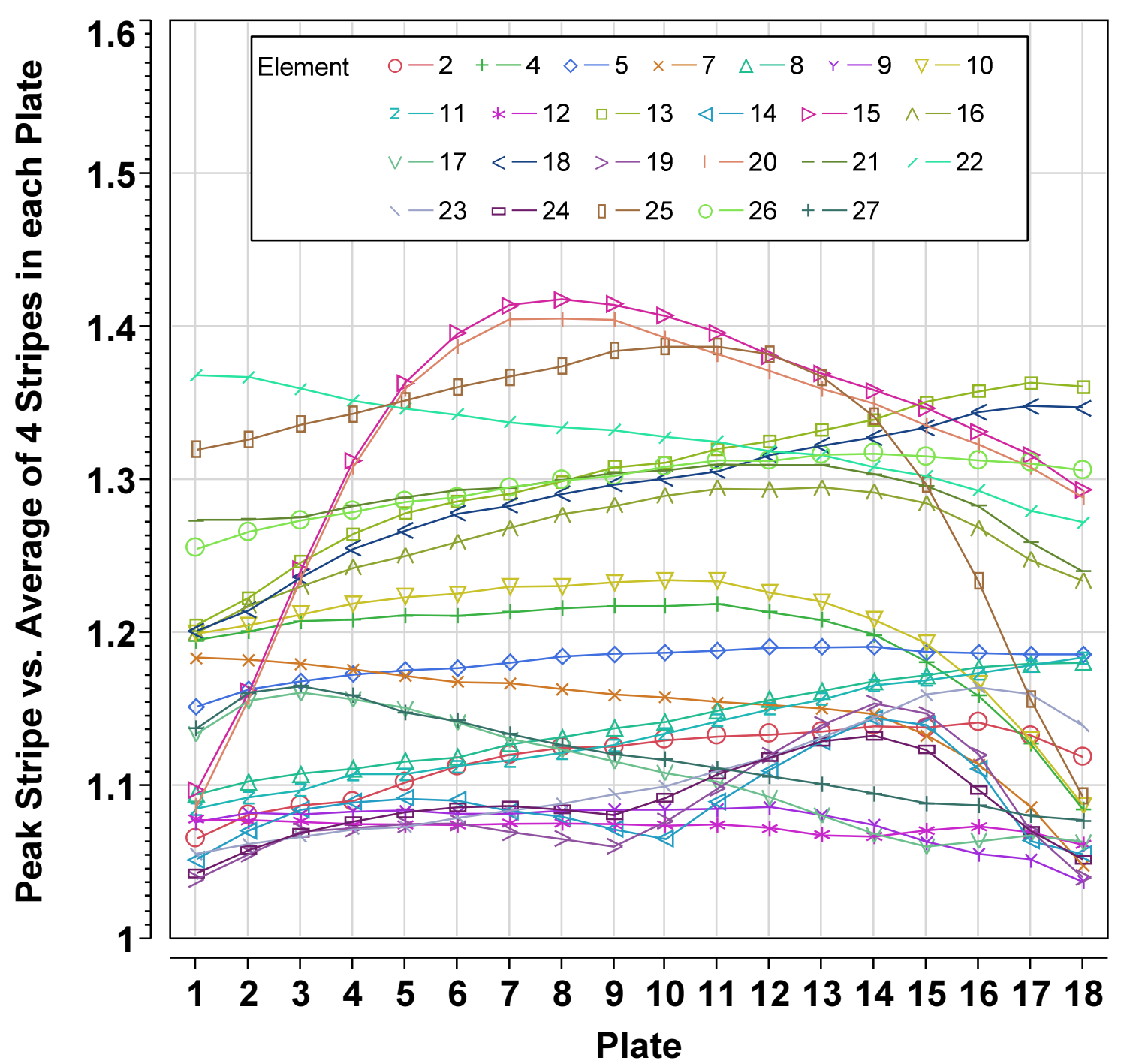

Figure D-38. Lateral peaking factor for each plate of each element (7 MW LEU Core 189 EOC). 


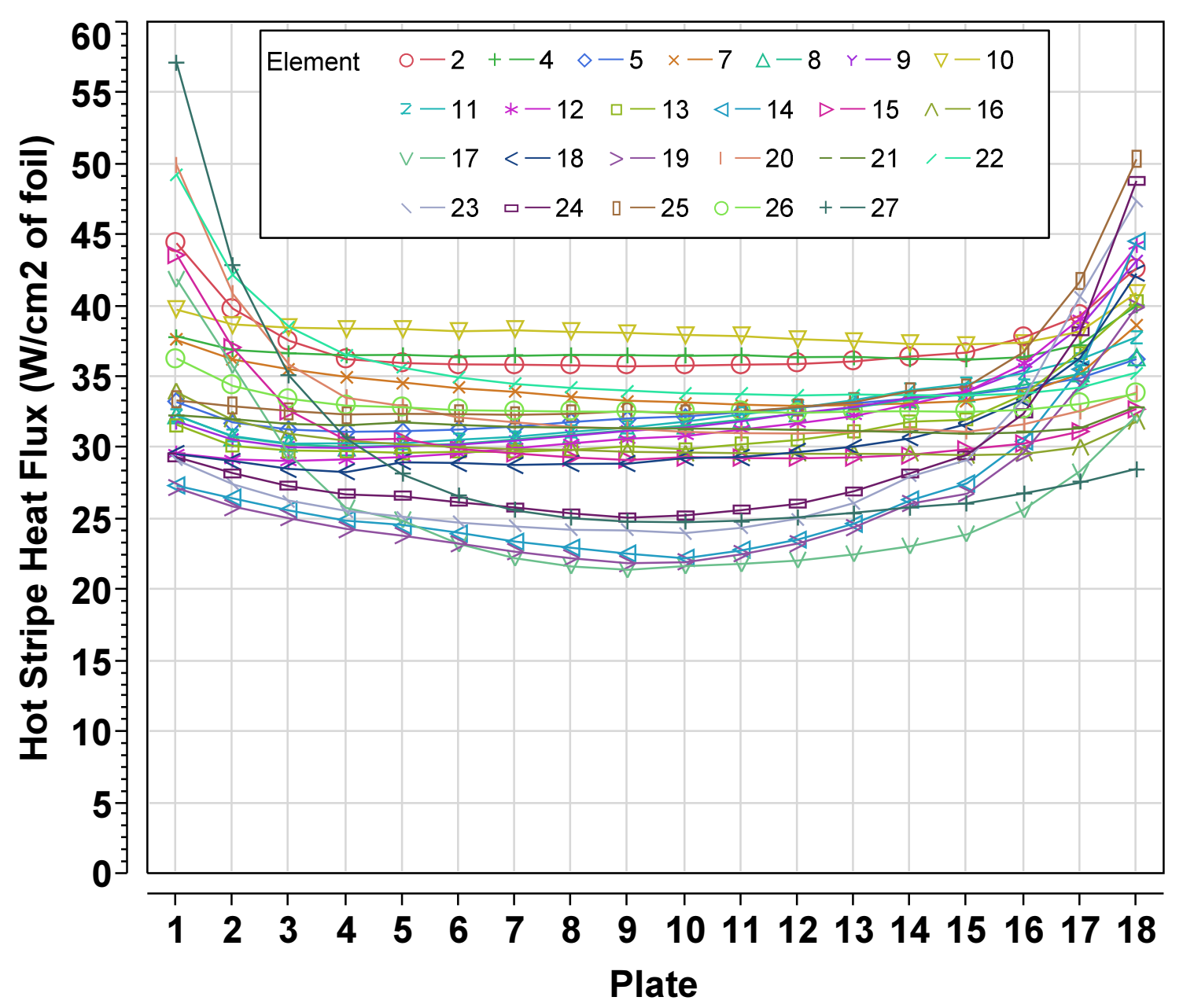

Figure D-39. Hot stripe heat flux for each plate of each element (7 MW LEU Core 189 EOC). 


\section{Argonne}

Nuclear Engineering Division

Argonne National Laboratory

9700 South Cass Avenue, Bldg. 208

Argonne, IL 60439-4842

www.anl.gov 